\title{
RELATIONSHIPS AMONG INDICES OF ADJUSTMENT STATUS
}

\section{DISSERTATION}

Presented in Partial Fulfillment of the Requirements for the Degree Doctor of Philosphy in the Graduate School of The Ohio State University

\author{
By \\ RALPH HAROLD TINDALL, A.B., M.A. \\ The ohio state University \\ 1952
}

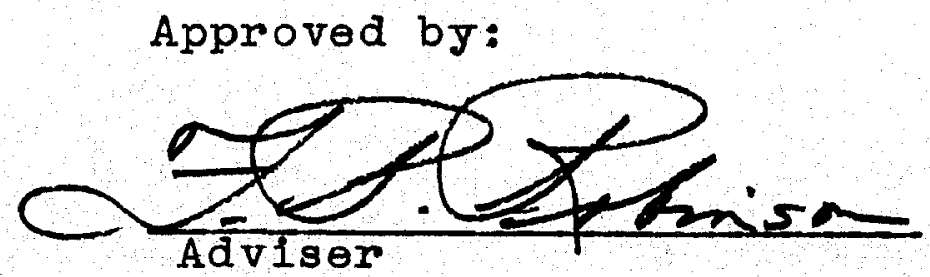




\section{ACKNOWLEDGMENTS}

This study required the cooperation and aid of many different persons, all of whom cannot be mentioned by name. Their holp was, nevertheless, gratefully appreciated. The writer wishes especially to express his appreciation to Dr. F.P. Robinson, Professor of Psychology, Ohio State University, who patiently directed and critloized this study. The guidance and suggestions of Drs. J.B. Rotter, J.R. Kinzer, S.L. Pressey, J.E. Horrocks, and H.A. Toops, faculty members of the Department of Psychology, The Ohio State University, were also appreciated. The tochnical assistance, given by Mr. Omar Goode and Dr. Sam Arnold, of the Bureau of Business Research, The ohlo State University, in the operation of the I.B.M. equipment, was most helpful.

The writer desires to express his appreclation for the cooperation glven him by Mr. F.R. Hartpence, Superintendent of the 0.S. \& S.O. Home. He also wishes to acknowledge the aid given by his colleagues at the 0.S. \& S.O. Home, J.M. Waldron, Supervisor of Academic Instruction, and J.E. Balmer, Supervisor of Vocational Education, for making students avallable at scheduled times. The sixty-six boys, the teachers, supervisors, and the deans, who particlpated in the study, aro also gratefully recognized. 
Finaily, in the writer's own office, he wishes to express his appreciation to his assistant, Miss Dorothy Hilty, for her hours of detalled scoring and checking, and Mrs. May Bowers, the writer's secretary, for her hours of checking, correcting, and typing. In addition, the contribution of the writer's wife, Thelma Tindall, is gratefully reoognized. 
TABLE OF CONTENTS

I INTRODUCTION TO THE STUDY..........

II A CONCEPT OF ADJUSTMENT..........

III DESCRIPTION OF ENVIRONMENT AND POPULATION OF STUDY.............. 54

IV GENERAL DESIGN, SELECTION OF INSTRUMENTS, AND PROCEDURES............ 68

V THE PRESENTATION AND DISCUSSION OF RELATIONSHIP AMONG ADJUSTMENT INDICES 126

VI FIVE CASE STUDIES REPORTING INDIVIDUAL SCORING ON THE ADJUSTMENT MEASURES ... 191

VII SUMMARY OF THE STUDY ............. 261

BIBLIOGRAPHY $\ldots \ldots \ldots \ldots \ldots \ldots \ldots \ldots \ldots \ldots \ldots, 279$

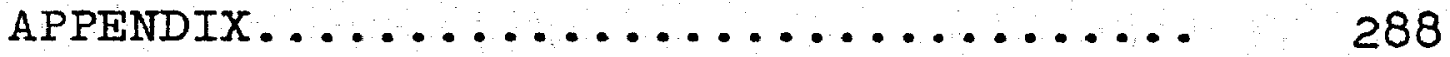


LIST OF TABLES

Table

Page

1 DISTRIBUTION OF TOTAL POPULATION ACCORDING

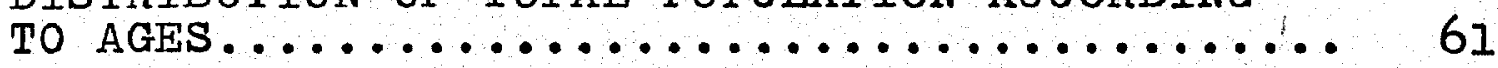

2 GRADE DISTRIBUTION OF TOTAL POPULATION...... 62

3 INTELLIGENCE DISTRIBUTION OF STUDY POPULATION COMPARED TO NORMAL EXPECTATION.............66 63

4 DISTRIBUTION OF POPULATION ACCORDING TO YEARS OF RESIDENCE IN THE 0.S. \& S.0. HOME ........ 64

5 CHARACTERISTICS OF ORIGINAL DATA........... 132

6 CORRELATION OF ADJUSTMENT INDICES WITH VARI-

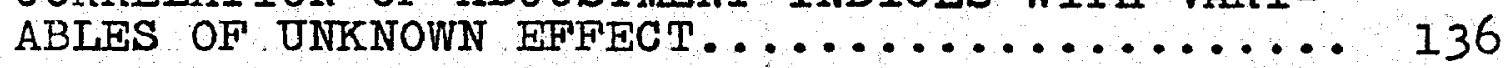

7 INTERCORRELATIONS OF ADJUSTMENT INDICES..... 142

8 INTERCORRELATIONS OF ADJUSTMENT INDICES SIGNIFICANT AT THE $01 \%$ level............. 145

9 INTER-TRAIT CORRELATIONS FOR THE HESTON PERSONAL ADJUSTMENT INVENTORY SCALES.......... 160 
1. SCORING ON ADJUSTMENT INDICES BY

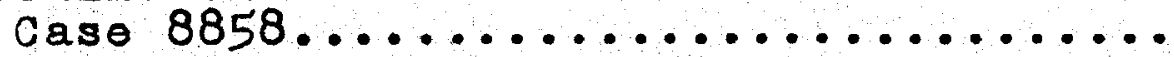

201

2 SCORING ON ADJUSTMENT INDICES BY

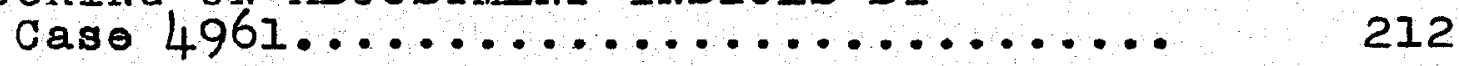

3 SCOR ING ON ADJUSTMENT INDICES BY

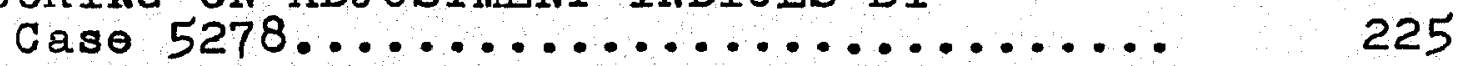

4 SCORING ON ADJUSTMENT INDICES BY Case $5609 . \ldots \ldots \ldots \ldots \ldots \ldots \ldots \ldots \ldots \ldots \ldots . \ldots \ldots$

5 SCORING ON ADJUSTMENT INDICES BY

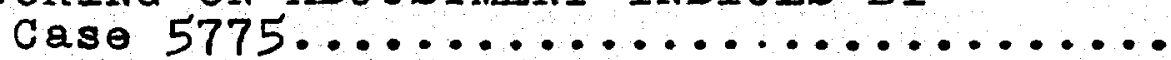




\section{RELATIONSHIPS AMONG INDICES OF ADJUSTMENT STATUS}

\section{CHAPTER I}

\section{INTRODUCTION TO THE STUDY}

Those who have been in the position of having to decide whether a child, a student, or an adult is dealing effectively with his environment, have no doubt experienced a frequent frustration as to what represents adequate criteria in order to have a basis for that judgment. It is from a series of such situations that the need for formulating some more precise notions in regard to such criteria arose. It was noted many times in working with dependent children within an institutional setting, that scores on various purported adjustment measuring tests and scales varied to the extent that one serlously questioned the validity of the instruments used. It was further noted frequently that the judgments of those in direct contact with certain children were in partial or complete disagreement as to just how effectively the child was functioning. Further, in discussing adjustment, even among members of the same profession with a comparable training background, one could not help but detect a certain lack of precise agreement as to what was meant when the concept of adjustment was discussed. It became clear at the outset that 
there was a definite need to explore the area of human interactions labeled "adjustment".

Whatever area of human endeavor we choose to examine, differences are demonstrated in the ways that human organisms meet the exigencles of the moment as well as in the way the same individual meets similar situations on a day-to-day basis. Both the behavior scientist and the layman evaluate the actions of others in terms of the observed efficiency of that action according to some value system. We would expect the scientist to attempt to be more impersonal and to have a clearer notion of the composition of the criteria used. We attach labels to self-behavior and other behavior that imply the existence of at least a continuum from behavior judged non-adjustive to behavior judged adjustive within a specified field of action. In relatively recent yearg we have sought to obtain more preclse indices of the adjustive quality of the actions of the human organism. This is rightly the province of the scientist. Personality is established as a legitimate area of investigation and, though the term may still be lacking an adequate definitive status, it is not too difficult to visualize a concept of adjustment as being an attribute of personality which can be conveniently marked off for special consideration.

We have long had a global concept of intelligence which, though later reduced to more elemental factors, still serves in the form of a rather blunt instrument that has been found fruitful in distributing poople along a continuum where an 
overall index was neoded. Further, there exists a variety of accepted measures within the professional repertory that, if the name of the instrument is given and a reasonably adequate summary of the conditions prevaling at the time of administration is reported, meaningful results may be communicated. A global concept of adjustment has fared less well. While Traxler ${ }^{I}$ estimates that there are approximately five hundred instruments in the fleld purporting to measure some aspect of personality, there appears to be far less agreement as to what the results mean in terms of comparability between instruments. It would seem logical that one of the first steps taken to examine the adequacy of adjustment criteria, would be to examine existing measures and apply commonly used ones as carefully as possible to members of a selected population within a reasonably stable environmental field. These results should be comparable from instrument to instrument if they are legltimately assessing the same thing. If results vary widely from instrument to instrument, then we must re-define what we are assessing and determine the why of such discrepancios.

Wechsler2 has recently suggested that intellectual abilIty as it is now conceptualized, is a manifestation of the whole personality. Similarly, another manifestation of the whole

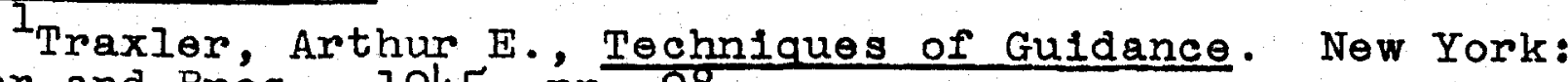
Harper and Bros., 1945, pp. 98.

${ }^{2}$ Wechsler, Devid, "Cognitive, Conative, and Non-Intellective Intelligence."' The Amer. Psychol., i950, 5: 78-83.
} 
personality could concelvably be the manifested adjustment level. If we follow the same line of thought, we frequently find that when measured ability level does not conform with the observed performance level, it is hypothesized that the degree of adjustment of the organism in question is such that the efficlency level of the individual has been reduced. If such a hypothesis is a reasonable one - and empirically it seems justifiable - then there is further reason to attempt to sharpen our concept of adjustment and criticaliy appraise the worth of our present instruments often used to establish criteria to form the basis of judgments in this area.

We have many measures of individual performance in a varlety of areas of scholastic achievement which seem to represent measurable aspects of the functioning personality that are intimately related among other things to the level of intellectual functioning, the accustomed method of attack, and the adjustment level. It has been demonstrated that the achievement level can be raised through the actual teaching of higher level skills. Robinson ${ }^{3}$ suggests that similarly it might be possible to raise the efficiency level through the teaching of higher level adjustment skills. However, prior steps to such ultimate application are: a definition of what we now mean by adjustment, the determination of communalities among measures, the development of a more precise

\footnotetext{
Robinson, F.P., Principles and Procedures in student Counseling. New York: Harper \& Bros., 1950, p. 240.
} 
concept of adjustment, and then the establishment of areas where such skilis may be taught.

\section{Objectives of the Present study}

In order to make a logical start in investigating adjustment criteria, it appears relevant to set up certain Immediate objectives and then to foresee certain other out comes which could grow from the attainment of the immediate objectives. Historically, we have commonly judged adjustment on the basis of immediate behavior. It is necessary to see if such an approach has reliability. Later studies will need to be devoted to the validity of such an approach.

For the present purposes, in order to stay within the scope of a single study, we arbitrarily set the problem to deal with our present concept of adjustment and a clarification based upon the agreement of authority as to what is contained in that concept. As the main purpose we propose to utilize existing representative measures of adjustment, which have been used frequently to establish criteria ratings of adjustment, and apply those measurements as carefully and as skillfully as possible to a selected population. The population to be selected, is to be so well known to the one conducting the study that it will be possible to interpret communalities or lack of communality between the existing measures on a group and an individual basis. The focus of the study is to be upon the agreement or disagreement of the 
selected measures as they apply to the group and to Individuals.

With this main purpose in mind and if this can be accomplished satisfactorily, it should be possible to answer some questions in regard to the appropriateness of the various measures used in establishing status of adjustment in individual cases. Further, such procedures may give leads as to the next steps possible in sharpening the concept of adjustment or even whether such a global concept is a profitable approach. With a clearer concept of adjustment, it should be possible to approach the maladjusted person with more insight into what goals may be attainable for the particular person. Perhaps such a study along with similar studies might be instrumental in suggesting new higher level adjustment skills or delineating skills already in existence which, when taught, would result in an increased efficiency level on the part of the person in his interaction with the environment.

\section{Related Studies}

The present study lays no claims to uniqueness in that such an effort to assess agreement on the part of instruments designed to measure adjustment, has not been done before. For nearly every test on the market today purporting to measure some aspect of personality related to assessing adjustive status, there have been studies made which can be classed as evaluative. For the most part these studies have compared 
the results secured by the particular test in question with results secured from a few other tests purporting to measure the same thing but with longer standing acceptability, with the judgments of experts, or with some related criteria such as school grades, clinic visitations, self-report of status, etc. None of these evaluative studies have compared more than a few measures of adjustive status on the same population. In many instances the results have been disappointing when applied to individual prognosis but have in some instances been encouraging when applied to differentiating between groups (1.e. delinquents vs. non-delinquents).

There have been a variety of approaches and numerous varlations within approaches to the problem of measuring adjustment. In his section on Character and Personality, Buros 4 includes a number of such instruments with representative bibliographies of studies testing their validities. The various approaches to measurement of adjustment lend themselves to a variety of classiflcatory schemes of which Greene, Jorgensen, and Gerberich's ${ }^{5}$ may be considered representative. They include (1) free association, (2) direct observation, (3) the approach through rating scales, (4) and the approach through personal reports. As varieties subsumed under freo association may be included such instruments as the Rorschach, word association, incompleted sentences, Thematic Appercep-

\footnotetext{
4Buros, O.K., The Third Mental Measurements Yearbook. New Jersey: Rutger's Pross, 1949.

${ }^{5}$ Greene, H.A., Jorgensen, A.N., and Gerberich, J.R., Measurement and Eváluation in the Sécondary School. New York:
} 
tion Test and other picture associations, finger painting and other creative techniques. Within the category of direct observation may be included specifled directed observation, anecdotal reports, behavior counts, time samples of behavior, and situational analyses. Rating scales include a variety of schemes used by judges to categorize or place the person judged along a continuum in regard to a specified dimension. As variations of the personal report category one can consider such means of appraisal as questionnaires, inventories, sociometric choices, self ratings, and interview responses.

As has been intimated, most of the studies to date have been concerned with one or two of these approaches as applied to the same population. The results of comparison between instruments, even though using the same approach, have oftentimes not been too encouraging. Ellis ${ }^{6}$ made a survey of the validation studies in the field of personality questionnaires which summed up the attempts to validate results secured from these instruments against groups with known historles of delinquency, against delinqueney diagnoses, against psychiatric or psychological diagnoses, against ratings mado by teachers, friends or associates, and against similar personality questionnaires. Out of a grand total of 259 investigations surveyed, 80 were positive, 44 questionably positive, and 135 negative or mainly negative. He arrives at the following general conclusion:

Ellis, Albert. "The Validity of Personality Questionna1res", Psychol. Bull., 1946, 43: 385-440. 
- . judging from tho validity studies on group-administered personality questionnaires thus far reported in the ilterature, there is at best one chance in two that these tests will validly discriminate between groups of adjusted and maladjusted individuals, and there is littlo indication that they can be safely used to diagnose individual cases or to give valid estimations of the ${ }_{7}$ personality traits of specific respondents.?

To attempt to cite all of the studies which have been made in an attempt to validate the numerous instruments purporting to assess adjustment level, would be a monumental task and represent an historical summation beyond the purposes of the present study. For present purposes it was felt to be more useful to go through the literature and select what were judged better studies from a representative sampling of typical approaches to the problem. Citing several of these studies appears more fruitful than an historical enumeration. Blair and Clark ${ }^{8}$ compared the results secured on 382 Ninth Grade pupils using the Multiple Cholce Rorschach and the California Test of Personality and secured a biserial $r$ of $.22 \pm .03$ when total scores were compared. Bonney ${ }^{9}$ using

7 Ellis, op. cit., p. 425 .

${ }^{8}$ Blair, G.M., and Clark, R.W., "Personality Adjustments of Ninth Grade Pupils as Measured by the Multiple Cholce Rorschach Test and the California Test of Personality." Educ. Psychol., 1946, 37: 13-20.

9 Bonney, Merl.E., "The Constancy of Soclometric Scores and Their Relationships tó Teacher Judgments of Social Success and Personality Self-Ratings." Soclometry, 1943, 6: 409-424. 
a Fourth Grade population compared the results secured from the California Test of Personality and sociometric scores and got a correlation coefficlent of $.49 \pm .06$. Jacks on 10 using $100 \mathrm{high}$ school puplls compared the results secured from the California Test of Personality, Woody Student Inquiry Blank, interviews and ratings by experts, teachers, and parents. He found an average correlation of 30 when all of the measures had been reduced to a five point scale. Peters 11 compared the results secured from the Bell, Iink, and Bernreuter inventories with scores derived from descriptions of persons ranking high and low on nine personality traits. He found validity correlations from -.078 to +.503 with an average of +.26. Sanford ${ }^{12}$ in an extensive study used observation procedures, interviews, tests of sentiments and interests, and a memory of fallures test. He analyzed those techniques lending themselves to it according to Murray's Needs and Press Theory and correlated with overt behavior. He found more positive correlations than could be accounted for by chance but ranging from -44 to +.41. Spinelle and Nemzik $^{13}$ utilizing all of the $7 \mathrm{~B}$ girls in a junior high school,

10 Jackson, J., "The Relative Effectiveness of Paper Pencil Test, Interview, and Ratings as Techniques for Personality Evaluation." Soc.'Psychol., 1946, $23: 35-54$.

${ }^{11}$ Peters, C.C. "Validity of Personality Inventories Studied by a "Guess Who' Technique." Psychol. Bull., 1940, $37-453$.

${ }^{12}$ Sanford, R.N. et al. Physlque, Personality and Scholarship. Monograph of the Society for Research in Child Development, 1943, Vol. VIII, No. I: 125-361.

13 Spinelle, Leo and Nemzik, Claude L. "The Relationship of Personality Test Scores to School Marks and Intelligence Quotients." Soc. Psychol., 1944, 20: 289-294. 
determined the correlation between I.Q.'s, C.A.'s, personality test scores as measured by the Iink Inventory, and honor point averages based on teachers' marks. They found correlation coefficients with the personality test scores ranging from -..19 to +.38. The literature contains many other such correlation studies but these seem to be better examples of the type of study related to the present one. With few exceptions such as that of Sanford 14 who worked within a particular frame of reference (1.e. Murray's Need and Press Theory) these studies have boen content with limiting themselves to a comparison of only a few criteria of adjustment as applied to the specific population.

Two other studies may be cited where correlation methods were not used but where an attempt was made to compare several different approaches to the measurement of adjustment. Feder and Baer ${ }^{15}$ compared the results secured from the Bernreuter Inventory and overt behavior as rocordod in the files of the office of the Dean of Women for 81 University of Iowa girls. They found that the Inventory was considerably more dependable for the discovery of the maladjusted student than

14 sanford, op. cit.,

15Feder, D.D., and Baer, Opal L. "A Comparison of Test Records and Cinical Evaluations of Personality Adjustment." Educ. Psychol., 1941, 32: 133-144. 
the behavior record. Darley ${ }^{16}$ utilizing the Minnesota scale for Survey of Opinions, The Adjustment Inventory, and the Minnesota Inventories of Soclal Attitudes on over 500 University of Minnesota students, concluded that the use of such scales would provide clues in 30 to 40 percent of the cases of maladjustment. He further stated that the use of such instruments in a large scale personnel program were warranted on this basis.

The present study is not designed to repeat and verify the findings of other similar studies primarily. It is hoped that a selective representation of the varied approaches have been chosen which will enable a more thorough comparison between measures within a particular category of approaches and between the various approaches. For the first time a careful comparison of representative methods has been made in an attempt to note general validity of existing methods. Such a comparison should povide suggestions for new approaches to the assessment of adjustment status.

\section{Proposed Approach}

In the ensuing chapters this study will deal first with the synthesis of the concept of adjustment as 1t now seems to be understood by those who have written about the problem. In Chapter II mention will also be made of commonly recog-

16 Darley, John G., "Tested Maladjustment Related to. Clinically Diagnosed Máladjustment." Appl. Psychol., 1937,
21: 632-642. 
nized adjustive mechanisms. This formulation will serve to or lent and to serve as a frame of reference for the study. In Chapter III an attempt will be made to set apart the group of adolescent boys used as subjects in this study. The detailed presentation of the characteristics of this group need to be set forth so that proper interpretation of the data can be made. Such a doscription should also act as a safeguard for any tendency to go beyond the data in any generalizations the reader may make upon examination of those data. Chapter IV will describe the general design of the study and attempt to show the rationale behind the selection of the various instruments used. It will also detall the exact procedure used in securing the data.

A concrete presentation using figures and tables as much as possible of the data secured will be attempted in Chapter V. The data, with possible implications and generallations will also be discussed in this Chapter.

In Chapter VI, 1llustrative cases will bo outlined with a tracing through in detall of individual scores on the varlous instruments. These data will be supplemented with case history background. It is hoped some basis for individual discrepancy or agreement on the various instruments may be shown. In the concluding Chapter a summary of the study as well as a looking ahead to some of the necessary next steps in dealing with the concept of adjustment will be presented. 


\section{CHAPTER II}

\section{A CONCEPT OF ADJUSTMENT}

\section{The Process of Adjustment}

Nearly every textbook of general, educational, social, child, adolescent and clinical psychology contains some reference to the concept of adjustment. Before an attempt is made to measure adjustment, it is necessary to take some time to try to summarize present thinking in regard to this concept and to arrive at some definite point of view as a guide to the use and interpretation of the criteria we propose to use. After some examination of the avaliable material in the fleld, it seems logical to deal with this concept by discussing the process of adjustment itself, by examining agreed-upon aspects or facets of adjustment, by considering recognized adjustive mechanisms and finally recognizing the difficulties of the measurement problem.

There seems to be major agreement among various writers that adjustment must be considered as a process -- an ongoing, dynamic kind of behavior -- which in the complex human organism begins with conception and ends at death. It is not a static state that can be reached and stabilized by 
the organism. Rather each time a state of balance is approached, there are new conditions set up necessitating adjustive behavior by the organism. Dysingerl calls attention to the progressive nature of adjustment. Morgan ${ }^{2}$ states that adjustment is a dynamic process not a static condition. Richards 3 says that the modern clinician thinks of the human being in a constant state of adjustment and re-adjustment. Traxler 4 states that a concept of adjustment as the persiatence of a state of perfect satisfaction and happiness is undesirable. Krech and crutchfield 5 describe adjustment in terms of everchanging forces within the psychological field where reaching one goal brings about a reorientation of the psychological field so that new tensions and instability are possible. Fenton 6 discusses a

lDysinger, D.W. "Signs of Personality Disintegration". (In) Pennington, L. A., and Berg, I. A. An Introduction to Clinical Psychology. New York: Ronald Press, 1948, p. 51.

2Morgan, John B. The Psychology of the Unadjusted School Child. New York: The Macmillan Co., 1937, p.9.

3Richards, W. T. Modern Clinical Psychology. New York: McGraw-Hill Book Co., 1946, p. 15 .

4Traxler, Arthur E. Techniques of Guidance. New York: Harper \& Bros., 1945, p. 335 .

5Krech, David, and Crutchfield, R. S. Theory and Problems of Soc1al Psychology. New York: McGraw-HIII Book Co., Inc., 1948, p. 41 .

GFenton, Norman. Mental Hygiene in School Practice. Stanford: Stanford University Press, 1943, p. 107. 
child's personality as an active dynamic process. Gates and others 7 state. that adjustment has two meanings,

In one sense it is a continued process by which a person varies his behavior to produce a more harmonious relationship between himself and his environment. - In another sense adjustment is a state, $1 . \theta$, the condition of harmony arrived at by a person whom we call 'well adjusted'.

If, then, we accept the proposition that adjustment must be considered as a process, what is the nature of this process? We find a number of experts agreeing upon a somewhat basic description of the process which stems from the explanation of adjustive behavior proposed by Dashiell 8 some years ago and follows his schematic diagram.
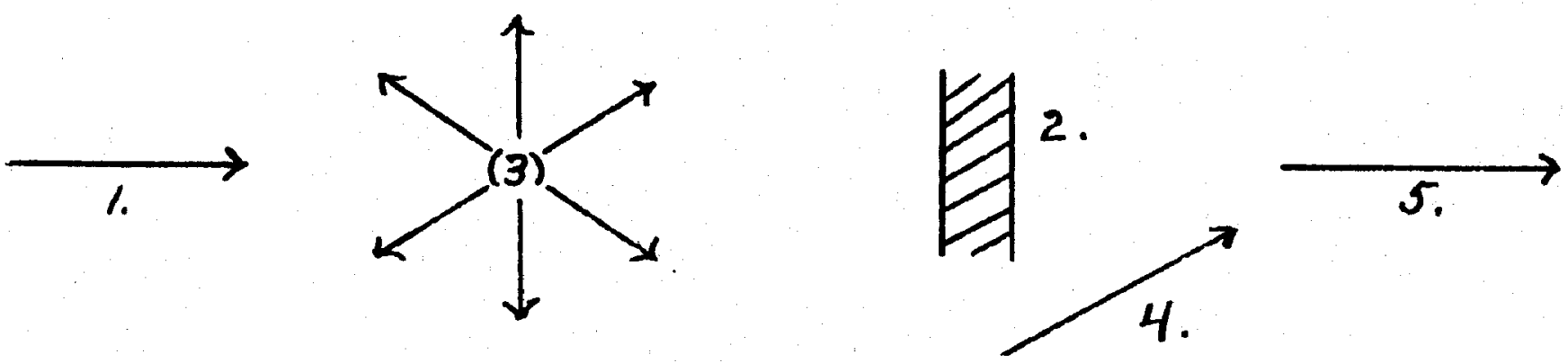

(1) may be described as some form of motivated activity, (2) an obstacle of some sort which serves to thwart the direct satisfaction of the motivated activity, (3) the varied responses made by the organism when satisfaction of the motivating conditions are not immediately forthcoming, (4) the solution response, (5) the attainment of the goal as measured by the reduction of the motivated activity.

TGates, A. J., Jers1ld, H. T., McConnell, T. R., and Challman, R. C. Educational Psychology. New York: Macmillan Co., 1949, P. 614.

8Dashiell, J. F. Fundamentals of General Psychology. Chicago: Houghton-Miffin Co., 1937, p. 35. 
Behavior in a complex organism like the human being is seldom as simple as the schematic presentation would lead one to believe. Further, opinion varies as to the exact nature of noed arousal, thwarting, varied behavior, goal attainment, and tension reduction, but there seems to be agreement among various authorities as to the basic description of the process itself which is fundamental to any explanation of behavior in terms of observable antecedent behavior and subsequent outcomes in behavioral terms.

It is, therefore, necessary to examine in some detall the components of the process realizing that the process operates as a dynamic system and that any segmentation of that system is real only for the purpose of convenience in discussion. Any discussion of a segment of behavior must be thought of in terms of the process itself.

What is the nature of the motivated activity? What sets off the action system of the organism and serves to direct it? Shaffer 9 includes under the motivating activity of the organism, such conditions as organic tension arising from states of hunger, thirst, sex deprivation, alr-getting needs, eliminative tensions, and glandular conditions; persisting stimuli from the external environment requiring an adjustive response; and motives further removed from. immediate internal or external environmental pressures such

\footnotetext{
9Shaffer, L. F. Houghton-Miffín Co., 1936, p. 111.

Chicago:
} 
as reside in the past habit systems and experiences of the organism. Morgan ${ }^{10}$ speaks of certain levels of adjustment and implies that the motivating activities of the organism spring from the needs of the organism to make an adjustment at the physical level, to make certain physical adjustments in the interest of self-preservation; at the biochemical level, glandular secretions, hormonic secretions, building up of wastes and poisons and reactions to infectious bacteria; at the emotional level, the use of the autonomic system In times of emergency with concomitant feelings; at the cerebral cortex level, whlch stems from the conscious thought processes which have accompanied activity in the past and may set off activity patterns at the moment; at the socio-moral level, which includes need for adjustment arising from the interaction of the organism with other similar organisms. Gates ${ }^{11}$ and others propose a neod of the organism as being responsible for the motivating state and subsume under the concept of need drives, impulses, goal sets, urges, motives, cravings, wants, desires, and wishes. They describe needs in the statements below.

(1) The degree of tension corresponds to the strength of the need -- the weaker the need the less the tension, the stronger the need the greater the tension. (2) When a need is latent,

lOMorgan, John J. B. The Psychology of Abnormal People. New York: Longmans, Green \& Co., 1948, pp. 42-43.

IlGates, J. J. and others.: Op. cit. p. 620. 
the person is not consciously aware of its existence but thought processes are likely to be influenced by the neod as tension increases. (3) After the tension reaches a certain stage of intensity (potential state), it is experienced as unpleasant, and its unpleasantness increases with increasing tension. (4) When a need reaches the active stage, the person engages In activity directed t oward the goal (if the goal is known), or is spurred to decrease the intensity of the need in some way. (If needs are anticipated by others and supplied to the person, the need may never become consclous). (5) When the goal is reached, the tension is discharged and the need loses its power to impel activity. The tension discharge is experienced as pleasant.

Krech and Crutchfield 12 belleve that the motivating activity stems from tension which is a result of unbalance in the immediate psychological field of the individual. Symond 13 states that from the psychological point of view, motivation can be considered in terms of need reduction and that needs can be satisfied only by an output of energy on the part of the organism.

There seems to be adequate agreement that the adjustment process is instigated by some need of the organism whether that need be conscious or unconscious and stems from a state of tension aroused either by internal organic

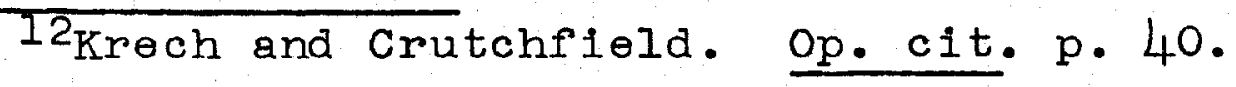

13 symonds, P. M. The Dynamies of Human Adjustment. New York: Appléton-Century-Crafts, 1946, p. 4. 
conditions of the organism or by external stimuli to which the organism has attachod some meaning which may or may not be common to other organisms. The need may result from tension due to imbalance at a basic physiological level or may exist at a level higher in the hierarchy at a complex psychological level. All seem to agree that basic to the adjustment process is a heightened activity level of the organism. This heightened activity level results in goal seeking (conscious or unconscious) behavior on the part of the organism. There would be no problem of adjustment if needs could be Immediately satisfied, but immediate satisfaction of all needs in an orderly fashion appears out of the question in dealing with an organism as complex as the human animal whose repertory of goal-seeking behavior becomes exceedingly complex even within the first few years of life. Thwarting is inevitable which brings about helghtened activity and varied response. What is the nature of the thwarting circumstances? It would seem impossible to enumerate $\theta$ ven in the case of one individual the variety of circumstances which defined in terms of Individual goal-se日king might serve as thwarting circumstances. Perhaps Shaffersil4 classification, which he admits is arbitrarily determined, is as comprehensive as any proposed. He classifies the sources of obstacles under three headings: (1) environmental obstacles (2) personal defects (3) conflicts with antagonistic motives. Included in the ${ }^{14}$ Shaffer, op. cit., pp. 117-119. 
environmental obstacle class are those laws and customs of soclety which block the immediate satisfaction of the needs of the individual organism. A simple instance might appear in the case of a man who has no money but who is very hungry. In our society it takes work at some productive task defined by society to secure money with which to buy food to satisfy the organic hunger need. If he has no money, he cannot immediately satisfy the pangs of hunger and must make some adjustive form of behavior. Also included in this category would be the actions of other people which often block the imediate satisfaction of the need. Another source of thwarting arising from the environment, is aroused when a need cannot be fulfilled because no adequate hablt is available to the individual. Almost any phase of the environment can, in a complex culture, serve to facilitate or thwart at some time or another the peculiar needs of the individual in question. Within the category of personal defects which may serve to block the fulfillment of need, are included such obstacles as physical defects, mental defects, defects arising from one's social position, and defects arising from educational lacks. The recognition on the individual's part of any defects of this nature tends to arouse an adustive response. The third category includes all those situations which are numerous in the human organism where two or more needs are competing for fulfillment but are antagonistic in nature. An example being the physiological sex need of the adolescent 
which, while demanding fulfiliment, is antagonistic to certain taboos of middle class culture. It would seem that almost any felt conflict situations would present an obstacle to goal satisfaction and ne日d reduction, thus giving rise to tension which makes necessary some adjustive behavior on the part of the organism.

From birth onward the human organism operating within its environmental field in search of physical and psychological homeostasis, inevitably is thwarted. It is acknowledged that such frustrating experiences may vary on a continuum of communality as they affect members of any particular culture. It is further concluded that almost any environmental situation, using the term broadly to cover elther internal or external fields of determination, may at any particular moment, varying with the needs of the organism, act as thwarting circumstances thereby increasing the need for seeking adjustive status.

When the motivated goal directed activity is confronted with an obstacle, the resulting frustration according to Mowrer 15 serves to cause the organism to vary the nature of the response. These varied responses, according to shaffer 16 are likely to be responses that have been effective in similar situations in the past. These responses may or may not

I5 Mowrer, 0.H., "What is Normal Behavior." (In) Pennington, L.A., and Berg,' I.A., An Introduction to Clinical Psychology, New York: Ronald Press, 1948, p. 48. ${ }^{16}$ Shaffer, op. cit., p. 120 : 
be effective in reducing the tension arising from the frustrating situation. They may be of such nature to enhance further the tension and increase the frustration. Depending on several aspects, these actions may be regarded as adjustive or non-adjustive which will be discussed later. Gates and others 17 have classified these varied responses as direct methods of reducing tension including direct assault, seeking another path, substitution and compromise; indirect methods including sublimation, withdrawal, and other psychological mechanisms; compensatory methods encompassing the various efforts at covering up the felt thwarting, and aggressive methods which involve inflicting injury upon the blamed obstacle or surrogates for the obstacle. However the varied responses are classified - whether overt and observable or at the symbol manipulation level, there does appear to be agreement that they do occur as a part of the adjustive process and as a result of goal directed activity meeting some kind of obstacle.

As a result of this varied activity, some solution response is eventually forthcoming which serves to reduce tension for that particular organism. Shaffer 18 says that the sole criterion for the occurrence of this response is need reduction. This response may be judged in terms of whether it is adjustive or non-adjustive in character which will be clarffied later when the aspects of adjustment are discussed.

17 Gates and others, op. c1t., pp. 647-693. 18 Shaffer, op. cit., p. 122. 
It is at this point, the solution response, where fudgment is usually made on an evaluative basis.

Eventually the organism attains a goal which is the oulmination of the solution response. Th1s goal may be conscious or unconscious. It may be described in evaluative terms from either the viewpoint of the individual or the viewpoint of his culture and associates. Attainment of this goal, however judged as to appropriateness or inappropriateness to the goals of society at large, does in some measure bring an approach to a state of equilibrium in the organism. This state is, however, not a defined point or period of behavior but merely a convenient point to verbalize and describe. In the process of attaining the goal, new needs and tensions are being evolved according to Krech and Crutchfield ${ }^{19}$ that now reorient the behavior of the organism and the whole process has a continuing quality and an ever-going character.

To recapitulate, adjustment has been described as a process which involves goal-directed behavior, meting in a complex situation, a thwarting circumstance which so heightens the tension that varied responses can occur which eventually result in a solution response. The solution response enables the organism to attain some goal which reduces the tension derived from that particular need-persistent behavior. So far nothing has boen said concerning the quality or the ${ }^{19}$ Krech and Crutchfield, op. cit., p. 41. 
kind of adjustment made. The process as described seems to be agreed upon by a number of writers in the fleld and it is this orientation which will be used in the study under immediate consideration.

\section{Facets of Adjustment}

If, then, the process can be agreed upon, it should be possible to look at what we mean by good adjustment as contrasted with maladjustive responses. Historically maladjustment has been emphasized as the delineation of maladaptive psychological mechanisms originated in psychlatric practico where treatment procedures were sought. The emphasis was placed upon restoring the personality to normalcy which Hacker 20 recognizes as never being adequately defined. Tyson $^{2 l}$ in his inventory lists many characteristics of good adjustment in the descriptive terms found in a survey of mental hygiene literature. Very little has yet been done to establish what is meant by superior adjustment.

What aspects or facets of the adjustment process enter into a concept of good adjustment that can be reasonably well agreed upon? Various writers in the field express themselves differently in regard to these matters and seldom define adjustment in exactiy the same terms or from the same point

${ }^{20}$ Hacker, F.J., "The Concept of Normality and Its Pract1cal Significance," Ámer. J. Orthopsychiat., 1945, 15: pp.47-64.

$21_{\text {Tyson, Robert, "Current Mental Hyglene Practice," }}$ J. Clin. Psychol., 1951, 7: pp. 9-16. 
of view. However, there do appear communalities in what are considered to be aspects of the well adjusted person which can be described. An attempt will be made to list some of these aspects in somewhat the order of frequency with which they appear in the writings of several well-known psychologists in various fields who have attempted to deal with the concept. All aspects are subsumed under seven categorized headings which are expressed in action terms. Since adjustment is to be considered as a process, it is felt that action terms can best be applied to a description of that process. These seven categories are somewhat arbitrary and not mutually exclusive, but seem to encompass fairly well the facets or aspects of that behavior characteristically called adjustive in the literature.

1. Maintaining an integrated personality. This category is mentioned frequently by varlous writers as a seemingly overall aspect of good adjustment. It seems to include a reconciliation of one's needs, abilities, past experiences, and patterns of behavior with the environmental opportunities, goals, and pressures so that one can present a harmoniously functioning united front to the observer. Integration includes the coordination of one's needs and goal-seeking behavior into smoothly functioning interaction with the environment. No one motive is over-emphasized and unusual thwartings can be met by the functioning organism without seriously disturbing its characteristic unity. Maintaining an integrated 
personality as a criteria of adjustment has been stated in several ways.

Traxler 22 states it in this manner:

In the last analysis, the best integrated and adjusted individuals seem to be those who have established some reasonable goals in line with their interests and abilities and who have settled down to work toward those goals serlously and steadily but without unusual tension.

A similar statement is mede by super ${ }^{23}$ :

- . one can think of the individual as a more or less organized and integrated unit, and of the process of emotional development as one in which an attempt is made to organize a variety of reaction patterns or modes of behavior into an integrated, smoothly working whole. One in whom a degree of integration appropriate to the demands made upon him by society has taken place, is an emotionally adjusted person.

Shaffer 24 puts it st1ll differently:

For a person to satisfy all his motives with regard for their functioning as an interrelated system, is good adjustment. To achieve this requires unified and integrated behavior, the presence or absence of which provides what is perhaps the clearest distinction between good or poor adjustment.

Krech and Crutchfield ${ }^{25}$ :

an integrated personality is one in which needs, demands and goals - Instead of func-

22.Traxler, op. cit., p. 335.

${ }^{23}$ Super, Donald E., Appraising Vocational Fitness by Means of Psychological Tests, New York: Harper \& Bros., 1949, p. 482 .

$24_{\text {Shaffer, op. c1t., p. } 138 .}$ 25 Krech \& Crutchfield, op. cit., p. 68. 
tioning as separate, segmented parts of the behavior - work together optimally in a way that is self-consistent, mutually reinforcing, and non-conflicting. And this integration is mainly possible through the individual's system of values, ideals, and ideology.

Kingsle ${ }^{26}$ expresses the same idea:

A wholesome personality is one that is well integrated. In the integrated personality the emotions, intellectual processes, and actions are coordinated so that they work together harmoniously for a happy adjustment to one's environment and for efficient intercourse with it.

Dysinger 27 repeats a similar idea in discussing personality integration:

The well integrated individual is one whose motivations, goals, and desires operate harmoniously within the limits imposed by one's physical and psychological oquipment and those of the physical and social environment.

Probably the most elaborate statement in regard to maintaining an integrated personality is made by symonds ${ }^{28}$ :

A well adjusted person presents a solid, unbroken front to the world and is free from competing trends within. . . He adopts compatible goals, that is, goals which permit him to Iive with harmonious purposes in an open and forthright manner; he is forced to expend little energy in fighting undesirable trends within himself. . . The integrated person, then, has achieved a reconcillation of freodom and discipline... .

${ }^{26} \mathrm{Kingsl} \theta \mathrm{y}$, Howard L., The Nature and Conditions of Learning. New York: Prentice-Hali, 1946, p. 413.

27 Dysinger, 으. cit., p. 25

${ }^{28}$ Symonds, op. cit., pp. 569-570. 
The energy of the drives of an integrated person is expended on the outside world for effective adaptation.

other examples might be cited in the literature but in the main they too phrase in a slightly different manner that which has already been sald. It appears that there is substantial agreement upon the importance of maintaining an integrated personality as one of the facets or aspects of behavior judged as adjustive.

2. Conforming to Social Demands. Another aspect of the whole concept of adjustment which has had and still has some vogue as an index to adjustment is the degree to which the individual can fit into the complex relationships involved in human socleties. It appears to be a minimal necessity to be able to appreclate the neods of others and to heed the rules of the particular culture in which one finds himself. To be able to satisfy one's needs without severe break with social regulations would appear to be a legitimate part of the concept of good adjustment. There appears to be no intent in the writings of those who have given the matter consideration, to demand rigid conformity as a sole criteria; most of them appear to recognize varjing standards with varying cultures as well as legitimate occasions for breaks with the cultural edicts of a particular social group. Dysinger 29 expresses his recognition of conformance to 29ysinger, op. cit., p. 52 . 
social demands:

the poorly adjusted person is often the one who fails to heed social and cultural demands or personal limitations in his efforts to satisfy his various needs and desires.

Morgan ${ }^{30}$ implies some emphasis on this aspect.

The very best indices of child adjustment are to be found in the attitude of the child toward other persons and in their attitude toward him. It is a good sign if he has a wholesome, cordial attitude toward the members of his family, toward his comrades, his teacher and those whom he meots casually.

Mowrer ${ }^{31}$ is quite definite in expressing his attitude toward this aspect of adjustive behavior:

Each Individual born into a human society is under pressure to adopt the approved ways of that soclety, and each individual experiences in the course of his own development some of the struggles, difficulties, and dilemmas which were involved in the evolution of his soclety. To the extent that the individual is able in his iffetime to assimilate the historically hard-won wisdom of society and to experience the fruits thereof, he may be sald to be normal; to the extent that ho fails, he is abnormal.

Kingsle $\mathrm{y}^{32}$ implies the importance of this aspect:

The emotionally well-adjusted adult possesses stable and mature emotional habits, which are in harmony with his intellect, coordinated with his behavior, and in accord with the happiness and welfare of other people.

School Morgan, John J.B., The Psychology of the Unadjusted

${ }^{31}$ Mowrer, op. cit., p. 45.

32 Kingsloy, op. c1t., p. 423. 
Anderson 33 combines the idea of integration with social sensitivity and emphasizes the plan for individual spontaneity:

The term 'socially integrative behavior' is applied to responses characterized by flexiblilty, to behavior which attempts to bring out differences in others and to find common purposes among differences. It is essentially growth behavior in which one can at the same time be spontaneous, have ideas of one's own and be harmonious with others.

Cates and others 34 indicate in making a concluding statement in regard to adjustment, the nocessity of encompassing the social aspect of adjustment:

In short, the well adjusted person is one whose needs and satisfactions in life are integrated with a sense of social feeling and acceptance of social responsibility.

From the above examples, then, it would appear that soc-

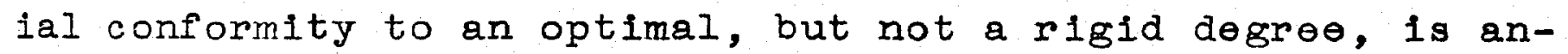
other important consideration when attempting to define the well adjusted person. It is not a discrete category but rather an aspect which must be appraised in conjunction with other aspects.

3. Adapting to Reality Conditions. A somewhat less frequently mentioned aspect is the ability to face reality. A person so characterized seems to be able to organize past experience so

33 Anderson, Harold H., "Domination and Socially Integrated Behavior." (In) Barker, R.G., Kounin, J.S., and Wright, H.F., Child Behavior and Development. New'York: McGraw-HiII, I943. p. 461.

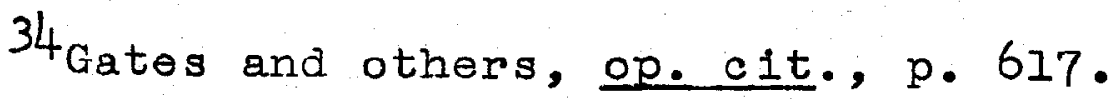


17. When I was younger

18. My nerves

19. Other kids

20. I suffer

21. I failed

22. Reading

23. My mind

24. The future

25. I need

26. Dating

27. I am best when

28. Sometimes

29. What pains me

30. I hate

31. At school

32. I am very

33. The only trouble

34. I wish

35. My father

36. I secretly

37. I

38. Dancing

39. My greatest worry is

40. Most girls 


\section{AUTOB IOGRAPHY}

I, Ralph Harold Tindall, was born in Cedarvilie, Ohio, March 29, 1914. I received my secondary education in the public schools of the village of cedarville, Ohio. My undergraduate training was received at Cedarville College, from which I received the degree, Bachelor of Arts, in 1935. I received the degree, Master of Arts, in 1946 from The Ohio State University. From 1935 to 1941, I was employed as a teacher in three public school systems: Whiteoak Townshlp, Beavercreek Township and Worthington Village. During 1941 and 1942, I served as a Boy Scout Exocutive for Tecumseh Council at springfield, Ohio. From 1943 to 1945. I served in the armed forces with eighteen months oversees dutj. Since 1946, I have been the resident psychologlst at the onto soldiers' and sailors' Orphans' Home in Xenia, Ohio. I have held this position while completing the requirements for the degree, Doctor of Philosophy. 
that he can react to the immediate situation with due regard to the consequences of his actions. He is also able to refrain from some activities so that long range goals may be accomplished. He is able to percelve his own weaknesses and strengths with an optimal degree of clarity and is able to establish clear-cut goals commensurate with his abilities. Various witers havecalled attention to this aspect in discussing adjustment.

Mowrer ${ }^{35}$ has been rather explicit in calling attention to this facet:

In order for a human being to be regarded as 'normal' in any soclety, he must have learned that the best way to safeguard his comfort and well-being in the long run is to 'face reality', 1.e., to expose himself on occasion to present hardship or suffering as the surest way of insuring future survival and satisfaction.

Johnson's 36 semantic approach to maladjustment is based on the vagueness of the person's verbalization of goals and can be subsumed under adapting to reality conditions. He summarizes his approach in this manner:

Bringing these observations together, we see in them a fundamental design, or sequence, which we may refer to as 'the I.F.D. pattern'; from idealism to frustration to demoralization. The statement, 'Things are not going as well as they should', Implies that some ideal or goal is being sought, that the individual is

\footnotetext{
35 Mowrer, op. cit., p. 36 .

36 Johnson, Wendel1. "The Semantics of Maladjustment." (In) Penningtion, I.A., and Berg, I.A., An Introduction to Clinical Psychology. New York: Ronald Press, 1948, p. 498.
} 
being frustrated in his efforts to achleve it, and that he feels discontented or demoralized in some way because of frustration. To put it crisply - maladjusted poople may be viewed as frustrated and distraught idealists.

Fenton 37 in discussing the acceptance of self, refers to the ability of the weIl adjusted person to accept his nice features and his ugly ones, his strong traits and his weak ones without extremes of anxiety or depression. Stroud 38 also discusses the resolution of the conflict between actuality and how one would like to appear to his peers and his friends, as a mark of good adjustment. Kingsle $y^{39}$ speaks about facing hard reality without disintegration.

symonds 40 discusses a person's ability to accept reality:

The person who is well adjusted recognizes the reality and the inevitability of the conditions to which he must adjust... . The well adjusted person learns frustration tolerance, that is, the ability to postpone satisfaction until conditions are ripe to grant them. . A person must learn to face the reality of his inner nature however much he has been taught that certain trends within himself are bad, evil, immoral.

The well adjusted man does not magnify his successes, and, at the same time admits his

37 Fenton, op. cit., p. 95.

${ }^{38}$ Stroud, James B., Psychology in Education., New York: Longmans, Green and Co., $\frac{1946 . \mathrm{p} \cdot 238 .}{196 .}$

${ }^{39} 9_{\text {Kingsley, op. cit., p. } 423 .}$

40 symonds, op. cit., p. 572, p. 578 . 
limitations; in particular, he avoids tendencles toward perfectionism which would be foolish whatever his talents or abilities.

There would seem to be sufficient agreement then, that taken in conjunction with those aspects already discussed, adapting to the realities of the situation is an important aspect to consider in attempting to define the well-adjusted person.

4. Maintaining Consistency. Some authors speak of consistency of response as a tempering condition to the conformity aspect of a well adjusted person. This is more of a qualitative category and seems to set the bounds within which instability of organization is acceptable. It is expected of the well adjusted person that over a reasonable period of time, his actions will be consistent with the standards he sets for himself. There will not be an excessive vacillation of purpose. His behavior is predictable within limits if the circumstances are known. This aspect has been referred to several times in the literature. Lecky 41 refers to this aspect of good adjustment when he says:

It is our view that behavior is usually

' in character' not because the separate

acts are related to one another, but because all. the acts of an individual have the goal of maintaining the same structure of values.

Bagby ${ }^{42}$ intimates that consistency is an important aspect 4l Lecky, Prescott, Self Consisteney: A Theory of Person-
al1ty. New York: Island Press, 1945, p. 10.
$42_{\text {Bagby, English, The Psychology of Personality, New York: }}$
Henry Holt \& Co., 1928, p. 24. 
when he discusses organized behavior:

In short, when an individual is under great emotional tension, he will be nervous and show diffusion unless organized behavior accomplishes release.

Morgan 43 borrowing a term "comfortable constancy" from Poffenberger conveys a similar idea:

Comfortable constancy does not mean ... a condition of inertness. Instead each arena of action can be considered as an area with a hypothetical center equidistant from all dangers and with an outer boundary line beJond which it is not safe to roam. A man may move around at his pleasure in any of these safe areas but is given various kinds of warnings when he gets too near the fringe of danger.

Symonds 44 calls attention to this aspect thusly:

The well-adjusted person is characterized by the persistence and depth of his loyalties.

Mowrer 45 again ties this aspect of adjustment in with conformity:

Whatever reason, non-conformity seems imperative, then openness therein and willingness to take the consequences are requisite. When non-conformity and inconsistency - In the sense of duplicity and evasion - are combined, the soll of social alienation is prepared and seeds of personal abnormality are sown.

Adding consistency, then, to our other aspects of adjustment seems necessary. It serves to enhance the quality of

43 Morgan, John J.B., The Psychology of Personality. New York: Longmans, Green and Co., 1948. p. 46.

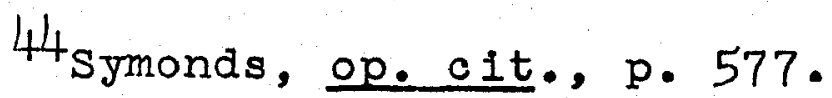

45 Mowrer, op.cit., p. 45. 
adjustment more sharply, delineated possibly by the maintenance of integration. It is the aspect which lends hope to the possibility of predicting within limits, future behavior from present behavior under certain conditions.

5. Maturing with Age. This facet of the well adjusted person takes care of the problem of ageing and permits variation of criteria to differences in age. It is not a pure aspect of the adjustment process in itself, but relates to the growth principle which must be considered in assuming the adjustment level of any individual. Until maturity is reached, it is expected that the process of integration, for example, will progressively become more complete. The same may be applied to adapting to reality situations. It would be expected that the younger child with fewer experiences would be less able to formulate with clarity the subsequent results of immediate behavior, but it would likewise be expected that growth proceeds with age in the well adjusted person. There would seem to be a direct relationship between later adjustment and earlier adjustment as the latter becomes the pattern for the former. It is also necessary to take into consideration the desirability of increasingly asauming the responsibility for one's actions which becomes another facet of the developing personality characterized as well adjusted. Morgan 46 hints at the necessity for maturity to be 46 Morgan, John. J.B., The Psychology of the Unadjusted School Child. New York: The Macmillan Co., 1937, p. 221. 
taken account of in considering the adjustment process when he says:

Personality is changed largely because of external pressure upon the individual; and if a child resists all influences, he becomes fixed as he is, or reverts to a more infantile state of existence.

Smith and others 47 take a more definite stand in regard to this aspect of adjustive behavior.

This complex of feelings and behaviors must be evaluated in terms of the status of the individual (i.e., his age, sex, position in society, etc.). The same bohavior may be evaluated differently when observed in the case of a six-year old and a sixteen-year old in a boy or in a girl.

We must include some reference to a maturational factor in a description of good adjustment. Process of adjustment is not just a reoccurring flow within a fleld of action, but a process that tends toward increasing complexity with the maturation of the organism. The inclusion of this facet seems justifled.

6. Maintaining an Optimal Emotionai Tone. It has been stated by a number of writers that the well adjusted person is a happy person. He can approach life with an essentially optimistic attitude. He can absorb the minor and major disappointments without becoming exclusively involved emotionaliy. He is not disturbed in regard to the fulfillment of simple organic neods such as eating and sex but permits himself to

47 Smith, Eugene R., Tyler, Ralph W., and the Evaluation Staff. Appraising and Recording Student Progress. New York: Harper \& Bros., 1942, p. 354. 
enjoy such within limits regarded unexcessive. He is quite capable of reacting to emotionally toned situations, if the occasion demands, but never lets himself become "thrown" by the process. He may show anger, sorrow, fear, and love when the circumstances are appropriate but he recovers his equilibrium quickly and is able to accept his reactions without excessive self-castigation or placement of blame on other environmental factors.

Fenton 48 mentions this aspect in discussing adjustment and maintains that the well adjusted person can accept himself and changing conditions of his environment with a fairly persistent state of satisfaction. He can teke part in the everyday affairs of life with reasonable assurance and cheerfulness.

Kingsley, 49 discussing the emotional aspects of the well adjusted individual, refers to "emotional stamina" which makes It possible for the person to suffer disappointment without being overwhelmed, to meet frustration without loss of temper and to face reverses with a spirit of optimism. The well adjusted person is also able to examine his desires, urges, prejudices, and feelings of guilt in terms of logical reasoning.

Symonds 50 deals rather extensively with the emotional 48 Fenton, op. cit., p. 95 .

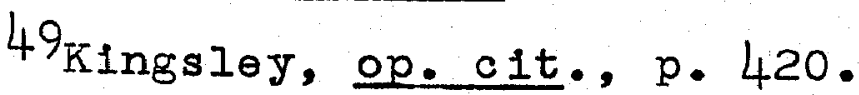
50 symonds, op. c1t., pp. 574-575. 
expression of the well adjusted individual.

The well adjusted man is one who, in addition to capacitios for self-control, has a certain freedom of emotional expression. - A satisfactorily adjusted person is content and maintains an adequate and satisfying emotional under-tone. . . The well adjusted person has adjusted his aspirations to reality that is, the reality of what he can expect of himself in the light of his talents, social position, and opportunities. - . He shows normal curlosity ... He is able to enjoy erotic pleasure without feeling it is somehow bad or sinful... adoquate sexual expression is recognized as a sign of good adjustment, but variations in terms of individual needs must also be recognized and can be contained in a concept of good adjustment. . . The well adjusted person is one whose emotions are under control and who does not permit them exaggerated expression.

There is in the human organism an accompanying feeling tone whenever adjustive processes are considered. How the particular individual handles these feeling tones - the limits within which he permits himself expression, merits consideration in an assessment of his adjustive status. A facet dealing with maintaining an optimal emotional tone seems to be a necessary inclusion.

7. Contributing Optimally to Soclety Through Increasing Efficlency. The facet now to be examined goes beyond conforming to social demands and sets up in value terms the increasingly efficient contribution to society by the individual who is considered well adjusted. This aspect demands a definition in value terms. It presupposes that what contributes to social good is known and that the individual who 
rates highly along every aspect discussed, up to the present, will be free to cope efficiently with problems that eventually lead to a more enlightened society, a happler one, and a more smoothly functioning one. Again, the limiting factors of ability and opportunity have to be taken into consideration in each individual's case. Contribution to soclety as a result of efficient living can be considered at any level. This is a facet of the well adjusted personality that doesn't pretend to stand alone and is perhaps, the least easily assessed of those discussed to this point. However, since increased efficlency can be an outcome of better adjustive techniques, it is included for consideration.

Mowrer 51 considers that any discussion of normalcy must involve a concept of efficiency in regard to striving for a goal or an ideal. Morgan 52 emphasizes that a person can not be considered soclally mature if his whole alm in life is to get all he can from others without contributing in return. Symonds 53 believes that effective adjustment involves the sublimation and soclalization of the basic impulses and drives. Kingsle $y^{54}$ seems to feel that successful adjustment

\footnotetext{
51 Mowrer, op. c1t., p. 37 .

$52_{\text {Morgan, John J.B., The Psychology of Abnormal People. }}$ New York: Longmans, Green \& Co., 1948, p. 86.

${ }^{53}$ Symonds, op. cit., p. 11 .

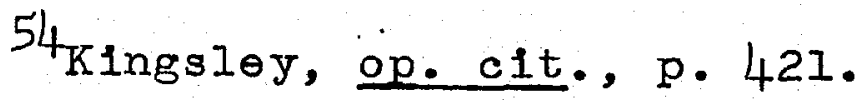


incorporates advancement of the individual in terms of continuously improved performance with a minimum of emphasis on outdistancing others and a maximum of emphasis on selfimprovement.

Hacker 55 equates optimal adjustment with maximum use of capability and that it does involve the making of an evaluative judgment.

By speaking of optimal equilibrium or maximal use of capability we express judgment as to value, namely, that one state of affairs is psychologicaliy better and consequently more desirable than another.

This facet which deals with optimal contribution to society through increasing efficiency is one that appears difficult to define and to set apart. However, it is the crux of the struggle for attainment of techniques judged adjustive. It is the facet which gives purpose in value terms to the struggle for satisfactory adjustment and as such warrants inclusion in our discussion.

It would be nalve to assume that all aspects of good adjustment can be subsumed under these seven major facets of adjustment. For practical purposes, however, these facets developed on the basis of agreement in regard to thein importance by writers in the field, seem to delineate the concept of good adjustment sufficiently so that representative measures of adjustment may, be selected. In order to move from good adjustment to superior adjustment through the medium of

55 Hacker, op. cit., p. 60. 
higher level adjustment skills mentioned by Robinson 56 , it would probably be necessary to create such a facet as that of optimal personal development. By this is meant the maximum use of the creative, aesthetic, social, and recreational outlets avallable and suitable for individual needs within a particular society. Such a step is at present bejond the scope of the immediate project.

In developing a concept of adjustment, it has first been emphasized that from the point of view of this study, adjustment is to be thought of as a process. Further, that this process be judged as to its adequacy in terms of an individual and his environmental field if the various aspects (1) maintaining an integrated personality (2) conforming to social demands (3) adapting to reality conditions (4) maintaining consistency (5) maturing with age (6) maintaining an optimal emotional tone and (7) contributing optimally to socity through increasing efficiency, are considered in their relationships and inter-relationships as parts of the total functionling personality. None of the proposed aspects can be considered in dealing with a functioning person as a single criterion for adustment. They are convenient headings under which judgments may be subsumed, but to have meaning, each aspect must be considered in relationshlp to the functioning whole.

It is, perhaps, well to emphasjze at this time that 56Roblnson, F.P:, Principles and Procedures in Student Counsel1ng, New York: Harper \& Bros., 1950, pp. 240-259. 
while various techniques purport to arrive at an assessment of adjustment, they are in reality based upon expression of bohavior and feeling. Behavior in any specific area mey be measured with the appropriate instrument along a particular dimension. When a label is placed on that behavior as to whether it is adjustive or maladjustive we enter the realm of values which takes us beyond pure objectivity. However, for practical purposes in flelds of therapy and counseling it is appropriate to investigate this concept but its essential subjective nature must be recognized.

In the following paragraphs we propose to develop further the concept of adjustment by briefly discussing agreed upon adjustive mechanisms by means of which the organism carries out the process of adjustment.

\section{Mechanisms of Adjustment}

The human organism is complex and maintains itself in a complex environment. When the organism's goal directed behavior is thwarted, it can arrive at solutions which may only partly reduce the tension created by the instigating need; it may stumble upon, in trial and error fashion, diverse forms of behavior which may act as substitute need reducers; It may select behavior which reduces the tension of the instigating need but may itself be so socially frowned upon that new needs and resulting tensions are created; it may be met with such frustrating clrcumstances for that particu- 
lar organism that partial or complete disintegration of behavior occurs; it may find as a result of thwarting that some form of symbolic behavior is partially tension reducing. There may occur substitutions through the conditioning of one response for another. So many discrete forms of behavior may be evolved from these complex situations that it may be next to impossible to trace back to the original instigating circumstances.

Adjustment appears to be related to age, sex, cultural level, abllity and opportunity of any particular organism. Any judgment formed as to adjustment level in any individual case has to take these many variables into consideration. Despite these difficulties, for large groups within our culture, there are certain recognized levels of behavior necessary for the organism to attain in order to maintain itself independently. When thwarting of any neod occurs, there are also commonly agreed upon mechanisms that organisms typically use, for affecting adjustment. These commonly agreed upon mechanisms, if carried to a degree judged inadequate by either the organism itself or the immediate associates of the organism, can be looked upon as symptomatic of the level of maladjustment. There are no hard and fast lines between that behavior judged well adjusted and that behavior judged maladjusted. Rather these two degrees represent opposite ends of a continuum and only by taking into account all the complex interactions and circumstancos operating at a given time, 
can a fudgment be made. Traxler 57 states it thusly:

(A basic tenent of modern psychology) ... individuals can never be clearly separated into normal and abnormal, or into the emtionally adjusted and the nourotic, but rather that abnormal psychological phenomena are either exaggerations or disguised developments of normal psychological phenomena.

An enumeration of all behavior names that at some time or another fall into the maladjustive class would be almost an endless one. It is possible to take the antagonistic aspects of the facets already described. for the well adjusted person and utilize them to describe the other end of the scale. This has already been implied in the discussion of these positive aspects. It is possible also to group symptomatic behavior in terms of psychological mechanisms which have been described by many writers in the fields of clinical psychology, educational psychology, mental hyglene, etc. These mechanisms seom fairly agreod upon as to their nature. Different writers have different organizational schemes to present them. Even a loose organization of adjustive mechanisms can not be all inclusive nor establish categories that are mutually exclusive, 1.e., mechanisms may take various forms and serve a variety of purposes. A recognition of these adjustive mechanisms is necessary in order to describe the modes of responses made by organisms faced with frustrating situations and it tends to clarify the quality of the facets

57 Traxler, op. cit., p. 336. 
of adjustment already described.

Traxler ${ }^{58}$ further remarks that adjustment is relative, that is, it is not the adjustive mechanism per se that is indicative of the degree of adjustment evidenced but whether or not a persistive adjustive mechanism becomes so habitual and out of line with the individual's concept of himself or with socially approved behavior to set the individual apart to the degree which would label him maladjusted. If the individual resorts to unacceptable mechanisms to overcome the thwarting of some motivating need and as a by-product arouses a degree of anxiety which makes it impossible for the organism to function in accordance with the aspects as previously set forth, then steps may have to be taken to ald the organism to find more acceptable means of reducing the need aroused tension. For our purposes we are more concerned with the adjustive mechanisms that are typically used by the thwarted organisms in order that we may gain some clues from the symtomatic behavior as to the level of functioning of the organism in order to make some appraisal of that functioning level.

Most writers mention various forms of adjustive behavior and various attempts have been made to classify typical behavior. Kretch and Crutchfield 59 divide such adjustive

58 Ibid., p. 335 .

59 Kretch and Crutchfield, op. cit., p. 72 . 
mechanisms into healthy and unhealthy and summarize in this manner:

Adapt1ve adjustments to frustration are found in intensification of effort toward the goal, reorganization of the perception of the problem of how to reach the goal, substitution of an accessible goal for an inaccessible one. Maladjustive consequences of frustration ( $1 . \theta$., those which may occur at the cost of the total healthy functioning of the individual) are found in the form of aggression, regression, withdrawal, repression, sublimation, rationalization and projection, autism, and identification.

But such a division fails to take into account the relative nature of adjustment and tends to encourage a dichotomy of adjustive mechanisms which may or may not be correct in a particular situation. Certainly some forms of withdrawal such as a severe break with reality would undoubtediy be considered maladjustive. However, there are occasions when a degree of withdrawal might, in the light of the functioning of all aspects, be judged quite adjustive as in the particular case of the research recluse who is quite content with his adjustive status and very acceptable because of the nature of his contributions to society. Louttit 60 Iists types of reactions indicating maladjustment and attempts to portray the overt behavior characteristics. He includes such typical reactions as inferiority feelings, jealousy, fear manifestations, day-dreaming, withdrawal, negativism and disobedience, hysteria, compulsions

\footnotetext{
Loutt1t, C.M., Clinical Psychology, New York: Harper \& Bros., 1947, p. 492 .
} 
and compulsive acts, obsessions and obsessive ideas, hypochondriasis, and depression-elation cycles. Manifestations of such actions need to be understood if one is to make any appraisal of adjustment level. Nearly any good clinical psychology text or mental hygiene text expands and clarifies each typical adjustive mechanism.

Perhaps one of the most convenient classificatory systems of adjustive behavior is that of Shaffer 61 who groups the adjustive mechanisms according to the modes of response displayed. He presents five groups (1) adjustment by defense, (2) adjustment by withdrawing, (3) adjustment involving fear and regression, (4) adjustment by allments, and (5) persistent non-adjustive reactions. Under defensive adjustment he includes such behavior manifestations as bullying, attention getting, unruly conduct, stealing, attitudes of inferiority, direct attack, identification, egocentrism, lying, rationalization and projection. In the category adjustment by withdrawing he includes solitary, shy behavior, sterotyped behavior, negativism, phantasy, and retrogression. As adjustment involving fear and regression, he includes persistent worry and anxiety, phoblas, residuals of traumatic situations, compulsions and repressions of thinking. In adjustment by a1lments he mentions timely illnesses, forgetting identity, malingering and stammering and stuttering. As persistent nonadjustive reactions he lists persistent visceral states, 6I Shaffer, op. cit., p. 145 . 
diffused motor activity, repeated motor movements, fatigue, weaknesses, insomnias, aches, pains, vague fears, irritability, depression, pessimism, attitudes of despair, and strong emotional reactions to inappropriate stimuli. No attempt is made by Shaffer to maintain that such categories are mutually exclusive but they do represent a convenient way of classifyIng the many types of adjustive behavior possible in thwarting situations. It is only in the examination of such typical reactions of a group of individuals or examining the behavior of a particular individual over a period of time that any judgment may be formed as to the overall adjustment level of the group or individual in question. Shaffer's classification seems as comprehensive and workable as any and us such merits inclusion in this discussion of the general concept of adjustment.

It may now be noted that there is considerable evidence for the existence of commonly used adjustive mechanisms on the part of large numbers of human organisms. Authority is not always in agreement as to how they should be categorized or at what precise point on the continuum any of these mechanisms shift in status from adjustive to non-adjustive. The process of adjustment can be described. Aspects of that process can be delineated which seem to differentiate between adjustment characterized as of value to the organism and that characterized as neutral or detrimental to the organism as well as the soclety in which it functions. There have also 
been described certain mechanisms which seem to be used by human organisms in acting out the process of adjustment. The formulation of such a concept of adjustment is in reality the background for attempts to make appraisal in individual or group terms of the efficlency of adjustment. It serves further to highlight the complexity of the task undertaken when any effort is made to appraise level of adjustment.

Problems in Measuring Ad justment

If adjustment is a process which may be evaluated in terms of various aspects or facets of the total concept as evidenced through manifest mechanisms and symptomatic behavlor, then it should be possible to sample such manifestations of behavior and derive measurements or indices which, when applied to individuals within a group, would differentiate them along a continuum from adjustive to maladjustive levels. Most measuring instruments and methods of appraisal have attempted to do just that. Whatever the approach questionnaires, projective techniques, controlled observations, judgments of associates, or fudgments of authority - all attempt to arrive at an evaluation of adjustment by sampling responses or actions of the organism in question.

The complexities involved in constructing any technique which adequately samples the behavior of the organism in question, in the light of a complex global concept of adjustment, appear almost insurmountable. When the relativity of 
adjustment to such variables as sex, age, ability, cultural grouping, opportunity, past experience, and momentary structuring of the environmental field are taken into account, the task becomes even more complicated. As a result of these difficulties it might be expected that most instruments are rather Iimited.

When it is considered that many tests such as the usual questionnaires and Inventories depend upon accurate reports of Individuals who may not desire to cooperate to the fullest extent or who, by the very nature of these typlcal patterns of reaction, are unable to report accurately, the task becomes increasingly difficult. Methods of appraisal which depend upon ratings and judgments of observers introduce the response patterns of the observer which may distort the results obtained. Indices of accomplishment may not always be particularly relevant to the appraisal of adjustment because, despite the existence of a high level of accomplishment, individual differences in ability and tolerance of frustration may confuse the issue. Projective techniques may permit a mirroring of unique differences but again the question of imposing the examiner's biases in the interpretation process may cause the results to vary in an unaccountable fashion. Despite these specific difficulties surrounding the measurement of level of adjustment by any one approach now in existence, we continue to use the instruments we have - imper- 
fect though we feel them to be - primarily because they are the only ones avaliable at the present time.

It is the purpose of this study to select certain agreedupon approaches to the measure of adjustment that seem to be representative and frequently used, and compare the results secured from these measures when applied carefully to a defined population in the hope that agreement or disagreement among the measures may be a contribution that will serve to help clarify some of the difficulties faced. Perhaps an accumulation of a body of such data with what is alroady available may indicate modifications in approach to the assessment of the level of the adjustive process. Perhaps by using a clearly defined population, well known to the investigator, some light can be shed upon next steps that might be available in setting up more effective criteria of adjustment. The Iimitations of the instruments used necessarily impose themselves upon the data and any conclusions drawn must take such into account.

In this chapter it has been demonstrated that a global concept of adjustment is 8 complex one which makes any attempt to measure adjustment adequately, a difficult procedure. Nevertheless, we are continualiy arriving at judgments In regard to both groups and individuals in the matter, which makes it imperative that we subject our commonly used ways 
53

of arriving at those judgments to close sorutiny. If we are able to subject our present criteria to sufficient test, then at least we should be able to recognize how much confidence we can place in those criteria. 


\section{DESCRIPTION OF ENVIRONMENT AND POPULATION OF STUDY}

\section{Environmental Background}

The study proposes to apply representative measures of adjustment to a population that is well-enough known that underlying rationale for agreements or disagreements between the various measurements, may be pointed out. At the time of the investigation the investigator was serving as the Resident Psychologist in a comparatively large orphanage known as the Ohio Soldiers' and Sallors' Orphans' Home located in Xenia, Ohio. Since the individuals residing in this institution were well known to the investigator, it was felt that some population within this larger group would serve the purposes. In order to provide some background to judge the collected data, it is felt necessary to present a brief description of the over-all environmental picture of the selected population.

The Ohio Soldierg' and Sallors' Orphans' Home was established by local G.A.R. units, shortly after the close of the Civil War to care for the children of Union veterans. It was soon taken over by the state of ohio and continues to 
function as an autonomous unit of the state, supervised by a board of trustees appointed by the Governor of ohio. In Its elghty jears of existence it has grown to be a sizeable institution with a four-hundred acre campus and over seventy modern buildings. The direct administration is supervised by a superintendent (appointed by the board of trustees) who functions through various department heads. The psychology department headed by a psychologist who resides on the campus, was established in 1938 and is one of the youngest administrative departments of the institution. The institution has at the present time an average of two hundred employees working in various departments. The population has fluctuated up and down over the years from less than onehundred children in its early years to nine-hundred during the depression years. At the time of this study the average population ranged between four-hundred and four-hundred twenty-five children in residence each day.

Children may be admitted from any of the counties or cities of Ohio but must be from families in financially destitute circumstances and must be proven to be children of a parent who served honorably in time of war in one of the military branches of service. They must be between the ages of four years and seventeen years and meet medical, psychological, and social standards as set by the Board of Trustees. At present these standards mean that a child must be free from severe physical defect - not handicapped to the extent of requiring special care or continuous hospitalization. 
The psychological standards mean that to be eligible, the child must establish or be capable of establishing an $I$. $Q$. of at le ast 75 on one of the Binet Scales as administered by a competent examiner, and that he not be so emotionally disturbed as to require intensive psychotherapeutic efforts. The social standards require that he not have a confirmed record of delinquency which can not be coped with within the institutional program. These are flexible standards and are varied in accordance with individual prognosis. Both parents may be living, in fact less than five percent of children now in residence are true orphans with both father and mother deceased. The majority of the population comes from homes broken by the death of one parent, divorce, immoral conditions, or by the institutionalization of one or both parents. Upon entering the Home, each child is held in semiisolation during the first two weoks. At this time he is subjected to a medical and psychological study and slowly introduced to the various routines of institutional living. From studying his background, individual potentials and educational history, a tentative educational program and housing arrangement is set up. He usually lives in a housing unit that accommodates fifteen or sixteen other children near his own age and developmental level. This unit is in charge of a woman employed as a supervisor. Whenever possible, a couple is employed to act as house parents instead of a sole woman supervisor. He is housed in modern cottage-style housing and shares a room with another boy. The house is comfortable with 
living room and basement for recreational purposes. Meals are provided in two centrally located dining halls where cottage groups eat together. His Iife is considerably more regimented than that of the child living in his own home, as regularity of such things as meal timo, cottage chores, bed time, bathing, etc. are inherent in large group management.

A child attends school within the institutional grounds. Small classes in the usual academic subjects are provided from kindergarten through the twelfth grade. In addition to the academic program beginning with the seventh grade, two hours a day are spent in exploratory vocational trades. At the tenth-grade level a child, with counsel, selects a major trade - many in skilled areas ( $1 . \theta$. mechanic, beautician, metal worker, electrician, etc.) in which to spend one-half of his school day. The curriculum includes vocal and instrumental music, dramatics, art, physical and religious oducation. Teachers are for the most part well qualified in the mastery of specific subject matter areas. Classes are grouped as nearly as posible along ability lines and are kept small. Ten months of the year are devoted to such a program. The other two months are spent with remedial school sessions, camping perlods, work experience programs for older children, and with vacations away from the institution either with friends or relatives.

Children are usually in residence until their eighteenth birthday or high school graduation. Some remain until nineteen or twenty years of age, if they have specific programs which require the extra time. Other children are placed upon reaching 
the age of sixteen, if they would appear to profit from work experience rather than a continued educational program. Still other children are placed back with their rehabilitated families whenever such a situation is made possible. A few are placed in approved foster homes when institutional residence seems inadequate for the needs of the child. Because all children are made wards of the applying court upon admission, very few are ever eligible for adoption and are not moved about wi thout the approval of the placing court. The population turnover is not great. Approximately sixty children per year are discharged and about sixty new children are admitted each year. More than half of those discharged are children who have completed their educational program.

Population Selection

It was recognized that in making the proposed study, it would be too time consuming to attempt to measure the total population within the institution as extensively and intensiveIy as was desired. Since our primary emphasis was upon agreement between measurements rather than upon the reactions of a large representative population, it was felt to be more in line with the task set, to secure a population within the institution whose membership characteristics could be clearly defined. Sizeable groups could be found at the elementary school ages of both male and female. Groups of sufficient number could also be found at the adolescent level. It was felt that in order to control the sex variable; only o ne sex would be used and all those of the same race - since the effects of these 
two varlables were unknown upon several of the proposed instruments.

Before the final selection of the group was made, a cursory survey of the avallable measures used to assess adjustment was made. Since many were more appropriate to the older age group, it was felt that one of the adolescent groups should be used. It was also necessary to take into consideration the factor of which group was most intimately known by the investigator. When this factor was considered, it was indicated that the adolescent male group best fitted the requirements of the study.

With this in mind the population finally selected was all of the white boys who had reached their fourteenth birthday by April 1, 1950. Also all boys included were to have been in residence for at least six months prior to April 1, 1950. Boys who were being discharged from the institution because of completion of their school work in June 1950 were not included, as it would be Impossible to secure measurements prior to their leaving. The population then was 100 percent of the adolescent white boys beyond fourteen years of age who were not being immediately discharged and who had been in residence for a sufficient length of time to have become well known by their peers and the adults working with them.

Population Characteristics

With the delineation of the population to be used in this study set forth in the last paragraph, it becomes posible to consider certain characteristics of that population. In 
subsequent paragraphs the cultural background of the group will be discussed; the age range defined; school grade placement considered; the intelligence range of the group shown; and the range of years in residency within the institution set forth. It is felt that such an explanation of these specific characteristics will clearly indicate the limitations of the data.

From a cultural standpoint an examination of case histories indicates that the majority of these boys are products of broken homes, located for the most part in the larger cities of Ohio. Fifteen of the sixty-six boys were full orphans with both father and mother deceased. Fifty-one of the sixty-six boys had at least one parent Iiving. Divorce within the immediate family ran higher than in families of the general population. There was frequent history of institutionalization of family members for criminal offense or for neurotic or psychotic disturbance. A number of these boys had experienced, since infancy, a series of unstable environmental placements - detention homes, foster homes, and other children's Institutions. Elght of the boys had resided continuousiy in the 0. S. \& S. O. Home since they were four years of age. It is possible to generalize and state that none of these sixty-six boys had ever experienced a stable home environment or the cultural advantage usually attributed to midale-class American living. Though all of these boys had experienced disturbed living situations and had experienced many similar cultural lacks, they exhibited a wide range in adjustment status. When the ages of the individuals participating in this group, were calculated as of June 1, 1950 (which was used as 
the anchoring date of the study) the range was from 14 years 3 months to 18 years 4 months. The mean age was 16 years. The sigma of the distribution in months was 13.4. Table I gives the distribution of the population studied according to age in years.

TABLE 1 . DISTRIBUTION OF TOTAL POPULATION Age in Years

ACCORDING TO AGES Number

14
15
16

17
14

17

20

13

The population was enrolled from Grade Six through Grade Eleven as of the close of the school year in 1950. That is, they were completing the grades in which they are listed in Table 2 . The average grade placement of the group was at the 9.5 grade level. Five of the boys were considerably over-age for grade, if compared to ordinary public school standards, but in the class groupings within the institutional school, they were with fellows of similar ages for much of their school program - even though classed at a lower grade level. 
TABIE 2. GRADE DISTRIBUTION OF THE TOTAL POPULATION

Grade

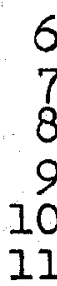

Number

Approximately every three years each resident of the 0 . S. \& S. 0 . Home is tested with an individual intelligence scale. The Revised Stanford Binet Intelligence Scale; elther Form L or Form $M$ had been used most frequently. In surveying the intellectual ability of the group, it was decided to take the latest resulting I. Q. from the Binet, regardless of form. Where there were discrepancies over the years of more than 10 points or where the boy had not been tested with the Binet Scale in the last three years, a new test result was secured. The total I. Q. range was found to be from 72 to 141 . The mean I. Q. of the group was 98. The sigma of distribution was 12.29. Table 3. shows in percent the differences between the chosen population and that expected of the normal population ${ }^{1}$. Where we expect $66 \%$ of the population to lie within the 85-114 range, we have $79 \%$. At the 60 - 69 range where normal expectation is $2 \%$, we have $0 \%$. At the 70-84 range we have $12 \%$ where expectation is

IBernreuter, R. G., and Carr, E. J. "The Interpretation of I.Q's and the L-M Stanford Binet." Jour. Edu. Psychol. 1938, 
14\%. Above 115 where we normally expect to find $17 \%$, we have only $9 \%$.

TABLE 3. INTELLIGENCE DISTRIBUTION OF STUDY POPULATION COMPARED TO NORMAL EXPECTATION

I. Q. Range

Population Percent Normal Expected Percent

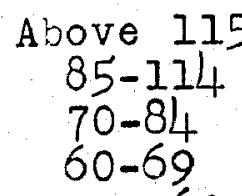

Below 60

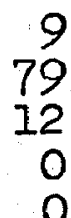

100

0
176

14

2

Totals

1

100

The population studied is somewhat skewed toward the lower average range of ability, but can be consldered as consisting of individuals within the normal range of ability. It has fewer superior individuals, and no individuals below what is generally thought of as borderline ability.

The range of residence at the 0. S. \& S. 0. Home of the 66 boys studied, is from 9 months to 163 months or from $3 / 4$ of a year to 13 years and seven months. The average months of residence for the group is 78.2 months or approximately 6 jears and 6 months. The sigma of the distribution is 38.0 months. Table 4 shows the distribution of the population by years in residence. 
TABLE 4. DISTRIBUTION OF POPULATION ACCORDING TO YEARS OF RESIDENCE IN THE O.S. \& S. O. HOME

Years of Residence

Number

1 year or less

$2-3$

$4-5$

$8-9$

$10-11$

$12-13$

Over 13 years

3
15
13
13
11
7
2
2

From these characteristics it is seen that the population of 66 boys comes from a family background that would rate rather low on a family stability scale. Their cultural background as a group is considerably below that characterized as middle-class American. They are adolescent according to the age range usually considered as such. They are somewhat retarded in school placement but within the average range of ability. They have resided at the 0.S. \& S. O. Home for a considerable length of time. The daily life of each person within the institution is similar in most aspects.

\section{Limitations of the Data.}

It is quite obvious that we are dealing with an atjpical group as far as their being representative of adolescent boys in the general population, attending public school, and living within a family group. The very fact that they have spent long periods living in an institution - subjected to diluted personal relationships - should make their adjustment problems more 
difficult.

While this group is atypical in some aspects and not optimum for a study of adjustment criteria, it has other characteristics that make it a reasonable group to study. In the first place the group's members were available for the intensive measurement and observation procedures. By virtue of the fact that the present environmental conditions are practically the same, variation due to immediate causes, is held relatively constant. By living in such a close group the boys are better known to those making the study than the members of a similar group would be known if drawn from the general population. This degree of knowledge should make it easier to describe variations between adjustment indices. In addition there is more known about the individual members in regard to background factors than with a population selected from a non-institutional group. Because the group is relatively stable, there is more opportunity for follow-up over a longer period than would ordinarily be the case.

In selecting this group, we are primarily interested in the adjustment variable. Observation will confirm that even with the atypical background and environmental circumstances experienced by this group, they do vary as individuals in their adjustment status. Some boys get along better than others within the institutional environment. When they are beyond the confines of the institution, they also vary in their abilities to meet the environmental pressures of the moment. If one considers them in regard to the aspects of adjustment outlined in Chapter 
II, a variation is readily apparent. Since this appears true, then regardiess of the atyplcalness of the group with which we start, we should find sufficient variation within the group reflected on instruments designed to assess the adjustment status to make comparisons from one instrument to another. If we had ideal instruments, a boy reflecting a relative degree of maladjustment on one instrument, should likewise reflect such a degree on a similar instrument designed to measure the same thing. This should be true within our chosen population even though considering its atypical aspects, the adjustment level of the group as a whole might be considerably lower than that of a representative sample drawn from the general population of adolescent boys of similar ages. Inspection indicates that the scores obtained by the varlous methods are distributed normaliy.

In generalizing certain findings that may be brought out when various instruments are considered specifically, it is necessary to recognize the atypical aspects of the group and modify one's generalization accordingly. However, it does seem reasonable that any agreement or disagreement found between instruments as applied to this group should be reflected, when applied to groups with different characteristics. By making recognition of the characteristics of the group with which we are working, we purposely set limitations on the study.

In summary this chapter has attempted to describe the environmental background from which the population was drawn and recognize the limitations placed on the data by virtue of 
1ts institutional character. Further, the population of 66 boys between the ages of fourteen and eighteen (comprising the group) has been characterized in detail in regard to such aspects as cultural background, age, school placement, intelligence, and years in residence. With this perspective the limitations of the data secured should be more evident. 


\section{CHAPTER IV}

\section{GENERAI DESIGN, SELECTION OF INSTRUMENTS AND PROCEDURES}

\section{General Design}

The general pattern of this study follows that of the typical correlational study. It is the intention to deal with the practical question as to whether there is agreement between representative techniques proposing to establish adjustment indices. Therefore, it is intended to apply a variety of measures purporting to assess adjustment to the same population. The population, 66 adolescent boys, was selected so that day-to-day conditions for each member were relatively similar, so that background was fairly common, and so that immediate cultural pressures were approximately the same for each member. Within this framework it was apparent that members of the population exhibited a variety of behavior which was distributed throughout an adjustive-non-adjustive continuum. Data secured through the application of various measurement techniques are to be subjected to correlational study.

It is hypothesized that the various techniques of evaluating a justment, if applied to the same population, should be comparable in the manner in which they differentiate individuals, 
If they are tapping relatively individual ways of adjusting in a reliable and valid fashion. If this situation, which has been described as the process of adjustment is fleeting and has no typical form, then these measures necessarily taken on. different days should have no pattern of relationship. Further, if each technique is tapping unique facets of a complex behavior process, there should be positive relationships between the techniques of any particular approach but not necessarily between different approaches. To ascertain the presence or absence of relationship between various measures and to develop some explanation of whatever state of affairs exists, becomes the imnediate problem of the study.

In order to approach the problem it becomes necessary iirst to determine what are the various approaches to the evaluation of adjusiment. Secondly, it becomes necessary to select representative measures within each approach that are suitable for use with the population chosen. Then it follows that these measures must be applied as skilifully as possible to the chosen population under well-defined conditions. This chapter will deal with these problems in the order set forth above.

\section{Categorization of Criteria Measures}

As has been mentioned previously, many specific techniques. are available which purport to be useful as aids in differentiating between people on an adjustment continuum. These 
techniques have been classifled or categorized in numerous ways for convenience in discussion or handling. It is the plan here to review the se typical classification schemes and arrive at a categorization scheme which will be convenient in fulfilling the purposes of this study and represent all the commonly used techniques. No claim is made for the uniqueness nor finality of any such scheme. Others have and will make divisions differently, which seems quite acceptable as long as all representative techniques can be encompassed logically within the proposed scheme.

We have already referred to the scheme proposed by Greene, Jorgensen, and Gerberich ${ }^{1}$ tho divided the various techniques into those (1) that employ free association, (2) that are based on direct observations, (3) that use rating scales, and (4) that depend upon personal reports. Hutt ${ }^{2}$ categorizes measures of personality as (1) those which can be considered as structured personality tests which permit no opportunity for organizing uniqueness and presuppose all subjects w1ll react to tests alike - inventories and questionnaires, (2) partially structured personality tests which presuppose some conmon stimulus reaction but allow for some organizational uniqueness -

IGreene, H. A., Jorgensen, A. N., and Gerberich, J.R. Measurement and Evaluation in the Secondary School. New York: Longmans, Green and Co., 1946. p. 247 .

${ }^{2}$ Hutt, Max I. "The Use of Projective Methods of Personality Measurement in Army Medical Installations."
I: $134-140$. 
Kent-Rosanoff Word Association, TA T, Bender Gestalt, Incomplete sentences, etc., and (3) the unstructured tests which permit the projection of the tests interpretation into the response given by the subject - Rorschach. Morgan ${ }^{3}$ Iists four important methods for getting at personality evaluation. He lists (I) subjective evaluations in which he includes interview appraisals and appraisals on rating scales, (2) clinical appraisals which are also subjective but oriented in proper perspective, (3) personality tests which permit little unique orcanization of responses, and (4) projective techniques which present the subject with relatively unstructured and ambiguous situations, and require him to do something about it. Bergh in discussing criteria measures used before and after therapy, describes the varlous approaches currently in use under the headings of (1) Ratings, (2) Psychological Test-Retest Techniques, (3) Physiological and Organic Measures, (4) Environmental and Achievement Correlates, (5) Verbal Behavior, and (6) Experimentally Induced Maladjustment. Traxler 5 states that there are two broad approaches to evaluation of personality, one by means of tests and the other by more informal procedures. He then

3 Morgan, John J. B. The Psychology of Abnormal People. New York: Longmans, Green and Co., 1937, pp. 101-108.

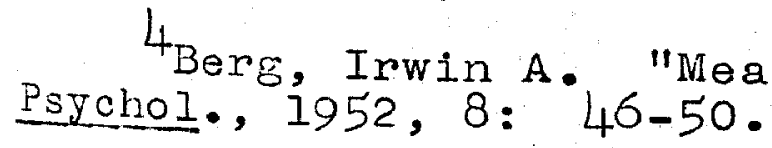

5 Traxler, Arthur E. Techniques of Guidance. New York: Harper and Bros., $1945 . \mathrm{pp} \cdot 98-154$. 
proceeds to break. these two broad approaches down into a ninefold classfication: (I) records of uncontrolled observations, (2) rating devices, (3) behavior descriptions, (4) self inventories, (5) tests utilizing life situations, (6) paper and pencil tests of broad traits, (7) scales for specific traits or attitudes, (8) free association, (9) laboratory techniques. Super 6 seems to agree for the most part with Traxler but emphasizes a throefold approach: (1) by means of tests, (2) through rating scales and (3) by projective techniques.

While the various authorities use somewhat different wording, there is basic agreement upon the techniques used. The categorization scheme developed for this study has taken into account the proposed approaches which purport to establish a quantitative index of the adjustive status of individuals. That is, all of the commonly used approaches applicable to an adolescent population. A development of this categorization scheme will be presented in the following paragraphs.

An examination of the various proposed classificatory schemes discloses that nearly all writers in the field include a category of personal report secured by the means of responses to questionnaires and inventories. Many of these questionnaires and inventories are designed for school populations and are used widely in the public schools. It is therefore important to include a major category encompassing self-reports in our study.

Super, Lonald E. Appraising Vocational Fitness by Means of Psychological Tests. New York: Harper and Bros., 1949, 
Various rating scales are also frequently mentioned and deserve a place in our scheme. Ratings made by adults teachers, parents, psychologists, and others with sufficient opportunity to observe adjustment, have had considerable popularity in the evaluative studies of many different techniques which attempt to establish an adjustment index. Ratings of adjustment by adults using a variety of ratings scales is included as a major category.

Several authorities also mention ratings by close associates or peers. In a population composed of immature people, it was felt imperative to include a category of ratings made within that population by its own members. That is, adolescents place great emphasis on peer status and since adolescents often know their own fellows more intimately than the adults who come into contact with them, these ratings become increasingly important. It has also been intimated that the adolescent uses different standards from the adult in rating one of his fellows which is an additional argument for giving consideration to a peer rating in a comparative study such as this.

The increasing use and mention of projective techniques as an approach to personality measurement, Indicates the need to incorporate in our study representative techniques in this area. At least those techniques that purport to arrive at an adjustment index as a facet of personality measurement, need to be represented. 
Finally, it was deemed necessary to include a category that dealt with systematized direct observation. This category was used to meet the need for including a type of modified time sampling technique designed to establish the frequency of observable reactions thought to be related to adjustment.

These five broad categories make it possible to include all of the commonly mentioned techniques purporting to assess adjustment that are applicable to our population. In addition it was felt necessary to include certain other data for comparative purposes. It was felt that certain extraneous variables might have an effect on the direct measurements of adjustment and should be taken into account.

\section{(a) Chronological Age.}

Though the age range from fourteen years through elghteen years was not large, nevertheless the effect of the se age differences had to be known. So chronological age was included as an additional measure.

\section{(b) Differences in Intelilgence.}

It was felt that differences in intellectual ability should be included in these additional measures as it has been hypothesized that those of higher ability tend to be better adjusted.

\section{(c) Length of Residence in the Institution.}

The other additional measure which might have an effect upon some of the measures of adjustment was the differences in length of institutional residence. It was 
considered possible that the length of residence in itself might be a factor that could introduce a spurious relationship into the correlation of some of the other techniques. It has also been hypothesized that lengthy periods of institutional living contribute to maladjustment at least partly through diluting the relationships conducive to emotional development. The effect of this variable needed to be ascertained.

(d) School Retardation.

A fourth variable was considered as some writers including Rogers 7 emphasize school retardation and school acceleration as an index of a child's adjustment and include such an index in their list of criteria for adjustment. however, when the population of this study was examined, there was very little acceleration or retardation within the group. Therefore, such a measure was not included.

It was found possible then, in view of the schemes set forth in the literature and consistent with the practical suspects of the s tudy, to consider approaches to determining adjustment criteria under five general headings: (I) Questionnaires and interviews, (2) Ratings by Adult Judges, (3) Ratings by Peers, (4) Adjustment Indices Derived from Projective Techniques, (5) Systematized direct observation. In order to take into account extraneous variables with an unknown effect

7Rogers, Carl R. "The Criteria Used in a Study of MentalHealth Problems." Educ. Res. Buli., 1942, 21 : $29-40$. 
uon the results secured through the use of techniques under these five headings, the following additional measures were made: (a) Chronological Age, (b) Intellectual Ability, (c) Lenrth of Institutional Residence. These latter variables will be referred to in the study as Variables with an Unknown Effect.

Selection of Representative Techniques in Each of the Proposed Categories

The next problem was to select under each proposed category of approach to assessing adjustment, techniques and instruments that would be representative of the class. A number of criteria were used as a basis of judgment in selecting such techniques or instruments. In the first place any test to be included must receive frequent mention by authorities in the field and be commonly used. Any technique or test selected had to demonstrate reliability or lend itself to reliability tests within the course of its application which would indicate acceptable rellability. Selected techniques had to be reasonably easy to administer, applicable to the age level, experience and ability of the group studied, and lend themselves to quantitative scoring. In the case of rating techniques they had to be within the scope of training and understanding of the persons making the rating. Further, each technique or test selected must give the appearance of tapping, in a logical manner, the process of adjustment as set forth in Chapter II. 
Within each approach it was felt that the representative techniques chosen should be somewhat different in make-up or emphasis but still represent the class to which they belong. To represent categories where a large number of similar techniques were available, two approaches were considered sufficlently representative of the class. Where similar techniques such as ratings were concerned, but with differing types of raters, representative types of raters available were exhausted.

\section{Group I. Questionnaires and Inventories: This}

group covers the many well known paper-and-pencil tests which require self-report on the part of the respondent. Nearly every author who discusses this group lists many tests that would be applicable to our population and meet the major criteria for selection as set forth. Ellis ${ }^{8}$ in his review of the literature lists the disadvantages in using these types of instruments, but since they are used frequently and because many publishers of such instruments encourage the applications of such tests in school situations, it is necessary in a study designed to use most of the commonly used approaches, to select at least two such instruments. It becomes necessary to try to select commonly used ones which have a somewhat different approach. The typical questionnalre or inventory is illustrated by such tests as the Bernreuter Personality Inventory, The Bell

\footnotetext{
8Elis, Albert. "The Validity of Personality Questionnalres". Psychol. Bull., $1946,43: 385-440$.
} 
Adjus tment Inventory, The California Test of Personality, The Cowan Adolescent Ad justment Analyzer, The Minnesota Multiphasic Personality Inventory, and The Heston Personal Adjusiment Inventory. Most of these tests are listed as common by Cronbach ${ }^{9}$, by Buros ${ }^{10}$, by Super ${ }^{11}$, by Greene ${ }^{12}$ and by others who discuss the measurement of adjustment. If the reported reliability and validity coefficients are compared, it is rather obvious that most of these instruments have a high reliability but frequently report low validity coefficients, or dismiss the validity problem by discussing the instruments' usefullness when discriminating between school groups and known. delinquents or some other group assumed to be composed of maladjusted persons. One test would appear to be about as good as another if judged on this particular criterion. Some are more applicable to the population of the study; for instance, the Minnesota Multiphasic is not applicable to an immature population according to present normative data available.

The selection finally made was somewhat arbitrary but both tests eventually decided upon meet the selection criteria. The California Test of Personality* was decided upon because it

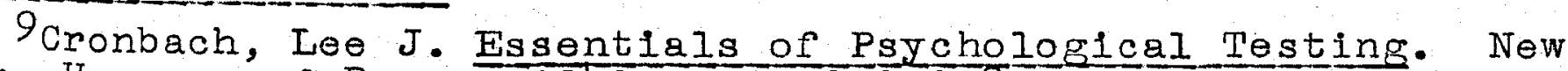
York: Harper and Bros., 1949. pp. 313-338.

10 Buros, $0 . \mathrm{K}$. The Third Mental Measurements Yearbook. New Jersey: Rutger's Press, 1949. pp. 23-114.

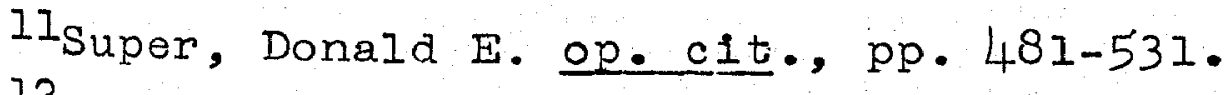

12 Greene, E. B. Measurements of Human Behavior. New York:

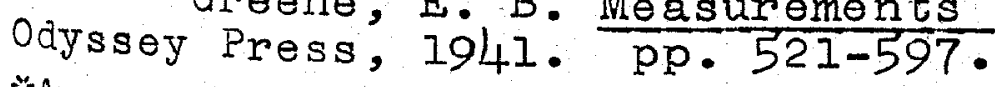
*Appendix pp 288-289. (Whenever possible ali tests and manuals used in this study are included in the appendix.) 
is frequentiy used in schools. It is easy to administer. Reliability figures reported are falrly high (see page 98 ). It is couched in language easily understandable for our group. It has been used a number of times in validation studies. The scoring is straight forward and one which gives a number of subarea scores which might be useful when comparing with other instruments. It seemed to tap the facets of adjustment through the medium of self-report by considering adjustment from the standpoint of self-integration and of social participation, both of which cut across the specific major factors developed in our concept of adjustment. The selection of The California Test of Personality was also somewhat influenced by a recent study of Edmiston and Baird ${ }^{13}$ who had used some members of the present population (when they were somewhat younger). In that study a comparison was made between adjustment ratings (as secured on this test) of institutional school populations and those of public school populations. This study concluded that in general, institutional children indicated poorer self adjustment than noninstitutional children, but evidenced higher social adjustment.

In order that we might have another measure based on the same self-report approach but from a slightly different angle, we chose to include as a second representative measure Heston's Personal Adjustment Inventory* . This test has not been used as

13 Edmiston, R. W., and Baird, Frances. "The Adjustment of Orphanage Children." Educ. Psychol. 1949, 40: $482-488$. * Appendix pp.290-291. 
frequently as the California Test of Personality, primarily because it is a much newer test. It differs from the California in that it measures six factors which were developed by the author through a factor analysis of older inventories and questionnaires as well as through numerous ltem validation studies. Items are not grouped categorically as in the California but are scattered throughout the test. A high reliability for the test is reported (See page 100). Validation studies are reported in more detail than for most similar tests and appear to be more adequate. It is easily administered and norms are available for an adolescent population. It is somewhat more difricult to score than the California, but is straightforward and meets this criteria demand. Its phraseology was considered to be a little difficult for some members of the population but this was not thought to be a serious disadvantage when other tests of its type were considered. It provided six scores that, when described as factors, could be reconciled with the developed concept of adjustment. By making six scores available of factors that have been described carefully and developed through statistical analysis, it gave more data for comparison with that secured from other approaches. While about as good arguments for selecting any one of several other tests of the questionnaire or inventory type might be advanced, these two, The California Test of Personality and The Heston Personal Adjustment Inventory, were belleved to be representative of this approach with all of its inherent strength and weakness, and as such were selected. 
Group II - Ratings by Adult Judges: Ratings have been employed for the measurement of various facets of individual behavior. They are a means of getting impressions in a quantitative comparable form from a number of qualified judges. If the typical sources of error mentioned by Cronbach ${ }^{14}$ such as halo effect, generosity error, ambiguity of terms, and a 11 or none category errors are taken into account, they may be made to furnish more reliable results. They may also be improved î the results of more than one rater's efforts are averacea.

In this study it seemed not only necessary to us o ratings secured from different persons in close daily contact with the subjects, but also ratings using different types of rating scales. Three different rating scales were therefore selected under this approach; each fllled out by persons representing a different category of judges.

The first rating that was needed was an over-all adjustment rating from adults in daily contact with the student in restion. Quite frequently measures of adjustment used in validating a particular instrument to assess adjustment have been so determined. The persons in closest daily contact with each boy of the population were his teachers and his houseparents. It was decided to use a rating s cale employing descriptions of ${ }^{14}$ Cronbach, Lee J. op. c1t., pp. 397-403. 
This scale was found to be appropriate for use by these raters. It meets our criteria for reliability (see page 105). It seemed to be tapping facets of our concept of adjustment in forcing the rater to make decisions on the basis of rather clear-cut behavior descriptions. Its appropriateness for inclusion seemed clear. Since neither of the above ratings was done by a highly trained professional worker and since this is frequently done in studies, a rating by a person with psychological training was used as a third type of approach. Within the institutional and school settings the psychologist is called upon to judge the adjustment level of particular individuals in order to facilitate planning with them. In this setting the writer has had to make adjustment ap praisals based upon the accumulated knowledge of the person's past behavior, his reactions in testing situations, and his reactions in an interview situation.* An over-all rating based on this type of knowledge, even though reliability and validity of the procedure was not clear cut, was felt to be justifiably included for the purpose of comparison with other measures. (For a more complete description see pages 107-108). Because such judgments are commonly made in a varlety of situations incident to counseling, therapy, occupational planning, etc., they should merit consideration in this study.

Group III - Ratings by Peers: Moreno, Jennings, Northway, Bonney, Bronfenbrenner and others have stressed the 
84

importance of peer status as an aspect of adjustment. The assumption seems to be that the degree of individual adjustment is reflected through the individual's acceptance or rejection by his own group. It has been reported by Bonney 17 , for example, that the correlation between self-reported adjustment as secured from the California Test of Personality and sociometric data using a fourth-grade population, was as high as plus .49. Although as Cronbach ${ }^{18}$ remarks, there is no assumption that reputation is a true report of personality - yet, there is significance in how one's associates view him. There are two slightly different methods of securing a rating of a sociometric nature that are rather prevalent: guessing whom a personality sketch represents and choosing a companion for a shared activity. It was felt desirable to include one of each in our comparison of adjustment measures.

The "Guess Who" technique, a common method in use by those considering group status, was introduced by Hartshorne and May $^{19}$ and required the naming of associates to fit certain thumbnail character sketches. It has been shown that the method is reliable (see page 109). Behavior sketches can be

17 Bonney, Merl E. "The Constancy of Sociometric Scores and Their Relationships to Teacher Judgments of Social Success and Personality Self-Ratings." Sociometry, 1943, 6: 409-4.24.

${ }^{18}$ Cronbach. op. cit., 407 .

19 Hartshorne, H., and May, M. A. Studies in the Nature of Character II- Studies in Service and self Control. New York: 
included that illustrate, in overt behavior form, the facets of adjustment suggested in Chapter II. In fact, the sketches based on the work of Tryon 20 fit our descriptions of facets of adjustment very well. These descriptions were developed according to the clusters of traits found acceptable and non-acceptable by boys in an age range similar to those included in the present study.* It can be used by the population of this study as each boy has experienced rather intimate group Ilving over a considerable period of time with each of the boys making up the study population.

The other method of establishing a sociometric rating which seems to get at such relationships from a slightly different angle is based on the work of Moreno 21 , Bronfenbrenner $^{22}$, and Jennings ${ }^{23}$. The latter's work 1llustrates the present approach where companions are chosen or rejected for

20 Tryon, C. M. Evaluation of Adolescent Personality by Adolescents. Monograph of the Society for Research in Child Development, 1939, Vol. IV, No. 483 p.

${ }^{2 I_{\text {Moreno, }}} \mathrm{J}$. L. Who Shall Survive? Washington D.C.: Nervous and Mental Disease Publishing Co., 1934. pp. XVI + 440.

22 Bronfenbrenner, Urie, "A Constant Frame of Reference for Sociometric Research". Sociometry, 1943, 6: 363-397.

23 Jennings, Helen H. "A Sociometric Study of Emotional and Social Expansiveness" (In) Barker, R. G., Kounin, J.S., and Wright, H. F. Child Behavior and Development: New York: McGrawH111, $1943,527-543$.

* Appendix pp. 297-298. 
specific activities. This technique might be designated a "Companionship Choice Test" where activities suggested are in harmony with those usually available in the selected environment. This too is a commonly used technique. It has been shown to be reliable in similar circumstances of use (see page 111). A score can be easily established and again it is adapted to use with this population as the boys are constantly making such choices within the group. It is not easytodemonstrate how it fits into the measuring of the concept of adjustment, unless we assume that level of adjustment is related to peer status. In the activities chosen we make the assumption that boys evidencing severe maladjustment will not be chosen by their peers to participate. Since it has been used where such an assumption has been implied or accepted, it is a technique which we can not a fford to leave out of our $s$ tudy scheme.*

\section{GroupIV - Adjustment Indices Derived from Projective}

Techniques: Numerous projective techniques have been proposed in the last twenty years to provide relatively unstructured situations in which the subject may organize the test stimuli in line with his unlque reaction tendencies. Cronbach ${ }^{24}$ states

\footnotetext{
${ }^{24}$ Cronbach, op. c1t., pp. 433-455.
}

* Appendix pp. 299-300. 
that the two most widely used techniques are the Rorschach and the Thematic Apperception Test. He also mentions the Mosaic Test, the Picture-Frustration Test, the sentence completions, spontaneous paintings, Szondi, the Verbal Summator, word association tests and the World Test. Bell 25 , and Anderson and Anderson 26 also mention similar I1sts. For our purposes it is necessary to select at least two of these techniques which purport to arrive at an adjustment score and meet our other. criteria. A number of these techniques, because of scoring problems, were not applicable to comparison with the other measures used with the population. Two techniques which were representative of this approach and which make claims for assessing adjustment status, lend themselves to group administration and provide methods for obtaining results in numerical form. These are the Group Rorschach and the Rotter Incomplete Sentence Test.

One technique chosen was the Group Rorschach* developed

25 Bell, J. E. Projective Techniques. New York: Longmans, Green and Co., $1948 \cdot \frac{X}{X I-533 .}$. Anderson, Harold H. and Anderson, Gladys L. An Introduction to Projective Techniques. New York: Prentice-Hall, Inc. * Appendix p. 301 . 
behavior based upon the seven facets of adjustment outlined in Chapter $I I^{*}$ as a basis for securing an over-all rating (See pages 102-10lfor a more complete description). It was further hoped to increase the reliability of this instrument by averaging the ratings of these teachers, at least two, and one houseparent. With all of the weaknesses of $\mathrm{s} u \mathrm{ch}$ a procedure it seemed that such a rating would come close to the kind of judgments in regard to adjustment usually made in school and institutional situations and should therefore be included for comparison with other measures.

It was felt that a second rating should be secured on each boy utilizi ng a commonly used standardized rating scale. Then the literature was examined for the type of scale available for the present population, it became evident that the HaggertyOlson-Wickman Behavior Rating Schedule $\mathrm{B}^{*}$ continued to be commonIy used and was favorably reviewed by such writers as Cronbach ${ }^{15}$ and Traxler ${ }^{16}$. It was found to be primarily designed for younger age groups but the literature reports satisfactory results when applied to adolescent groups. It was found possible to secure independent ratings from the two men in the Dean of Boys' office who had close contact with each boy in the population.

\footnotetext{
* Appendix pp. 292-293.

* Appendix pp. 294-295.

15 IbId., p. 400

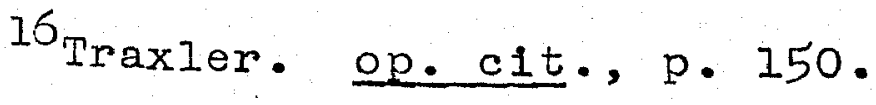


by Harrower-Erickson ${ }^{27}$ and modifled to give a numerical adjustment score by Munroe 28 . This technique met our major criteria. It was appicable to the population group. It was possible to arrive at a fairly straightforward score. The method had been used frequently with groups. Reliability and validity studies had been made (see pages $111_{1-115}$ ). It was based on a structuralized concept of personality that could be rationalized with certain facets of the concept of adjustment as developed. For example, this technique assumes an integration of personalIty which, if in existence, will be reflected by balance between particular types of Rorschach responses. So, the inclusion of some form of the popular Rorschach technique was felt to be necessary in this study.

The other technique chosen was the Rotter Incomplete Sentence Test* developed during World War II by Rotter and Willerman ${ }^{29}$ and further adapted to a college population by Rafferty 30 under Rotter's direction. This test purports to

27 Harrower-Erickson, M. R., and Steiner, M. E. Large Scale Rorschach Techniques. Soringfield, Illinois: Charles C. Thomas, $1945 \cdot V+419$.

${ }^{28}$ Munroe, Ruth L. Prediction of the Adjustment and Academic Performance of College Students by a Modiflcation of the Rorschach Method. Applied PsychologJ Monograph No. 7, Stanford, California; Stanford University Press, 1945.

29Rotter, J. B., and Willerman, B. "The Incomplete Sentence Test as a Method of Studying Personality." J. Consult. Psychol. $1947,11: 43-48$.

30 Rafferty, J. E. A Study of the Incomple te Sentence Method of Personelity Investigation Applied to College Men, Unpublished M. A. Thesis, 0.S.U., 1947 .

* Appendix 302 . 
$88 a$

yield a quantitative score that may serve as an index of adjustment. A high school form existed though scoring norms had to be adapted from those of college students to the high school group. The procedure was approved by Dr. Rotter in a personal interview. Reliability and validity data were avallable (Seo page 117). It assumes that maladjustment will be reflected through an accumulation of well defined conflict responses. It attempts to get at adjustment through the reflection of emoilonal tone in the verbal expression area. Because of its ease of administration, its stralghtforward scoring, and claims as an adjustment assessing instrument, it was included in the study. Since it is fairly recent in its present form, it had not been used as commonly as some of the other included measures. Group V-Systematized Direct Observation: Many writers including Cronbach ${ }^{31}$ mention direct observation in various every-day situations as an approach to securing an adjustment assessment. It is commonly recognized that such a technique is fraught with errors as no two circumstances - even though outwardly appearing similar - can be experienced exactly the same by the respondent. It is difficult to secure enough of a sampling of such typical behavior in ordinary situations to be sure that you have a record of typlcal behavior. In addition, there are errors arising from differences in the way

\section{Cronbach. op.c1t., pp. 386-395.}


the observer views the behavior exhibited. He is subject to attention lapses unless what he is looking for is very well defined. It is difficult to observe without the presence of the observer changing the fleld of behavior in whlch the one observed reacts. Nevertheless, since there have been clalms made in regard to this approach, it was decided to include some form of systematized direct observation if only so that 1 ts merits or difficulties might be compared with the other measures.

In making a decision as to what technique would best represent this approach, it was felt that the work of 01 son $^{32}$ might be used as a basis to construct a modifled time sampling technique that would provide as objective approach as possible and sample as many situations as possible within the time available. Since our population was accustomed from time to time to seeing members of the psychology department drop into classrooms, work shops, and recreation areas for the purpose of observation, it was felt that a schedule of such observations could be conducted without specific knowledge on the part of the boy observed that he was being observed. It was possible to select defined behavior occurrences related to the concept of adjustment. Inter-observer reliability was possiblo by using two observers for a sampling of the observations. (See pages 119-120.) Since some form of time sampling seemed to be

$3201 s o n, w . C$. The Measurement of Nervous Habits in Normal Children. Minneapolis: The University of Minnosota Press, 1929. pp. 2-87. 
necessary in order to reduce sampling, biases, observer biases, and situational biases, this was the technique finally selected to provide comparison with other approaches.*

Variables With an Unknown Effect

As has been mentioned previously, it seemed necessary to include for comparative purposes certain variablos known to exist within the population group. It was known that chronologlcal age differences were present and in view of observed differences in adjustive status, it seemed imperative to see whether these measures were applicable to the age range of the population without reflecting differences in age range.

It was also known that the intellectual potentlalities as usually measured were different within the group. Since we have such differences, what relationship do they have with the measures supposed to reflect adjustive status? It was felt that a mental age in months, if compared with the data secured from the other measures, would indicate if there were a relationship and with what particular approach the relationship would be most apparent.

Since the members of our population had resided for varying periods of time within the institution, it was desirable to see If length of residence would be reflected by the techniques used to assess adjustive status. Some consideration was made of the possibility that the boy who had resided longer in the institution 
might reflect some differences when appraised by the usual criteria in contrast to the more recent arrival. By including this variable some light might be thrown upon the question which is of ten asked: What effect does a long period of institutional residence have upon the usual measures of adjustment?

The measures discussed in this section were chosen to be included in the study. A more detalled description of each technique and how it was used in the study will follow in the next section. To recapitulate and to group all selected indices so that they may be easily viewed, the following outline of the selected approaches and included measures is presented. Group I - Questionnalres and Inventories

1. California Test of Personality

a. Self Adjustment

b. Soc1al Ad justment

2. Heston Personal Adjustment Inventory

c. Analytical Thinking

d. Soclability

e. Emotional Stability

f. Confidence

g. Personal Relations

h. Home Satisfaction

Group II - Ratings by Adult Judges

1. Rating by teachers and houseparents.

1. Average rating of two teachers and one houseparent.

2. Rating using Haggerty-Olson-Wicleman Behavior

Rating Schedule.

j. Average rating by personnel in Dean of Boys' office

3. Rating by psychologically trained personnel

$k$. Rating by psychologist based upon case material, close acquaintance, and a semi-structured interview. 
Group III - Ratings by Peers

1. Using the "Guess Who" technique

1. Algebraic score derlved from selection for favorable and unfavorable descriptions.

2. Using the "Companionship Choice" technique.

m. Algebraic score derived from choice and rejection.

Group IV - Adjustment Indices Derived from Projective

1. Group Rorschach Techniques

n. Score derlved through adaptation of Munroe.

2. Rotter Incompjete Sentence Blank

o. Score derived through adaptation of Rafferty's norms 。

Group V - Systematized Direct Observation

1. A modified time-sample of behavior

p. Score based on occurrence or non-occurrence of specified behavior within a given time IImit.

In addition certain extraneous variables were measured.

For convenience they may be listed below:

Varlables with an Unknown Effect

1. Age differences

q. Chronological age in months

2. Differences in Intelilgence

r. Mental Age in Months

3. Length of Residence

s. Months of residence in the O. S. \& S. 0 . Home. 
Detailed Description of Each Technique Chosen and Specific Procedures in Using Each Technique

General Considerations. Beginning early in April of 1950 all tests which could be administered to the group as a whole, were scheduled one week apart. During the first testing session all the boys were told that they had been selected for a series of tests which by their honest and full cooperation might help the psychologist to understand them better and also might help other boys of their age to be better understood. They were told that the test protocols would not have their names upon them and that only the writer would be able to identify their paper from the code number. They were further reminded that in the past they had been most frank in their expressions of feelings in personto -person interviews and that the same performance was expected in a group situation. All members of the group met in the same room each week and were subjected to exactly the same testing situations. Three cases of lilness during the testing were tested Immediately in the office of the writer after the boys were released from the hospital.

The group tests were administered over a perlod of five weeks. All sessions were scheduled for approximately an hour perlod with a two-hour period schoduled for the Group Rorschech. The California Test of Personality was used the first session. The "Guess Who" was scheduled for the second session, the Rorschach at the third, the Heston Personal Adjustment Inventory 
94

at the fourth, and Rotter's Incomplete Sentence Test and the "Companionship Choice Test" at the fifth. Throughout the group testing cooperation appeared satisfactory, as all boys stayed at the tasks set for them. Almost all of the protocols were completely filled out and all were scoreable. No scoring was at tempted until the other measures were secured.

While the group testing was being done materials for securing ratings from teachers, houseparents, and deans were distributed by personal contact. All materials were explained and the task outlined through a personal interview with each person concerned. All persons making such ratings were requested to return all materials by June 15, 1950, the close of the school year. As materials were returned they were checked by the writer's assistant to see if the task set forth had been performed, and were filed away until such time as all data were in so that no ratings were known to the writer until after he had made his own.

After the group testing was completed, the time sampling was carried out by the writer and his assistant by conforming to a pre-arranged schedule during the last six weeks of school. During July, Aug., \& Sept. of 1950 the personal interviews which formed a part of the background for the psychologist's rating were conducted and recorded under code numbers. Other measures were easily obtainable from the files in the department. 
To insure a minimum of bias in handing the protocols obtained by the varlety of techniques, a code number was used for each boy. This code number was assigned at the beginning of the study. It consisted of the four digits of telephone numbers taken from a page of the local directory and assigned through the process of drawing the names of the boys from a hat. Each answer sheet or rating record had the boy's name stapled to the sheet and the code number on the sheot. Whoever completed the record simply tore off the stapled name leaving the protocol identifiable only by the code number. This method permitted the handing and scoring of all data without knowledge of whose record it was until the scoring was complete.

The level of rapport throughout the study was judged to be high, perhaps higher than that usually found in most situations. This was possible since most of the boys were well known to the writer through mutual participation over several years in a variety of activities. The psychologist had been on excursions, camping trips, fishing trips, recreational teams, etc. with all of these boys. Within the institution the psychologist serves as a counselor without disciplinary duties. He had frequently discussed with individual boys such dificulties as anti-social activities, pranks, rule infractions, etc. but in a nonpunitive capacity. Over the years he had shared many intimate confidences to the extent that there seemed to be a feeling of frankness in almost all of his relationships with these boys. As a result of 
mutual trust most of the participants in the study appeared to be trying as honestly as possible to respond conscientiously to the measuring techniques used. Perhaps an example or two will illustrate the general level of rapport existing. One boy had developed a serious stealing behavior pattern but had been trying to understand his situation and do something about it. During the time of this study he had found the accessibility of class funds too tempting and had stolen five dollars. A few days after spending the money, he came to the psychologist and laid out the facts and asked for help in getting the situation straightened out and also advice on how to improve his habits in the future. With counsel he was able to work out a satisfactory solution for the immediate situation and take some positive steps to reduce the occurrence of the unacceptable behavior. Needless to say, had there been no confidence the boy would have attempted some other way out. Another boy who had rather extreme sexual conflicts was quite frank in reporting such interpretations on the Rorschach. If he had felt that his problem was not understood, he would hardly have done this. Still another boy who was quite disturbed over the fact that an older brother had just been sentenced to a penal institution, came in to discuss the situation before there was general knowledge of the occurrence. These examples could be multiplied but will serve to illustrate the level of relations existing between the boys making up the population and the person conducting the study. 
Description of Each Measure and Procedure Followed in Administration. In the following pages a detalled description of each instrument will be made. A more detalled description of administrative procedures will also be made. Steps taken to derive comparable numerical scores for all measures will be presented. The various instruments will be taken up in the order presented in the outline on pages 91-92. The appendix of this study contains coples of test blanks, manuals, and rating scales.

\section{Group I - Questionnaires and Inventories}

\section{The California Test of Personality-Secondary Form A, for Grades} 9 - College was used. Form $A$ at this level had not been used with this population previously. This test contains two principle sub-topics, Self Adjustment and Social Adjustment. Each sub-topic is made up of six sub-tests consisting of fifteen questions to be answered by drawing a circle around either "yes" or "no". The authors, Tiegs, Clark, and Thorpe have taken care to phrase each question to minimize the student's tendency to protect himself through the painting of a better self portralt than actually exists. The 1tems chosen as stated by the manual were selected through a study of over a thousand adjustment situations facing students of these ages. The items were included on the basis of judgments by teachers and princ1pals as to their significance and validity, by student reactions 
as to willingness and ability to respond and an item analysis by means of the biserial $r$ technique. Reliabilities computed by means of the Spearman-Brown Formula based on populations ranging from 272 to 292 are reported for total scores to range from .918 to .933. Reliabilities for the two major components range from .857 to .908 . The sub-test reliabilities are lower ranging from .60 to .87 . Data given in the manual in regard to validity is discussed under four headings: selection of items, personality components, test item disguise, and limitations. These discussions relate to the intrinsic nature of the test and its usage. No evaluative studies are provided which might indicate the usefulness of the instrument in indicating adjustment level as validated against some agreed upon outside criterion. Buros 33 reports some twenty-four studies which have utilized this test as a criterion for adjustment. The reviews in Buros question the authors' claims for the test on the basis of the vagueness surrounding the validity data.

The test was administered to the sixty-six boys making up the population group in strict accordance with the directions for administration found in the test manual. Since this test was the first in the series to be given, rapport bullding statements as previously mentioned were made prior to actual administration. Prior to the testing situation each test blank had the name of the boy stapled to it and the code number of the boy

${ }^{33}$ Buros. op. cit., pp. 55-58. 
written on the blank itself. Upon completion of the test each boy removed his name from the test. Scoring was accomplished by following the scoring directions found in the manual. The test is designed to show a profile of scores in each of the twelve sub-test areas in percentiles. For our purposes it was decided to use the raw score total for each of the sub-toples since relatively higher scores in these two major areas indicated relatively higher adjustment according to the claims of the test. This method provided us with a measure of self adjustment and a measure of social adjustment with scores apparently distributed normally.

The second major instrument chosen in this group was the Heston Personal Adjustment Inventory. This test measures six traits of personal adjustment: (I) Analytical Thinking, (2) Soclability, (3) Emotional Stability, (4) Confidence, (5) Personal Relations, (6) Home Satisfaction. These traits of adjustment were developed through the process of analyzing existing tests including Bell's Adjustment Inventory, Darley and McNamara's Minnesota Personality Scale, Guliford's Inventory of Factors STDC R, Guilford and Martents Invontory of Factors G A M I , Evans and MCConnelI's Minnesota $T-S-E$ Inventory, and Thurstone's Personality Schedule. The test consists of 270 questions to which one may reply with a "yes" "no" or lundetermined". Each item refers to only one of the trait scores. The items for each trait are systematically scattered throughout the 
test. High school norms are based upon testing in four different Indiana High Schools. Reliabilities reported in the test manual were computed by means of the spearman-Brown Formula based on 100 students, 50 men and 50 women. Reliabilities for each trait score are reported as follows: analytical thinking .855 , sociability .910 , emotional stability .852 , confidence .835 , personal relations .800 , home satisfaction .867 . These reliability coefficients are reported to be of the same magnitude as those obtained from two other similar studies. The validity problem was approached by three different methods (1) internal consistency, (2) psychological meaningfulness of the items, (3) and validation against independent criteria. Items were refined through three internal consistency studies where items to be included had to discriminate successfully between the upper and lower 27 per cent of the samples chosen. Through the second method no 1tem was assigned to a scale on the basis of discriminatory value alone. The item had to make sense psychologically in the judgment of the author and his coworkers. By the third method thirty-four De Pauw faculty members were asked to agree with, disagree with, or refuse to judge each student's percentile scores when compared with their judgement on the basis of acquaintanceship with the student. These faculty members agreed about 65 percent of the times, disagreed about 10 percent, and refused 25 percent of the times on five of the traits. Half of the judgments were refused 
on the home satisfaction trait. Armstrong reports in another study quoted in the test manual that the correlation between the scores made on the six traits and ratings made by seven close acquaintances range from .28 to .70 . Another study is reported showing $r^{\prime} s$ between scores and self ratings on the se traits ranging from .31 to .62 . Another study comparing the scores on the Heston with scores on the Minnesota Multiphasic, show positive agreement between similar traits making up the two scales. The manual also reports two studies by Cook which indicate that the Inventory differentiates better between college men and men who are inmates of a reformatory than between high school boys and boys who were inmates in a juvenile correctional school.

This test was administered at the fourth session of testing following the recommended directions as set forth in the manual. The same general procedure as described earlier was followed. Three boys were in the hospital and were re-tested the following day after being discharged from the hospital. The scoring was done by hand using the stencils provided. Since hich scores in each tratt were supposed to represent the better adjustment, these raw scores were used to establish a score for each trait to be compared with other measures.

Group II - Ratings by AduIt Judges

To secure ratings in regard to adjustment on each of the 
55 boys, a Student Adjustment Rating Sheet was designed following the analysis of the aspects of adjustment set forth in Chapter II. (See Appendix pp. 292-293). The format followed to a certain extent that of the American Counc1l on Education Personality Report. Each facet of adjustment was defined as clearly as possible. Five behavior descriptions were set opposite the description of each facet. These descriptions ranged from behavior judged by the writer and his assistant as very good - - to behavior judged as very poor. The teacher or supervisor was required to check the most applicable description under each of the seven facets and then to make an overall rating on a scale elghteen centimeters long on the final page of the scale. Above this dotted line the degrees of adjustment were described as maladjustment, somewhat maladjusted, average adjustment, falrly well-adjusted, and well-adjusted. This provided a guide for the judge in helping to decide just where the boy should be marked on the adjustment continuum. A manual was prepared to accompany the test which covered the concept of adjustment and explained the rating system. This manual is included in the appendix.

This instrument was used to secure an average rating by having two teachers who had had close acquaintanceship with the boys of the study, make independent ratings of each boy. At the same time the boys' houseparents were asked to make independent ratings on each of their boys using this same instrument. The Student Adjustment Rating sheot and the 
accompanying manual were explained individually to each rater. They were asked to remove the stapled name of the boy which appeared on each sheet to be rated by a particular rater. A discrete score was secured for each individual by measuring along the 18 centimeter scale and reading the score in millimeters. This scheme follows the recommendations made by Champney and Marshal1 34 on securing optimal refinement of the rating scale. Scores were thus secured from three different raters for each boy and in order to increase their reliability, as Cronbach 35 suggests, they were combined into an average rating.

Interjudge coprelations give some indication of the rather low reliability of the instrument when used by single rater. When the ratings of two teachers were compared, an $r$ of $.486 \pm .063$ was secured. When the ratings of Teacher $A$ were compared with the ratings of a houseparent, the correlation was only $.268 \pm .077$. The correlation between Teacher $B$ and the houseparent was $.363 \pm .072$. The average rating including the independent rating of the three judges has a slightly higher reliability of $.582 \pm .055$. These low correlations were found despite efforts to reduce halo effect, to eliminate generosity error, to reduce ambiguity of terms to a minimum and to make clear the rater's task.

\section{Champney, Horace, and Marshall, Helen. "Optimal} Refinement of the Rating Scale," J. Appl. Psychol., 1939, 23: $323-331$.

${ }^{35}$ Cronbach, op. cit., p. 402 . 
The inclusion of such unreliable data can only be warranted when one considers the frequency of the use of such criteria. For example, Ell1s ${ }^{36}$ lists forty-four attempts to validate personality questionnaires against the ratings given by teachers, friends, associates and others.

The next rating of adjustment status in this group was secured by using the Haggerty-Olson-Wickman Behavior Rating Schedule B. * It is one of the older and more frequently used scales employing a forced cholce technique. While originally deslgned for elementary pupils, it has boen found by the authors to be applicable to high school students as well. They report in their manual that age and grade differences in scores are negligible. Schedule B is composed of four divisions of tralts: intellectual, physical, social, and emotional. There are a total of thirty-five graphic rating scales assigned to traits distributed in these four areas. Below each trait are five descriptive phrases which are to assist the rater in making a quantitative judgment. Each of these five descriptive phrases has been assigned a weight in terms of its relationship to schedule A which consists of frequencies of occurrence of fifteen behavior problems related to adjustment.

An overall score from the Heggerty-Olson-Wickman Behavlor Rating schedule B, may be secured by adding the weights

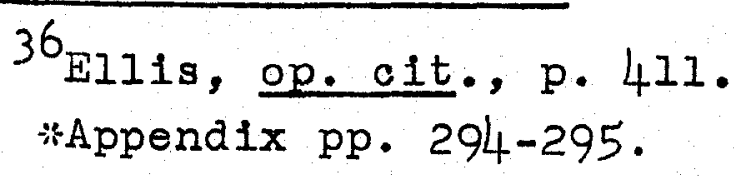


assigned to the item checked by the rater on each of the thirty-five graphic scales. This rating was secured in this study through instructing the two men in the Dean of Boys! office to make such a rating independently after a personal conference with the writer to insure understanding of the manual and the schedule. Each was famillar with the boys in this study as this office directly supervises housing of the boys and deals directly with related problems. Both men had the equivalent of the training of high school teachers and were capable to make such a rating. In order to improve the reliability the two scores for each boy secured through these independent ratings were averaged. This procedure is recommended by Traxler 37 in his review of this schedule as a method to increase its rellability.

I'he authors report a reliability coefficient of .86 between repeated ratings by the same teacher on elementary school children. The reliability of a single rating, when split halves are used, is reported by the authors as .92 . The intercorrelation botween the raters in the present study was found to be $.70 \pm .04$. The reliability for the average rating made by the two Deans using the Spearman-Brown prophecy formula becomes $.82 \pm .03$. I'he scale has been validated against frequency of referrals to the principal's office in one school and correlated .76 with such referrals. Scores $37_{\text {Traxler, op. cit., p. } 150 .}$ 
have also been validated against Schedule A which lists frequency of overt behavior disturbances and resulted in a correlation of .60 . The authors state that they feel the scale over-emphasizes the aggressive types of nervous and emotional disorders.

A third rating in this group was made by the writer who was serving as the resident psychologist for the institution. As stated by Greene ${ }^{38}$ interviews have frequently been used to arrive at important conclusions in regard to a client. Much depends upon the skill of the interviewer, the degree of rapport, and other similar factors. The trained person's rating has been used frequently in clinical work wherecase histories, testing records, and interviews are combined to arrive at a diagnosis of client behavior. At the O.S. \& S.O. Home comprehensive records are kept by the Social Service Department, The Psychology Department, and The School. AlI of these sources plus an acquaintance of several years with many of the boys in the study, were used to arrive at an overall rating of adjustment. Over a period of three years during the writer's employment at the institution hundreds of evaluative interviews have been held with students. Over that period of time it has been possible to develop a sequence of topics to be covered which have seemed to be empirically justified as aids in clarifying the adjustment status of students. Over this same period a very good de- 
gree of rapport has been built up between the department and students. As a result most of them, knowing that their problems are treated confidentially and in an objective manner, are able to discuss problems with a remarkable degree of frankness. The interview outline used in this study is the result of experience and covers six major areas: Interests, School Adjustment, Cottage and Campus Adjustment, Health, Social, Emotional and Sexual Adjustment and Family Relationships. Each area contains a number of sub-topics which have been found pertinent to reveal the student's reactions in those areas. The order of occurrence of toples has been found to be such as to arouse the least resistance but no inflexible moving from one toplc to another is used. Rather each area is approached naturally and easily without a serles of probing questions and answers. The interview outline merely serves as a guide and notes are jotted down during the guided conversation. It is understood in the beginning that as an aid to memory, facts will be jotted down but that they will be avallable only to the psychologist.

To make these ratings the psychologist scheduled interviews during July, August and September of 1950 with each of the sixty-six boys in alphabetical order. Not more than two interviews were conducted per day, each lasting approximately an hour. Prior to an interview with each boy the department files, the school files, and the social service files were carefully studied. Each interview followed the outline pre- 
sented in the appendix.* In the early rapport-bullding stage a remark like this was made to each student, "You won't mind my jotting down some of the things we discuss as we go along, as I find my memory won't permit me to remember how you feel about certain things. Of course these notes are for our own use in recalling at a future date, just what we discussed and won't be used by other persons on the campus." This has always seemed to work well as such personal matters as involvement with authorities, relationships with other students, intimate family problems, severe behavior problems, sexual problems, etc., appear to be discussed frankly and no more resistance is encountered than would be expected when discussing any conflict area.

Immediately following each interviow a rating was made on an eighteen centimeter adjustment scale exactly like the one used by teachers in filling out the student Adjustment Rating Sheet. Discrete scores were computed in the same way by reading off in millimeters the distance toward the well adjusted end of the scale.

Reliability figures for the instrument were obtained for a sample of twenty students by having the writer's assistant independently go through the same process prior to the interview and then listen to the interview and make an independent rating. This was accomplished by means of a hidden microphone connected through a public address sys*Appendix, p. 296. 
tem to a speaker in the assistant's office. A rank order coefficient of correlation of .76 was found which was indicative of the reliability of the method. Validity of such a method may be clarifled somewhat through comparisons of other measures used in this study.

\section{Group III - Ratings By Peers}

The first of the ratings to be secured in this group was obtained through a "Guess Who" test. This test (Included in the appendix)* was composed of twenty-five brief descriptive phrases of behavior couched in language understood by the boys in this population. The descriptive phrases were based upon the work of Tryon 39 . The phrases described the traits showing highest degree of favorability for boys of this age when subjected to cluster analysis. Phrases were also constructed for the opposite type of behavior to show unfavorability. This is much the same procedure used by Tyron in constructing her opinion Test. Twelve pairs of opposites were taken directly from her work and one further trait description was added which had been found to mark certain boys who are rejected by their peers at the 0.S. \& S.O. Home.

It is hypothesized that the boys chosen on the basis of exhibiting favorable traits are accepted by their peers

39 Tryon, op. c1t., pp. 1-83.

*Append1x, pp. 297-298. 
and are thus reflecting a higher degree of adjustment to their environment. Reliability figures were reported by Tryon in regard to the opinion Test which is very similar to this test. She reports a reliability ranging from .49 to .90 using the split half method and applying the SpearmanBrown formula. On two tests ten days apart she reports with several groups, reliabilities of .75 and better. We found with a split half method and then applying the spearmanBrown formula a reliablity coefficient of .95 .

This test was given to all sixty-six boys in the second session of group testing. Along with the test each boy was given a sheet containing in alphabetical order all of the boysl names in the study. It was requested that selection be restricted to the boys' names appearing on the sheet. Prior to the test the group was reminded that we were interested in finding out more about boys of their age, their likes, their dislikes, and how well they could size up each other. They were further reminded that their replies would be confidential and would not be used against any boy in any manner. They were instructed to attempt a guess for each description, to use full names, and to refer to the alphabetical list if they needed help with spelling. Nearly every protocol was completely filled out. Scores were determined in the same manner that Tryon 40 determined her scores. If a boy was mentioned for a favorable description

40 Ibid. 
which were items $A, C, F, G, I, J, M, O, P, R, W$, and $Y$ he received a plus I credit for each time mentioned. If a boy was mentioned on an unfavorable item $B, D, E, H, K, I, N$, a, S, T, U, V, and $\mathrm{X}$ he received a minus $I$ credit on each item mentioned. Total scores were the algebralc sums of times mentioned. The scores indicated a normal distribution after a constant had been added to make all scores positive with the more frequently mentioned person on favorable characteristics receiving the highest $s \operatorname{cor} \theta$.

In order to secure another measure of social status, hypothesized to be related to adjustment, the other instrument used in this grouping was a "Companionship Choice Test" (included in the appendix)*. This was based on the work of Moreno ${ }^{41}$, Bronfenbrenner 42 , Jennings 43 , and others. This test was given at the beginning of the fifth session of group testing. It consisted of setting up five activities that were desirable and natural for the environmental setting and asking each boy to make a cholce 1,2 , and 3 , of those boys whom he would prefer to share such an activity with him.

$41_{\text {Moreno, op. cit. }}$

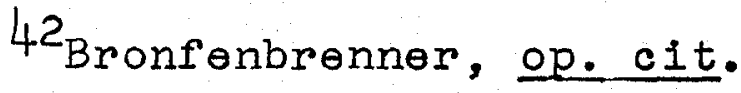

43 Jennings, op. cit.

*Appendix, pp. 299-300. 
He was also requested to name 1,2 , and 3 boys with whom he would not wish to share the activity. This last step was felt to permit us to meet Gate's and othersi44 criticism directed at limiting such tasks to positive choices:

We cannot always infer that the persons who are ignored when people name whom the y like are persons who would be singled out if their associates were asked to name whom they actively dislike.

Jennings 45 reports reliabllity figures based upon retests at four-day intervals on a test similar to ours. She reports a reliability coefficient of .96 for positive choices and one of .93 for rejection. The reliablitty over a longer interval appears to drop as she found a reliability coefficlent of .65 for positive cholces and .66 for rejections when the interval was increased to elght months between testing. Her study was based upon girls in a state training school. Using a split-half technique and the Brown-Spearman prophecy formula, we found a reliability coefficlent of .97 . The boys were given the cholce blank and careful instructions in regard to using full names, restricting their choices to members of the study population, ete. Again the alphabetized list of the boys in the study was given each boy to aid in spelling and to keep the list of those in the study before him. Most protocols were completely filled out and all were scoreable. The scoring of such soclometric

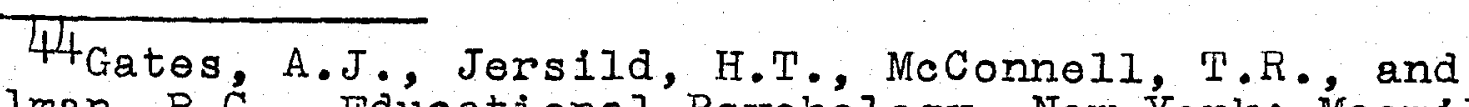
Challman, R.C. Edúcational Psychólogy, New York: Macmillan Co., 1949, p. 544.

45 Jennings, op.cit., pp. 532-538. 
techniques has varied from simple count of times a child is chosen in first, second, or third cholce position through arbitrary weighting of choices, and more elaborate systems based upon the probability of being chosen. For our purposes we followed Bronfenbrenner 46 who states that when the number of criteria and choices remain constant with as many as three criteria and five choices allotted, a count of total number of choices for each child will provide a reliable index of social status. He also states that weighting is an arbitrary matter as one cannot be sure of the difference in first, second, and third choices to the point of being able to say that a first choice is worth five points, a second three points, and a third two points or any other similar system. This may be particularly true of our population as past experience with boys living in such intimate groups seems to indicate that any given boy may frequently have difficulty choosing between one or two close companions. Therefore, it was decided to give a credit of plus 1 for every choice and a credit of minus 1 for every rejection securing as a total score the algebraic sum of these credits. The derived scores, when a constant was added to eliminate negative values, gave the appearance of normal distribution.

46 Bronfenbrenner, op. cit. 
Group IV - Adjus tment Scores

Derived from Projective Techniques

The Group Rorschach developed by Harrower-Erickson 47 was the basic technique used to secure Rorschach protocols for each of the sixty-six boys in the study. The test 1tself consisted of the ten original Rorschach ink blots on standard $35 \mathrm{~mm}$. koda-slides. Responses were written in a semi-dark room in the Group Rorschach booklet published by the Psychological Corporation (included in the Appendix)*. Since the protocols were scored by using Munroe's 48 check list method which is explained in Appendix $B$ of her monograph, some attention to both reliability and validity of the method should be reported. She reports that by using the protocols of eleven students and eleven competent Rorschach examiners an average rank-order correlation between examiners of plus .65 was secured. She further states that this indicates substantial agreement between examiners. In this study to test further the reliability of the measure, the writer (after the lapse of over a year) rescored one out of every three of the original records, which the writer's secretary had copied with no scoring marks on unused test blanks. Rank-

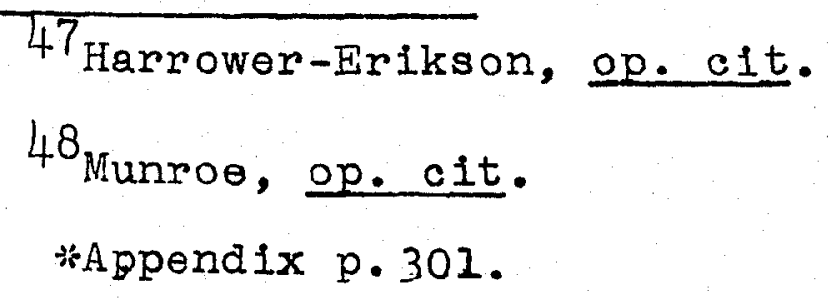


order correlation between the two scorings was .786. In making evaluative studies of her technique Munroe used Sarah Lawrence College students. She used such external criteria as referral to a psychiatrist, cases requiring much faculty consultation, and a committee rating of teacher reports. Three-hundred and forty-elght students rated for four degrees of adjustment by use of the check list were compared against these three criteria and a corrected coefficient of contingency of .55 was reported. Munroe 49 insists that, "this indicated a rather strong positive relationship between maladjustment as measured by the Rorschach and as established by external criteria."

The Group Rorschach was administered at the fourth session of the group testing. None of the participating boys had ever been presented with the Rorschach Test previously. The $35 \mathrm{~mm}$. sildes were projected on a classroom screen in semi-darkness as the window blinds of the testing room were not completely opaque. Directions of administration as presented by Harrower-Erikson 50 were strictly followed. Directions in securing the marking of the responses and the inquiry were likewise followed carefully. A local camera shop prepared a demonstration slide which was used to explain the directions prior to the inquiry. It took approximately one and one-half hours to complete the securing of

\section{Ib1d., p. 39.}

50 Harrower-Eriks on, op. cit., pp. 30-45. 
protocols. All were scoreable and cooperation level was high. In fact the group presentation seemed to increase the number of responses (this is based upon the comparison of twelve later protocols on these same boys where individual administration of the Rorschach was used. The writer had had formal instruction in Beck's ${ }^{51}$ method of scoring Rorschachs under J.B. Rotter at The Ohio state University. Prior to this scoring the Klopfer and $K e l l y^{52}$ method was studied carefully. In addition, twenty-five individual Rorschachs given to students not in the study, were scored according to Klopfer and Kelly and compared with published protocols. After scoring by the method of Klopfer and Kelly, Munroe's 53 check list was used to secure a quantitative score.* Scoring and applying the check list required from thirty to forty-five minutes for each protocol. Distribution of resulting scores appeared to be normal. Each obtained score was subtracted from a constant so that higher scores would mean better adjustment. This facilitated comparison with the other measures.

The second Index of adjustment was derived from the use

5I Beck, Samuel J., Rorschach's Test I Basic Processes. New York: Grune and Stratton, 1944, VII + 223.

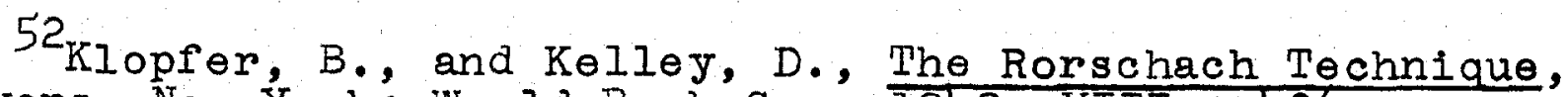

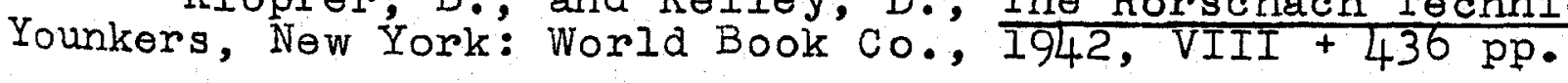

53 Munroe, op. c1t., pp. 79-101. *Appendix p. 301. 
of the Rotter Incomplete Sentence Blank, Adolescent Form (included in the appendix p. 302). This test in its present form consists of forty beginnings of sentences which are to be completed by the respondents. According to Rhode 54 the earliest published incomplete sentence test was that of Payne in 1928. She reports forms of this technlque used by Fendler, Lorge and Thorndike, and Sanford. The present test is an outgrowth of Rotter and Willerman's studies 55 during World War II in using the incomplete sentence test to evaluate the psychological fitness of convalescent soldiers to return to duty. This technique was further explored by Rafferty ${ }^{56}$ with college men. Rotter and willerman ${ }^{57}$ report a split half reliabilIty coefficient of .85 and an average inter-scorer correlation coefficient of .89 . They also report validation based upon case history information, health and personality inventories, admission diagnosis, tests of mental dysfunctioning and the psychological interview with a triserial $r$ of .61. Rafferty 58 reports a split half reliability coefficient of .75 and an interscorer reliability coefficient of .91. She also reports validation with the judgment of five judges and found a biser-

54Rhode, A.R., "Explorations in Personality by the Sentence Completion Method", J. Appl. Psychol., 1946, 30: 169-181. 55 Rotter, J.B., and Willerman, B., op. cit. ${ }^{56}$ Rafferty, J.E., op. cit. 57 Rotter and Willerman, op. cit. 58 Rafierty, op. cit. 
ial $r$ of $.60 \pm .05$ when students were judged as adjusted or maladjusted. The writer and his assistant independently scored the test protocols obtained and found an interscorer reliability coefficient of $.88 \pm .02$.

This test was administered to the entire population durIng the latter part of the fifth group testing session. Scoring follows the principles set forth in the manual for the test. Briefly, the scoring is based upon a six-point scale ranging from severe conflict signs to favorable positive signs. The responses are compared with example responses reported in the manual ranging from severe conflict responses scored 6, through neutral responses scored 3 to positive responses scored 0 . A score may be computed by using the formula

$\frac{40}{40 \text { minus omissions }} \times$ Total Score $=$ Score. The higher
the score the greater the degree of maladjustment. The secured score was subtracted from a constant so that high scores would indicate good adjustment and lower scores indicate poor adjustment. The scores were distributed in a normal fashion.

$$
\text { Group V - } \begin{gathered}
\text { Systematized Direct } \\
\text { observation }
\end{gathered}
$$

The technique used to secure a quantitative measure by systematized direct observation was a modification of time sampling after $01 \operatorname{son}^{59}$ who states:

5901son, op. c1t., p. 88 . 
Time sampling is the observation of each individual in respect to a particular category of activity upon which information is to be obtained during a period of time that is kept constant for each individual observed.

The technique used here was to observe each boy five minutes at a time for ten pre-scheduled five-minute periods. Four of these periods were academic classwork, four were in a work shop or work activity, and two were in a recreational activity. There were three categories of behavior felt to be related to adjustment status observed. These three categories were oral habits, dominative behavior, and solitary behavior.

Oral habits as observed by $01 \operatorname{son}^{60}$ were found to be highly related to other forms of nervous movements: hirsutal, nasal, aural, and caputal. He found the existence of oral habits to have a validity coefficient of .77 in terms of total nervous habits. He reports the reliability of two observers to be indicated by a coefficient of .75 on the basis of agreement on seven ten-minute intervals. Using several observers with twenty five-minute observations, he reports reliability coefficients ranging between .68 and .94 with .87 the most representative value. Oral habits were used as a symptomatic expression of maladjustment on the hypoth-

$$
60 \text { Ibid., p. } 30 \text {. }
$$


esis that they and other nervous habits stem from unresolved tensions. The definition of occurrence of an oral habit was that, if during the five-minute period of observation, a boy sucked his thumb, finger, or object such as a pencil, or if he bit his nails, or if he protruded his tongue between his lips visibly, he was checked for presence of oral habit on the observation sheet. It was possible to receive only one check during the five-minute period as 01 sen 61 reports that reliability is much better when such a procedure is followed.

The second category of behavior to be observed during each five-minute period was designated Dominative behavior. This category was developed from the work of Anderson 62 who states: "It is assumed that high frequencies or increases in domination of other children are undesirable." In his study of socially integrative behavior he used a classification which he breaks down into $\mathrm{N}-1$ (demands, commands, and uses force $\theta$ and $\mathrm{N}-2$ (attaoks of other children.) He reports no reliability figures for observation of such behavior but he does assert that it remains fairly stable over a considerable period of time. For this study we defined this category as the occurrence of any of the following instances of behavior within the five-minute behavior observation period: demands that he be given speclal consideration - a particular

6I I Id., p. 2I.

${ }^{62}$ Anderson, Harold H., "Domination and Socially Integrative Behavior," (In) Barker, R.G., Kounin, J.S., and Wright, H.F., Child Behavior and Development. New York: McGraw-Hill, $1943,459-483$. 
task or assignment regardless of conflict with the group activity; commands another to do something he is quite able to do for himself - pick up a pencil, get equipment, run an errand, do his assigned task; shoves or pushes another to make way for himself - the use of body contact to secure some objective; verbally attacks the status of some other child - makes disparagling remarks concerning the efforts of another. This category was used on the hypothesis that the better adjusted Individual does not need to dominate the situation but is more socially sensitive in his personal contacts with others. It was believed that characteristic display of dominative behavior as defined tends to make for rejection on the part of others rather than acceptance and a cooperative soclally integrative state of affairs.

The third category of behavior to be observed in each five-minute period was designated Solitary behavior. It has been hypothesized earlier that behavior which is characterized by optimistic particlpation in harmony with the group is more adjustive than behavior which is directed toward withdrawal from the group and solitary pursuits when there is ample opportunity for participation in group oriented activity. Since the observations made were in the fields of group activity, a presence of solitary behavior, if characteristic, was hypothesized as indicating maladjustment. We defined this category as the presence of behavior not 
attentive to the group - staring out the window when others are abosorbed in discussion or participating in assigned tasks; engaging in doodling or drawing when others are engaged in group activity, closing eyes and evidencing regular breathing of sleep when group is engaged in an activity; pursuit of individual activity when others are working as a team - standing on side lines when he is supposed to be participating in a game, evidencing no interest in outcome of game even though he is a member of the team - such as, throwing stones idly with back to activity. The occurrence of any one of these behavior items during any five-minute period rated one check on the observation sheet opposite solitary behavior.

Observations were recorded on individual sheets designed to cover one five-minute period. There were ten such sheets for each boy. Observations were pre-scheduled to cover a six-week period. No boy was observed in consecutive fiveminute periods in the same scheduled hour of an activity. Each period was so scheduled that a boy was not observed always at the beginning of the period or at the end of the period but in five-minute periods that were scattered over the hour period itself. The observations were made by either the writer or his assistant from a side-front position in the room, playing field, shop, or other area in which the activity was being conducted, in such a manner that no boy was aware of his direct observation. Timing was done by a stop watch. 
In order to secure some indication of reliability of the observers, both observers noted the same boys during seventy identical five-minute periods. It was found that there were 210 chances for agreement and that actual agreement was secured $86 \%$ of the time. Scores were derived for each boy through transferring the data from the observation sheets to a master sheet for each boy. Scores could range from 0 to 30 but they actually ranged from 1 to 18, while normally distributed a very narrow interquartile range, 1.e., 3 was found. This technique was found to involve a complicated scheduling process, take a tremendous amount of time, and produce results which do not seem to differentiate well between members of the group.

Variables with an Unknown Effect. After securing the various comparative measures of adjustment, it was nocessary to calculate chronological age, mental age and length of residence since it was decided that these varlables might have some influence on the measures of adjustment secured. Chronological age was computed for each of the sixty-six boys in the study by subtracting date of birth from June 1 , 1950, the anchoring date of this study. This measure was expressed in months. Mental age was secured by entering the Binet 63 tables with the latest established I.2. on either Form L or Form M of the 1937 Stanford Revision of the Binet

63 Terman, L.M. and Merrill, Maud A. Measuring Intelligence. New York: Houghton-Miffiln Co., 19 $\overline{37}$, Appendix. 
Scale, and the boy's chronological age and reading off the resulting mental age. This procedure introduces some error as all of the boys were not subjected to exactly the same testing conditions and it assumes a stable I.Q. over the years. I.Q.'s used were all established within the last three years. However, it was thought to differentiate between varying intellectual potentials for the purposes of this study. Length of residence for each boy was calculated by subtracting the recorded date of his admission to the O.S. \& S.O. Home from the anchoring date June 1, 1950. This measure was also expressed in months.

\section{Summary}

The representative measures which have commonly been used to establish adjustment criteria, have been outlined in detail. The rationale behind the selection of each of the ten techniques used to establish the sixteen different measures has been presented. It has been demonstrated that these ten techniques meet adequately the pre-determined criteria for their selection. It is admitted that there are many other commonly used moasures for assessing adjustment but because of their unsultability for this age group, the limit of time involved in the study, or other similar reasons, they could not be included. It is felt that the measures selected for comparison do represent a wider range 
of approaches to this problem than has ever been accomplished heretofore.

The general procedures used in securing, through the described techniques, comparable measures on the population of sixty-six adolescent boys residing at the O.S. \& S.O. Home have been shown in deta11. Speciflc directions concerning the group-administered tests can best be secured by referring to specific test manuals which are included in the appendix of this study whenever practicable. Scoring of protocols was carefully checked by two independent scorers whenever possible. With such instruments as the GroupRorschach a careful re-appraisal of each score was made as each protocol was completed. All scores were entered on a master sheet and verified by reading back from the chart and comparing the original protocols by the writer and his assistant. Every effort was made throughout the securing of the various measures to prevent bias by using code numbers instead of names. Scores secured by any technique were not matched with the name of the boy until all scores were established on all of the various techniques.

After the measurements were secured by the various techniques outlined in this chapter, it becomes necessary to make certain statistical comparisons between the measures. The results secured through the application of correlational procedures to the data and the conclusions reached in regard to agreement between various measures purported to assess adjustment, becomes the next matter for consideration. 


\section{CHAPTER V}

THE PRESENTATION AND DISCUSSION OF RELATIONSHIP AMONG ADJUSTMENT INDICES

\section{Introduction}

It is the purpose of this chapter to express the relationships among the scores made by the population group on the various selected measures of adjustment by correlational methods. An analysis of the intercorrelations among these indices, many of which have been used in various studies as independent criteria of adjustment, should help to answer the major hypothesis of this study. Further, such an inquiry into these interrelationships may help to determine the present status of our attempts to measure the global concept referred to as adjustment.

At this point it seems necessary to re-state the major hypotheses: If present measures purporting to assess adjustment status are measuring the same concept or related aspects of that concept, they should be positive in their relationship and differ significantly from zero. As an addenda to this major hypothesis it is necessary to state: If there exists positive correlation differing signiflcantly from zero between measures purporting to measure adjustment, such relationship lends support for the existence of such a global concept. 
In addition to this major hypothesis it was also proposed to examine certain other related hypotheses: (a) Certain extraneous variables-chronological age, mental age, and months of residence in the O.S. \& S. O. Home - are not positively and significantly related to measures of adjustment. (b) Wherever similar techniques are used to assess adjustment, the relationship among similar techniques will be greater than the relationship between different techniques. (c) In the application of representative techniques for assessing adjustment, certain techniques or combinations of techniques may demonstrate unique advantages or disadvantages.

In the pages to follow, it is proposed to review briefly the methods used to gather the data, to summarize the characteristics of the original data, and to examine the intercorrelations of adjustment measures with the extraneous measurements. The intercorrelations among the various adjustment indices will be examined for significance, and the logic of existing correlations will be developed. A discussion of various points brought out by the data themselves will follow. Recommendations and conclusions based on an evaluation of the data will conclude the chapter.

\section{Presentation of the Data}

In Chapter IV a detalled discussion was devoted to the gathering of the data. Briefly reviewed, scores were secured - from sixty-six adolescent male residents of the $0 . S$. \& $S .0$. Home during a six-month period in the spring and summer of 1950 by representative techniques of assessing adjustment. Sixteon 
scores purporting to appraise some aspect or aspects of adjustment were secured on each boy in the population. These sixteen scores were obtained by means of five groups of techniques representing questionnaires and inventories, adult ratings, peer ratings or socimetric techniques, projective techniques, and direct observation. Representative measures were selected within each technique so as to insure the most complete intercorrelational analysis yet attempted through including as many differing types of adjustment indices as possible. Original protocols were ldentifiable only through the use of code numbers to prevent any conscious or unconscious carry-over between assessments. Scoring was done independently by the writer and his assistant as a check where ever the technique so lent itself. No scoring was undertaken until all assessments had been accomplished.

When all tests had been scored and all ratings tallied, a chart was prepared including code numbers and boys' names with a column devoted to each measurement variable. Raw scores were entered in appropriate columns. It was decided to utilize raw score data rather than to attempt to record some measures in percentiles or standard scores which were provided by test constructors in instances of standardized techniques. In order to facilitate handilng of scores, it was necessary to transmute the scores in six arrays by adding or subtracting constants so that all arrays would be arranged in such a manner that high scores indicated relatively high adjustment level and low scores indicated relatively poor adjustment level. The means of both 
the transmuted scores and the original scores are set forth in Table 5, page 132 .

These resulting scores on the varlous adjustment indices were recorded on another chart along with the scores derived from chronological age, mental age, and months of residence in the $0 . S . \& S .0$. Home. These resulting nineteen arrays were then transmuted to Interval scores ranging through one to fifteen, preparatory to securing the one-hundred and seventy-one correlation coefficients nocessary to determine the various interrelationships. These transmuted scores were punched into I. B. M. cards and the punched cards, one for each of the sixty-six boys and were verified. I. B. M. equipment was used in accordance with Dr. Toops'l suggestions. The I. B. M. cards were sorted twenty times, once for each variable and once for the sum check column. After sorting, the cards were run through an I. B. M. machine wired so that simultaneous sums for the twenty variables could be secured. ${ }^{2}$ After each sort on each variable, the cards were run through and sums were obtained and checked on each of the twenty variables. These sums, representing cumulative scores of each variable with

$I_{\text {Toops, Herbert D. "Some Possibilities of Statistical }}$ Analysis Rendered Possible by Recent Applications of Punched Card and Sorting Equipment." Ohio College Association Bulletin No. 131. Columbus, Ohio. Ohio State University pp. 2508-2514.

${ }^{2}$ Dwyer, Paul S. "Simultaneous Computation of Correlation Coefficlents with Missing Varlates" Proceedings of the Research Forum, Endicott, New York. Aug. 26-30, 1946. New York: International Business Machines Corporation, pp. 20-27. 
Itself and the cross product sums with every other variable, were then utilized in solving Toops' 3 I formulas to secure the mean and sigma of the variable as well as all of the intercorrelations. All of these solutions were checked independentiy In order to eliminate errors arising from this source. Characteristics of Data. Prior to presenting the resulting intercorrelations, it sëems well to review for ther eader the. characteristics of the data which were discussed somewhat at length in Chapter IV. Table 5 on page 132 is presented, which provides at a glance much of this previously discussed material along with means and standard deviations of the score arrays secured in this study. This table, reading from left to right, shows by vertical column headings the five major types or techniques, the types, 1.e., California Test of Personality, the Indices of adjustment or measured variables used, the mean of each index, the standard deviation of each index, its reported or determined reliablitty, and the percentile level of mean scores when available.

An examination of Table 5 indicates the following facts which need to be kept in mind when interpreting the relationships among the variables.

(1) The mean score established on the California Test of Pepsonality both in the area of Self-Adjustment and Social Adjustment indicates that the average individual in this group

3roops, op. c1t., p. 2514 . 
expressed more signs of maladjustment than the median individual expressed in the group upon which the test was standardized. When the median scores of the present population are examined we find the median score in Self Adjustment to be at the 20th percentile level. The median score of our group in Soclal Adjustment is at the 30th percentile. The mean score of Self Adjustment is at the 20th percentile level and the mean score on the Soclal Adjustment is at the 25th percentile level. (2) The reported S. D. on Self Adjustment is 11.5 and reported S. D. on Social Adjustment is.10.0. A comparison of these figures with our secured S. D. of 11.32 on Self Adjustment and 11.91 on Social Adjustment would indicate that our group, while scoring lower on the test as a whole, has a range of scores comparable to the $r$ ange of the group upon which the test was standardized.

(3) The percentile levels of the mean scores of our group on the six factors of the Heston Personal Adjustment Inventory are somewhat lower than median score percentiles reported by Heston. However, when you consider that his percentiles were derlved from the scores of 217 high school seniors while the present group was of an avarage age of high school sophomores, our somewhat lower levels may be partially explained on the basis of immaturity in the reaction to some of the material included. Heston reports no standard deviations in his manual but with the exception of the 4.52 S. D. secured on the Analytical Thinking Factor, the reported S. D.'s appear typical and are large enough to give a wide range of $\mathrm{scores}$ in a correlational study. 
TABLAR 5

Characteriatice of Original Data

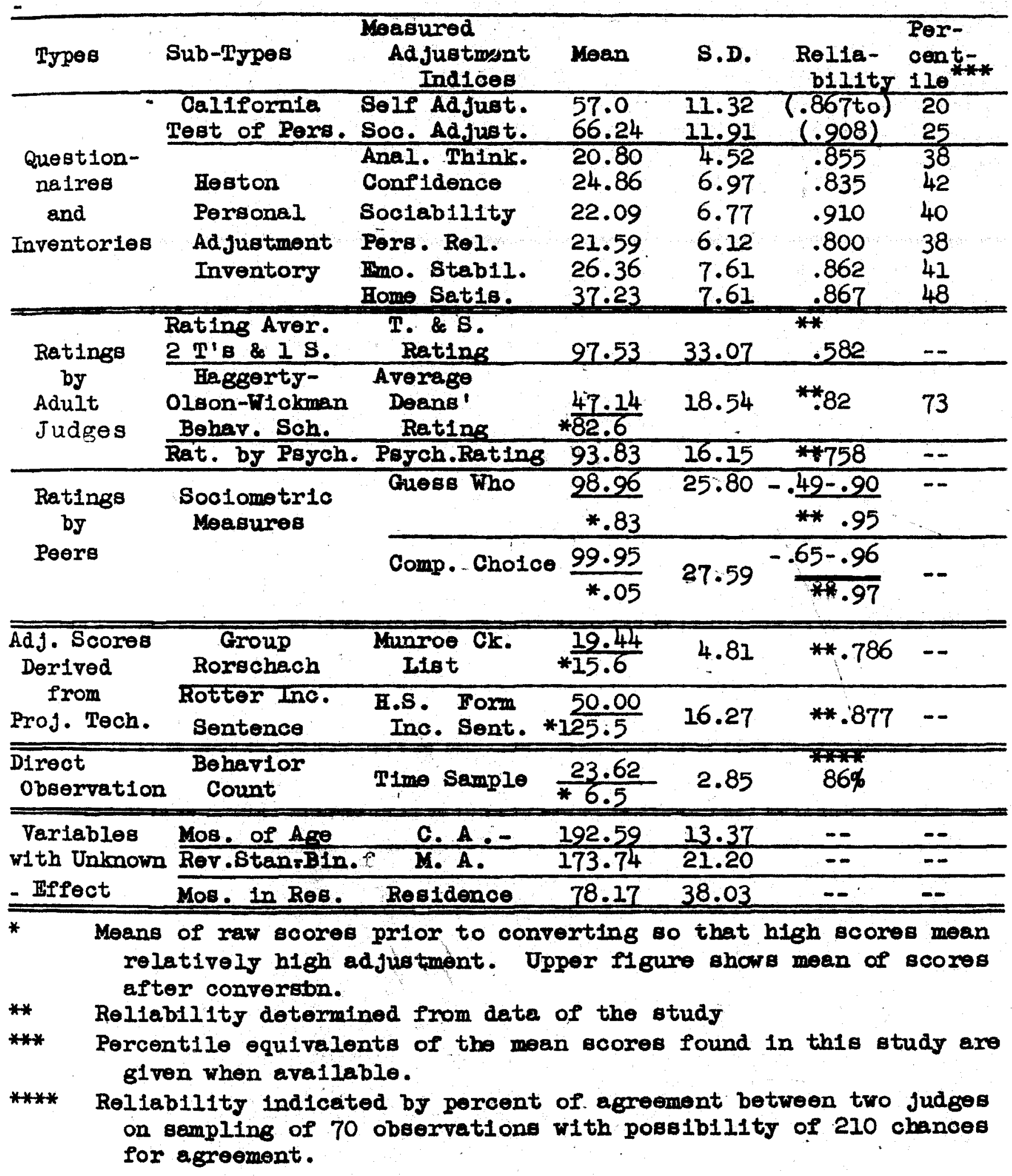


(4) Any interpretation of correlational data with the average of two teachers and one supervisor's rating should be done cautiousiy in view of the low reliablilty coefficient found when using this index. This rating instrument did distribute the population normaliy on an adjustment continum and the S. D. of 33.073 is quite large.

(5) The data secured by using the average rating on the Haggerty-Olson-Wickman Rating Schodule B was compared with the mormative date contained in the manual. The manual reports a mean of 72.4 on a population of 7473 -boys without stating age characteristics. Our obtained mean of 82.6 which is at the reported 73 rd percentile level would suggest that our group indicated more evidence of maladjustment than the normative group. The obtalned.S. D. of 18.53 is in almost exact agreement with the reportied $S$. D. of 18.4 .

(6) The psychologist's overall rating using the same 18 rm scale as used by teachers and supervisors, has a comparable mean $(93.83$ vs. 97.53$)$ but has a smaller S. D. (16.15 vs. 33.07) The reliability of his rating is higher, however 1.76 vs. .58). This would seem to indicate a more conservative tendency on his part to rate these boys as less widely different in their adjustive status.

(7) In examining the means and standard deviations of the Sociometric measures, it is readily seen that both measures distribute the group similariy, having almost identical means and standard doviations. It is apparent that as set up in this study, they are closely related techniques securing a similar 
distribution of peer relationship. The wide range of scores obtained should permit any relationship to other tests to show up. The obtained reliabilities of .95 for the "Guess Who" and .97 for the "Companionship Cholce" are as high as those reported in similar studies.

(8) In comparing our results using the Rorsahach Check List with those of Munroo (who developed the instrument while working with girls of college age), we find our mean of 15.6 checks falls in her classification of severe maladjustment. It is quite possible that the population she worked with is so different in age, cultural, educational, and intellectual status that the statements made in regard to the number of checks reflecting maladjustment are not applicable in our very different population. The S. D. of 4.8 indicates a falr distribution when total range possible is considered (1.e. a range of 1 to 30). Munroe does not report the $S$. D. found in her manual.

(9) Rotter reports in his manual the normative data secured on 214 male college freshmen. He reports a mean of 127.5 with an S. D. of 14.2 . Our obtained mean of 125.5 with an S. D. of 16.268 is certainly a comparable distribution despite the fact that we are using a much younger age group, of probably considerably lower intelligence, and the High School Form of the test.

(10) In the case of the Time sample technique the obtained S. D. of 2.85 indicates the lack of discriminatory value of this method as applied in this study. Any conclusions drawn in regard to intercorrelation of indices obtained from this method with indices secured from other techniques, must be 
made with cautious reservation.

(1I) Chapter III contains a detalled description of the variables with unknown effect so that mention need only be made that the mean age of the population was sixteen years with a S. D. of approximately on year and two months. The mean mental age was fourteen years and six months with a $S$. D. of approximately one year and nine months. The mean years of residence was $s 1 x$ years and six months with a $S$. D. of approximately three jears and two months.

In evaluating the data presented, it is well to maintain before us certain salient facts brought out in Table 5 . (a) We need to consider that on several measures the population used indicated more maladjustment than the normative populations. This is particularly true on the Gelifornia Test of Personality and the Rorschach. (b) However, all measurements were distributed normaliy and in most cases showed wide range of scores. Relationships between these tests, if present, should show up. (c) Beeause of low reliability and limited range of scores, however, lower correlations will have to be expected in the case of "T \& S" ratings (average rating of 2 teachers and 1 supervisor) and the Time sample rating. The results on these particular tests seem comparable to those obtained by others and should give evidence of the value of these methods. Effects of Extraneous Variables. In setting up the study there appeared to be three variables whose effect upon indices of adjustment in the present population were not known. These extraneous variables were measured and correlated with each of 
TABIP 6

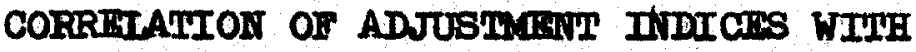

VARTABIDS OF UIKROWI EHTHECT

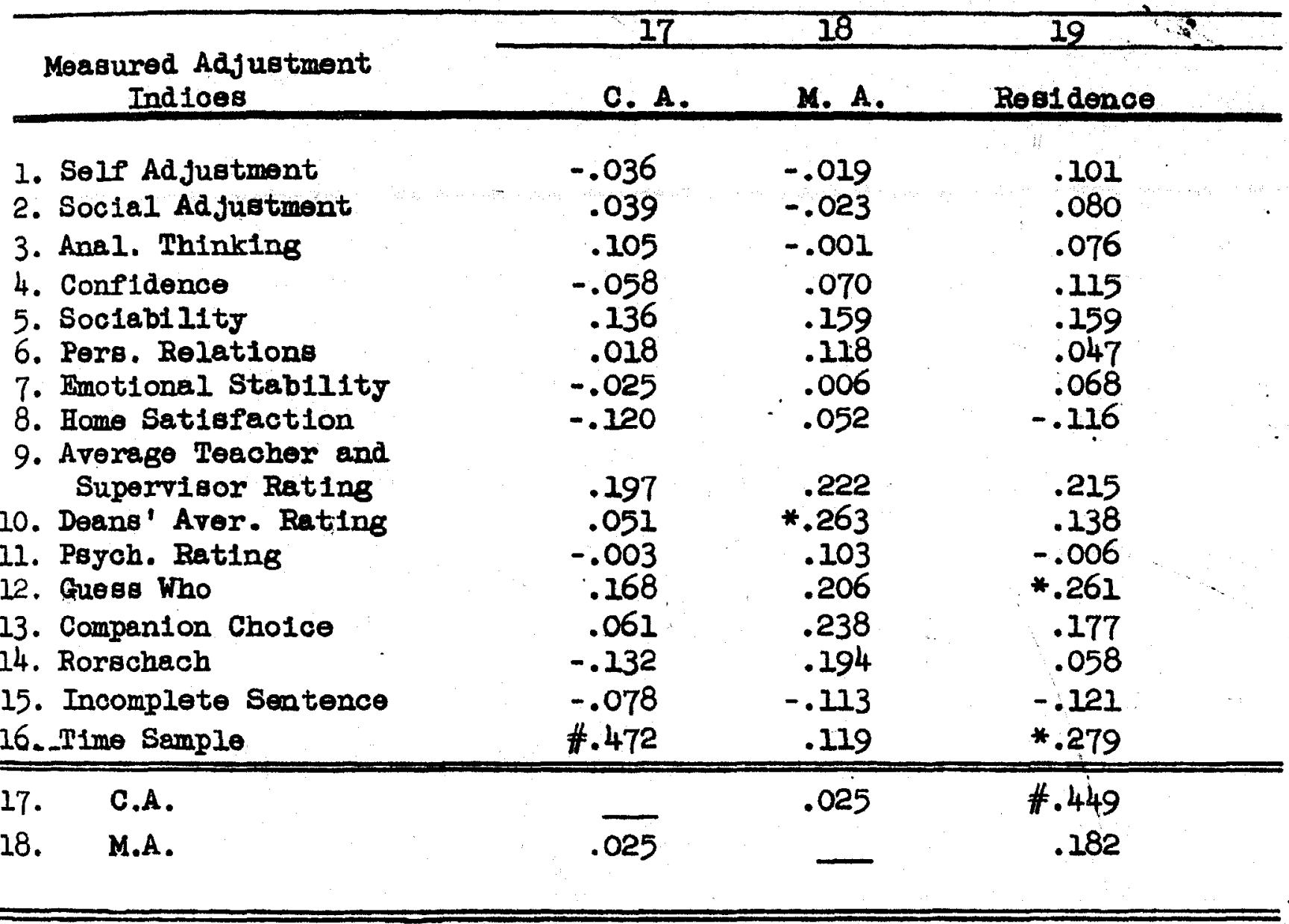

$* r=.243, .05$ level of significance

\# $r=.316, .01$ level of alenificance 
the adjustment indices. Table 6 page 136 presents the results of those findings. Reading left to right in Table 6 we note that of the 48 possible correlations 14 are negative and 34 are positive. Of these only one is significant at the ol percent level while three others are significant at the 05 percent level. 4 This is Iittle more than could be expected by chance, but each of these significant relationships is examined in the following paragraphs.

(1) The average rating secured on the Haggerty-01son-Wickman Behavior Schedulo B, made by the $t$ wo men in the Dean's office, and the mental age of the population, established through the use of either Form $L$ or $M$ of the Revised StanfordBinet Intelligence Scale, when correlated resulted in a correlation coefficient of .263 . This is a positive relationship and is significant at the .05 percent level. Schedule B of the Haggerty-Olson-WIckman Scale contains four divisions or areas of adjustment* within which specific ratings or judgments are made. Division I, containing seven of the thirty-five possible judgments on the total scale, is devoted exclusively to fudgments in regard to what we usually think of as intelligence. Number 1 in this division, for example, asks the rater, "How intelligent is he?" and provides five cholces, (a) Feebleminded, (b) Dull, (c) Equal of average chlld on the street,

4Fisher, R. H. Statistical Methods for Research Workers, New York: Hafner Publishing Co., 1950 p. 209.

(All references to significance of correlation coefficients in the pages to follow are drawn from Fisher's Table V.A.)

isee appendix, p. 294 . 
(d) Bright, (e) Brilliant. It seems very reasonab le then that any rating secured on the Haggerty-0lson-Wickman Rating Scale should, if used by competent judges, be positively and significantly related to measures of intelligence. Such a positive and significant relationship is indirectly of value in pointing up the validity of the judgments made.

(2) The second signiflcant relationshlp found was between the array of scores on the "Guess Who" test and he months of residence in the institution. The correlation coefficient between these two measures was .261, which is positive and significant at the 05 percent level. There seems to be possible explanations of this occurrence in that boys, who had been in longer residence -- there were 35 boys out of the 66 who had lived in the institution for six years or more -- had to be able to make relatively better adjustments to their peers in order to have remained in the institution. The severely socially maladjusted boy would not be found in this group of older residents, as by institutional policy he would have either been aided in making more adequate social adjustment or placed in an environment more in keeping with his needs. Since the "Guess Who": is based upon descriptions of traits shown to bo characteristic of adolescents, approved and disapproved by adolescents, we would expect the boy with more years of Iiving in the institution to reflect more of those approved traits regardless of his chronological age. We might say that the data 
suggests that there is a tendency for long periods of group living to have some relationship to the adopting of characteristics acceptable to one's adolescent peers if the individual can respond to the pressures of his environment.

(3) There are two signiflcant relationships found in connection with the data secures from the Modified Time Sampling technique. It was found that the array secured from direct observation of behavior through time sampling was related to chronological age with a resulting correlation coefficient of .472 . This is significant at the 01 percent level. This relationship must be considered with reservations as the Time Sampling technique was not felt to be adequately discriminative in placing members on an adustive-maladjustive continuum. There may be some reason for this relationship when we consider that the characteristics rated seem to be reactions more typical of the younger boy. Empirically, it seems that the older boy under pressures of the group has learned to be more covert in his reactions that are readily observable in group situations. We would be led to expect from experience that the evidences of maladjustment in the older boy within the institution are not as readily apparent in overt behavior terms as in the younger boy who is in the process of developing a more complex reaction system.

There was also found a relationship between the direct observation scores and the months in residence. A coefficient of correlation of .279 was determined, which is significant at the 05 percent level. Again the time sample data must be 
regarded with reservations but here again we may be dealing with a tendency toward selective elimination. In other words, with years of living in the group situation, those with the more obviously overt reactions of the maladjusted have either been exposed to remedial measures within the institution or have been removed to a different environment.

(4) The only other relationship in Table 6 requiring comment is that found between two of the extraneous variables, chronological age and months in residence. These relationships between extraneous variables are included for convenience of comparison below the double line at the bottom of Table 6 . The correlation coefficient existing between these t wo variables within the designated population was .449 , which is significant at the 01 percent level. This is a relationship we might expect as in general the older boy had had an opportunity to establish more jears of residence in the institution, although this state of affairs was not universally true with this group as some of the younger boys in our population had resided for a longer period of $t$ ime in the institution than some of the older particlpants in this study. However, the general conditions prevaling would adequately explain this correlation.

To recapitulate and point out the facts highlighted by Table 6 we can state that the majority of the relationships expressed are positive but nelther significant at the .05 nor the .01 level of significance. In the main, our indices of adjustment were not related to any one of the three extraneous variables. Out of sixteen indices only three were found to 
enter into significant relationships with these variables. The rating secured from the Haggerty-Olson-Wickman could bo expected by its nature to show relationship to intelligence. The "Guess Who", in its relationship to months in residence, seems to indicate a trend toward establishment of more admired peer characteristics with longer residence. The Time Sample seems to be related to both chronological age and to months in residence, but this relationship cannot be taken too seriously because of the discriminatory value of the instrument. In brief, then, our measures of adjustment are not significantiy affected by these extraneous factors.

Relation Between Various Measures of Adjustment. Table 7, presented on page 142 , presents the 120 coefficients of correlation possible when each of the indices of adjustment are correlated with each other. These are presented for convenience in an intercorrelation table with the coefficients of correlation between similar techniques boxed in red. Those coefficients meeting elther the 05 or 01 percent level of significance are starred.

At first glance it is apparent that there is a general lowness of relationship between the varlous indices. However, most of these relationships are positive and a considerable number are signiflcant when the 05 percent level is used. It is also quite apparent that there are a number of fairly high relationships between techniques belonging to the same general class.

If the median correlation coefficient of .228 is considered, 
TABIE 7

INTHERCORRELATIONS OF ADJUSTMENT INDICHS

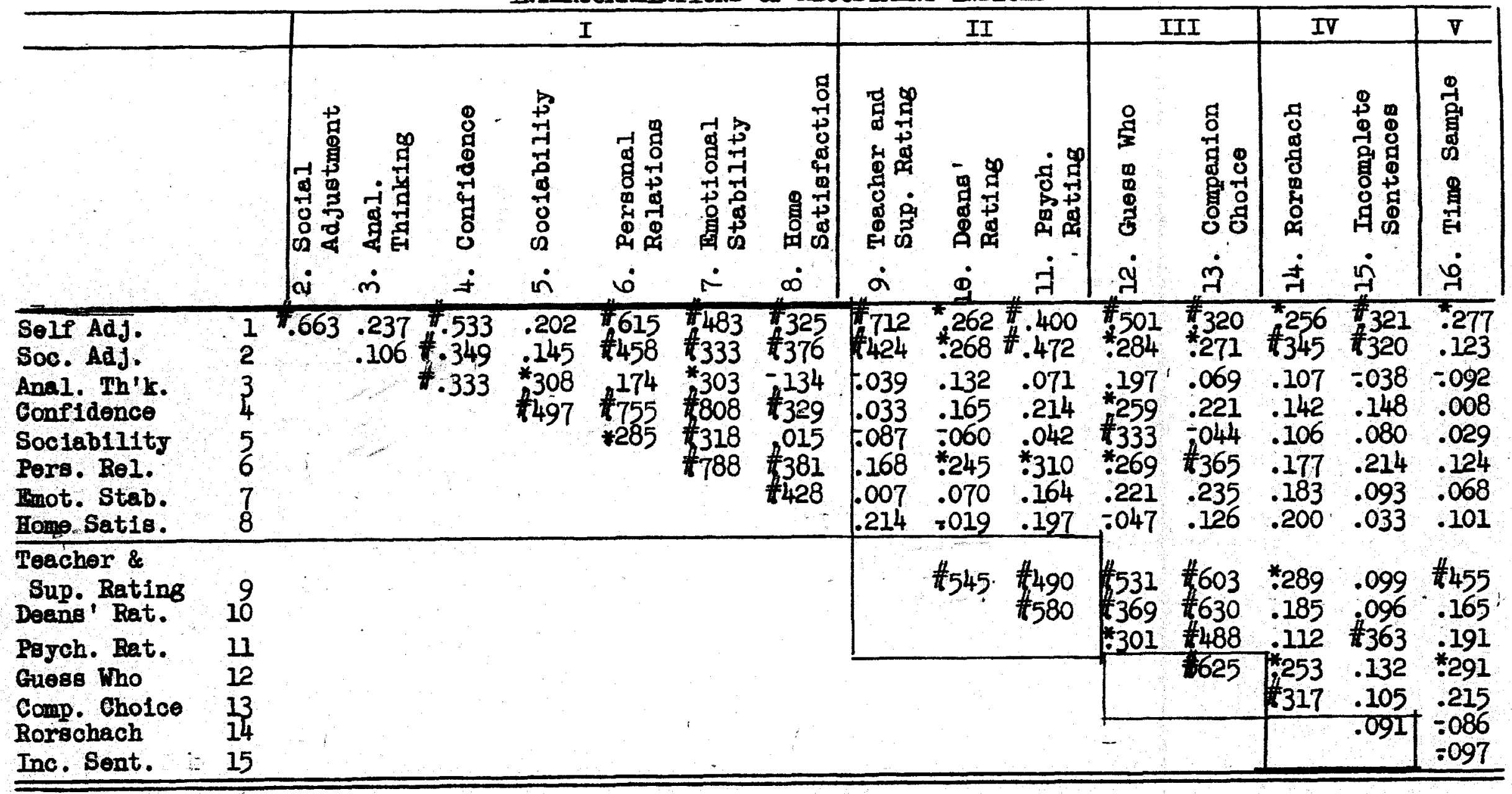

$* r=.243, .05$ level of eignificance

$\# r=.316, .01$ level of significance 
we conclude that there is a very low positive intercorrelation among measures purporting to assess the saine thing. This median correlation is below the 05 percent level of significance. In other words, the median relationship of these arrays of indices of adjustment is too small indicate much more than chance relationships.

When the sign of these relationships is considered, we find only 11, out of the 120 possible relationships, with a negative sign. None of these are of sufficient magnitude to be significant. In fact 10 out of the 11 are above - . 10 in magnitude. Therefore it is reasonable to state that in the main the indices of adjustment used are positively related to each other.

Of the 120 relationships expressed we find 58 of them, or nearly half, of sufficlent magnitude to be considered significant at the 05 percent level. Of these 41 , or one third of the total, are significant at the 01 percent level. These facts point to the general trend for a number of the indices of adjustment to sh ow low but signiflcant relationship. This appears to lend support to the existence of either common or coexisting factors of adjustment that may be measured by a variety of techniques.

In the paragraphs to follow it is proposed to examine certain of these relationships. It is felt that, in a study of this type, we should confine ourselves to a close examination of those relationships signiflcant at the ol percent level, with perhaps a more cursory examination of those relationships 
144 significant at the 05 percent level. Here we shall be reasonably sure we are not dealing with a chance relationship and be more secure in our search for the whys of such agreements. It may later be profitable to examine certain absences of relationship as well.

Table 8, presented on page 145 , is an intercorrelation table reporting only those relationships signiflcant at the 01 percent level. These are the relationships which we propose to examine at some length in the paragraphs to follow. If we first consider the significant correlations within certain groups of techniques, it is possible to find certain situations prevaling. In the group of indices established by questionnaires and inventorie's, we found it possible to establish eight indices through the use of only two published tests. It was possible, therefore, to find twenty-eight significant relationships among these indices, but we found 18 significant relationships within the group. On the other hand there were only 11 instances of significant relationship with the other 8 indices out of 56 possible correlations. In other words, most of the relationships within the group are significant even though the one instrument used, The Heston Personal Adjustment Inventory, was made up of six factors derived through factor analysis.

In the group encompassing ratings by adults, we had three indices and could expect three significant relationships. This is precisely what was found. We also note that there are il instances of significant relationship between these three ratings 
TABTE 8

INTHRCORREIATIONS OF ADJUSTMIENT INDICHS SIGIIFICANT AT THE * O1\% IEVET

\begin{tabular}{|c|c|c|c|c|c|c|c|c|c|c|c|c|c|c|c|c|}
\hline & & \multicolumn{7}{|c|}{ I } & \multicolumn{3}{|c|}{ II } & \multicolumn{2}{|c|}{ III } & \multicolumn{2}{|c|}{ IV } & $\mathbf{v}$ \\
\hline & 8 & 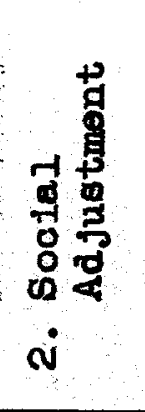 & 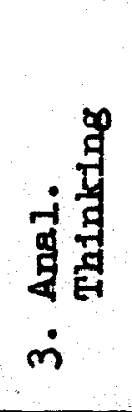 & 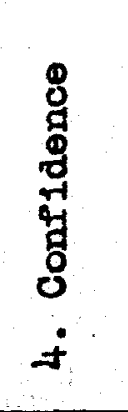 & 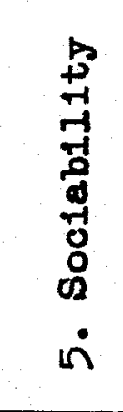 & 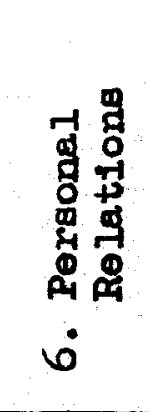 & 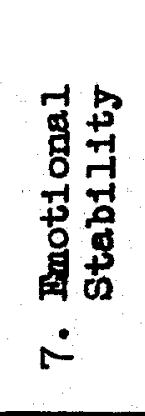 & 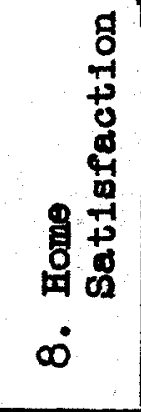 & 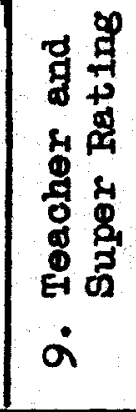 & 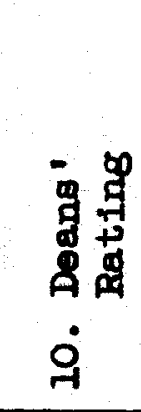 & 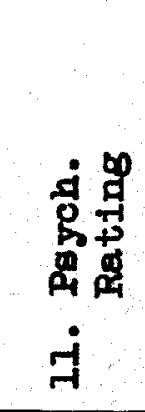 & 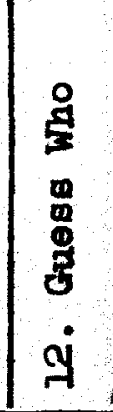 & 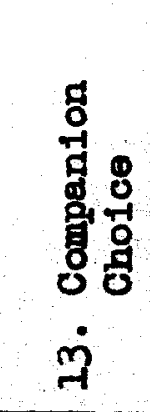 & 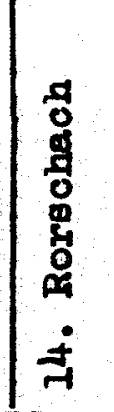 & 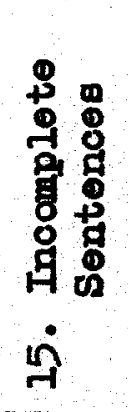 & 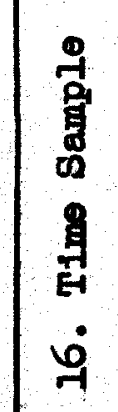 \\
\hline $\begin{array}{l}\text { Self Ãdj. } \\
\text { Social Adj. }\end{array}$ & $\frac{1}{2}$ & .663 & - & $\begin{array}{l}.533 \\
.349\end{array}$ & $\therefore$ & $\begin{array}{l}.615 \\
.458\end{array}$ & $\begin{array}{l}.483 \\
.333\end{array}$ & $\begin{array}{l}.325 \\
.376\end{array}$ & $\begin{array}{l}.712 \\
.424\end{array}$ & -- & $\begin{array}{l}.400 \\
.472\end{array}$ & .501 & .320 & .345 & $\begin{array}{l}.321 \\
.320\end{array}$ & -- \\
\hline Anal. Th'k. & 3 & & & .333 & -- & $\overline{--}$ & -- & -- & - & - & - & -- & - & - & -- & - \\
\hline $\begin{array}{l}\text { Confidence } \\
\text { Soclebility }\end{array}$ & $\begin{array}{l}4 \\
5\end{array}$ & & & & .497 & .755 & $\begin{array}{l}.808 \\
.318\end{array}$ & .329 & -- & -- & -- &.$\overline{--}$ & - & -- & -- & -- \\
\hline Pers, Rel. & 6 & & & & & & .788 & .381 & -- & -- & -- & - & .365 & -- & - & - \\
\hline mot. Stab. & 7 & & & & & & & .428 & - & -- & -- & $\therefore$ & -- & -- & -- & -- \\
\hline Homo Satis. & 8 & & & & & & & & - & -- & - & - & - & -- & - & -- \\
\hline T - S Rat. & 9 & & & & & - & & & & .545 & .490 & .531 & .603 & -- & -- & .455 \\
\hline Deans' Rat. & 10 & & & & & & & & & & .580 & .369 & .630 & $\because$ & - & . -- \\
\hline Pejch. Rat. & 11 & & & & & & & & & & & -- & .488 & -- & .363 & -- \\
\hline Guess tho: & 12 & & & & & & & & & & & & .625 & - & -- & -- \\
\hline Comp. Cholce & 13 & & & & & & & & & & & & $z$ & .317 & -- & - \\
\hline Rorschach & 14 & & & & & & & & & & & & & & -- & -- \\
\hline Inc. Sent. & 15 & & & & & & & & & & & & & & & - \\
\hline
\end{tabular}


and the other 13 indices involving a possible 39 correlations.

In Group III, which was composed of the two sociometric indices, we could expect one significant relationship and that is what occurred. The sociometric indices were significantly related to the other 14 indices in 10 instances (28 possible correlations). This give the highest outside agreement so far met in comparing relationship between types of techniques.

In Group IV, which contained two measures derived from projective techniques, we could expect one significant relationship, but none was found. In fact there were only 5 significant relationships found with these two measures when they were correlated with the other 14 indices (out of 28 correlations).

There was only one technlque used in Group V. No comparable measures were used within this technique with which the Time Sample could be compared. It was related to only one of the fifteen other measures at the ol percent level of significance.

It would appear that in Groups I, II, and III the techniques used to establish the various indices were rather closely related within the groups. With projective techniques chosen there was less relationshlp. It also seems evident that Group III, the ratings made by soclometric techniques, are not only closely related to one another but also more highly related to the various indices established than in any other single group. This would appear to be a supportive argument in favor of using sociometric tochniques when screoning for maladjusted individuals in a group situation. 
So a first factor seems to be type of measuring instrument or source of judgement. Let us look, however, at other possible factors through a closer inspection of significant correlations. In the pages to follow ( $148-176$ ) the intent is to take each index of adjustment and examine those relationships between the specifled index and every other index that is significant at the 01 percent level. The occurrence of such relationships as set forth in Table 8 will be examined as to magnitude and for possible causal factors. A discussion of the implications of these findings begins on p. 176. .

(1) An index of self Adjustment was established on the first division of the California Test of Personality by means. of the respondents answering 90 yes or no questions in subareas of self-reliance, sense of personal worth, sense of personal freedom, feeling of belonging, freedom from withdrawing tendencies, and freedom from nervous: symptoms. This index was related significantiy at the $O I$ percent level of confidence to ten of the other fifteen indices of adjustment. With social Adjustment, the two arrays were related as indicated by a correlation coefficient of .663 , which is not only significant but fairly high. The authors report in their manual a correlation of .54 between the two sections of the test which is somewhat lower than the one obtained in this study. This correlation between the rather artificially set forth areas of self and social adjustment is quite consistent with the fact that these two aspects are not, and cannot be, mutually exclusive. When you ask in the self adjustment section, for example Sec. I A 
(2),"Is it easy for you to introduce or be introduced to poople?" and then turn around in the section devoted to Social Adjustment and ask, Sec. 2 B (106), "Do you often introduce people to each other?" you have answers that are likely to be related if there is consistency in the respondent's personality pattern. There are sufficient incidents of sameness in content with, it is true, a different point of departure in the two sections of the test, plus the overlapping of self and social reference in any psychological concept of personaltiy, to adequately account for the relationship found.

When the array of scores, established through the use of the Self Adjustment index, is compared to the six arrays of scores, established on each factor of the Heston Personal Adjustment Inventory, we find no significant relationships with the factors deslgnated as analytical thinking and soclability. Analytical thinking, as described in the manual*, is characteristic of a person who theorizes, plans for himself, is persistent in planning and solving problems. While this is an important characteristic for those of higher level intelligence, we question its having a great deal to dowith the adjustment of our population, which suggestion will be further explored later. Sociability is characterized by an extrovertive personality, or one who takes the lead in soclal participation, according to the manual, and should according to expectations have been related to self-adjustment. But when one closely examines the questions in this area they are found to demand either a cholce between

*Appenalx p. 291 (p. 15 of manual) 
leadership and little participation or to mirror feelings of shyness and uncomfortableness in social situations. In an institution, or in any closely regulated group situation, it has been observed that there is a tendency to gravitate toward the norm of the group. To be exceptionally outstanding in any institutional activity results in a certain amount of group disapproval, which may explain boys preferring to show a preference for moderate participation in social activity. The test questions in this area seem better adapted to the more mature student as the developmental age of our population group - that of early and midadolescence - is usually considered as fraught with indecisions and considerable insecurity in tentative soctal attempts.

The Self Adjustment index was related to the factor of Confidence as indicated by a correlation coefficient of .533 . The manual describes this. factor as typifying persons who feel sure of the value of their own judgments, who enjoy approval of their associates, who are optimistic, and who have a satisfactory concept of their own physique and appearance. It is readily seen that this factor as described resembles many of the concepts incorporated in the questions on the Self Adjustment section of the California Test of Personality. A careful examination of both instruments reveals enough similarity to account for this relationship.

The scores on Self Adjustment were related rather highly to the score on the factor designated by Heston as Personal Relations. A correlation coefficient of .615 characterized 
this relationship. Here again we find considerable duplication In question content between the two instruments. Personal Relations is a factor which, according to the manual, reflects two basic attitudes, (I) a feeling of mutual trust and congeniality and (2) a freedom of annoyance and irritability in conjunction with reaction to other persons' behaviors. It can readily be seen that such a factor cuts across many of the inquiries in regard to self adjustment and, as a result, a rather high relationship was found.

A somewhat lower but nevertheless positive and significant correlation coefficient of .483 was found between Self Adjustment and the factor designated Emotional Stability. The manual describes this factor as one indicating a reality concept of Iffe, a moderately high frustration tolerance, and a uniformmess of emotional reaction. Several of the questions in this area are similar to the questions in the sub-divisions regarding freedom from withdrawal tendencies and freedom from nervous symptoms on the Self Adjustment section of the Callfornia Test of Personality. There is, perhaps, enough similarity of context in these questions to account for some of the relationship found.

Finally, in dealing with the factors on the Heston Personal Adjustment Inventory, there is a positive, low but still significant, correlation coefficient of .325 found between the factor denoted Home Satisfaction and the index of Self Adjustment under consideration. This factor is described as an awareness of home responsibilities, an awareness of healthy emotional 
relationships, and feelings of mutual understanding and respect. This relationship is rather difficult to explain when one considers the lack of typical home experiences enjoyed by the members of the population under study. It is further complicated by a confusion on the part of the boys responding to the questions. They may have answered the questions from an unrealistic standpoint as many are known to have formed a protective halo around their concepts of relations to their own parents and to belittle the qualities of their relationships with parent surrogates. Others in this group were known to have accepted their obvious rejection by their own families and set about to establish satisiactory relationships with parent surrogates. Others were known to have established few clear cut attitudes or concepts in the family area. Perhaps, as an adjustment pattern, some of those who expressed more adequate feelings of self adjustment also had formulated either real or fantasied concepts in regard to home relations that at least partially accounted for the relationship found. It would seem that there is a tendency for those who report themselves at a higher lovel of self adjustment to also have more positive ferlings of home satisfaction whether they exist on a real or fantasied level.

There was a rather high relationship reflected between the report of self adjustment on the California Test of Personality and the average rating secured from two of the subject's teachers and his supervisor. This relationship is indicated by a correlation coefficient of .712 . This size correlation is 
surprising when it is recalled how unreliable those adult ratings were. The relationship is high enough to suggest that those subjects reporting a more satisfactory condition of affairs in regard to the way they looked at themselves were judged better adjusted by the adults with whom they were in close contact on an overall rating scale. The feeling of self well-being apparently is reflected in sufficient magnitude in daily environmental contact to Influence the judgment of the adults in this particular case.

The Self-Adjustment index was not related at the 01 percent level of signiflcance to the average Dean's rating secured from the use of the Haggerty-Olson-Wickman Behavior Rating Schedule B. However, if one refers to Table 7, page ly2, it is seen that such relationship is significant at the 05 percent level. This lowered relationship may perhaps be explained by the emphasis of Schedule B on observed overt social behavior rather than any attempt to interpret just how the person feels during his periods of conformance or non-conformance. However, this does not detract from our former statement that a feeling of selfadequacy tends to be mirrored in environmental contacts, as a positive and significant relationship even though low is still found.

With the Psychologist's rating derived from acquaintance, case history, and semi-structured interview, the self Adjustment index was significantly related. This relationship was indicated by a correlation coefficlent of 400 . Whilo this is not a high degree of relationship, It does tend to point again toward a 
trend in those, who report themselves more satisfled with themselves, to show more of the aspects of that which we term good adjustment and fewer of the exaggerations of psychological mechanisms subsumed under the heading, poor adjustment.

The Self Adjustment index was related significantly to the score established on the "Guess Who" test. The correlation coefficient expressing this relationship was .501. This, too, is a fairly high relationship continuing to bear out the trend that seems to be holding that those reflecting higher selfadjustment on this instrument also reflect more of the traits which make them acceptable to their peers. Here again we find elements of self-adjustment and soclal acceptance interwoven. to the extent that it is at this point impossible to differentiate clearly between the two as we cannot think of the human organism in strict terms of isolation from similar organisms. We can note the relationship and perhaps regard self-concept and lts implications for social adjustment as one of the basic facts illuminated by the data of this study.

To a lesser extent, but still significantly related, we find the self Adjustment index and the score secured from the "Companionship Choice" text. We found a correlation coefficient of .320. We note, when comparing the original data secured from the two soclometric techniques, that the subject exhibiting the most accepted adolescent characteristics is not always the chosen companion. This is a point that merits more careful consideration when these two indices are compared later. It is this point, however, whlch seoms to account partially for the 
lower degree of relationship found in this particular instance. The fact that the $r$ elationship is positive and significant further supports a trend toward positive feelings of self adjustment to be related to social acceptance.

The Rorschach Check List score was not related to the Self Adjustment index at the $\theta l$ percent level of significance. If again reference is made to $T a b l e 7, p .142$, it can be seen that there is a significant relationship at the 05 percent level and that this relationship is positive. Here again we can say that the relationship, while of a low order, is Indicative of a trend for those who report more adequate feelIngs of self adjustment to reflect such feelings on a projective instrument designed to throw light upon the various interpersonality predilections of the subject. The low relationship found does not negate the trend but rather point to the presence of other factors in what we commonly think of as global adjustment.

The Self Adjustment index was significantly related at the 01 percent level to the index established by means of Rotter's Incomplete Sentence Test. The relationship is expressed by a coefficient of correlation of .321 which, while not of a high order, nevertheless indicates a tendency for the two arrays to be somewhat related. This, too, is in the realm of reasonable explanation when we consider that many of these incomplete sentences refer to the self. Sentences for example that begin like \#12," "I feel " provide for the occurrence of a 
statement of conflict arising in the realm of self or a statement of adjustment in the realm of self. It is also true that many of these beginnings of sentences could concelvably bring forth irrelevant, flippant, or refused answers. Other sentences, for example \#16, "Sports____ are oriented more exclusively toward group pursuits. It is possible that becalse there are divergent directions that answers may take, as well as divergent attitudes that the respondent may take, we find low correlation. Again the trend is still evident that those who report themselves better adjusted on the Self Adjustment inquiry of the California Test of Personality tend to reflect that adjustment when other techniques are used to assess adjustment status. Between the Modified Time Sample index and the Self Adjustment index there was no pelationship at the 01 percent level of significance. Again when Table 7 on page 142 is consulted, we find a positive relationship expressed by a correlation coefficient of .277 , which is signiffcant at the 05 percent level. This further supports the trend for this self report index to be related to other indices of adjustment, even though the Time Sample data must be taken rather lightly. The index of adjustment as established through response to questions in regard to self adjustment contains a throad of relationship to every other index used in this study with the exception of sociablilty and Analytical Thinking inalces established on thé Heston Personal Ad jus.tment Inventoby $+1,4 \times, \times)$

(2) The next step w111 be to, look at the significant relationships in Table 8 between the social Adjustment index and 
the other adjustment Indices. The Social Adjustment Index was related positively and signiflcently at the 01 percent level to the factors on the Heston Personal Adjustment Inventory designated as Confidence, Personal Relations, Emotional Stability, and Home Satisfaction. This index was not significantiy related to those factors designated Analytical Thinking and. Sociability. This is a duplication of the pattern of relationships found betweon Self Adjustment as secured from the California Test of Personelity and the same factors on the Heston. Most of the same tentative explanations can be given for these relationships since it is indicated that the distinction made between Self Adjustment and Social Adjustment by the authors of the California Test of Personality appears to be a matter of approach rather than one of content. Since the two indices established on the California Test of Personality are so closely related, we would expect their pattern of relationships with a similar technique to be quite similar.

There is one relationship between Social Adjustment as secured from the California Test of Personality and the factor designated by Heston as Soclablilty that needs some consideration. Here one would expect between two slmilar sounding indices, using self report as the technique, to find a falrly high relationship. Such does not exist. When the two instruments are examined you find the Califomia Test of Personality deals with social skills, the presence or absence of anti-social tendencles, feelings of rapport in school, family, and communlty, and knowledgo of standards of social conduct. The Heston soclabllity factor on 
the other hand deals with the soclal extrovert - the one who makes friends easily, converses readily and froely, and takes the lead in group activities. In an institutional society, where there is a tendency toward conformance to the group rather than struggle to lead the group, these two instruments bring forth unrelated responses. Whether they would do the same in a soclety less socialistic in nature is a matter for future testing.

The Social Adjustment index, Iike the Self Adjustment index, was related significantly to the average teacher and supervisor rating and to the rating made by the psychologist. It was not related significantiy at the $0 I$ percent level to the average Dean's rating but when Table 7 , page 142 , is examined it is found to be related at the 05 percent level and of the same magnitude as that of the self Adjustment index. With this group then the same pattern of rolationship was found. Here again we have the same tentative reasons for explaining these relationships. In general the two indices appear as similar aspects of the same self report. One's feelings in social situations seem to mirror his feelings about himself and appear to bo of the same emotional tone. These are then reflected when adult raters view the Individual in his milieu.

In considering the subject's own report of his foeling of social adjustment and that relationship with the score established on the sociometric measures - the "Guess Who" and the "Companionship Cholce" - one would expect a rather high relation- 
ship. Such was not the case as the relationshlp between each of these measures and the social Adjustment ind ex were of such magnitude as to be below the 01 percent level of significanco. From Table 7, on page 142 , we find the se relationships to be significant at the 05 percent level. The correlation coefficient between Social Adjustment and the "Guess Who" is .284. The correlation coefficient between social Adjustment and the "Companionship Choice" is .271. Why do those boys who rate rather weIl with their peers not report more accurately a feeling of social adjustment logicalif in keeping with acceptance? It may be that many boys who report adequate social adjustment are really not acceptable to their age mates. The Social Adjustment protocols of the lowest ranking two boys in both the "Guess Who" and the "Companionship Cholce Test" were checked. These almost unanimously rejected boys established very low adjustment scores. The Social Adjustment protocols of the two boys ranking high in acceptance on the "Guess Who" and the "Companionship Choice" were also looked at and were found to reflect falrly high feelings of social adjustment. However, the rank and file, those who are not at the extreme positions, seem to be rather unsure of thelr social status. We found some boys, who rank fairly low in accoptance status, reporting adequate feelings of soclal adjustment and others, fairly well accepted, reporting very Inadequate foelings of social adjustment. It appears that, whilo there is a trend toward relationship between these two measures, that there is also a discrepancy in many individual cases betweon reporting foelings of social 
adjustment and social accoptance and rejection unless that social acceptance or soclal rejection is of sufficlent magnitude to leave no doubt in the person's mind as to how he stands. This, too, is a question that bears further careful investigation. Such findings are further indications of the presence of poor insight in regard to social acceptance on the part of the majority.

The Soclal Adjustment Index was significantiy rolated at the 01 percent level with both Munroe's Rorschach Check List and Rotter's Incomplete Sentence Test. The correlation coefficient between the Soclal Adjustment index and the Rorschach index was . 345. This relationship, while not high, indicates a trend for those who report themselves better adjusted soclally to show less signs ldentified with maladjustment in their responses to the Rorschach stimul1. With the Rotter Incomplete Sentence array of scores the Social fidustment index showed a coefficient of correlation of .320. While low in magnitude there is an indication of a tendency for those who report positive social relationships to indicate less conflict on a more indirect form of report. The Soclal Adjustment index showed no signif1cant relationship to the index secured from direct observation using a Modified Time Sample tochnique. If the latter had beon a more discriminating instrument, the social contacts observed should heve established an index that would have reflected inter-personal relationships.

(3) The relationships botween the California Test of Personality and the Heston Personal Adjustment Inventory have 
been discussed. We now need to deal brlefly with the interrelationships among the various factors making up the Heston Personal Adjustment Inventory. From all evidence present this instrument has been more carefully devised than many of 1 ts predecessors in the inventory area. However, its factors are not presented by the author of the test as pure in the sense of belng unrelated. In Table 9, on page 160, we have presented the inter-correlations between the factors as we found them on our population and have also, for comparative purposes, included the inter-correlations reported by the author in his manual. It is necessary to take more than a casual glance at these relationships before comparing the various factors with the remaining adjustment indices.

Heston, in his manual, remarks that he found that the degree of relationship between pairs of traits varied rather widely from near zero to magnitudes definitely significant. The same may be said of the present findings as Table 9 shows. In the main our findings, using an adolescent male population, parallel his findings using 50 men and 50 women, who were freshmen at the De Pauw University in 1947.

He reports that traita "C", " $P$ ", and " $E$ " formed a significantiy related triad. Our present data would indicate the same patterning with a slightly higher magnitude of relationship indicated. Heston states that this state of affairs is both logical and reasonable and that it represents, in numbers of respondents, the co-existence of Independently describable 
TABLE 9

INTER-TRAIT CORREIATIONS FOR THE HESTON PERSONAL ADJUSTMENT INVENTORY SCAIES*

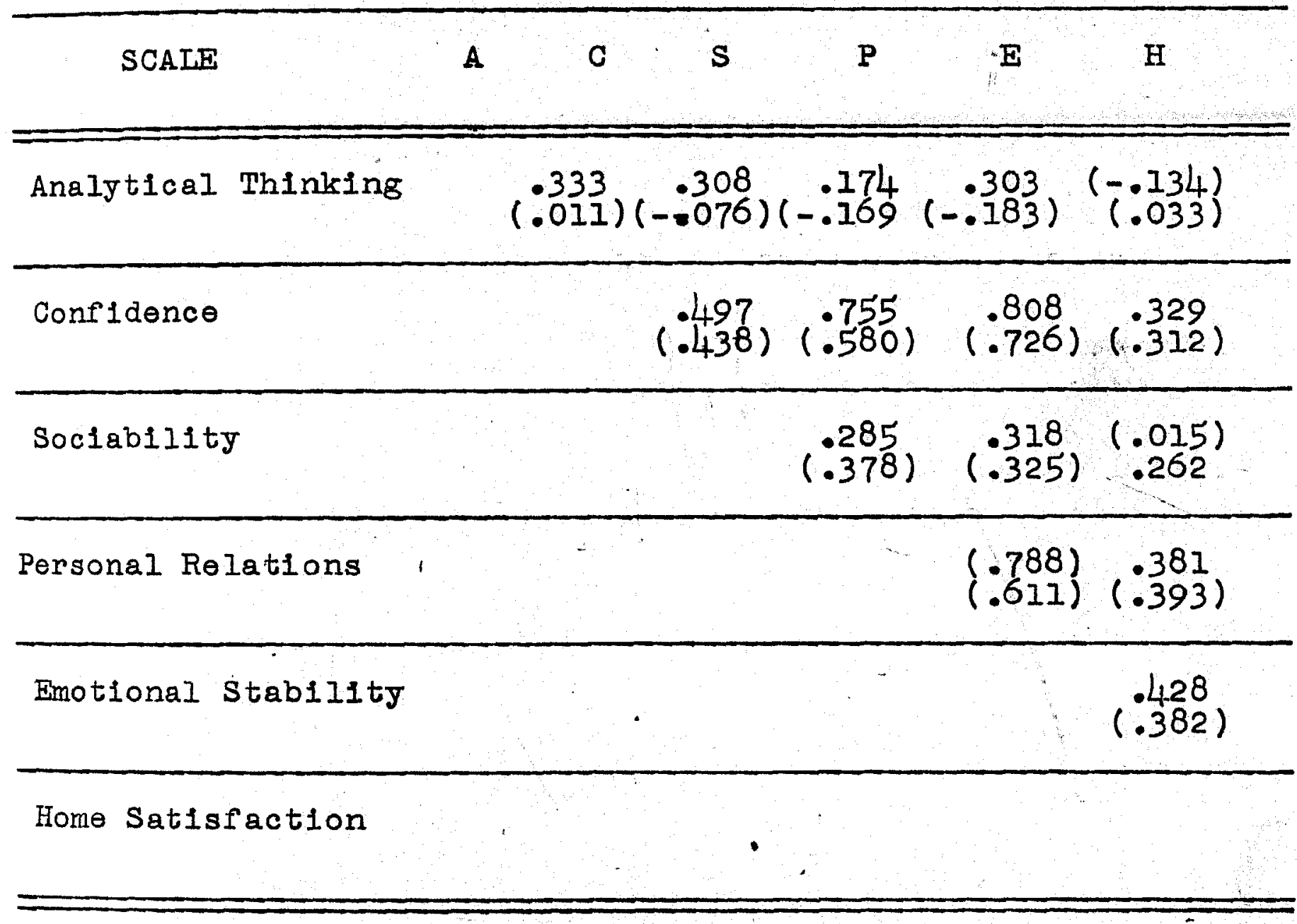

* Top figuro in oach row indicates the relationship found in the present study. $N=66$ adolescent boys, Lower figure, in brackets, in each row indicates the relationship found by using 50 men and 50 wopien from DePauw University and reported in the test manual. 1

${ }^{I_{\text {See }}}$ append1x p. 291 (manual p. 32) 
traits that are desirable for good adjustment. Then the question is raised as to the purpose of measuring all throe traits if they are so highly related. Heston answers by reporting an experiment in which percentile levels on the three traits were compared in 50 randomly plcked cases. It was found that in at least half of the cases the difference between scores on the three traits are at least 25 percentile points. He foels that this is sufficient reason to measure all three factors which appears to be loglcal if one is going to utilize scores on an individual basis as derived from this instrument.

Similar findings to those of Heston were found in regard to the factors "H" and "S". We found them to be positively correlated to "C". "P". and "E", but at a much lower magnitude. Heston's findings and ours differed in that he found " $H$ " and "S" to be significantly related while we found a near zero coefficient of correlation of .015 between the two." This discrepancy may be explained by the rather muddled concepts of home relationship existing in the present population. With a population to whom the common home environment of our culture has not existed for lengthy periods in their life, it would not be unreasonable to expect unusual reactions in this area as we have indicated in previous discussions.

Table 9 also shows that the "A" factor was the least related to other factors and was the most independent in Heston's findings. Present results indicate that within our population It was significantly rolated to factors "C", "S", and "E". In other words those boys evidencing more intellectual independence 
tend to evidence more confldence, report more social extroversion, and to indicate more emotional stability. Perhaps these aspects of good adjustment co-exist to a greater degree in a younger population than in the college freshman group which is as atypical in many respects as that of our own group. Upon the examination of the factors describing traits of adjustment upon which scores were secured on the Heston Personal Adjustment Inventory, we found consistent interrelationship. Of the 15 coefficients of correlations secured 12 of them are sufficiently related to be significant at the 05 percent level, while 9 of them are sufficientiy related to be significant at the OI percent level. This situation might be used as an argument for the usefulness of a global concept of adjustment as there does appear to be a consistent trend for these described traits to co-exist in a sufficient number of persons to establish significant relationship.

(4) From Table 8, page I45, the relationships between the Heston factors and other indices of adjustment not discussed thus far may be survejed. The trait, Analytical l'hinking, was found to be unrelated to any other index of adjustment at a significant level outside of the relationships between itself and the other factors of the Heston wich have already been discussed. This factor described as intellectual independency does not soem to be related to any other measure of adjustment with which we have worked. Heston reports it as being most closely allied to academic achlevement at the college level. Whether it is related to achievement at the Junior and Senior 
High School level remains to be tested.

(5) Confidence, the second factor to be surveyed, was likewise found to be unrelated at the ol percent level to indices established by other than the questionnaire and inventory techniques. At the 05 percent level of significance there was a relationship expressed by the coefficient of coirelation of .259 with the "Guess Who" results. This finding is rather surprising when we compare the comparatively high relationship this "C" factor had with expressions of self Adjustment and the many positive relationships that index was found to have with other indices. Perhaps the lack of assurance shown by many adolescents, which should be reflected by this factor, is recognized by other techniques as a developmental state of affairs and discounted. This would be true of ratings and the projective techniques to a certain extent.

(6) The index of Soclability was found to show only one significant relationship at the 01 percent level outside of the Inventory-Questionnaire technique grouping. It was found to be related significantly to the "Guess Who" Index as expressed by the correlation coefficlent of .333 . This seems to indicate a tendency for those boys who express some degree of social extrovertiveness to exhiblt more acceptable traits than those who are inclined to prefer follower positions. However, the possession of social traits of an extrovertive nature does not guarantee that he will be a chosen companion for preferred activities as the -.044 coefficlent, of correlation between 
Sociability and "Companionship Cholce" points out. Adult raters of all classes, using a variety of techniques, do not take this self report of the existence of social extrovertiveness into consideration in arriving at an adjustment index if our data can be used as any indication as the se relationships are of the zero order. Neither is the "S" trait related to either of the indices established through use of projective techniques. It is likewise unrelated to the observed characteristics elicited by the Modified Time Sample technique.

(7) The factor, Personal Relations, was found to bo related to only one other index beyond Group I at the 01 percent leveI of significance. This relationship was found to be expressed by the coefficient of correlation of .365 with the "Companionship Cholce Test". This is a logical relationship as this factor is intended to ellcit favorable responses from those who have positive trusting feelings toward others and those who are least annoyed by behavior aberrations of others. Those who are least irritated by another's ldeosyncrasies tend more of ten to be selected as chosen companions. This point is highlighted when we consider the relationships between the "Guess Who" Index and the "Companionship Cholce" where we find that those with admirable characteristics are not always chosen as closo companions.

When we look back at Table 7, page 142, we find that this "P" factor does show relationship at the 05 percent level with the Dean's Rating, the Psychologist's Rating, and the "Guess Who". This factor is not related to the Teacher-supervisor 
rating, either of the projective techniques, or the modified time sample of behavior. It appears that this factor is a characteristic of those techniques that seok to draw upon material that relates to individual acceptances by members of soclal groups more apt to be ellcited by the techniques described in Groups I, II, and III than by those techniques described in Groups IV and $V$.

(8) An examination of the factor, Fmotional Stability, reveals that within Group I it is significantly related to all indices except the factor, Analytical Thinking. Outside of Group I this factor is related to none of the other indices. It appears that what is described under this factor " $E$ " - one who reports himself freo from tension, free from fears, aklo to relax, and able to see reality - is elther not readily elicited by the other techniques for establishing an index of adjustment or that it is a particular facet of the conception of self that is not readily mirrored in any other manner than by self-report and has little to do with the overt signs of adjustment upon which we usualiy make a judgment.

(9) Home Satisfaction is anothor factor of a dustment according to the Heston Personal Adjustment Inventory. We $f$ ind the "H" trait to be unrelated beyond the inventory-questionnaire group. Here again we may bo dealing with those feolings of an individual in regard to himself and his environment that may be a definite part of his self-concept, but whlch do not seem to be related to the way he makes observable ad justments. This 
seems to be true providing our other groups of techniques can be relied upon to make valid assessments of adjustment.

In summarizing an examination of the relationships established through correlating the various factors of the Heston Personal Adjustment Inventory with the other Indices of adjustment, we find that there are few relationships that are significant beyond the group of inventories-questionnaires. There is more evidence of positive and significant relationship between the described factors than between any of the other indices. The "C", "P", "E", and " $H$ " factors are positively and significantiy related to the indices of Self Adjustment and Social Adjustment established on the California Test of Personality.

(10) We have already discussed the relationships between the indices secured from the inventory-questionnalre group and the index secured by using an average $r$ ating from two teachers and a supervisor by means of a rating sheot encompassing the seven facets of adjustment. Next, we consider this average teacher and supervisor rating which must be considered cautiously because of its low reliability as it relates to the indices of adjustment not yet discussed.

Within its own group - Group II, Ratings by Adult Judges we find positive and significant relationships to povail. The "T and S" (average teacher and supervisor rating) was correlated With the average rating made by the two mon in the Dean's offico using the Haggerty-01son-W1 ckman Behavior Schedule B. The

* Ser Appendix p. 292. 
correlation coefficient between these two measures was . 545 which is signiflcant at the $0 I$ percent level and of falriy high magnitude. This is an expocted state of affairs as both classes of raters might be expected to make their ratings on the basis of acquaintanceship with overt bohavior characteristics.

The "T and $S$ " rating, when correlated with the rating made by the psychologist, was expressed by a correlation coefficient of .490 , which is also significant at the 01 percent level. Perhaps some of this agreement might be partialiy explained through the use of the same basic scale of adjustment. Disagreement might be a derivative of less frequent observation on the part of the psychologist, a difference in the manner in which the rating was secured, a different emphasis on $\mathrm{c}$ overt behavior, or many other similar variations between the classes of raters. The fact that the correlation between the "T and $S "$ and the deans' rating was somewhat higher than the correlation between the "T and $S$ " and the psychologist's rating may be in part due to the similar backgrounds of the two classes of $r$ aters. Adult judges, although using different techniques, observing at different times, and with different backgrounds, tend to arrive at ratings of adjustment that are related. With the sociometric indices, the "T and $s$ " rating appeared to be rather highly related. With the "Guess Who" scores a correlation coefficient of .531 was ostablishod which is significant at the 01 percent level. With the"Companionship Cholce" a correlation coefficient of .603 was established which is of even higher magnitude. We might conclude that there is 
rather a strong tendency for teachers and supervisors to admire the same characteristics in an adolescent that are admired by his peers and make judgments accordingly. Also we might say that those adolescents more of ten chosen for close companions by their peers are judged by teachers and supervisors to be better adjusted.

The "T and S" rating was not found to be related to elther of the Indices established by use of projective techniques at the 01 percent level of adjustment. However, the "T and $S$ " rating is found to be related to the Munroe Rorschach Chock List at the 05 percent leveI when Table 7, page 142 , is consulted. The "T and $S$ " rating was found to be signiflcantly related at the .01 percent level with the index derived from the Modified Time Sample. Since the rellability of the "T and $S^{\prime}$ rating is questionable and the discriminatory powers of the Modified Time Sample is questionable, it is doubtful if much confidence can be placed in this relationship. It might be inferred rather cautlously that the behavior noted in small samples of behavior terids to be consistent with the impressions gained by teachers and supervisors as related to assessing adjustment status.

(II) It has already been noted that the average rating secured from the Deans, using the Haggerty-OIson-Wlckman Behavior Schedule B, was not signiflcantly rolated at the 01 percent level to any of the indices established in the inventory questionnaire group. It was also noted that 1 t was related to 
the "T and S" rating at the 01 percent level of slgnificance. The Dean's rating was found to be significantly related to the Psychologist's rating with an established coefflcient of correlation of .580. This would appear to indlcate that ratings established by these two groups of raters, using different rating instruments, still arrive at similar judgments in many cases. However, it also indlcates that there are many instances of disagreement which might partially be traced to the emphasis on overt behavior of the Haggerty-Olson-Wickman Behavior Schedule B, the differences in training of the judges, differences in experience with the particular individuals rated in differing environmental circumstances, and other similar variables.

The Dean's rating was found to be significantly related to the indices established through the use of soclometric techniques. A correlation coefficient of .369 was tablished between the Dean's rating and the "Guess Who" score which is significant at the 01 percent level. Between the Dean's rating and the "Companionship Cholce" score there was established a coefficient of correlation of .630 which is not only significant beyond the 01 percent level but of a fairly high magnitude. These relationships would indicate that there is some tendency for those exhibiting characteristics favorable to peers to be rated higher on the Haggerty-OIson-Wickman Behavior Schedule B. There is a decided trend for those who are more acceptable as close companions to be rated better adusted on this rating 
schodule. Perhaps those who are freest from overt behavior. problems are more acceptable in social situations. In other words, the more one reacts overtiy in ant1-soclal behavior terms the less likely is ho to find the satisfaction of close friendships.

This rating, established on the Haggerty-Olson-Wickman Behavior Schodule B.was not found to show significant relationship with elther of the indices derived from projective measures. Neither was it found to be related to the Modified Time Sample index.

(12) The relationship between the rating made by the Psychologist, using case history, personal knowledge, and a semi-structured interview as a basis for his global rating, and techniques in Group I, and the ratings of other adult raters has been discussed. In comparing this rating with the soclometric techniques it was found that there was a significant relationship at the $O I$ percent level with the "Companionship Choice" score. The coefficient of correlation was .488 . Again It seems that those boys who were more acceptable as close companions evidenced less non-adjustive mechanisms as seen through the eyes of the Paychologist in his contacts with them. While not related at the 01 percent level, the Psychologist's rating and the "Guess Who" scores were related at the 05 percent level. InoTable 7, page 142 , this relationship is expressed by a coefficient of correlation of .301 . 
In comparing the relationship between the Psychologist's rating and those indices established by use of the chosen projective techniques, a significant relationship was found between this rating and the score derived from Rotter's Incomplete Sentence Test. The coreolation coefficient was. .363 , which is significant at the 01 percent level. The conflicts expressed through this technlque tend also to be seen by the Psychologist in his experiences with these adolescents, although there is no consistent agreement between these indices in individual cases. With the Munroe Rorschach Check List there is no significant relationship with the Psychologist's rating. Neither is there a significant relationship between the $r$ ating made by the Psychologist and the Index secured through the use of the Modified Time Sampling technique.

In discussing theratings made by various adults we find that they tend to be signiflcantly related to each other. They also tend to be related significantly to the adjustment indices established through the use of soclometric techniques. There are afew instances of rather high relationships to certain indices derived through the use of questionnalres and inventories. In one instance there was positive relationship to an index established through the uso of a projective technique.

(13) The relationships between the indices found in Group III - the Soclometric Techniques - and Indices secured in Group I and II have been alscussed. It is now necessary to discuss relationships between indices in this group and those of groups not previously discussed. 
Whthin Group III we have two slightly different techniques, the "Guess Who", composed of characterizations found acceptable and non-acceptable by adolescents, and the "Companionship Cholce", where members of the population are elther chosen or rejected for desirable activities. Between these two indices a relationship indicated by a correlation coefficient of .625 was found. This is signiflcant beyond the 01 percent level and of falriy high magnitude. A large chart, showlng each individual's positive and negative ratings on each item of the two instruments, was constructed in order that some general tendencles might be mor e clearly seen. From this chart it was clear that for many individuals there was a consistency between being nominated as the possessor of an approved or disapproved characterlstic and being chosen or rejected as a close companion. However, there were a number of individual discrepancies that at least bear a passing consideration and surprisingly these seem to fit into two classes: (1) The strong athletically inclined extrovert, who takes very positive stands and rules his more passive fellows through sheer physical ablilty, was most often chosen to possess admired characteristics but was very frequently rejected as a companion in a shared activity. (2) The colorless rather passive boy, who easily follows the suggestions of others or the good fellow who is always willing to go along with a more positive individual's direction, was seldom high in numbers of admired charecteristics, but quite frequently chosen by the more positive type of boy as a companion. There are enough of these discrepancles that fit rather easily into these two categories to account for a considerable amount of the lack of relationship. 
The "Guess Who" Index was not found to be related to either of the indices derived from the use of the projective techniques at the 01 percent level of significance. When Table 7 , page 142, is consulted, it is noted that there was a relationship between the "Guess "ho and the Rorschach Index at the 05 percent level, which is expressed by the coefficient of correlation of .253. This is indicative of a positive and slight relationship between these two indices. There was also a relationship at the 05 percent level between the "Guess Who" scores and the Modified Time Sample expressed by a correlation coefficient of .291 .

(14) The "Companionship Choice" index was found to be related to the Munroe Rorschach Check List index as expressed by a coefficient of correlation of .317. This $r$ elationship is at the 01 percent level of significance. In other words, there is a tendency for those who are most of ten selected as close companions to show less evidence of maladjustment on the Munroe Rorschach Check List. The "Companionship Cholce" Index was not significantly related to either the Rotter Incomplete Sentence Test index or to the Modified Time Sample Index. In reviewing the relationships found between the sociometric technique indices and other indices we find that not only are they related to each other to a considerable extent, but that they are related to indices found within every other group. They are most highly related to the indices found by using adult raters. 
(15) Most of the relationships or lack of relationships between the two projective technique indices and other indices have been discussed. It will be recalled that the Munroe Rorschach Check List was significantis related at the 01 percent level and above to the Social Adjustment index and to the "Companionship Choice" Index. The Rotter Incomplete Sentence Test was significantly related to the self Adjustment index, the Social Adjustment index, and to the rating mado by the psychologist at the 01 percent level of significance. None of these relationships were of a magnitude higher than that expressed by a correlation coeffictent of .345 . It is interesting in view of the wide interest expressed in projective techniques to note that there were few of the common indices of adjustment that were related in a significant manner to either of these indices. It is also noteworthy that wherever there were two techniques in the group of techniques available, we usually found significant relationships between similar approaches: In the case of agreement between the Munroe Rorschach Check Iist and the Rotter Incomplete Sentence Tost we found relationship of a zero order. Categorizing a technique as projective is not as apt to bring similar results in assessing adjustment as if wo use two techniques classifled as inventories or questionnalires, for example. It is possible that the projective techniques chosen are measuring facetscof adjustment ignored by other techniques. It is also possible 
that they do not lend themselves to establishing a numerical index of adjustment status comparable to other commonly used measures. Neither of these projective technique indices were found to be significantly related with the Modified Time Sample index.

(16) Of the groups of indices usod, the Modifled Time Sample index seemed to be in the same class with the index established on the Heston factor of Analytical Thinking. The only relationship between the Time Sample index and other Indices that was significant at the 01 percent level, was that found between it and the "T and $S$ " rating wich hesalready been discussed. The major factor in its lack of relationship to other indices purported to assess adjustment seemed to be its poorness in distributing the subjects over a sufficient range on the adjustment-maladjustment continuum.

\section{Discussion}

An intensive examination has been made of the intercorrelations resulting from a comparison of the sixteen arrays of adjustment indices with each other. An attempt has been made as each relationship between arrays was examined to express what appeared to be logical explanations for elther the existing relationship or lack of relationship. In Chapter VI another approach to these relationships between adjustment indices will be made. Here an intensive consideration will be given to the relationship of the various adjustment indices as they are revealed when applied to selected Individuals. Prior to discussing individual application, there are certain polnts which 
have been brought out by the data which merit. discussion in the remaining paragraphs of this chapter.

General Agreement. The data show that for this particular group of adolescent boys there is, in general, a positive but low correlation between the selected measures purporting to assess adjustment status. This finding has implications for those who use such techniques for purposes of diagnosis prior to instituting therapy, for those who use such instruments as a basis for individual guldance, and for those who use such instruments to assoss outcomes of guldance, counseling, or therapy procedures. The immediate implication is that it would be inaccurate and risky to draw more than tentative hypotheses in regard to an individual's adjustment status on the basis of any one score on any one of these measures. In fact, it would be hazardous to draw any hard and fast conclusions on the basis of results secured from only a few of these measures. The practice of using one index as a criterion of adjustment when evaluating different environmental influences or the efficacy of a particular therapeutic approach does not seem to be warranted by the data presented in this chapter. The low magnitude of the intercorrelations makes prediction in individual cases a precarlous procedure.

Since forty-one correlations or approximately one third of the possible intercorrelations were significant at he 01 percent level, some common relationships between the various indices of adjustment status is indicated. Moreover, the fact that seventeon additional intercorrelations between the varlous indices 
were significant at the 05 percent lovel adds support to this indication of relationship. This evidence cannot be dismissed lightly as it does lend support to the existence of some general characteristic of human behavior termed adjustment that can be measured by a variety of techniques. However, since the magnitude of such relationships was generally low, It appears that such a global concept is of limited usefulness as it lacks preciseness and common meaningfulness. For example, when the global concept of adjustment is compared to the global concept of intelligence, it is found to be less communicable in terms of scores established by instruments purporting to make such an assessment.

Factors Affecting Relationship Found. In considering the intercorrelations that were presented in Table 7, page 142 , a number of factors other than adjustment appeared to have a bearing on the relationships between the various inaices. In a comparable manner there appeared to be certain other factors that partially accounted for some of the lacks of relationship found. In the following paragraphs certain of the se factors are briefly discussed.

The first factor which deserves mention and appears to account for some of the relationships found is the type of technique used. Among the indices established by questionnalres and inventories there were found to be eighteen intercorrelations out of a possible twenty-elght which were significant at the 01 percent level. This was a much higher proportion of significant relationships than found when these indices were 
correlated with indices established by other techniques. Here it was found that there were eleven significant relationships out of a possible sixty-four. This same factor appears when ratings made by adults with different backgrounds and using different scales are examined. Here again there are much closer relationships between indices within the technique than botween the rating indices and indices established by other techniques. The same thing appears between the two soclometric techniques. This state of affalrs does not exlst between the projective techniques chosen. Similarity of technique in at least three groups of indices may be a factor accounting for some of the relationships found.

When the relationships within and between these three groups of techniques (inventories and questionnaires, adult ratings, and sociometric techniques) are considered, another tentative factor accounting for part of the relationship found may be pointed out. It is possible to look at the questionnalre and inventory used as a self rating. The rating scales used by adults may be termed adult ratings. The sociometric indices could concelvably be thought of as peer ratings. It then seems within the realm of possibility that some of the relationship found between indices in these three classes of techniques might be accounted for on the basis that the person himself, the observing adult, and the observing peer reject and accept some common characteristics of a person's behavior in a related manner. The fact that all are established through personal observation and report may account for some of the observed 
thread of relationship. It is possible that all of these ratings are influenced by the character reputation of the person. If such were the case, this then would be the common factor.

In the case of the California Test of Personality, where a correlation coefficient of .663 was found between the sections labeled Self Adjustment and Social Adjustment, it was pointed out that the boundary between self and social is an arbitrary. one that is difficult to draw with precision. The overlap that was demonstrated rather clearly between these two indices may be the manfestation of a factor making for relationship when these indices are compared to other indices. Some of the significant relationships pointed out can very well be a result of the relationship existing between these two measures. This is demonstrated clearly when the two indices arefound to show relationship with the other fourteen indices in an almost identical pattern and in many cases at approximately the same magnitude. The major exception is found in the relationship of these two indices with the soclometric measures where the Self Adjustment relationships are significant at the 01 percent level and the Soclal Adjustment relationships are at the O5 percent level.

The lack of relationship at a significant level between the adjustment indices of the two projective techniques chosen deserves some comment. It is recognized that many of the common projective techniques in use do not attempt to describe by a numerical index any particular status of adjustment. How- 
ever, the two chosen are so adapted to do just that. When a relationship of the zero order was found between the Munroe Rorschach Check List and Rotter's Incomplete Sentence Test, it poses the question as to the usefulness of these techniques for this particular purpose. With this particular population an overall index secured by either technique seems to have little meaning in terms of adjustment status as defined by the other types of measures. When it is considered that the Munroe Rorschach Check Iist index was related to only the Social Adjustment index and the "Companionship Choice" Test index at the 01 percent level of significance out of the fifteen other Indices of adjustment, it appears that this instrument is measuring something different than most of the other techniques. Further, the Rotter Incomplete Sentence index was related at the 01 percent level of significance to the self Adjustment index, the Social Adjustment index, and the Psychologist's rating. It appears logical then that the demonstrated lack of relationship between the projective indices and other adjustment indices is a factor in reducing the number of significant relationships found.

Another factor in the lack of significant relationships was found in the use of the Modified Time Sample to secure an index of adjustment. This particular scale was found to distribute the population poorly, $1 . e$. , there tended to be a compactness of score groupings around the mean. While two observers were falrig reliable in thelr observations (agreoing in $86 \%$ of 
the classifications in a sampling of 210 instances), this limited range would tend to cut down the relationships of this test to other Indices of adjustment. In fact, there was only one instance where there was established a coefficient of correlation at the $O I$ percent level of significance and that with the Teacher and supervisor rating. The fourteen instances of non-significant relationships at the $0 I$ percent level contributed to the overall picture of lack of relationship found.

A surprising finding was the lack of relationship found between some indices bearing simliar labels. Perhaps the outstanding example was the lack of relationship between the Social Adjustment scale of the California Test of Personality and the factor labeled Soclability on Heston Personal adjustment Inventory. The differences between the results secured through the use of soclometric indices and the indices mentioned above were also quite apperent. It is plain that labels as applied to tests designed to measure particular aspects of adjustment are apt to be misleading. There exist problems of definition that have not been adoquately met in describing certain areas of adjustment. These unsolved problems of definition make it impossible to state that an individual is socially maladusted or lacks sufflcient soclal rapport on the basis of results secured from a test that may carry the label "social" in its title.

The influence on the results obtained by the factors which 
have been described are probably insufficient to account for all of the relationships found. Iikewise they are probably inadequate in explaining all of the lacks of relationship found. When all of these various influences have been pointed out there still remalns a possibility of a general factor which might be called adjustment remaining to account for some of the relationships found among the varlous arrays of adjustment indices. Apparentiy this factor does not loom large in accounting for relationships found among the common means for assessing adjustment used in this study. Theoretical Implications. Lack of well defined relationships among measures purporting to assess adjustment status raises the question that possibly there is no such thing as "adjustment." On an empirical basis, it is not so"easy to pulo out a characteristic of personality labeled "adjustment" which has enjoyed such long usage. The data at hand clearly indicatos the lack of agreement among techniques used to assess adjustment status. It becomes necessary then to postulate that present techniques are el the rery inadequate in tapping related facets of a common process labeled "adjustment," or that they are measuring different kinds of adjustment. There is a further possibility that both inadequacy of present techniques and existence of spocific types of adjustment co-exist to complicate the problem of measurement.

Present finding are not conclusive in helping to answer these questions. Obviously, if there exist many "adjustments" 
that have little in common, there is need for separate clarification and definition. Until there exists a body of research data which clearly points to preclse adjustment concepts, which can be communicated, the use of the term "adjustment" merits cautious reservations.

There is another question which can be raised in regard to the agreement among various indices purporting to measure adjustment. Is high intercorrelation a guide to those tests which are best, or is the entirely unrelated test, e.g., the projective, measuring an heretofore lgnored and important aspect of adjusting? Obviousiy this question can not be answered without further analysis of the adjustment concept. The answer appears to hinge upon whether there exists separate "adjustments" or unrelated co-existing facets of the adjusting process and their relative importance.

Next Steps. The fact $r$ emains that the adjustment concept is st1ll a hazy one and that present tests are not clear as to just what they are measuring. It seems necessary to make a detailed analysis of adjustment in operational terms so that precise definitions may be formulated. Perhaps one of the first steps is to agree upon what constitutes commonly experienced situations in our culture at various age levels and then proceed to analyzo those situations in terms of adjustment. This is obviously a large project demanding the cooperation of many interested in making the concept of adjustment more precise. For the present those who use the term 
"adjustment" ap pear to be obligated to define clearly what they mean when they speak of adjustment, if they are to be understood by those with whom they seek to communicate.

Some would suggest that a next step would be to analyze further the data presented in this study by the method of factor analysis in an effort to define the factors accounting for the thread of relationship noted in applying the various techniques. While such an analysis would be of some value, the correlations appear to be much too low to result in the development of conclusive new factors. In addition, the patterns of intercorrelations have suggested probable factors which have already been noted. To factor analyze the data brought forth in this study would not be basing such procedures on as representative a population as would be necessary to make such a procedure profitable. Elaborate statistical procedures would not change the basic data and might lead to generalizations that are premature. A factor analysis study by cattell and saunders ${ }^{5}$ using personality variables secured by three media lilustrates the difficulties in working with varlables drawn by diverse techniques.

A more logical next step, after commonly experienced situations can be defined in terms of adjustment, is to construct tests that will measure those situations. When such

Scattell, R. B. and saunders, D. R. "Inter-Relation and Matching of Personality Factors from Behavior Rating, Questionnaire, and objective Test Data". J. soc. Psychol., 1950, 31 :
243-260. 
tests are constructed and made as reliable and valid as possible, they can be applied to representative populations. It would then be profitable to subject these results to factor analysis in an effort to purify further the techniques used. A series of such constructions should eventually result in techniques whose results can be communicated with less ambiguity.

In the process of constructing better tests, it is evident that those who deal wi th concepts of adjustment must be trained to use those concepts at a high level of proficiency. It was noted through the data of this study that the relatively well trained adult raters were more in agreement than those who had not been especially trained in this area. It was also noted that the relatively untralned rater was more reliable when using a technique defined in specific behavior terms - such as the Haggerty OIson Wickman Behavior Schedule B - than when using the more non-specific overall rating scale such as the "T and $S$ " rating. If we must depend upon judges rating adjustment status as a present criterion of adjustment, the argument Is for using those who are as well trained as can bo secured. In the process of constructing better measures of adjustment and training judges to use those measures, there is another technique for measuring adjustment which should be explored. After this study was in progress and too lato for modification, the need was felt for some measure of adjustment which might be derived through the means of a situational tost. When using 
the Modified Time Sample technique, it developed that it might be profitable to devise some situation or serles of situations that could be standardized for each subject where he would have to make an immediate adjustment which could be judged for appropriateness along the adjustment-maladjus tment continuum. If this study were to be repeated, some such measure would merit inclusion.

There is a need to investigate further if completely unrelated tests, $\theta . g .$, projective, are tapping important. new aspects of adjustment or actually studying material unrelated to the level of adjustment. OnIy a few of the projective tests are recommeñded as userul in establishing a global index of adjustment. It needs to be determined more definitely if some of the projective tests can be used in this manner or if the nature of some of them makes it impossible for the results to be expressed in a single index. Immediate Suggestions for Evaluation of Adjustment. In the light of present findings in regard to the use of tests or techniques purporting to establish a measurement of adjustment status for screening purposes with groups, what procedures can be recommended for immediate use until further research can be done?: In order to answer the above question with any degree of satisfaction it must be taken into account that in this whole area of adjustment there are factors present that are not only difficult to define but whlch have not been clearly designated. 
Since it is not possible at this time to clearly define independent factors or even co-existing factors in this area and measure them accurately, it seems best to use techniques for screening which are apt to show most relationship to a number of existing techniques. (If unrelated measures are used, then designation should be made that more than one kind of adjustment is belng studied and the scores are not summated.) From the data presented in this study it appears that two types of measures, one of self acceptance secured through self report and one of soclal acceptance secured by a soclometric technique, are probably useful to point out the individuals who are most in neod of immediate help.

It was found in this study that the self Adjustment index as secured on the California Test of Personality wascorrelated at the 01 percent level of significance with ten of the other fifteon indices used. It was related to five other self report indices Including the "C", "P", "E" triad of the Heston Personal Adjustment Inventory. It was also related to five of the remaining indices from other groups of techniques. If we want an index that is most iikely to reflect what a group will do on a variety of techniques purporting to measure adjustment status, this one wlIl be holprul. To make the identification of those needing help more definite, a "Companionship Cholce" Test, similar to the one in the study, may be used as it was found to be related at the 01 percent level to seven 
of the other fifteen Indices. S1x of these relationships are with techniques from groups other than the soclometric group. These two indices might best be used together with a particular group, if group status in ing with a variety of adjustment appraisals 1s desired.

In particular, it would be recommended from the experience with this group (See Chap. VI also) to secure these two measures and then examine the lowest quartile scores in each index. Scores in the lowest quartile on these measures would have picked out (with the least investment of time) the boys who appeared to be demonstrating the most serious conflicts with their environment. It is then with these individuals so screened from the group, that more intensive work could be planned. It is during this intensive work that the experienced diagnostician will find helpful the cues elicited through projective techniques, behavior ratings by adults, direct observation, interviews, and other techniques. There 1 s no intent to belittie the contribution made by such techniques as the projective, for example, in providing the source for hypotheses necessary in working with individual cases. When the chosen projective technlques were used to establish overall scores of adjustment, they were not found to bo in close agreement with scores established by means of other commonly used techniques. If these commonly used measures of adjustment lack definite agreement among themselves, what can be done to improve the 
immediate situation? First, it is necessary to discard the practice of using the results of one technique as "the criterion" to measure difference between groups on the adjustment variable. Since there appear to be no preclse criteria of adjustment now avaliable, those who report results of therapy, counseling procedures, or environmental manipulations in terms of change in adjustment as measured by existing techniques, should include a variety of measurements secured through the use of many of these techniques. If statistically significant difference can be shown between compared groupl on a varlety of measures purporting to assess adjustment, more trust can be put in those results.

Summary. To recapitulate, the data shows positive but low correlation in general between the various indices of adjustment. This furnishes some evidence for a global concept of adjustment. However, sach factors as related techniques, overlap between tests designated self adjustment and social adjustment, and elements of character reputation may have increased the number of significant relationships found. Such factors as the unrelatedness of projective techniques, the inadequacy of the Modified Time Sample technique, and the confusion of terms as indicated in the unrelatedness of similarly labelod tests may have accounted for part of the lack of relationship found.

Recommendations have been made in regard to the use of 
present techniques for screoning purposes with an emphasis on a self report of adjustment and a peer report of adjustment. Recognition has been made of the use of other existing techniques as bases for hypotheses in individual cases. Some of the next steps have been formulated to deal more effectively with the concept of adjustment. The need of using many test results instead of one or a few in criteria studies has been emphasized. A more detailed analysis and definition of adjustment should lead to the construction of better techniques and to the training of judges to use those techniques. 


\section{GHAPTER VI}

\section{FIVE CASE STUDIES REPORTING INDIVIDUAL SCORING ON THE ADJUSTMENT MEASURES}

\section{Introduction}

Having considered the relationships existing between the various measures used to appraise the adjustment status of the study population, it becomes a logical next step to consider individual cases. One of the fudgments made in Chapter $V$ after comparing the group data was that, in attemptIng to study individual adjustment, extreme caution must be used in an interpretation of any one score derived from a particular technique. It was recommended that, because of the lack of communality of concepts in the adjustment area, perhaps the only approach, with any merit toward assessing adjustment in an individual case was to utilize many techniques in arriving at hypotheses in regard to individual adjustment. Since the data is avallable in regard to each individual particlpating in this study, it might be profitable to examine a few example cases.

It is the purpose here to review as concisely as possible the environmental background of each of the chosen cased and then to present the scoring of the individual on the various tochniques for assessing adjustment status. An attempt 
w1ll be made to formulate certain hypotheses in regard to the rationale behind the scores presented in the light of what is known about the subject's typical behavior prior to the study. An effort will also be made to evaluate the diagnostic significance of the test results in the light of subsequent behavior in the more than two years following the appraisals. Any conclusions drawn will necessarily be limited by the uniqueness of each case. The complexitios of environmental and individual characteristics and their patterns of interaction make for an admitted subjectivity. However, since we have found no consistently high relationships between the various adjustment appraisals within the group, the individual approach may be profitable in clarifying reasons for this apparent lack of high relationship.

The five cases chosen to bo examined as individuals were chosen to meet the following criteria: (I) two cases to be chosen who scored in the upper quartile on the california Test of Personality SeIf Adjustment Scale and also in the upper quartile on the "Companionship Cholce" Test; (2) two cases to be chosen who sconed in the lower quartile on these same measures; (3) one case that did not meet these two criteria; (4) all cases chosen should be boys about whom there was fairly complete knowledge both prior to tho study and following thetesting period; (5) cases should cover boys who had remained in the institution and boys who had gone from the institution; (6) inasfar as possible cases should 
demonstrate certain unique features that might possibly be reflected on the measures of adjustment.

Each case chosen will be treated in the following manner. A summary of background prior to admission to the 0 . S. \& S. O. Home will be made. A summary including records of school achlevement, behavior observations, psychological data, and medical data will be presented. A patterning of individual scores on the varlous adjustment measures, in comparison with the group mean, will be made. A summary of subsequent history in the two years following the study will be presented. Tentative conclusions will be drawn in regard to each case in connection with the diagnostic features of the adjustment scores wherever possible. Names of persons and places will be omitted as is customary with such personal data. However, the facts as found will be reported with no attempt to fictionalize any evidence from the environment or behavior observations in the interest of making clearer 1llustrations. Obviously, any one of the cases of the sixtysix participants in the study would have its own unique contribution to make to this inquiry, but time and space warrants only the consideration of the five ohosen. 
Presentation of Cases

Case \#8858

Date of Birth $12-4-33$

Age as of June $1,195017-2$
Admitted to $0 . S . S . O$ Home $5-6-40$ Age at time of Admission $6-5$

Years of Residence as of June 1, 1950 10-1

Family Background: Case \#8858 came from a family with a rural background. Father and mother both grew up on noighboring farms. The father was born in 1897 and the mother in 1901. Both paternal and maternal relatives were known as small farm owners with satisfactory community standing. Investigation did not reveal any existing court records which would indicate any major conflicts with soclety on elther side of the family.

The subject's father served in World War $I$ and was honorably discharged in 1919. The father marrled the subject's mother in 1922. The father was interested in mechanics and left the farm shortiy after marriage to become a mechanic in a nearby medium-sized town. During the early and mid-thirties he owned his own garage and his own home. He was known as a good workman until his health falled. The marriage was reported to be happy and there was consclentlous regard for the children.

The subject's mother was a farm girl, who had a reputation for running a neat, clean home. She was reportedly happliy married and took pride in her family. She died 10-13-1935, when the sublect wo unian t... 
After the mother's death, the father held the home together with the ald of the paternal and maternal grandparents until his health failed in 1939. The father at that time was told he had developed a serlous heart and rheumatic condition that demanded a warm climate.

The subject was the youngest of five children. He had a sister who was ten years of age when he was born. One brother who was nine, one seven, and one three when he was born. These children were all described as normal with no serious behavior deviations. No particular patterns of rivalry or poor relationships among the children were noted. After the father's health failed, he sold the home to provide funds for a now start in Florida. The oldest girl, at this time sixteen years of age, remained. In a family where she could continue high school and earn her keep by helping with smaller children. The oldest brother, who was now fifteen, accompanied the father to Florlda. The next oldest boy was placed in a boarding home by local agencies. The two younger boys lived for a few months with the paternal grandparents, who were quite old, on a farm, pending their accoptance at the O.S. \& S.O. Home.

The subject and his next older sibling, six and nine years of age respectively, were admitted to the 0.S. \& S.0. Home on 5-6-40. Subsequently, both boys graduated from the O.S. \& S.O. Home. The oldest boy graduated in 1948 and the subject graduated in the spring of 1952. The oldest girl 
graduated from Ohlo State University and prior to her marriage taught for a time in a small mid-western college. The next oldest boy entered military service at the beginning of World War II and remained in the service. The next boy graduated from ohio State UnIversity and now holds a commercial position in a large mid-western city. The older brother, who entered the O.S. \& S.O. Home, graduated from that institution with honors and a good record. He became a printer by trade and attended Ohio State University for several quarters before being called into military service. The father is still living and resides in a Veterans' facility in the state of California.

Summary of Subfect's Residence at the O.S. \& S.0. Home

Psychological Records: Upon admission to the Home the subject was examined with Form $M$ of the Stanford-Binet Intelligence Scale. His chronological age was $6-5$ at the time of testing. He established an M. A. of 7-2 with a resulting I.2. of 112. This was thought to be a minimum rating as the boy was recovering from an 1liness and was not feeling up to par. His fallures on several 1tems were by very narrow margins. He was described as responding willingly to the testIng procedures and displaying no outstanding emotional reactions. His performance was characterized by careful observation and deliberate action.

The California Test of Personality was given at the age 
of 11-1 and again at the age of 13-4. At eleven he showed an overall adjustment level at the 40 th percent1le, reporting a lack of feeling of personal worth and a lower than normal feeling of belonging. He reported some nervous symptoms in the nature of poor appetite, bad dreams, and being easily susceptible to colds. He also reported lack of knowledge in the social skill area and poor community and school relationships. At $13-4$ his overall adjustment rating was at the 50th percentile level. He reported improving conditions in every area except thase of personal freedom, knowledge of social skills, and community relations. Mechanical aptitude tests, given in 1948, indicated average to superior comprehension in mechanical areas. He was retested in 1948 on the stanford-Binet Intelligence Scale. At the time he was 14 years, 4 months, of age. He established a mental age of 19 jears, 7 months, with a resulting I.2. of 141. At the same time he established an M.A. of 18-9 on the Grace Arthur Performance Scale. When interests and attitudes were compared with other elghth graders by means of the Prassey Interest-Attitude Test, he was found to be more mature in this area than eighty percent of his peer group. On the T.A.T. some cynicism was expressed. There seemed to bo some conflict arising from his desire for group approval whlch did not seom to always bo meted out according to his porsonal standards of conduct. $H_{\theta}$ expressed some hostility directed toward authority, which seomed to 
mirror a certain impatience with the routinized institutional mode of living. In personal interviows most of his reactions were positive with the exception of considerable criticism directed toward the adults in direct charge of his supervision. Some of this critical attitude was probably based on justifiablo provocation. He did reveal considerablo insight into his feolings. It was roported at this time that the subject frequently withdrew from group activities to ongage in the more solitary activitios, such as reading, listening to the radio, and brooding, but these were not felt to be extreme. He reported a normal sexual development with no attitudes that would demonstrate severe conflict in this area.

This boy was never referred as a severe behavior problem by other departments. Concern was shown at times by school areas when it was felt that he was underachieving. He occasionally came in to the department on his own whin he felt the need to discuss some problem such as procedure to get approval to make a summer visit out of the state or to secure advice on some school course selection.

School Records: He had begun the first grado prior to admission but had been out of sohool from December until May with whooping cough. He was re-assigned to first grado the first year after admission. Progress from then on was satisfactory. The subjoct was described as a quiot chlld with a 
tendency to become bored. It was noted that he was solitary, careless, and forgetful. His teachers felt that he did not work to capacity. In the intermediate grades he was described as an avid reader but very careless in subjects demanding dotailed accomplishment. Toward the end of this period the quality of school work was noted to be improving. He was reported to be becoming increasingly able to discipline himself. Throughout Junior High his yearly achievement scores on standardized tests wore usually two years ahead of his grade placement. However, he was still reported as doing careless daily work. At the tenth grade level grades were a verage to above.

Teachers over the years rated him consistently as a good student but one who had to be challenged. He was noted for his quietness and inclination to carelessness. He was never reported as a difficult behavior problem in the school area.

Dean's Records: Upon admission he was a quiet, docile child in the cottage. Ho was onuretic until nino years of age. He had a tendeney to withdraw from the larger group and take part in quiet activitios with a few close friends. He became moro activo as ho grow older and during his early teons was quite interested in scouting, camping, fishing, otc. He was interested in athletios and took part as a member of toams but was never outstanding. 
He was noted by supervisors as inclined to be sarcastic and to evade doing his share of work in the group living quarters. He was seldom deflant and, while normally mischievous, he never was in severo difficulty. In, his early teons he did participate in some petty thievery within the cottage but never became habitual in this behavior.

Medical Records: He had a $T$. and $A$. at seven jears of age. Two jears later the subject began wearing glasses. His ejes became steadily worse until he reached a $20 / 300$ rating without glasses, which was corrected to $20 / 30$ with glasses. His most common allments through the years wero upper respiratory infections and numerous stomach upsets. He was a tall, slender boy who was always underwelght (as much as twenty pounds) but seldom actualiy ill or complaining of iliness. In summarizing his record at the 0.S. \& S.O. Home, it can be said that the subject is a boy of superior mental ability, who does not distinguish himself in any area. Howover, he seomed to adapt himself to his envirommental circumstances with a minimum of conflict. He was always known as a hesitant participant in group activities. There appears to be no evidence of any severe degree of instability and maladjustment, but there is evidence that at no time did those working with him foel that ho was accomplishing at a level consistent with his ablilty potential.

A Discussion of the scoring of Case \#8858 on the Adiustment Indices: With this background of the subject that has 
STANDARD SCORRS

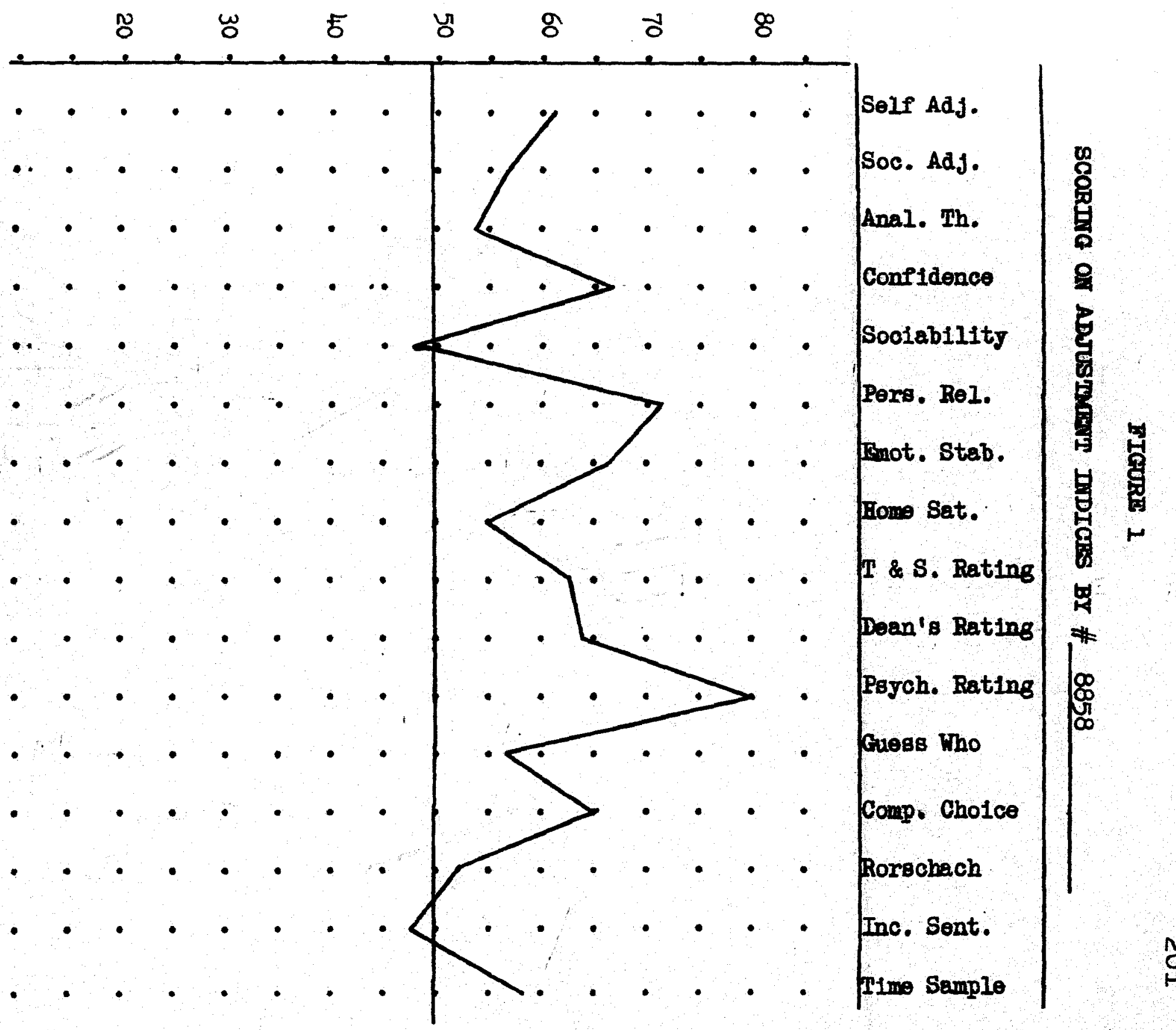


just been presented, it is now possible to discuss his scoring on the individual measures. In order that this comparison may be facilitated, all adjusted scores on each instrument have been changed to standard scores. Figure 1 , on page 201 , presents the individual profile on the various indices. An examination of this profile immediately suggests that on a majority of the Indices used to assess adjustment that this subject would be rated above average. The psychologist's rating was the highest index. The lowest indices were identical in magnitude and established on the "SociabilIty" factor of the Heston scale and on Rotter's Incomplete Sentence Test. These latter scores were only slightly below the mean standard score. The profile would suggest average to above levels of adjustment with no particularly outstanding features.

When we search the history and attempt to associate this profile with the environmental evidences, a certain consistency can bo noted. Here is a bright boy, who is not particularly outstanding in the quality of adjustment he has made to his environmental circumstances, and on the other hand he has absorbed the misfortunes of an early loss of what is considered a normal home life wl thout too much loss to his personality integration. He ovidencos under-particlpation in group activities and an accompanying shying away from a great deal of social involvement but certainly not to an abnormal degree. In fact, ho was above average in his accoptance by 
the group. The profile in this particular case seoms to bo rather well substantiated by the case history evidence available up to the time of testing.

\section{Subsequent History: Since June, 1950, the subject took} more pains in his scholastic ondeavors. Upon graduation he had achieved the highest grade point average in his class. He became interested in continuing his education and contacted the Psychology Department for guidance in the seloction of courses, and increased study habit effleiency. He took increased interest in extra-curricular activities, especially dramatios and music. He played the lead in several dramatic productions. Upon graduation in the spring of 1952 , he made arrangements to enroll in the small mid-western college under a scholarship provision there his older sister had taught. He was serlously considering a journalistic course as ho had taken printing as a trade with the hope of eventually doing work in the newspaper or magazine area.

During his last year in high school he took part in boy-girl activitios and was usually seon with a date at the weokly parties hold by older students on the Home Campus. He continued to have diffleulty in the cottage living where he gave more voloe to his dissatisfactions in regard to the routinized living. However, this usually took the form of frank expression of disagreement with his cottage supervisor which might be considered as onl" the normal seoking of a 
204

boy of this age for independent status.

In 1952 this boy made a 93 centile rating on the $0 . S . P . E$. form 23. This was the only recent test data of psychological nature available.

Summary: This subject was known to have met his environmental situations in an acooptablo mannor. Whilo cortainly of above average ability, ovidence would indicate a slowly developing drive to become a more efficient person in keeping with his ability level. While not optimally well adjusted he could not be considered maladjusted. Most of the adjustment indices used in this study substantiated his average to above average adustment status.

In this particular case it appears that the two scores recommended -- one of self adjustment and one of soclal acceptance -- would have for all usual purposes placed him in about the proper category. Depending upon one's purposes, the data could have been further analyzed in terms of specific responses where we are able to get clues as to Individual preferences and individual annoyances. In this particular case such an analysis would not contribute enough to the present picture to warrant inclusion. 
Case \#4961

Date of Birth $9-4-34$
Admitted to O.S.S.O. Home $3-23-44$

Age at time of Admission 9-7

Age as of June 1, 1950 15-9

Years of Residence as of June 1, 1950 $6-2$

Family Background: The subject was born into a family whose court record goes back to 1923. Occurrences such as vagrancy, eviction, non-support, drunkenness, prostitution, and public support were the common state of affalrs. Prior to the subject's admission to the Q.S. \& S.O. Home, he had been in and out of County Children's Homes a number of times. The family had moved around a great deal. The family unit was always characterized by instability and turbulent family emotional situations.

The subject's father was born in 1895 in a mid-western city and was orphaned at the age of twelve. He was reported to have had only a small amount of formal oducational experlences. He was a packing-house worker, moving from city to city and from one job to another. He was constantly getting intoxicated and losing one job after another as a result of not showing up for work and continuous brawls with fellow workers and his bosses. He took little or no interest in his children and never adequately supported them. He was discharged honorably from the army in 1919. He served a six month sentence in 1942 for non-support. When the children were admitted to the 0.S. \& 5.0 . Home in 1944 hIs where- 


\section{6}

abouts were unknown and he has not been heard from in the last eight years.

The mother of the subject was born on an Ohio farm in 1901. She was thought to have had an elementary education. She was marrled at an early age. Prior to her marriage to the subject's father she had elready been married twice and divorced from both husbands. Sho worked off and on as a waltress in low class cafes. She was a poor housekeeper and agencies early reported that she and the children were content to live in filth and neglect. She was listed in police records as a prostitute and lived promiscuously during her married life. BJ 1944 she was reported to have had fourteon pregnancles with flve miscarriages. She was never consistent in her disclpline with the children. She would take her children across town to whatever cafe in which she was then working and feed them rather than prepare meals at home.

The subject is one of the male twins born after the mother had had three previous children while married to the subject's father. There were also two younger siblings born during this partioular marriage. The subject's oldest brother, born in 1930, was convicted of stealing in 1942 and sentenced to Boys' Industrial school. Prior to this offense he had been truant from school and had run away numerous times from a County Chlldren's Home. The next brother, born In 1932, established a court record in 1943 with continued 
running off from the Chllaren's Home and Incorrlgibllity. He, too, was sent to the Boys' Industrial school. The older sister, born in 1933, was admitted to the 0.S. \& S.0. Home in 1944 at the age of eleven. In 1949 she was reported as very unhappy and was placed in a boarding home. While in this home, she became very despondent and attempted suicide by an over-dose of sleoping pills. She was admitted to a mental hospital and responded to psychiatric treatment. Sho received training as a nurses' aide and at the present time is making a satisfactory adjustment. The twin sibling has always been weaker physically and slower mentally. He is one year retarded in scholastic progress when compared to the subject. He is still at the 0.S. \& S.O. Home but con-. tinues to evidence instability. He was recently away without leave from the Home and is requesting permission to enlist in a branch of the armed service. A younger sister, born in 1937, was placed in a boarding home and seems to have made an adequate adjustment. The youngest brother, born in 1938, resides at the O.S. \& S.O. Home. He is a very bright boy, who makes excellent scholastic progress but is considered moody, occasionaliy very unreallstic, a bully with younger children, and rather unstable omotionally.

The subject had resided falrly regularly in a large children's home near ono of Ohio's largo industrial areas since the age of $\mathrm{s} 1 \mathrm{x}$. When he was $9-7$ ho was admitted to the O.S. \& S.O. Home, along with his twin, an older sister, and 


\section{8}

a younger brother. Admission was requested upon the basis that these were eligible children for the 0.S. \& S.O. Home and as usual the institution in which they were living was crowded and needed the vacaney created by moving these children for those not eligible for placement elsewhere.

The subject was reported as having made a satisfactory adjustment at the Children's Home. He had presented no serfous problems and had advanced scholastically to fourth grade status. He has lived in the 0.S. \& S.0. Home continually since admission with little or no contact with members of his family other than those siblings also living at the 0.S. \& S.O. Home.

Summary of Subject's Residence at the 0.S. \& S.0. Home.

Psychological Records: Prior to the subject's admission to the Home he was examined on 3-6-44 with the 1916 Revision of the Stanford-Binet Scale. He was 9 joars and 6 months of age at the time of this examination. He established an M.A. of 10-6 with a resulting I.Q. of 110. After admission he was re-examined on 3-27-44 with Form $M$ of this same scale. He established an M.A. of 9-10 with a resulting I.Q. of 103 . At this time it was reported that cooperation was excellent. It was folt since many tests were failed by a narrow margin that he would be able to demonstrate at least high average ability under favorable environmental conditions. On 6-5-48 he was re-examined with Form $L$ of the stanford-Binet Scale. 
At this time he was 13 years and 9 months of age. He established an M.A. of $15-1$ and a resulting I.Q. of 112 . His reactions were normal and he seemed to be reflecting positive feelings toward his environment and sohool program.

When he was $12-6$ he responded at the 80 th percentile level on the California Test of Personality. He showed some inadequacy in his knowledge of social skills but feelings were for the most part positive. In the spring of 1949 he was given a battery of mechanical aptitude tests. At the time he was nearly 15 years of age. He showed average to high average levels of aptitude on all of these tests.

This boy was nover reforred directly to this department by other departments as an observed behavior problem. He did come in several times to confer in regard to cottage problems. In those interviews he was noted to have a higher sense of right and wrong than usually found in institutional boys. He was always rather reticent and self-sufficient but still maintained a high cooperation level. Nothing except a certain felt tenseness and emotional brittleness indicated that he was not functioning at an optimal level.

School Records: Because of a rather poor showing on standardized achlevement tests and bocause he was a year accelerated, he was roplaced at the third grade level when admitted to the Home. His early school reports indicate that he was inattent1ve, lacked inftlative, but was dependable. 
In his second year at the Home there were increasing reports pointing toward good citizenship and dependability. In the middle grades scholastic progress became very good with achievement a year to two years ahead of grade placement on standardized tests. He was reported as a good student who was not satisfied with mediocre work.

During the Junior High years he was consistently rated at the $B$ level and above in all subject areas. He chose printing as a vocational pursuit and early establishod a record of dependability and conscientlousness in that area. He became a leader in his class as well as taking responsibilitles in the Junior R.O.T.C. program, scouting, athleties, and band. By the time he was finishing the ninth grade he was making full use of time avallable.

Dean's Record: The subject soon became a leader in his cottage group. He was dependable and of ten given responsible jobs. As he grew older he was frequently the envy of other boys as he was able to earn more privileges through being dependable. There were times when the subject was in conflict attempting to make himself accoptable to authority and also to his peer group. However, ho made a good showing in athletics and could back up his stand with physical power if necessary so that he was able to resolve this conflict with no serious breaks with elther the group or authority.

He began to be interested in boy-girl affairs at an early age. He demonstrated no severe problems in his sexual 
development. Ho was occaslonaliy intolved in pranks and mischlef but never had any record that would indicate delinquency trends. His worst fault seemed to be that of making weaker boys do things which, though approved behavior, need not have occasioned the use of foroe.

Medical Summary: When admitted as a new child the subject showed some evidence of nervous tension as indicated by a habit of fingernail biting. Ho was found to be slightly underwelght but otherwise in good health. Through the jears most admissions to the hospltal were as a result of injuries most serious of which was a dislocated elbow. He has had. several minor lacerations and some otitis media.

In summarizing this subject's history; it can bo said that he was subjected to early environmental traumatization in the family areas which did not seem to leave a severe lasting effect. He is a bright boy who has seemingly been able to respond to environmental stimulation and to accopt the ethical codes of a culture somewhat different from the code of the culture in which he was born. He seems to have made use of his potentialities for development and, with the exception of a certain emotional aloofness, ho has maintained a satisfactory rapport with all elements of his environment.

A Discussion of the sooring of case \#4961 on the Ad justment Indices. With the historlaal background of the subject before us it is possible to examine his scoring record on 
STARDARD SCORBS

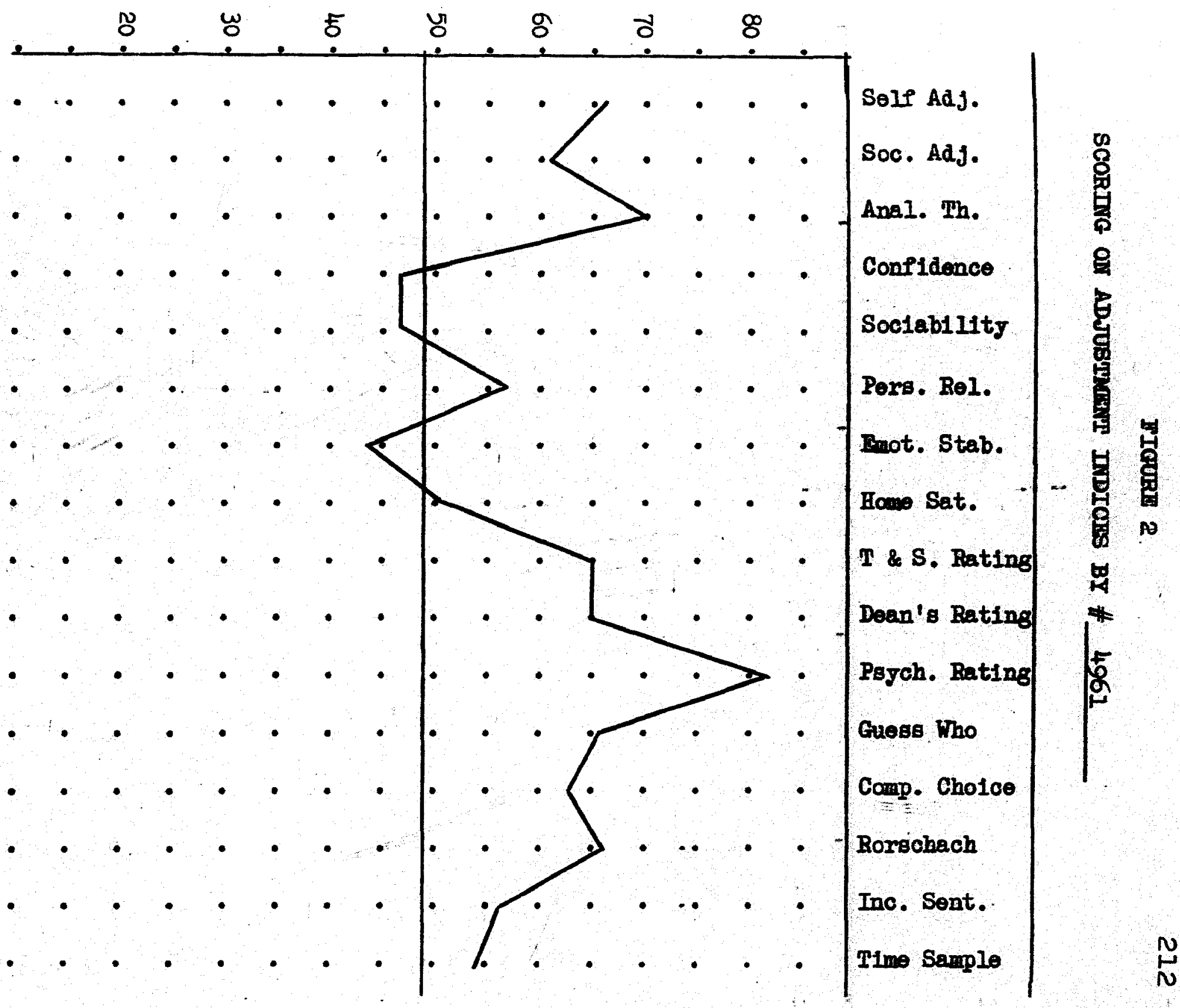


the individual adjustment indicos. In Flgure 2, page 212, the profile of the subject is presented.

An examination of the subjects profile indicates that on a majority of the indices used his standard scores show average to above average levels of adjustment. It is interesting to note that those indices obtained on the Heston Personal Adjustment Inventory, which were found to be most closely correlated, are the ones which show the lowest adjustment status. Five of these indices fall around the standard score mean. These indices if used alone would have indicated only an a verage degree of adjustment, which in this particular case would seem to represent a minimal plcture when compared to the case history data. The psychologist's rating showed the highest level which is perhaps logical when it is remembered that this rating was arrived at initially by taking into consideration the environmental stresses through which the individual had come. The rather high rating found on the Analytical Thinking "factor" of the Heston scale is consistent with the inteliectual drive ovidenced by this particular boy which bears out the author's point that such a factor is not identical with ability but more in line with intellectual ambitiousnoss.

When the historloal data is compared to the resulting profile we find consistency in this partioular oaso. The outstanding feature of this case is the inconsistency between early experience in a very unstable family constellation and 
the later apparent satisfactory relationship with all elements of his environment. What are the factors involved that enabled this boy to make a relatively good adjustment while siblings, experienoling similar strosses, wero not ablo to make comparable adjustments: In this case we have a nonidentical twin with which to make comparison. The differences between the two seem to be the existence of lower ability and poorer physical development. Are these two factors able to account for manfest difference in adjustment status? These questions cannot be answered with anj degree of certainty because it is now impossible to trail all of the complex differentials in treatment, experience, physiological structure, etc. However, we can safely report that, in this instance, early environmental elrcumstance was not the prime influence in the level of adjustment achleved.

Subsequent History: The subject will be a member of the 1953 Sentor Class at the 0.S. \& S.O. Home. He has continued to make excellent scholastio progress. He has consistently recelved the highest grades in his class and has made good progress in printing which he chose as a trade. He has been outstanding in athletios - taking part in all major sports. He reached the Eagle rank in Scouting and has continued to serve in leadership positions in that organization. He has been active in all group activitios on the campus and has attained the highegt rank in the Jr. R.O.T.C 
Unit. He will, in all probabllity, graduate with honors. He has become more relaxed in his relationships with authority but has lost some of the popularity he once had with the group because of his drive to go beyond mediocre achievement. Perhaps as a result of some peer criticlsm he has struck back on several occaslons bJ bullying those who are weaker physically. Even in these instances he responds to counsel and seems to endeavor to make of himself a dependable conscientious citizen.

On 2-9-52 he was retested, using the Wechsler Bellevue Intelligence scale. On this instrument he established an overall I.Q. of 119. There was some difference botween the Verbal I.Q. of 123 and the Performance I.Q. of 109 . He was still found to exhibit considerable tension, which seemed to stem from an anxiety in regard to quality of performance. On the O.S.P.E., Form 23, he established a 43 rd cont1le rank.

\section{Summary: A review of this case reveals a bright boy,} who had suffered a very poor family environment at an early age, reaching average to above average adjustment levels as measured by representative Indices by the time he had reached mid-adolescence. Subsequent development would ind1cate a continuation of those levels of adjustment with an eventual lovel of efficlency consistent with ability potentials.

In this case the screening technique recommended would 
have placed this boy in a category of adjustment status that seems consistent with case history materlal. There is, in this case, some evidence of tenseness and lack of deop emotional ties that seom at present to be sublimated through acceptable environmental acoomplishments. It is difficult to predict just how much more stress this particular personality might be able to withstand. At the present riting there does seem to be an overall consistency between obser able behavior and the overall pleture developed through the use of the several indices of adjustment.

Case \#5278

Date of Birth $3-15-36$

Age as of June 1, $195014-3$
Admitted to 0.S. \& S.0. Home $1-11-48$

Age at Time of Admission $11-10$

Years of Res Idence as of June 1,1950

Family Background: The subjoct's family were industrial workers in one of ohio's larger cities. The family comes from the semi-skilled to skilled labor occupational groupings. They had an unstable economic background tied to the economical fluctuations of the timos. When work was plentiful they lived well without much preparation for more difficult times.

The subject's father was born in 1890 in the industrial area of Pennsylvania. He completed the sixth grade, leaving school to go to work as a Western Union messenger at the age of eleven. He eventually became fairly well skillod in carpentering but was perlodioally unemployed. He was married 
In 1916 to the subject's mother. After his first wife's death in 1936, ho re-marriod in 1938. This seoond marriage lasted soarcely a year. His second wife secured a divorce on charges of cruelty and neglect. He again re-married in 1942, with the third wife dying in 1946. He was discharged from the army in 1919, partially disabled. During the perlod after his first wife's death he drank excessively and made advances to housekeepers, which made it difflcult for him to secure anyone to look after his children. He was arrested a number of times for drunkenness and cruelty to his children. On $8-22-47$ he was diagnosed as an active case of tuberculosis and sent to a Veterans' hospital. Ho is reported to have fluctuated in his attitude toward his children - boing excessively cruel at times and over-solicitous at other times.

The mother of the subject died just three months after the subject was born from scarlet fever. She, too, came from the semi-skilled laboring class. She completed grade seven. Prior to her marrlage to the subject's father, she had had an illegitimate daughter. She was supposed to have beon a good mother, establishing a fairly close tie with her older children, and kooplng the home operating even when finances were scarce. During the subject's early Iifo ho was cared for by a succession of housekeopers and finally the second wife. This woman was reported to be cruel to the children and the home was frequently disrupted by domestie 
altercations. The third wife was reported to have treated the children well and to have been especially fond of the subject.

The subject was the joungest of seven siblings. In fact there are six years between himself and his nearest sister. An older brother, born in 1917, was grown and on hls own at the time of the subject's birth. A sister, born in 1920, was arrested in 1938 for Imoral sex behavior and sent to Girls' Industrial School. She was discharged in 1941 and has since married and seems to be making an adequate adjustment. A brother, born in 1922, was apprehended in 1939 for burglary and sent to B.I.S. He was discharged from that institution in 1940. $H_{\theta}$ was kilied in 1952 in an explosion in the steel mill in which he worked. A brother, born in 1926, grew up In a boarding home in which he was placed in 1936. He is at present married with two children and seems to be fairly stable and well adjusted. Another sister, born in 1928, lived for a short time with the last mentioned brother until she was married. The sister next to the subject was born In 1930 and I1ved for the most part with the married brother. She works in a factory and continues to live with this brother. She has never been in conflict with society. The subject lived in rented rooms with the father after the third wifo's death. He was inadoquately supervised as the father was intoxicated much of the time. The boy ran the streets, was truant from schobl, and was in a number of 
minor escapades, such as stealing bicjcles, breaking windows, etc. After one of these escapades juvenile authorities, feeling that he was rapldiy becoming a delinquent, placed him in a boarding home that already contained five younger children. The subject became an immediate source of difficulty for the boarding-home mother. He bullled the younger children, stole from the boarding-home mother and was difficult to manage.

Since the subject had shown difficulties in control and had been over-indulged and inadequately supervised by his father, the court sought other placement for him. In 1939, admission had been sought for the subject and some of his siblings in the O.S. \& S.O. Home but, because of adequate finances and the foeling that the community had not used a.1 of its own resources, admission had been disapproved. Since the father's physical condition now mado it imperative for some other placement for the boy, he was admitted to the Home in 1947.

Since the subject's admission to the Home, the father has boen discharged from the tuborculosis santtarium. Ho Ilves for a time with oach of his married children. He continues to drink excessively and writes elaborate promises to the subject in regard to taking him from the Home. The subject continues to hope that ho may 80 with his father. His married brothers and sisters take the subject for infrequent vacation perlods but he beems to view them only as 
a source of money and pleasure.

Summary of the Subject's Resldence at the O.S. \& S.O. Home

Psychological Records: Prior to the subject's admission to the Home, he was examined on $9-29-47$ by means of Form $L$ of the Stanford-Binet Inteliligenee scale. At the time of this examination he was 11 years and 8 months of age. Ho ostablished an M.A. of 13 years and 0 months, with a resulting I.Q. of 11I. He was reported friendly and cooperative in the examining situation. His vocabulary lovel was outstanding. His poorest performance was on tests involving visual Imagery and visual memory. Upon admission to the 0.S. \& S.0. Home, he was tested with the Grace Arthur Point Scale of Performance Test on 1-13-48. At the time he was 11 joars and 10 months of age. He established an M.A. of 17 years and 0 months on this instrument. He was found to be quick and efficient in manipulatioe situations and to be superior in planning effective methods of attack in these performance tests. He appeared enthusiastic and was intrigued by the self-competitive situation. on $1-21-48$ he was examined using Form $M$ of the Revised Stanford-Binet Intelilgence Seale. He established an M.A. of 13 years and 4 months, with a resultIng I.Q. of 113. He cooperated well but did not display the enthusiasm noted previousiy on the Grace Arthur Scale. His vocabulary level was high but he again demonstrated some lack of visual memory. 
on 1-11-48 the subject was given Rogers! Test of Personality Adjustment. His overall score indicated an average level of adjustment but ho mado a high score in the social Maladjustment area. His responses indicated considerable desire to reach an exaggerated position in the eyes of his associates, which he now felt he did not enjoy. In early Interviews he was quite friendly and talkative as long as the family area was not mentioned. Any reference to his home life or his father evoked resistance and tears. He assumed no responsibility for past acts and projected blame on associates and the boarding-home mother. He could not discuss adjustment in the sexual area though it was known that he had engeged in mutual sexual stimulation with some of his peers prior to his admission. He indicated interest in music, art, and creative activities.

In the two years prior to this study the.subject has been referred bj othèr departments for continuing infantilism. $H_{\theta}$ has been in several stealing opisodes involving some shoplifting in downtown stores. He has been hostile toward his women supervisors, cursing, them out on occasion. Ho has run away several times but has always returned on his own volition. He has been moody, shifting from clown-like antics to sulky depressions. He has always responded to counseling in a friendly manner but has never made any strong identifications or been seriously concerned about his development. Most adults like him as he usually appears smiling and on- 
thusiag̣tic, but all have at one time or another complained about his mischievousness and lack of responsibility.

School Records: The subject had been in Grade 5 prior to admission and had been reported as a good student. His score on a standardized achievement test upon admission was high enough to indicate at least a 6 th grade placement. $H_{\Theta}$ was so enrolled in the middle of the year and made very good progress, showing a 9.4 grade placement on a standardized achievement test given at the close of the school term. Teachers reported a very good classroom adjustment.

He did not make as much progress in the next two years of school attendance at the fome sohools but he did recelve average grades and was promoted both years. Teachers increasingly complained of his uneven achievement from day to day. There were times when he did an excellent piece of work and other times when he would do as little as possible for several days in a row. He would take part in extracurricular activities for a littlo while but then lose interest and, if permitted, would soon drop out. He showed aptitude in music, art, and dramatics, but soon lost interest. He continued to take instrumental music but had to be forced to practice and particlpate in the band activitios. He was well coordinated and apt in athletics but would soon get angry at the coach or his fellows and quit the teams he tried out for. 
He had a flair for creative writing and turned out sere eral original themes and poems that merited publication in the institutional fournal. He took numerous books from the school library and did a great deal of independent reading.

Dean's Records: The subject would at first do no work in the cottage at a11. He entered the group with a chip on his shoulder. When he wouldn't even make his bed the other bojs were scornful of him. He seemed to desire to be made the center of attention and was continually testing the authority of the person over him. He has a long record of continuous breaking of institutional rules in regard to boundarles, smoking, and care of property. $\mathrm{He}$ has been in continuous conflicts wherever he has had to be supervised by women. He has been defiant and on several occasions cursed those in charge.

He has been a compulsive smoker since entrance and has stolen and bullied others to supply him with cigarettes. He has run off tirice in two years with other boys. He has aIways turned himself in or returned when ho has become tired and hungry. He was involved in some shoplifting but when found out returned the merchandise without ovidence of guilt. He has always complained that he wasn't being given a fair deal even when poople had gone out of their way to secure some privilege for him. He has been counseled, punished, and worked with on an individual basis but he st111 
remains irresponsible, self-centered, and the clown. Medical Records: Ho was found to be a normal healthy boy on admission. He has had fow clinic or hospital admissions since entrance. His medical record indicates excellent physical development. He has been treated several times for lacerations and contusions, recelved while participating in football and other active games.

In summarizing his history, It appears that the subject is a bright boy who is erratic in his adjustment to his environment. His unevenness of development, with behavior now mature and then infantile, indicates a lowered adjustment status. His delinquent acts without apparent guilt speaks of a poorly developed value system. His inability to express himself in conflict areas further substantiates the existence of poor psychological integration. His spurts of scholastic achlevement and his general likeableness when not in a depressive mood are indications of his potentials for adjustment.

A Discussion of the Scoring of Case \#5278 on the Ad justment Indices: With the bockground of the subject presented, it would be expected that the indices of adjustment should reflect some degree of maladjustment. In Fig. 3, page 225, this subject's profile is presented in terms of standard scores.

Inspection of the profilo portrayed in F18. 3 shows that on twelve of the indices he scores below the mean standard score. However, on four of the indices he rates considerably 


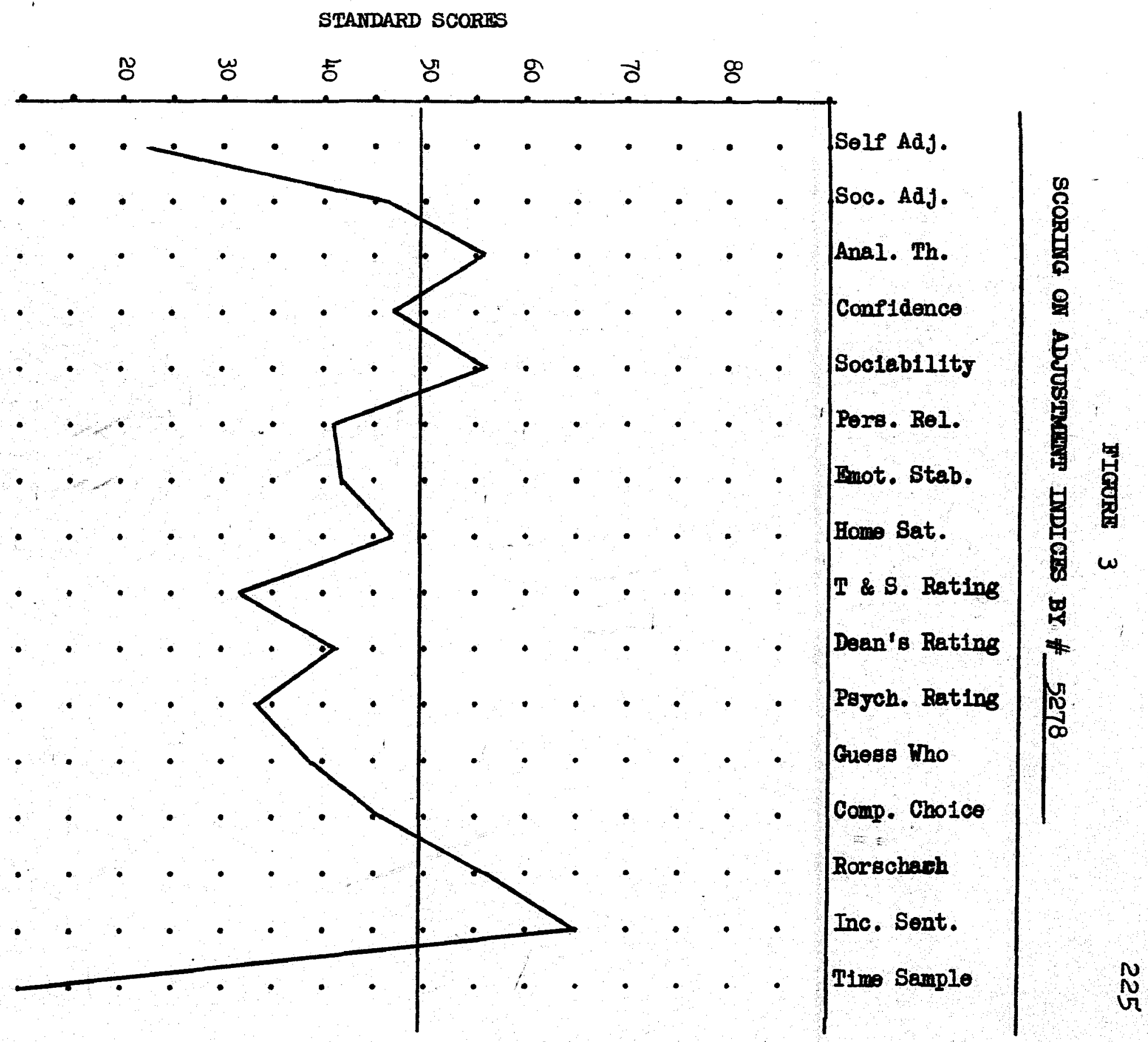


above the mean. His score on the time sample is the lowest, followed closely by his reported score in the self adjustment area. His highest score was on the Rotter Incomplete Sentence Test. His scores on the Rorschach, the Analytical Thinking "factor" of the Heston, and the Soclablilty factor of the Heston were all well above the mean.

When one attempts to consider the profile in the light of what is known about the subject there are certain pertinent factors that appear. The high score on the Rotter Inoomplete Sentence Test occurred as a result of his taking each beginning possible and using it to refer rather jokingly to the Cleveland Indlans' Baseball team. This instrument failed to get him involved emotionally and he used the technique of avoliling involvement, which in other circumstances was noted as a mechanism of his maladjustment. The Incomplete Sentence as scored fails to take account of such a mechanism. The high score on Analytical Thinking reflects his sporadic intellectual ambition but does not reflect the unevenness of day to day performance. The hlgh soclabllity score coincldes with his evident drive for social leadership, but tells nothing of the ineffectual methods used to attain achlevement of those ends. An examination of his Rorschach protocol shows his high potentials for creativeness, which is how he used the instrument. He sought artistic balance and originality which did not reflect his true level of adjustment. A close examination of the protocol on an individual 
basis does give indication of Immature omotional adjustmont. His very low score on the Time Sample technique was occasioned by his excessive bids for attention in the group situation and his compulsive oral activity in which he constantly was observed with something in his mouth. His very low standard score on the self Adjustment index mirrors extreme dissatisfaction with himself. In every area tapped he mirrors feelings of inferiority and inadequacy which may partially explain his constant seeking of attention in group situations. The ten other indices, not discussed individually, all reflect below average adjustment.

Subsequent History: The subject continues to reside at the 0.S. \&. S.O. Home. He has been able to progress from grade to grado until he now is at the eloventh grade level. His school progress continues to be uneven. There have been several instances when he has been deflant in the classroom, refusing to meet assignments. Whenever such crises arise he tends to project blame on teachers and school authorities, claiming he does not get a fair deal. He usually winds up by stating he will try to conform to roquirements but is seldom able to follow his stated intentions for any lengthy period. At other times his work is good to excellent but he never seems to feel proud of his endeavors and usually works only for immediate rewards.

He continues to have difficulty in ohore situations around the institution. He has tried several trades but us- 
ually gets into difficulty with his teachers or his fellows on the job. Occasionally ho does an acceptable job when there is money involved which he can spend. He has never been able to budget his money- spending it immediately for whatever strikes his fancy. Ho seldom finishes any project which he starts. He has run away from the institution several times, but after the excitement wears off in a few days he returns on his ow accord. He responds to male guidance better than to female direction. He continues, from time to time, to pick up things that belong to others and when caught accepts the necessity of replacement but does not show any genuine concern for his anti-social act. He resists counseling by either refusing to discuss his problems by not admitting that he has any problems or by crying so that it is impossible to discuss his situation. However, he does drop into the Psychologist's office and discuss sports, cars, and other matters not having individual reference.

In mechanical aptitude tests ho makes low average percentile ratings, indicating a poor understanding of mechanical principles. On projective tests, he indlcates wishes for exaggerated success and acclalm. $H_{\theta}$ indicates preoccupation with fantasy in which he seos himself as a great hero. However, he never recognizes the detalied obstacles that must be overcome to secure the helghts that he desires. 
Summary: A review of this case seoms to indicate a bright boy who was early subjected to fluctuating attitudos on the part of a father. Deprived of a mother's care at a very early age he seems never to have secured enough attention and affection. He presents a history of uneven emotional development, seeking always to feed his Insecurities without developing efflcient techniques of dealing with his environment. In general the techniques used to assess adjustment reflect this state of affairs. The highs and lows of his profile are more understandable against a background of case history material. The low self acceptance index in combination with a below average soclal accoptance Index would have screened this boy from the group for individual investigation.

Case \#5609

Date of Birth $1-16-34$

Age as of June $1,1950 \underline{16-5}$
Admitted to 0.S. \& S.O. Home Age at Time of Admission $13-8$

Years of Residence as of June 1,1950 $2-9$

Family Background: This subject's immediate family were rural laborers. The family belonged to the cultural group who reside as tenamt farmers and day-laborers in and around small towns. As is frequently found, and true of this family, such families have a number of children, live in sub-standard houses, inadequately clothed, and with inadequate diets. 
The father of the subject was born in 1895 into a rural laboring family. He was the only son in a family with two daughters. He worked with his parents on tenant farms, quitting school in the eighth grade. He was married in 1917 before being drafted during World War $I$. He servéd overseas and was discharged in 1919, partially disabled. He worked as a farm laborer until 1942, never adequately supporting his family. In 1942 he moved his family to an industrial area where he went to work on a factory assembly line. The family was better provided for during this period than it had ever been until his death in 1945 of septicemia.

The subject's mother was-born in 1899 in a small town where her father was a day-laborer. She was the oldest of three children and always considered dull and inadequate. She was taken out of school at the fifth grade level because of a physical and nervous condition, diagnosed as st. Vitus Dance. She remained at home with her parents until her marriage at the age of seventeen to the subject's father. She is described as dull, crude, and unattractive. During her husband's last illness, she is reported to have had numerous sexual relations with other men. She would frequently brag to the neighbors about these affairs while her husband was still living. She was remarrled seven months after her husband's death to a man who had six children of his own. She is reported to have screamed and hagged at her children one moment and call them terms of endearment the next. There were 
no regular routines in the home with children and adults eating and sleeping whenever they so desired.

The boy in this study is the sixth child in a family of eight. His oldest sister, born in 1918, left school early to be married. She had two chlldren and was then divorced. She made her living as a waltress. Her whereabouts have not been known since 1945. The oldest brother, born in 1920, was married at nineteen after leaving $s$ chool in the eighth grade. He is very hostile in regard to his mother and has little to do with the rest of the family. The next sister, born in 1924, left school when sixteen to be married. She lives with her husband and took care of the younger children for a time following her father's death. A brother, born in 1925, left school early, was married, and lives with his family in marginal financial circumstances. He grooms race horses and follows the tracks in a trailer with his family. The sister, next to the subject, was born in 1927. She follows the occupation of waitress and is very hostile toward the mother. Two younger brothers than the subject, one born in 1937 and one born in 1940, were admitted to the 0. S. \& S. 0. Home in 1948 where they still reside.

The subject lived part time with his mother after his father's death and part time with his next older brother who made a living grooming horses. Neither took any responsibility for the subject, who wandered between the two homes and around among the neighbors in the respective homes. He paid no 
attention to his mother and while never in serious trouble within the community attended school irregularly. His mother went to the juvenile court, complaining that she nor the stepfather could control him. He was reported to have engaged in temper tantrums and to be hateful and disagreeable with his associates. Since the home situation did not seem to be providing adequate training and supervision, the subject was admitted to the O.S. \& S. O. Home.

Summary of the Subject's Residence at the O.S. \& S. O. Home

Psychological Records: Prior to Admission to the Home the subject was examined on 8-26-47 using Form $I$. of the Revised Stanford-Binet Intelligence Scale. At the time of this examination he was 13 jears and 7 months of age. He established an M. A. of 10 jears and 6 months, with a resulting I. Q. of 78 . He gave evidence of hyperactivity and emotional disturbance throughout the testing situation. On $9-17+47$ he was examined using the Grace Arthur Point Scale of Performance. He was 13 years and 8 months of age at this time. He established an M. A. of 10 years and 4 months. Infantilism shown by impulsiveness and lack of forethought was evidenced. On 9-19-47 he was given Form $M$ of the Revised Stanford-Binet Intelligence Scale. At the time of this examination he was 13 years and 8 months of age. He established an M. A. of 10 years, 10 months, with a resulting I. Q. of 81 . Agàin he evidenced hyperactivity, 
impulsiveness, and strong needs for reassurance.

on 9-17-47 he was given Rogers' Test of Personality

Adjustment. Maladjustment was indicated in al I areas with the exception of the area of personal inferforlty. He mirrored particular maladjustment in social and family aroas. On the T. A. T., given on 9-19-47, the subject seemed to indicate a rather extreme state of anxiety which was expressed in infantile expressions and preoccupation with details. He expressed ambivalent feelings in regard to his mother. Most of his stories dealt with tragedy, crime, and dime novel heroics. He appears to have a strong need to play the hero part to balance his felt rejection and insecurity. On 8-2-49 the California Test of Personality indicated an adjustment status at the 1 percentile level. In no area did he express adequate positive feelings.

On a battery of mechanical aptitude tests, given in 1949 , the scores indicated poor ability in dealing with mechanical apparatus. Scores on all tests were at the fifth percentile level or below.

Between admission and the time of this study, the subject was referred on an average of once a month to the Psychology Department. He was never in any difficulty which is usually classed as delinquency, but was in constant difficulty with his peers in cottage situations. He was very frightened of physical contact with other boys. He would aggravate others and, when 
the other boy would retaliate with fists, the subject would run and tattle. Several times other boys would taunt him to run away and would even offer to help him pack. He constantly set himself up as an authority in every Iine and would always attempt to top any tale told by another. He talked constantly and was unable to excel in any area to back up the talking. He was slow in physical development and was the butt of many taunts on this score. The subject, over many counseling sessions, developed considerable insight into his objectionable behavior and would lay positive plans to make himself more acceptable. However, he was seldom able to carry out those plans partially because he had already aroused such ire on the part of his peers. He continued to be infantile and to engage in solitary activities. He was still being seen frequently at the time of this s tudy.

School Records: When the subject came to the Home he had failed the sixth grade and was due to repeat it. He had also repeated the second grade. Though testing at the 5.6 grade level on standardized achievement tests, he was placed in a slow seventh grade section because of already severe retardation. He made some progress the year he spent in a slow moving seventh. He was here, as in the cottage, a social misfit but he appeared to put forth effort and made measurable progress.

The following year after $r$ emedial help in the summer session he continued to make satisfactory achievement in a slow 
moving eighth grade group. Enough so that the following year he was placed in the average section of the ninth grade where he continued to do satisfactory work. Teachers reported continuing social non-acceptance but continuously improving achievement.

Dean's Record: The subject was never in difficulty for overt delinquent acts but was constantly the source of dissension among those with whom he lived. When cottage supervisors would attempt to-aid him in making more satisfactory adjustment it would place the subject still further apart from the group. Small boys would bluff him on the campus and would delight in teasing and tormenting him. There were times when he would storm and rage in unreasonable temper tantrums only to calm down and go on with every day routines. Adults pitied him and his peers heaped on the punishment cruelly. He attempted to join the scouts but was soon dropped at his own request when the group could not tolerate him.

He ran away once to a sister who immediately brought him back. He was irresponsible but never vicious. He finally managed to learn to swim after months of gentle persuasion and encouragement. He became the campus authority on sports events, memorizing whole tablos of batting averages, lists of All Americans, and sports records. Here again his over-zealous behavior made him obnoxious in the eyes of the other boys as he would not hesitate to contradict another's statement in the most positive manner. It was felt that gradually he was becoming 
tolerated and temper tantrums were not as frequent as upon admission.

Medical Records: The boy has a deformity of the left elbow from an improperly set fracture which occurred at the age of three. The arm is usable but appears awkward. Eyes were $20 / 100$ but were corrected with glasses to $20 / 20$. He has poor distant vision. He has a $2^{\prime \prime}$ scar on abdomen from an early appendectomy. He had a T. \& A. In 1948. He has been a slowly maturing boy, but, with the exception of a few G. I. upsets and a few minor injuries, has maintained good health.

In summarizing the subject's history prior to the present study, it appears that he was functioning at a low ability level and suffered severe school retardation. He presents a history of unstable, erratic early treatment in the family constellation. He mirrors anxiety and insecurity which reveals itself in very poor social rapport with his environment. He appears infantile in emotional development with a poorly developed physical structure. Ho had established inadequate techniques for dealing with his felt rejection which served to make him further rejected by his peers. The necessity of making an adjustment in a group situation imposed further stresses. on an already inadequate control system.

\section{A Discussion of the Scoring of Case \#5609 on the Adjust-} ment Indices. A review of the subject's history would lead one to conclude that this subject, would Indicate maladjustment 
on several of the indices used to assess adjustment. The standard scores of the subject are presented in profile form in Fig. 4, page 238.

A glance at Fig. 4 confirms our expectations as all Indices are well below the mean standard score. There is a definite group of extremely low scores, the lowest being the Psychologist's rating. The next three lowest scores were the ones secured on the "Companionship Choice Test," the "Guess Who", and the Emotional Stability factor of Heston Scale. Highest scores were secured on the Rorschach, by the Time Sample technique, and on the Home Satisfaction factor of the Heston Scale. The entire picture is fairly consistent with the history sketched up to the time of the study.

The extremely low rating made by the Psychologist in contrast to the medium low ratings made by other raters can perhaps be partially explained by the lack of overt delinquency tendencies present in the subject's behavior. These raters were aware of the nuisance element of the subject's behavior but tend to place more emphasis on behavior that strikes more directly as a challenge to authority. With what we know of his social non-acceptance, it is easy to reconcile his scores with the observed history. His infantilism and erratic behavior seem to be reflected in his low score on the Emotional Stability factor. His relatively high score on the Personal Relations factor can only be explained by his lack of sensitivity as to why he was non-acceptable in the eyes of his peers. 
FIGURR 4

238

SCORTMG ON ADJUEIMAHI MDICIES BY Gase $\|^{*} 5609$

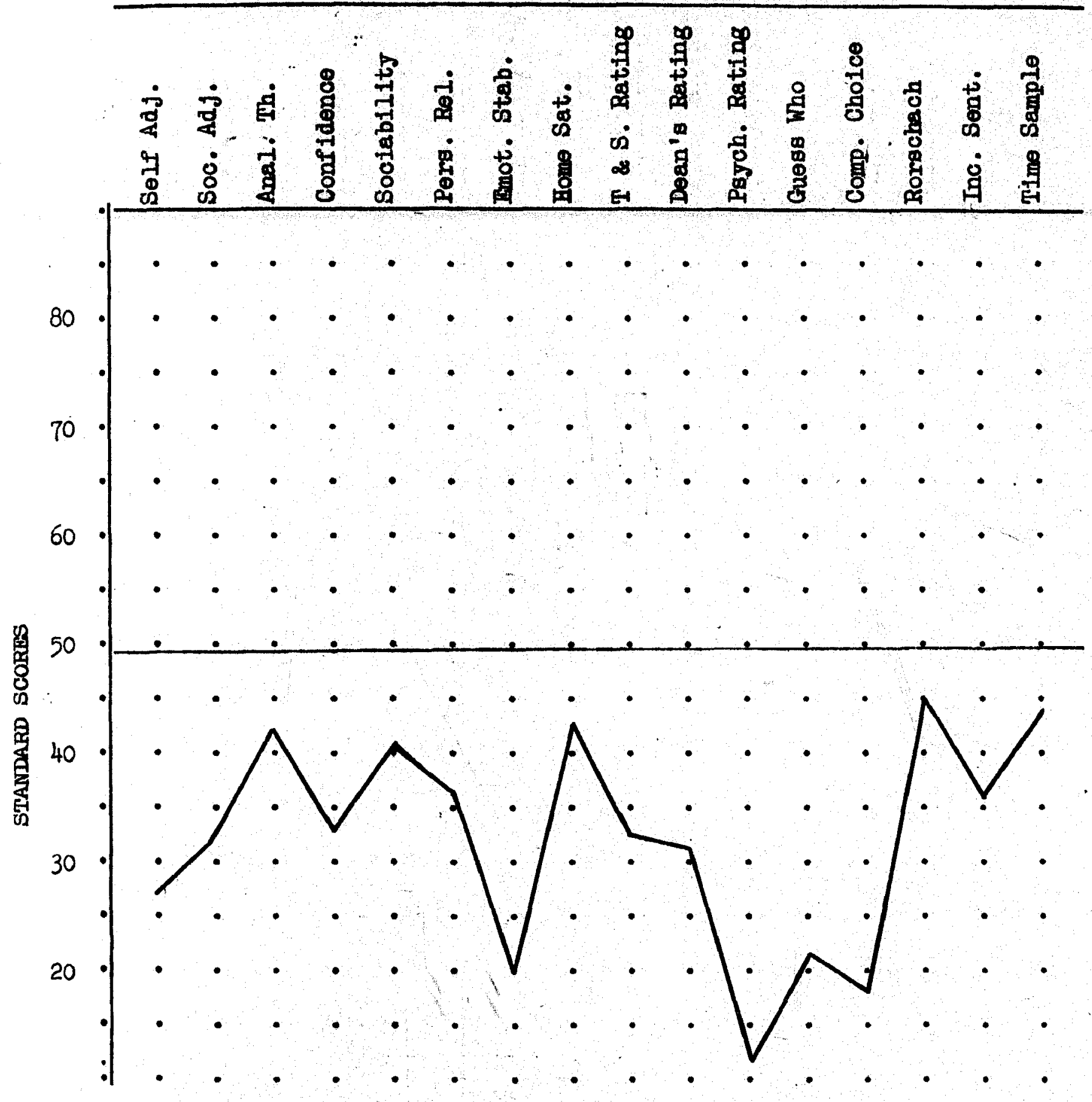


The higher scores on the projective techniques may be, in the light of his subsequent history, andindication of his positive response to a more stable environment. Using the criteria of low self acceptance and low social acceptance scores, this subject would be picked out as a maladjusted individual. The overall picture, as presented in the historical sketch, seems consistent in this particular case with the scores established on all of the adjustment indices used if you consider that the entire profile falls below the mean standard score.

Subsequent History: Since these adjustment indices were applied, the subject has continued to make satisfactory school achievement. He has gradually brought most of his grades up to an average level. At elghteen he would normally be discharged, but, since he still has one year of school to complete, he made an application that he be granted an extra year which was given him so that he might complete the necessary credits for graduation. He has made a more tolerable place for himself in the group. He has learned to swim, to dance, and to play a fairly decent game of baseball. He is more able to make and carry out plans for further improvement than at the time of the testing.

He continues to irritate others with his positiveness and his attempts to monopolize the center of the stage. He continues to have infrequent flare-ups of temper and is still very afraid of physical threat $\theta$ ven if it comp-s from a much smaller boy. 


\section{0}

He continues to have difficulty carrying out responsibilities and is frequently hyperactive but there is gradual progress along these Iines. When past the age of seventeen he entered puberty and is less conscious of physical difference in peer activity. He had considerable sexual conflict during the onset of pubescence, but was able to clarify those problems in an interview situation, and, while still not much beyond the stage of self absorption, he is beginning to reach out for acceptance in boy-girl group affalrs.

Recent psychological data is also indlcative of a reduced emotional tension with a corresponding higher functioning level. on 3-8-51 he was given the Wechsler-Bellevue Intelligence scale, Form I. At the time he was 17 years, 2 months, of age. He established an overall I. Q. of 93. H1s verbal I. Q. was 96 and his performance I. Q. was 89 . He was not as hyperactive as he had been on former testings and seemed to be in much better control of his emotions. These results indlcated such a signiflcant increase over his former functioning level that he was rechecked on 3-12-51 with Form L of the Revised StanfordBinet scale. With a chronological age of $17-2$ he established an M. A. of 14 years and 2 months, with aresulting I. Q. of 94 , which was felt to corroborate the Wechsler results.

Summary: The subject presented emotional maladjustment and very poor personal efflciency. His poor adjustment was reflected on all indices after over t wo years of a more consistent environmental experience. In this particular case, his extremer 
anxieties and insecurities were felt to have resulted in exaggerated bids for acceptance from the group. In an environment where group acceptance assumes even more importance than in a stable home situation, the subject was able to respond to individual counseling and to environmental pressures. The adjustment profile presented seemed to adequately present the picture of the moment, but did not lead to prediction of the future course of adjustment. The subject is still felt to be infantile in many respects and to be unable to fully meet the responsibilities of independent living, but there has been marked improvement in adjustment status.

\section{Case \#5775}

Date of Birth $1-29-32$

Age es of June 1, $1950 \quad 18-4$
Admitted to 0.5 . \& $S .0$. Home $3-18-38$

Age at Time of Admission $6-2$

Years of Residence as of June 1,1950 12-2

Family Background: This subject came from a family with a background of irregular employment and If $\theta$ in low rent districts of a large Ohio clty. Members of the family were involved in drunkenness, extortion, theft, and prostitution. Only a minority of the family, whose historles are known, could be considered as living without major 
conflict with soclety.

The subject's father, born in 1901, left school while still in the intermediate grades and was irregularly employed thereafter. He served in World War $I$ and was discharged in 1919. He married the subject's mother in 1920. He continued to be employed irregularly at unskilied jobs during his married life. He had a court record for drunkenness and neglect of his family. He died in 1932, eleven months after the subject's birth, following a drunken brawl caused by drinking poison liquor.

The subject's mother was born in 1905 and completed the sixth grade. She began work at 12 years of age in the market stands. She was married in 1920 at the age of fifteon. She was in difficulty frequently with the court for neglect of her children, who were described as dirty and half clothed. She spent six months in the workhouse on a charge of adultery. She drank heavily and was known to be promiscuous sexually. After her husband's death, she was ploked up by police on a charge of prostitution. She re-marrled shortly after her husband's death and was divorced in 1935. Her younger children had been 
placed, in 1933, in the Jewish Orphans Home. They were replaced in 1935 in a large County Children's Home. The mother never took much interest in her children, visiting them only once in 1936 after theis placement. She has continued to take little interest in her children over the years. She has made her living by doing unskilled housework, factory work, and by serving as a housekeoper for numerous widowers. At one time she and her sister were Implicated in an extortion case which supposedly natted them a rather large sum of money. The last time she was contacted, in 1951, she continued to over-dress and behave in a loud, vulgar manner. She owns and operates several tenements in low rent nelghborhoods:

The subject is the youngest of seven children, all of whom were removed to an orphanage in 1933. The oldest sister, born in 1921, was placed in throe orphanages where she was a constant source of difficulty. At the age of seventeen, she went to work in a wage home and shortly afterward ran off to be married. Her marriage did not last long and she has since done factory work to support herself and child. She is known as a good worker. The next sister, born in 
1923, was also placed in throe different orphanages. She was very unhappy in the last placement and finally ran off to Iive with her older sister. She has been married, divorcod, and re-married to the same individual. They now live in a newer part of the city and things seem to be working out better for her and her family. A brother, born in 1925, caused endless diffioulty in the County Children's Home. He stole and constantly ran away. He was finally placed in a boarding home where he was permitted. to go to work at the age of sixteen. He now holds a respansible job and has seemingly become a good father and cltizen. Another brother, born in 1927, went through placement in the same three orphanages and presented problems of stealing and running away. $H_{\theta}$ was crippled following an undiagnosed lilness. After poor adjustment ho was finally placed by the court in the third institution. At sixteon he began working at a series of low skilled jobs and contues to float from job to job. The next brother was born in 1930. He, too, was a severe behavior problem, stealing, bullying, forcing younger boys into sexual acts, and running away. He was finally discharged to the court from the 0.S. \& S.O. Home. He made little or no response to an educational program. Eventually he enlisted in the Army where he subsequently got into difficulty as an habitual alcoholic and A.W.O.L. Ho is rocolving correctional treatment within the Army at the present time. The youngest sister, born in 1931, was diagnosed as too low 
mentaliy to profit from an educational program and was discharged to the second oldest sister from the 0.S. \& S.O. Home. She recolved some training in classes for slow learners and eventually was able to help support herself by babysitting and working in the kitchens of restaurants.

The subject was scarcely a year old when placed in his first institution. At the age of three, he was placed with his siblings in the County Children's Home. Because the children were the children of a veteren, they were eligible for placement at the O.S. \& S.O. Home. During the years of difficulty with the older children, the subject continued to reside in the 0.S. \& S.0. Home. During this period of institutionalization, only the paternal grandmother took any interest in visiting the children or providing them with short vacations. The mother visited only infrequently in all the years the subject resided at the Home. The older siblings, after leaving the Home, seldom wrote or visited the subject.

Summary of the Subject's Residence at the 0.S. \& S.O. Home

Psychological Records: The subject was first examined on 1-26-38 by means of Form I of the Revised Stanford Binet Intelligence Scale. He was 6 jears and 0 months of age at the time. He established an M.A. of 4 jears and 3 months, with a resulting I.Q. of 71 . At the time he was diagnosed as of inferior mental ability but not feeble minded. He was 
noted to be inferior in his social and emotional reactions. He was at this time as well doveloped physically as the average boy of elght. He was again examined on 1-17-39 with Form $M$ of the Revised Stanford-Binet Inteliligence Scale. At the time of this examination, he was 7 years and 0 months of age. He established an M.A. of 5 years, 10 months, with a resulting I.Q. of 83 . He was described as demanding activity every second and to have extreme difficulty in focusing attention on the task at hand. It was noted that he was motivated by success but that conscious fallure resulted in active defiance. He was retested on $4-24-47$ with the Wechsler-Bellevue Intelligence scale. At this time he was 15 years and 3 months of age. He established an overall I.Q. of 83. This was the result of a Verbal I.Q. of 78 and a Performance I.Q. of 93. He was noted at this time to have exaggerated drives for success and to react defiantiy to failure. He was again tested on 3-8-50 with Form I of the Revised Stanford-Binet Intelligence Scale. At this time he was 18 years and 1 month of age. He establishod an M.A. of 14 years and 0 months, with a resulting I.Q. of 93 . $\mathrm{H}_{e}$ was still found to bo well motivated by success. His verbal facility and reasoning were considerably weaker than visual perception and non-verbal elements.

'he subject took the Galifornia Test of Personality on $1-12-44$ at the age of 12 years. H1s overall adjustment status was at the 35 th percentile level. There was consid- 
erable discrepancy between his expressed feelings of personal worth at the 65th percentile level and his other feelings in the self adjustment area, ranging from loth to 35 th percent-io ile levels. He evidenced feolings of poor school relations, poor community relations, and low social standards with accompanying anti-social tendencies. On $3-20-47$ he again responded to the California Test of Personality when 15 years and 3 months of age. His overall adjustment level at this time was at the loth percentile mark. Withdrawal tendencies were reflected. He showed negative feolings of belonging and self reliance. Anti-social tendencies and poor school relations were in conflict with his social standards and knowledge of social skills.

On mechanical aptitude tests, given through the years, he showed uneven abilities. He showed good ability in the spatial relationship tests, but poor understanding of mechanical principles and tool usage.

From 1946 until the Spring of 1951 the Psychology Department was in direct contact with the subject on an average of twice weekly formal Interview sessions with many more informal contacts. He was referred by other departments for defiant behavior, continuous disobedience of institutional regulations, stealing, runaway behavior, and moodiness. Prior to 1946 he had been referred, according to the records, as early as the age of six for exhlbitionism and attempted 
fellatio with cottage mates. Subsequently, he was referred as a school problem where he early disrupted the group and presented a problem in learning, stealing, and running away. Recognizing a boy who was starved for affection, with anti-social habits, and beginning severe behavior aberrations, the writer instituted therapy with the subject when he came to the Home in 1946. To cope with the many problems presented by the subject within the institutional setting and maintain an acceptance of him as an individual was frequently a frustrating experience for the theraplst. However, his drive for acceptance and hunger for recognition and affection kept difing him into sharing more of his problems and slow progress was made in reducing some of his needs for anti-social reactions which enabled him to enter into more satisfactory relationships with others and keep out of major difficultios.

School Records: The subject was placed in the kindergarten when he entered the 0.S. \& 0.S. Home as it was felt that he was not then ready for first grade work. In the 1939-1940 school year he was finally placed at the first grade level because of physical maturity. He made slow progress. In the second grade he continued to be demanding of attention and to be a poor sport. In the third, fourth, and fifth grades, there was noted improvement in achlevement but continued striving for the center of attention, and, when given special attention, he was prone to over-reach to 
it and take advantage of the person giving it. In the sixth grade he became increasingly insolent and tended to discount the efforts of classmates.

During Junior High School he maintained average progress in a slow moving section. If given a feeling of success, he was found to work very hard, but he could not take fallure or criticism without becoming sullen and deflant. During this period he was noted to be moody with periods of elation and conformance to rules, followed by periods of depression and sulking where he flagrantly broke all rules. He chose agriculture as his vocation and became quite interested in a number of farm projects. He continued to make average progress in the loth grade. He began to take an active part in athletics and dramatics where he gained some recognition.

In the summer of 1949 he was placed out of the Home on a dairy fam for work experlence. He was irresponsible, but proved to be a good worker. In the fall of 1949 he was placed on another farm near a neighboring city. The cultural background of the family was high. The subject was expected to help with chores and continue going to High school in the nearby city school. He made adequate school progress and was quite popular with certain groups in the school. He played football on the first team. Ho had difficulty motIng the standards of the family with whom he lived and. was intensely jealous of the two small children in the family. He returned to the Home the second semester and continued 
his eleventh grade work.

Dean's Record: The records report incidents of extreme deviant behavior reaching back to his admission to the Home. He was an early exhibitionist, being proud of his large genitalia. He masturbated openly and forced other boys into a variety of sexual practices. Instances of homosexual activIty continued to occur infrequently all through the years. He had an early record of stealing, which continued with more infrequent instances through the years. He was often defiant to cottage personnel but, because of the times when he reached out for affection and because of his seemingly unlimited enthusiesm, most crises could be weathered. He never seemed to hold grudges and was frequently, in his better moods, going out of his way to help a supervisor or younger boy.

On several occasions he ran away -- usually after he had stolen something. He was generally apprehended within a few days and returned to the Home. On several of these ocalsions he had to spend a night in jail until someone could return him.

He was a hard worker in the cottage and, if given a Iittle praise, he could accomplish more than most boys. He was always loud and bolsterous. Other boys accepted him but oftentimes made fun of his clowning and open expression of affection. If he liked someone he expressed it through physical contact which was not of the gentlo varlety. 
Medical Records: He was always well above average for his helght and age. Ho was healthy and well developed. After being hospitalized for chicken pox and measles shortly after admission to the Home, he neoded very little medical attention. His most common complaints were infections on fingers and feet and numerous furuncles. Ho continued to need instruction in personal hygiene and was never careful about personal cleanliness.

In looking back over this subject's history we find that he spent his Iife from early infancy in child caring institutions. At an early age he seemed to reflect impoverished experiences and inadequate emotional development in a very low ability level. Responding to individual programming and therapy, designed to meet some of his needs, he was able to reach low average functioning lovels. His history shows a continued exaggerated drive for recognition, taking the form of anti-social behavior. His unanswered neods for affection in a setting where early identification with parents was impossible, seem to have given rise to a disturbed emotional I1fo. Early exposure to aberrant sexual practices, in addition to his infantile emotional lovel and precocious physical development, seem to have led him into homosexual practices. His drives for success and his physical prowess did enable hlm to make some adjustments that negated complete rejection. 


\section{STANIAARD SCORHS}

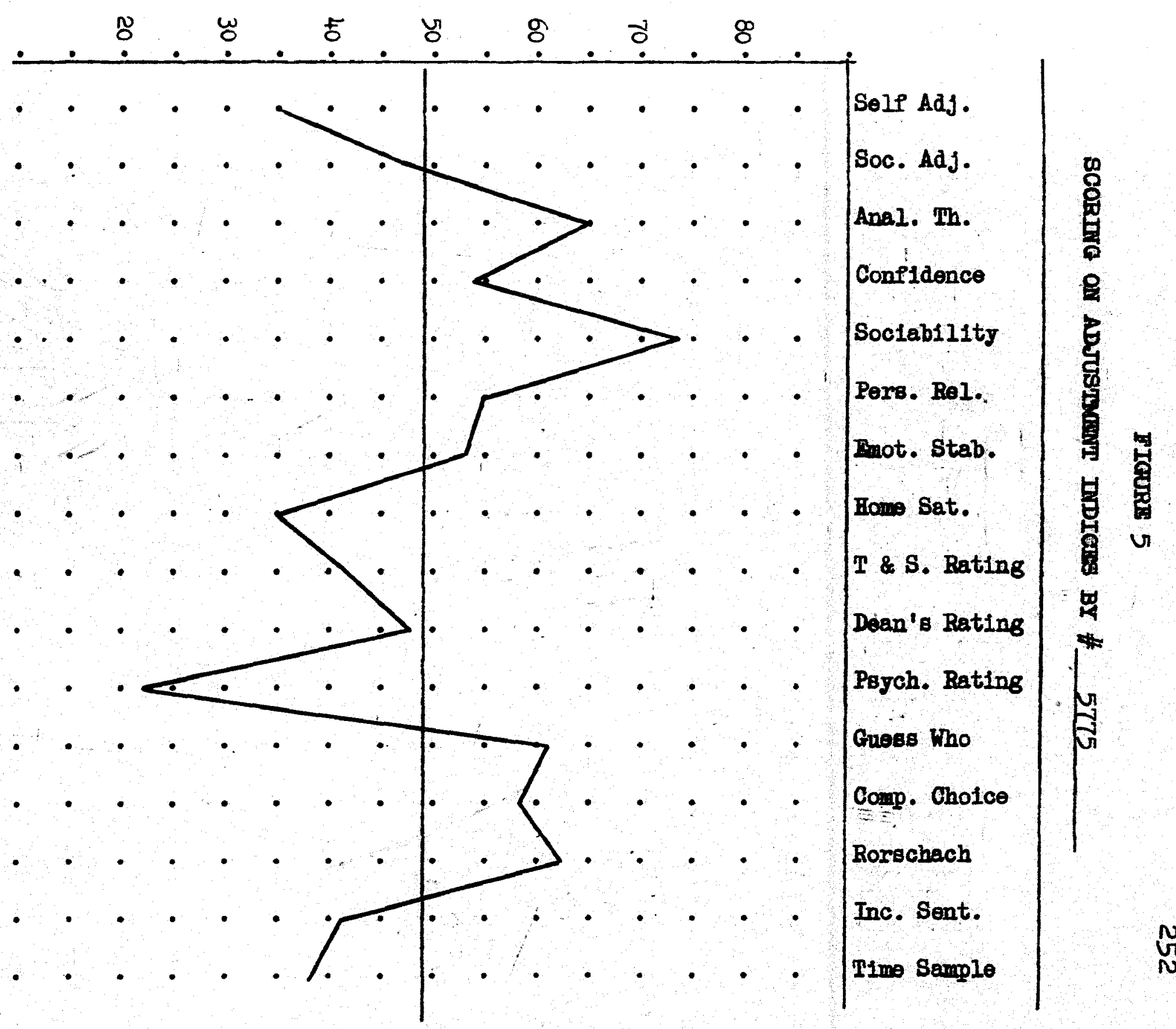


A Discussion of the Scoring of case \#5775 on the Adjustment Indices. With the history reviewed thus far of this subject we might expect considerable maladjustment to be indicated on the various indices made for this study. Figure 5, page 252, presents a profile of the standard scores made by this subject.

A glance at Figure 5 shows that elght of the indices lie above the mean standard score while an equal number lie below the mean standard score. Five of the indices, Iying above the mean standard score, are factors from the Heston Personal Adjus tment Inventory -- Analytioal Thinking, Confidence, Sociability, Personal Pelations, and Emotional Stability. Two of these are the indices established by the sociometric techniques - "Guess Who" and "Companionship Choice." The other index showing favorable adjustment is the Rorschach. Below the mean lie both indices derived from the California Test of Personality, with the self adjustment score definitely lower than the social adjustment score. The Home Satisfaction factor of the Heston scale lies below the mean. All three ratings by adults lie below the mean, with the rating of the Psychologist lying well below the other two. Both the Incomplete Sentence index and the Time Sample rating are below the mean.

Here is a case where disagreement among the various indices is apparent. When it is sought to compare the case 
history with the various scores, one is in immediate difficulty but certain points do stand out. It is noted that high scores on the sociometric techniques in this particular case might be expected as he did recolve a certain amount of social acceptance even though there were other aspects of his relationship with his environment which were out of adjustment. His high score on the sociability factor of the Heston scale might be a reflection of his drive for recognition and leadership, which was observably greater than that of the average boy in the population. His drive for academic success might be reflected in his better than average score on the Analytical Thinking factor. The Confidence, Personal Relations, and the Emotional stability factors on the Heston, which were just above the mean standard score, pose a problem but perhaps we might attribute these scores to a lack of insight on the subject's part as he was in the process of therapy and known to project many of his difflculties upon the environment. There is, of course, the possibility brought out before that this instrument is inadequate when appraising those with lower mental ability. The high score on the Rorsohach would seem to indicate adequate adjustment. An examination of the protocol indicates inner balance on a falriy mature level. There are few instances where he ovaded reality. He was normally productive and seemed in good contact with his fellows. Here, because his problems were expressed openly and overtly, this instru- 
ment might be loss revealing than if he had beon beset with unexpressed conflicts and repressions.

The low score achleved on the Psychologist's rating was probably a reflection of the many intimate detalls known as a result of several years therapy and may be depressed below his actual level. His low index of self Adjustment indicates that he still is not satisfled with his gains. Home Satisfaction is low and probably reflects a mixture of dissatisfaction after long periods of institutional residenco and a realization of family rejection which was beginning to be verbalized on an insightful level at this time. The ratings of teachers, supervisors, and deans were undoubtedly colored by the growth the boy had made at this point in comparison with earlier behavior. The Incomplete sentence mirrored much of his conflict in the family areas. The Time Sample was low as a result of oral preoccupation and striving for group dominance.

The inconsistency of scores on adjustment indices in this case seem to reflect the unevenness of progress toward a relatively higher level of adjustment in a case whero fairly sucoossful thorapy was occurring. It also is a rather clearcut 111ustration of how placing dependency on any one technique or score in dealing with adjustment can be very misleading. Finally, it appears that this case 11 lustrates the nocessity of knowing case history background in a detailed fashion $1 \mathrm{f}$ one is to begin to interpret test- 
ing results of this nature. It is also of interest that none of these tests would give strong clues to the subject's unacceptable sexual ad justment with the exception of the Rorschach protocol which did contain several responses which would indicate a suspicion of oral aggressive tendencles.

\section{Subsequent History: The subject asked for an extra}

year to finish his High School education in the spring of 1950. This was granted him. He returned to the dalry farm where he had worked the summer before and held his job satisfactorily. He developed quite on emotional attachment to the owner of the dairy and was quite upset when the latter's wife did not treat him as a member of the family. He roturned to school and completed his credits for graduation. He continued to flare up out of school and there were several instances of stealing. However, in each case he would come and confess what he had done and would then set about making good his theft. He took an active part in athletics, social affalrs, and dramatios. HIs drive to complete his education seomed to stem from a desire to show up his family by being the first to graduate from high school. On the night of his graduation he waited until the last moment for some member of his family to appear. Theydlsappointed him by not being there. He expressed considerable bitterness over this disappointment.

He returned to the dairy farm to work following graduation. The owner thought it time to bogin treating the subject like any other worker. Heretofore he had been helping 
hIm budget his money and had permitted him to Ilve as a member of the family. The subject, in the meantime, had purchased a used car and began to need more monoy than he was making. He had also been moved to a defense house near the dalry which he interpreted as rejection. By fall he was rather bitter in regard to his job and one morning made a small collection on a bill, pocketed the money, and drove home to his sister. The car was not pald for by the subject. The owner of the dalry, who had paid for the car and was taking it out of the subject's wages, located the boy who returned the car and squared himself flnanclally with the dairyman. Shortiy after this episode the subjeot was drafted and placed in the Marines. He continues to make marginal adjustment but has not at this time become involved in serious trouble. He continues to need a great deal of support and is still closely tied to the Home and 1ts personnel. He has begun to make some heterosexual advances but continues activity with other males. He has never learned to handle money responsibly and continues to have spells of depression.

Summary: The adjustment indices were not consistent in the ir appraisal of this case. When the historlcal background is considered there are some loglcal reasons which might account for this inconsistency. This subject who was starved for affection and met only diluted personal relationships from infancy nevertheless made progress over the years that 
in some respects is rather remarkable. It is still quite possible for this subject to come into severe conflict with society which may throw him back on early non-adjustive behavior patterns. The very inconsistency of the rating of the varlous adjustment appraising techniques seems to mirror the uncertaintios in the subjectls behavior. This case tends to point out the need for as complete a knowledge of the subject as possible in order to utilize test results.

If the self acceptance score and the soclal accoptance score had boen used as screoning devices in this case, it would have been necessary to have examined the case more carefully bocause of the differing results. An examination of the case would likely have thrown light on the difficulties present. If such cases of striking disagreement between self acceptance and social accoptance are investigated, the usefulness of those two scores as screening dovices can bo recommended.

\section{Conclusions}

Five cases have been presented with an attempt to illustrate how the establishod indices of adjustment compare with environmental data. In four of the cases we find an overall consistency between environmental data and test scores. In the fifth case we find scores betweon the varlous adjustment measures disagreeing rather definitely. In this case we also find the same disagreement between phases of behavior. 
When the facts of behavior were compared with the adjustment Indices there was a falrly close agreement between indices and overt behavior.

A study of these five cases seoms to confirm the findings brought out in studying the group data. Any one score reputed to assess adjustment status is inadequate whon working with either groups or individuals. The cases lend support to the suggestion that a score indicating self acceptance and one indicating social acceptance are likely to be profitable as screening techniques when seeking to point out those individuals in a group who seom to bo having the most difficulty meeting environmental pressures. The data brought together in these case studies emphasize the use of detailed case history material to clarify scores made through the use of various appraisal techniques.

It has been demonstrated in these five cases that present assessment measures, while cortalnly imperfect, are useful if we use enough of them. It has been suggested that treating adjustment as a global concept may bo less fruitful than an approach that may be termed operational. These cases illustrate the possibility for setting up definite, commonly experienced environmental sitautions which can be defined in speciflc terms so that we may say given the following set of circumstances in an individual case we observe the ensuIng behavior. This subsequent behavior might also be defined speciflcally and rated on a well defined scale as adjustive or non-adjustive. That is, if we find it important to cato- 
gorlze behavior in such speciflc terms. It begins to appear that at present when working with the concept of adjustment in an individual oase the worker must bear in mind as many individual facts, gleaned from observation and testing, as he can comfortably manipulate and then set about teaching the individual to set reasonable immodiate goals which are in line with a reasonable goal developed by the therapist who has considered carefully what might be an appropriate projected goal.

One cannot make sweoping generalizations from the five cases considered. However, the contribution of this chapter seems to be that of pointing out the usefulness of present techniques for diagnostic and therapoutic purposes when used against a background of historical data. For screoning purposes they can point out where the time should be spent in digging out historical date and with which individuals. None of the indices used independently, which have been applied in this study, appear useful in the role of independent criteria of adjustment. They do appear to have limited usefulness when used as a group or in conjunction with environmental data. 
CHAPTER VII

SUMMARY OF THE STUDY

Summary of the objectives

The present study grew from the felt inadequacles of currentiy used criteria for adjustment. Too frequently it was noted in reviewing psychological. Ilterature dealing with diagnostic and therapeutic efforts that groups and individuals were labeled relatively well adjusted or relatively maladjusted on the basis of a single or, at the best, a few indices purporting to assess adjustment status. In many instances, efficacy of thempoutic attempts was evaluated on the basis of changes in one or two of these same adjustment indices. Results of validation studies of various adjustment Indices over the years have pointed to the weaknesses of using these indices as independent criteria. The writer in his work had often questioned just how much confldence could be placed In the various techniques avallable for assossing adjustment and yet was forced by the demands of day to day pressures to utilize such indices in making appraisals of adjustment status. In order to clarify this situation it was determined to examine in detail the relationships among results obtained by using 261: 
many of the commonly accepted technlques for assessing adjustment, then carefully apply them to a known population and compare the results.

It became the first objective of the study to select representative approaches purporting to measure adjustment and then to apply those approaches carefully to a population observed to consist of individuals who varied in their adjustment status. After applying these techniques it was necossary to subject the results to a correlational analysis in order to establish some logic for agreement or disagreoment found. As longer range goals, it was hoped to shed some light upon what was necessary in order to Improve such existing techniques. It was further hoped that certain issues in regard to the concept of adjustment as frequently used might be raised, leading to clearer delineations within which was felt to be a legitimate area of personality study.

\section{Summary of the Approach}

Nature of Adjustment. In a review of the literature dealing with the concept of adjustment, it was found that representative writers, while using different terminology, were in essential agreement as to the nature of adjustment. Synthesis of agreeing statements points to a description of adjustment as a process that covers the individual ifo span operating within a complex environmental fleld. The process appears to be goal directed behavior instituted by a need which may be 
aroused at any level within a hierarchy of neods that may stem from baslc physlologlcal urges all the way through to the most complicated psychological symbolizations. The process of adjustment is propelled in a complex situation when this goal directed behavior meots a thwarting circumstance which serves to helghten tensions so that varied responses can occur. One, or a combination of these varled responses, eventually leads to a solution response which onables attainment of a transitory goal which results in reduction of that particular tension. The very process ltself of attaining a transitory goal oftentimes establishes the circumstances in a complex environmental fleld that perpetuates the process.

During the persistent process of establishing and reestablishing a semblance of Individual adjustment within an individually unique environmental field, measurements may be made as to the efficacy of the process. It is here that agreement was found in the writings of the experts in the field as to the characteristics or facets of those adjustments termed good. Seven facets of good adjustment were delineated. There was no implication that these facets were independent or mutually exclusive. Rather it was found they were descriptive terms which frequentiy coexisted and complemented each other In the behavior of individuals termed well ad justed. These seven facets were found to be recognized by a majority of 
writers in the fle ld and are briefly recounted at this point. (1) Maintaining an Integrated personal1ty. This aspoct of good adustment dealt with the coordination of one's needs and goal-sooking behavior Into smoothly functioning interaction with the environment. (2) Conforming to social demands. Complimenting the first facet, this characteristic emphasizes hamony without giving up individual spontanolty with the standards of one's cultural group. (3) Adapting to reality conditions. The emphasis here is upon one's ablilty to expose himself to present hardship conditions for gains toward long range goals. Thero is also expected a reasonab le tolerance to frustration. (4) Maintaining consistency. This is a qualitative facet which makes for predictability in behavior and allows hopes for assessment of adjustment. (5) Maturing with age. This is the facet which makes allowance for maturetion and development in the individual with concomitant growth of more complex adjustment processes. It permits the learning of more complex processes with the accruing of profit from experience through the medium of increasing contacts with the environment. (6) Malintaining an optimal emotional tone. In the face of emotionaliy loaded situations the well adjus ted person is nelther constricted in emotional involvement nor thrown by his emotional reactions. (7) Contributing optimaliy to society through an Increasing efflclency. This facet summarizes the result of well adjusted behavior that insures 
against an Interprotation of behavior that is not purposive beyond self interest.

In addition to describing the adjustment concept as a process and delineating certain agreed upon facets of this process, recognition was made of the various common mechenisms that are usod in carrying out this process. It was found that while there were certain agreed upon mechanisms of adjustment (1.0. wi thdrawal, projection, sublimation, introjection, direct attack, otc.) thero was far loss agreoment as to what degree of usago of any mechanism constituted enough to cause a shift along the adjustment continuum. It was concluded that each mechanlsm as it revealed itself must be judged in the light of the total complex environmental. picture rather than automatically rating 1 t toward either the non-adjustive or adjustive end of the continuum.

The concept of adjustment was shown to be a complex one. Since it is a perpetual process and may exhibit itsolf at any point along an increasingly complicated hierarchy where symbolization p lays an increasingly important part, and because of the necessity to take snto consideration the many complex forces of the environmentel field, the inherent difficultios of measurement were noted. Despite these difficulties, attempts continue to be mado to assoss adjustment status. It was felt that such attempts were legitimate and merited more complete evaluation. 
Selection of Population. Since the study was to examine relationships between techniques designed to assess adjustment status, a clearly defined population was necessary. As the writer was acting as resident psychologist at the Ohio Soldiers' and Sallors' Orphans' Home at the time, it was felt that within the largor population a sultable one for study. could be defined. The best known population consisted of all of the white boys who had reached their fourteenth birthday as of April 1, 1950, who had boen in residence at least six months, and who were not up for Immediate discharge. The chosen population consisted of sixty-six adolescent boys who were observed to vary in thelr adjustive status. This group was found to be within the average ability range but somewhat retarded scholastically by school placement standards. They would have rated low on a family stability scale.

The cultural background was somewhat bolow that usually considered middle class. The average boy in the group had lived for approximately six years in the orphanage. While the backgrounds and living situation made for a somewhat atypical group, the Immediate onvironmental field was similar for each boy and members of the group were avallable for close study and follow-up. Since the study emphasized agreement or disagreement botween techniques purporting to measure adjustment, this chosen population lent itself rather uniquely to the problem. 
Selection of Instruments. After developing a concept of adjustment and solocting an appropriate population, it was necessary to categorize existing techniques of assessing adjustment and select representative measures within those techniques. It was found that a categorization scheme of five major types would encompass the existing ways of assessing adjustment status. The major types consisted of: Questionnaires and Inventories; (2) Ratings by adult judges; (3) Ratings by peors; (4) Adjustment indices secured through projective techniques, and (5) systematized direct observation. Representative techniques were selected under each major type in accordance with established criteria that took into account the sultability to the group, the stralghtforwardness of scoring, differences of approach within the major type, and practicability of application. As a result The California Test of Personality was selected under Typo (1); It provided two indices of adjustment; self adjus tment and social adjustment. Also under type (I) and representing an inventory constructed by factor analysis was the Heston Personal Adjustment Inventory. This inventory gave s ix indices of adjustment: (a) Analytical Thinking, (b) Sociability, (c) Emotional Stability, (d) Confidenco, ( $\theta$ ) Personal Relations and (f) Home Satisfaction. To represent type (2), Ratings by Adult Judges, an average global rating was socured using the independent ratings of two teachers and one supervisor. These 
global ratings were made after consldering standing on oach of the seven facets of the adjustment process. Another average adult rating was secured by having the btwo men in the Dean of Boys' office rate each boy using the HaggertyOlson-Wickman Bohavior Rating, Schodulo B. A third adult rating was secured by having the Psychologist make a global rating of each boy's adjustment on the basis of case history material, close acqualntancobhip, and material galned from a semi-structured interviow. Type (3) which consisted of peer ratings secured through the use of soclometric techniques was represented by a "Guess Who" rating based upon a cluster analysis of characteristics approved and disapproved by adolescents. A "Companionship Choice" test was also used to secure a comparable soclometric rating. In type (4) 1t was necessary to choose projective techniques which purported to give adjustmont Indices. Munroe's Rorschach Check List was used as one of these techniques. The high school form of Rotter's Incomplete Sentence Test was used to establish the other representative index wi thin this type. Type (5) was exemplifled by using a Modifled Time Sample technique to gain an Index based upon systenetized direct observation of behavior. Each boy was observed ten pre-scheduled flve-minute perlods: four classroom activities, four vocational or work-tralning periods and two recreational perlods. In addition to theso sixteen indices of adjustment, it was felt necessary to establish measurements of threo extraneous variables whith 
were unknown in their effect upon the adjustment indices. These throe variables were: (2) chronological ago, (b) mental age, and (c) months of residence in the institution. Summarizing the Prosentation of Data

After selecting the techniques to be used, these techniques were applied with the utmost care taken in measuring and scoring to insure maximum validity. Raw scores were transmuted so that relatively high scores indicated relatively good adjustment, while low scores indicated relatively poor adjustment. The sixteen resulting arrays were inspected for normalcy of distribution and other characteristics. Rellabillty studies were made with the data where indicated. Those characteristics were reported in detall in Table 5 , page 132. One of the outstanding characteristies of the group which deserves emphasis was that on several measures, The California Test of Personality, The Heston Personal Adjustment Inventory, The Haggerty-OIson-Wickman Behavior Rating,Schedule B, and the Munroe Rorschach Check Ilst, the mean score of this group was considerably below the mean score of the standardization group, the implication belng that in general the group whose scores were distributed normally gave more indication of bolng malad justed on these several measures than the groups chosen for standardization of the technique. It was a lso polnted out that the inter-rater reliability correlation coefflelent of the average teacher-supervisor rating of global adjustment was too 
Low to assure confidence in this particular index. It was also pointed out that the index secured through the use of the Modifled Time sample technique distributed the population over a too narrow rango of scores.

Intercorrelations were secured between each of the sixteen indices of adjustment as well as between each of these sixteen Indices and the throe extraneous variables. Since the effects of these three variables were unknown, it was first necessary to compare their relationships with each of the adjustment indices. The rasults of this comparison were summarized in detall in Table 6, page 136. In general. It was found that these variables were not rolated at a significant level to any of adjustment indices. However, there were a few instances of significant relationship which were examed. It was found that The Haggerty-0Ison-Wickman Behavior Rating, Schedule B was s ignificantly related to M. A. which was not surprising since this technique devotes one whole area to scales concerning ability status. The "Guess Who" was found to be significantly relatod to months in residence which seemed to indicate some trend toward adopting the characterlstics admired by the group when over the Individual was ablo as he experienced continued group living. The Modified Time samplo was found to be significantly related to both C. A. and months in residence. This situetion seemed to be occasioned at least partially by the tendency to become 
more covert in the overt behavior observable with age. Since the Modifled Time Sample was judged to be a rather poor Index of adjustment, IIttlo Importance was attributed to these relationships.

The one hundred and twenty intercorrelations presented in Table 7, page 142, resulting fom comparing each of the sixteon arrays with each other, were next examined for significance and other characteristics. In general, a positive but low correlation was found between the various arrays of adjustment indices. The median intercorrelation, was .228. This is sufficient to indicate just a thread of relationship between common approaches purporting to assess adjustment. The results were insufficient to support strongly a global concept of adjustment that is directly communicable in terms of results secured by any one technique being used to predict accurately in terms of results of other techniques.

A closer examination revealed that forty-one of the one hundred and twenty intercorrelations were significant at the . OI per cent level or above. In addition, seventeen more of these intercorrelations were significant at the 05 per cent lovel. These facts rovealed that a variety of the techniques were tapping related processes and lend support to the loglc which aggues for the existence of a global concept of adjustment. However, the lowness of these relationships and the infrequency of their occurrence detracts from the usefulness of that global concept in that it lacks general communicabllity. 
In fact, when spoaking of the adjustment of a specific group or of a specific individual, it is not nearly as clear what is meant as when one speaks of the general abllity level of the group or of the individual.

It was apparent from the data that certain factors were present which could account for some of the inter-relationships found. These factors seemed to influence the amount of relationship found above and beyond the matter of "adjustment." Basicaliy, there was considerable more relationship within and between three of the major groupings. Questionnalres and inventories, ratings by adults, and ratings by peers are all established by some form of personal report which could plausibly account for some of the relationship found. It was also found that relationships between techniques within each of these types were more frequent and at a higher level than between the various types. Another factor accounting for some of the relationship found appeared as the overlap betweon self adjustment and social adjustment. While ap proachod from different angles these two concepts were not easily definable and are certainly inextriaably bound together in any particular individual as he functions in his environmental field.

A s tudy of the data brought out other factors which could logically account for some of the lack of relationship found. One of these was the lack of relationship between the fowo projective techniques purporting, to establish an adjustment 
Index, and further the lack of relationship found when these indices were compared with the indices established by other techniques. These projective methods at their present state of refinement did not seem, with this particular population, to establish a comparable numerical index but were valuable in an individual interpretation in the matter of aiding in constructing hypotheses in regard to individual behavior dynamics. Another factor accounting for lack of relationship was the inclusion of the Modified Time Sample which was related at the $0 I$ percent level to only one of the other fifteen indices. Since the range of distribution on this population was so narrow for this technlque, this may account for some of the lack of relationship found. Another finding possibly contributing to the lack of relationship found, was the low correlations established between similarly labeled techniques, such as social adjustment and sociability. This fact pointed toward a need in the adjustment assessing area for a more specific definition of terms if communicability is to be improved. After examining the da a in terms of the group, it was necessary to include some examples at the individual level to complete the picture in terms of agreement or disagreement between the various measures in individual cases. It was felt that such an inclusion might point the way toward more intelligent use of the techniques presently avaliable. Five cases were examined in accordance with certain criteria. The data suggested that low scores of self adjustment, as secured through the questionnaire, and low scores of soclal adjustment, 
secured by peor rating, would screen out those individuals evidencing most severe conflict. It was also necessary to use individuals about whom rather oomplete case history material was known, both prior to the study and for a period of two years followling the inftial measurement. Hence, two cases were plcked who evidenced hlgh quartile scores in self adjustment and social adjustment and two cases picked where low scores on these measures were evidenced. One case was picked where there was disagreement between these scores. All scores on all indices were transmuted to comparable standard scores. These scores were then examined in a detalied fashion with extensivo caso history material as a background.

The study of these five cases emphasized the fact that no one score could be depended upon to adequately assess adjustment in an individual caso. Even in cases as clear cut as several of these were, where all the knowledge available pointed to elther adequate adjustment or rather severe maladjustment, various technlques might point in the other direction.

Individual study brought out the usefulness of the suggested self adjustment score and the soclal ad justment score as screening devices when 1 t was necessary to discover quickly those maladjusted individuals with whom more intensive work could be planned. It was further lilustrated that where 
there was an evident discrepancy between an individual's scores in these areas that these cases would merit closer investigation.

The study of individual cases emphasized the need to use present techniques for assessing adjustment in conjunction with all of the case history material avallable, on each individual. The data indicated that even though none of the Indices used were felt to be adequate as an independent criterion of adjustment, each had its usefulness when used with other Indices against a background of environmental material. The chief uses of these indices appeamed to be in providing hypotheses in regard to behavior dynamics and also In adding support to hypotheses made on the basis of past observances. In no instance was it discovered that any of these Indices could bo used alone as a basls for prognosis as to future adjustment status. However, a profilo, such as was established through the use of many of these measures, was felt to be a useful Indicator of future adjustment status. Suggestions for Present Use and Future Development

For the present, at least, the data secured in this study seem to Indicate that tochniques designed to appralse adjustment status are Imperfect and have only threads of relationship with each other. They are not entirely worthless, however, as they can be used as screening devices preparatory to more intensive study of groups and individuals. They are also useful to help form hypotheses and to furnish evidence of 
support or denlal for hypothoses a lready formed in studying particular groups or individuals. The fact that several measures pointed to a lower adjustment level of this group of adolescent orphanage residents, when compared to standardization groups, is in IIne with logical expectations, considering the traumatic psychological events known to have occurred in most of these boys' lives.

The current practice of reporting adjustment status in the terms of one index, derived by one technique, is inadequate according to the findings of this study. A better practice at the present time would be to use many indices rather than one or two. More confldence could be placed in studies where the results of several indices are included to indicate the direction along the adjustment continuum.

The study has pointed out the need for clearer definitions when dealing with concepts of adjustment. Present usage of terminology in this area leaves much to be desired. It appears that there is a need to speak in concrete terms when discussing the adjustment of groups or Individuals. In describing a subject's adjustment, It would soem necessary to point out in behavior terms the ovidence for adjustment or maladjustment. This makes ltt necessary to speak in specific terms rather than making general statements in regard to global adjustment.

Before current techniques can be Improved it seems necessary to define in operationąl terms certain common adjustment situations for specifled populations. If, when these 
situations are determined, a means of measurement can be found, then these techniques can be applied to representative populations. The sesults ostablished can be used through statistical analysis to delineate factors of adjustment that should meet the requirements of those seoking to establish more clearly defined criteria.

With the improvement of techniques, rather than the addition of more and more examples of specific techniques, there should come progress in communicability of results. If such a time comes, when techniques can be improved, it wl ll be necessary to improve the training of those using the techniques. In this study those with the least training in psychological fields were least in agreement among themselves in their judgments.

It was hoped as the study was planned to shed some light on what areas might profitably be examined for higher level adjustment skills. Little progross was made in this effort but there was evidence that measures designed to increase feelings of self acceptance wouda be profitable. Likewise, in the area of soclal acceptance, at least with this age. group, any steps which could be taken to 1 mprove the acceptance of one by his peers seemed related to growth toward better adjustment. These trends strengthen the approach of counselors and tthoeaplsts who have sought to help tho subject gain clearer insight in these areas. Perhaps a detailed inspection of those Who evidence high performance in elther of these areas might result in outlining certain superior practices which could be 
taught those seoklng to operate at a more optimum level of ad jus tment. 


\section{BIBLIOGRA PHY}

1. Anderson, Harold H. "Domination and SoclallJ Integrative Behavior." (In) Barker, R. G., Kounin, J. S., and wright, H.,F. Chl la Behavior and Development. Now York: McGraw-H111, 1943, 459-483.

2. $\quad$ "Soc1a1IJ Integrat1ve Behav1or." Psychol., 1946, 41: $379-384$.

3. Arrington, Ruth E. "Time Sampling studies of Child Behavior." Psychol. Monogr., 1939, 51: 3-193.

4. Bagby, Engl1sh. The Psychology of Personality. New York: Henry Holt \& Co., 1928.

5. Beck, Samuel J. Rorschach's Test I Bas1c Processes. New York: Grune \& Stratton, 1944.

6. Rorschach's Test II A Varlety of PersonaI1ty Platures. New York: Grune \& Stratton, 1945 .

7. Be11, J. E. Projective-Techniques. New York: ${ }_{\text {Grengmans, }}^{\text {Long }}$

8. Berg, Irwin A. "Measures Before and After Therapy." J. CIIn. PsychoI., 1952, 8: 46-50.

9. Bernreuter, R. G., and Carr, E. J. "The Interpretation of I. Q.'s and the I-M Stanford-Binet." J. educ. Psycho 1., 1938, 29: $312-314$.

10. Blair, G. M, and Clark, R. W. "Personallty Ad Justments of Ninth Grado Pupils as Measured by the Multiplo Cholco Rorschach Test and the Callfornia Test of Perso nal1ty." J. educ. Psychol., 1946, 37 : 13-20.

11. Bonney, Merl E. The Constancy of Sociometric Scores and Their Relationiships to Teacher Judgments of Soc1al Suceess and Personality Self-Rat ings." Soclometry, $1943,6: 409-424$

12. Bott, E. A., Blatz, W. E., Chant, N., and Bott, H. McM. "Obsarvation and Tralning of Fundamental Hablts in Young Chilaren." Genet. Pstchol. Monogr., 1928, 4 : $5-161$. 
13. Bridges, K. M. B. "Occupational Interests of ThreeYear-01d Children." J. genet. Psychol., 1927, 34 : 415-423.

14. Bronfenbrenner, Urie. "A gonstant Frame of Reference for Soclometric Research." Soclometry, 1943, 6: 363-397.

15 .

"A Constant Frame of Reference for Soclometric Research, Part II Experiment and Inference." Soc1ometry, 1944, $7:$ 40-75.

16. Brown, Andrew W. "The Change in Intelligence Quotients In Behavior Problem ChIldron." J. educ. Psychol., $1930,21: 341-350$.

17. Buros, 0. K. The Third Mental Measurements Yearbook. New Jersey: Rutger's Press, 1949.

18. Cattell, R. B. and Saunders, D. R. "Inter-Relation and Matching of Personality Factors from Bohavior Rating, Questionnaire, and Objective Test Data", J. soc. Psychol., 1950, 31: 243-260.

19. Champney, Horace, and Marshall, Helen. "Optimal Refinement of the Rating Scalo." J. appl. Psychol., 1939, $23: 323-331$.

20. Cronbach, Lee J. Essentials of Psychological Testing. New York: Harper \& Bros., 1949.

21. Darley, John G. "Tested Maladjustment Related to Clinically Diagnosed Maladjustment." J. appl. Psychol., $1937,21: 632-642$.

22. Dashioli, J. F. Fundamentals of General Psycholiogy. Chicago: Houghton-Mlffiln Co., 1937.

23. Dwyer, Paul S. "Simultaneous Computation of Correlation Coefflclents with Mlssing Varlates." Proceedings of the Research Forum, Endicott, New York, Aug. 26- 30, 1946. International Business Machine Corporation, pp. $20-27$.

24. Dysinger, D. W. "Slgns of Personallty Disintegration." (In) Pennington, I. A., and Berg, I. A. An Introduction to CIInIcal Psychology. New York: Ronald Press, 1948.

25. Edmiston, R. W, and Baird, Frances. "The Adjustment of Orphanage Ch1laren." J. odue.Psychol., 1949, 40: 482-488. 
26. Ellis, Albert. "The Validity of Personality of? Questlonna1res." Psycho1. Bul1., 1946, $43: 385-$ 440.

27. Feder, D. D., and Baer, Opal L. "A Comparison of Test Records and Clinical Evaluations of Personality Ad Jus tmont." J. odue. Psycho1., 1941, 32: $133-144$.

28. Fenton, Norman. Mental Hyglene In School Pract1ce. stanford: stanford University Press, 1943.

29. Flscher, R. P. "Fmotional Maladjustment and Academic Personne1." J. H1 gher Edue., 1944, 15: 43-44.

30. RlsherfiRbeA. Statistical Methods for Research Workers. Now York: Hafner Publishing Co., 1950.

31. Gates, A. J., Jersild, H. T., MoConnelI, T. R., and Challman, R. C. Educational Psychology. Now York: MacMilian Co., 1949.

32. Goodenough, F. I. "Inter-relationships in the Behavior of Young Children." Child Develpm., 1930, 1: 30-31.

33. Greene, E. B. Measurements of Human Behavior. New York: Odyssej Press, 1941.

34. Greene, H. A., Jorgensen, A. N., and Gerberich, J. R. Measurement and Evaluation in the Secondary school. New York: Longmans, Green, and Co., 1946.

35. Gu1lford, J. P. Psychometric Methods. New York: McGraw-H111, 1936.

36. _ _ and Gullford, R. B. "Personaltty Factors D, R, T, A." J. abnorm. soc. Psychol., 1939, 34 :

37. _ Personality Factors $\mathrm{S}, \mathrm{E}, \mathrm{M}$, and The1r Measurement." J. Psychol., 1936, 2: 109-127.

38. . , and Martin, H. "Age Differences and Sox Differences in Some Introvertive and Emotional Traits." J. gen. Psychol., 1944, 31: 219-229.

39. Hacker, F. J. IiThe Concept of Normallty and Its Practical Signiflicanco." Amer. J. Orthopsychlat., 1945, 15: 47-64.

40. Harrower-Ertckson, M. R., and Steiner, M. E. Large-Scale Rorschach Techniques. Springfieid, IIIinols: Charles C. Thomas, 1945 . 
41. Hartshorne, H, and May, M. A. Studies in the Nature of Character II Studies in Service and Self Control. New York: MacMlilan, 1929.

42. Healy, WIIliam. Mental Conflict and Misconduct. Boston: Iittle, Brown, and Co., 1930.

43. Hertz, Marguerite R. "Modiflcation of the Rorschach Ink Blot Test for Largo Scale Application. A Amer. J. Orthopsychiat., 1943, 13: 191-211.

44. Hutt, Max L. "The Use of Projective Methods of Personality Measurement in Army Medical Installations." J. clin. Psycho 1., 1945, 1: 134-140.

45. Jackson, J. "The Relative Effectiveness of Paper-Pencl I Test, Interview, and Ratings as Techniques for Personality Evaluation." J. soc. Psychol., 1946, $23: \quad 35-54$.

46. Jennings, Helen H. "A Soclometrlc Study of Emotional and Social Expansiveness." (In) Barker, R. G., Kounin, J. S., and Wright, H. F. Child Behavior and Development. New York: McGraw-H111, 1943, $527-543$.

47. Jersild, Arthur T. Child Psychology. New York: PrenticeHail, Inc., 1947.

48. Johnson, Palmer 0. Statistical Methods in Research. New York: Prentice-Hall, 1949.

49. Johnson, Wende11. "The Semanties of Malad justment." (In) Pennington, L. A., and Berg, I. A. An Introduction to Glintcal Psychology. Now York: Ronald Press, 1948.

50. Kingsley, Howard I. The Nature and Condittons of Learning. New York: Prentice-Hal I, 1946.

51. Klopfer, B, and Kelley, D. The Rorschach Technique. Yonkers, Now York: WorId Book Co,, 1942 .

52. Krech, David, and Crutchfleld, R. S. Theory and Rroblems of Soclal Psychology. New York: McGraw-HIII Book Co., Inc., 1948 .

53. Kuhlen, Raymond G, and Ie日, Beatr1ce J., "Personality Characteristics and Social Acceptabllity in Adolescence." J. eduo. Pstcho 1., 1943, 34: 321-339. 
54. Lechy, Prescott. Self-Consistency: A Theory of Personellty. New York: Island Press, 1945.

55. Louttit, C. M. Clinical Psychology. New York: Harper \& Bros., 1947 .

56. Love11, Constance. "A Study of the Factor Structure of Thirteen Personality Variables." Educ. psychol. Measmt., 1945, 5: 335-350.

57. Maller, J. B. "Personality Tests." (In) Hunt, J. McV. Personality and the Behavior Disorders. New York: Ronald Press, 1944, 170-213.

58. Masserman, J. H., and Balken, E. R. "The Clinical Appilcation of Phantasy Studies." J. Psychol., $1938,6: 81-88$.

59. - The Psychonalytic and Psychiatric Phantasy." Psychoanalytic Rev., 1939, 26: 343-379.

60. Moreno, J. L. Who Shall Survive? Washington D. C.: Nervous and Mental Disease Publishing Co., 1934.

61. Morgan, John J. B. The Psychology of Abnormal Poople. New York: Longmans, Green and Co., 1948.

62. The Psychology of the Unedjusted School Child. New York: The MacMilian Co., 1937.

63. Mower, 0. H. "What is Normal Behavior." (In) Pennington, L. A., and Berg, I. A. An Introduction to Clinical Psychology. New York: Ronald Bress, 1948.

64. Munroe, Ruth I. "An Experiment in Large-Scale Testing by a Modification of the Rorschach Method." J. Psychol., 1942, 13: 229-263.

65. Pnediction of the Adjus tment and Academic Performance of Colloge Students by a Modification of the Rorschach Method. Psychol. Monogr. No. 7, Stanford, California: Stanford University Press, 1945.

66. Northway, M. I, "outsiders: A study of the Personality Patterns of Children Least Acceptable to Their Age Mater." Soctometry, 1944, 7: 10-25.

67. 01son W. C. The Measurement, of Nervous Habits In Normel.

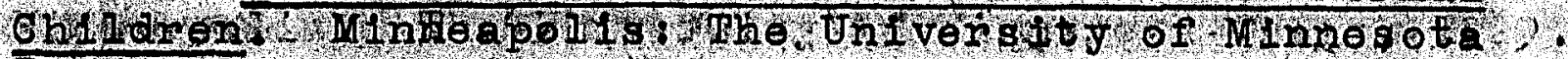
Pross, 1929. 
68. Reports. - "The Waiver of Signature in Personal

69. Parten, M. B, "Soclal Participation Among Pre-Schoolchildren, I6 abnorm. soc. Psychol., 1932, 27: 243-269.

70. Peters, C. C. "Validity of Personality Inventorles Studied by a 'Guess Who' Technique." Psychol. Bull., 1940, $37: 453$.

71. , and Van Voorhis, W. R. Statistical Procedures and Their Mathematical Bases. NeW York: McGraw-Hill, 1940 .

72. Powell, Lee, and Laslett, H. R. "A Survey of the Social Development of the 10th, 1lth, and 12 th Grade Puplls in a Small High School." J. exp. Educ., 1940-41, 9: $361-363$.

73. Rafferty, J. E. A Study of the Incomplete Sentence Method of Personality Investigation Applied to College Men. Unpubilshed M. A. Thes1s, 0. S. U., 1947.

74. Rapaport, David, Gill, M., and Schafer, R. Diagnostic Psychological Testing. Chicago: Yearbook Publishers, Inc., 1946 .

75. Rhode, A. R. "Explorations in Personality by the Sentence Completion Method." J. appl. Psycho1., 1946, 30: 169-181.

75. Richards, W. T. Modern Clinical Psychology. New York: MeGraw-Hill Book Co., 1946 .

77. Richardson, L. H. "The Personality of Stutterers." Psychol. Monogr. 1944, Vol. 56, No. 260.

78. Robinson, F. P. Principles and Procedures in Student Counseling. New York: Harper \& Bros., 1950.

79. Rogers, Carl R. Counseling and Psychotherapy- Chlcago: Houghton-Mifflin Co., 1942 .

80. Health Problems." Educ. Res. Bul1., 1942-21: $29-40$.

81. Rorschach, Herman. Psychodiagnostics. Translated by Lemkau, P., and Kronenberg, Bd, Berne, Switzerland: Verlag Hans Huber, 1942 . 
82. Rosenwald, A. "The California Personality Scale as a Diagnostic Instrument." Psychol. Bull., 1942, 39, 599.

83. Ross, C. C. Measurement in Today's Schools. New York: Prentice-HaI1, Inc., 1947.

84. Rotter, J. B., and Willerman, B. "The Incomplete Sentence Test as a Method of Studying Personality." J. Consult. Psychol. 1947, 11: 43-48.

85. Sanford, R. N. "Personality Patterns in School Children." (In) Barker, R. G., Kounin, J. S., and Wright, H. F.: Child Behavior and Development. New York: MeGrawH111, 1943, 567-589.

86. ot al. Physique, Personality, and Scholarship. Monograph of the society for Research In Child Development, 1943, Vol. VIII. No. 1: 125-361.

87. Shaffer, L. F. The Psychology of Adjustment. Chicago: Houghton-Miffin Co., 1936.

88. Shneldman, Edwin S. "A Note on the Experimental Study of the Appraisal Interviow." J. appl. Psychol., 1943, 27: $196-205$.

89. Smlth, Eugene R., Tyler, Ralph W,, and the Evaluation Staff. Appraising and Recording Student Progress. Now York: Harpor \& Bros., 1942.,

90. Spinelle, Leo, and Nemzik, Claude L. "The Relationship of Personality Test Scores to School Marks and Intelligence Quotients." J. soc. Psychol., 1944, 20: $289-294$.

91. Stroud, James B. Psychology in Education. New York: Longmans, Green and Co., 1946 .

92. Super, Donald E. Appra1sing Vocational Fitness by Means of Psychological Tests. New York: Harper \& Bros., 1949.

93. Symonds, P. M. Adolescent Fantesy. New York: Columbia University Pross, 1949.

94. __ The Dynamios of Human Adjus tment. New York: Appieton- Century - Crofts, 1946 .

95. ___ and Jackson, C. E. "An Ad jus tment survey." J. educ. Res., 1930, 21: 321-330. 
96. Terman, Lewis M. and MIles, Maud A. Measuring Intelilgence. Boston: Houghton-Miffiln Co., 1937.

97. Thomas, D. S. "An Attempt to Develop Prociso Measurements In the Soclal Behavior Fleld." Soclologus, 1932, 8: 455-456.

98. Toops, Herbert A. "Some Possibilities of Statistical Analys is Rendered Possible by Recent Applications of Punched Card and Sorting Equipment, " Ohio College Assoclation Bulletin, No. 131, Columbus, oh10: Ohio state University, 2508-2514.

99. Traxler, Arthur E. Techniques of Guldance. New York: Harper \& Bros., 1945.

100. Tryon, C. M. Evaluation of Adolescent Personality by Adolescents. Monograph of the Soclety for Research in Child Development, 1939, Vol. IV, No. 4: 83.

101. Tschechtelin, Sister Mary A. "Comparability of ChIld and Adult Personality Rating Scales." J. educ. Pstchol., 1944.

102. Tyson, Robert. "Current Mental Hyglene Practice." J. clin. Psychol., 1951, 7: 1-90.

103. Washburne, John W. "Factors Related to the Social Ad justment of Colloge Girls." J. soc. Psychol., 1941, $13:-281-289$.

104. Wechsler, David. "Cognitive, Conative, and Non-Intellective Intelligence." Amer. Psychologist, 1950, 5: 78-83.

105. Wittman, M. P., and Huffman, A. V. "A Comparative Study of Developmental Adjustment, and Perso nality Characterlstics of Psychotic, Psychoneurot1c, Delinquent, and Normally Adjusted Teen-Age Youths." J. genet. Psychol., 1945, 66: 167-182. 


\section{APPENDIX}

$$
287
$$


CALIFORNIA TEST OF PERSONALITY-SECONDARY, FORM A A PROFILE OF PERSONAL AND SOCIAL ADJUSTMENT

Devised by Ernest W. Tiegs, Willis W. Clark, and Louis P. Thorpe

\begin{tabular}{|c|}
\hline ...Birthdoy \\
\hline Date \\
\hline $\begin{array}{l}\text { PERCENTILE } \\
\text { (Chart student's percentile rants here) }\end{array}$ \\
\hline$-C-1 C^{10}$ \\
\hline 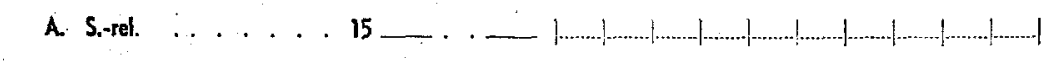 \\
\hline 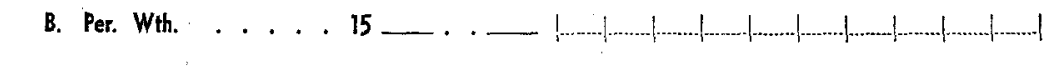 \\
\hline 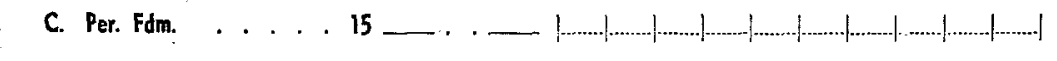 \\
\hline 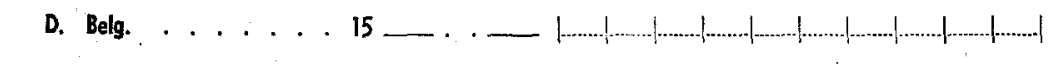 \\
\hline 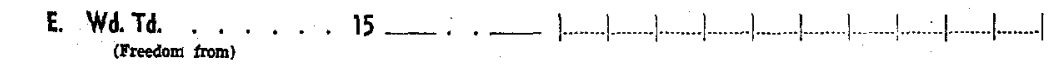 \\
\hline$-1-1+1+1+1+1+1$ \\
\hline-1 \\
\hline 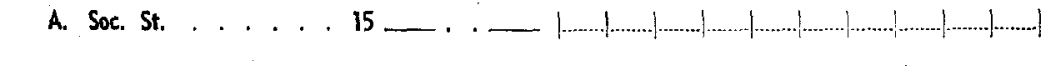 \\
\hline 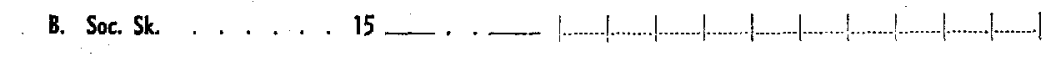 \\
\hline 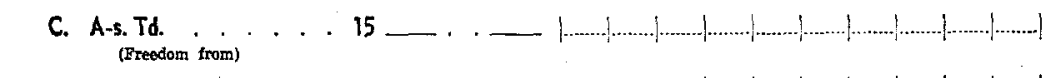 \\
\hline 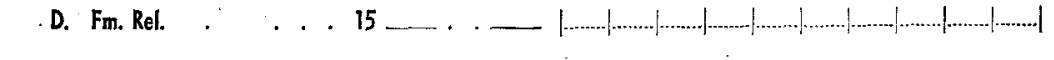 \\
\hline 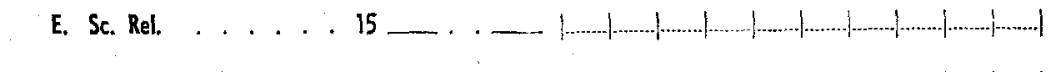 \\
\hline 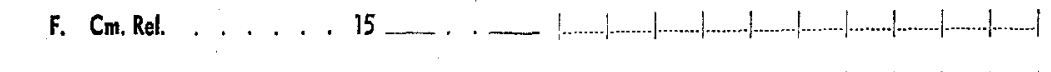 \\
\hline$--_{10}$ \\
\hline
\end{tabular}

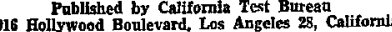




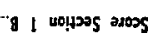

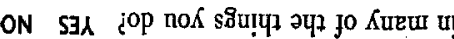

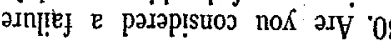

ON SBX

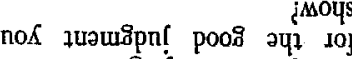

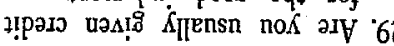

ON SBA ¿P[noys Кәчз se sutpuets je!ros Inoर วz!U

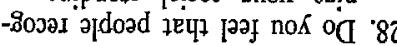

ON $S$

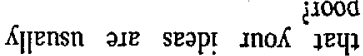
yuryt of waวs spuraly InoS of $\angle 2$

ON $53 x$

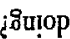
วIE noא sâuly วदा uा paisว

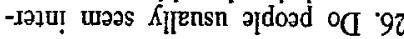

ON SIX ¿ุก

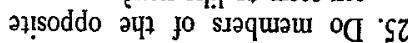

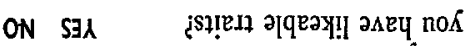

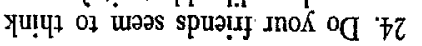

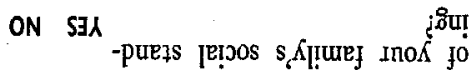

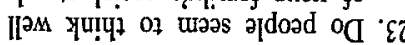

ON SYR

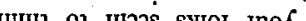

ON S3X pue spuauly inox fo 7 sour of

ON $23 \lambda$ jexpluted je!jos

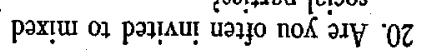

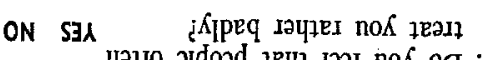

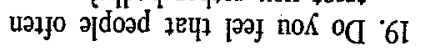

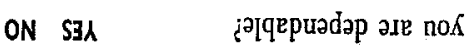

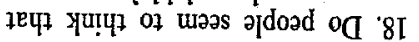

ON SAג ißjuou sutipueq te poos KraA

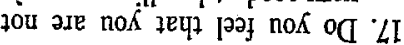

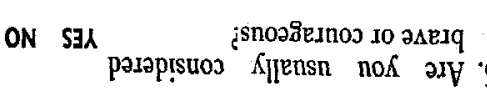

g ! NOILOJS $-\varepsilon-$

ON S3A

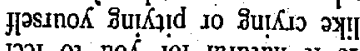

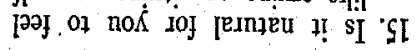

ON 5 inok

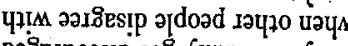

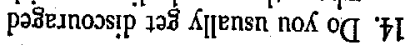

ON S3A ¿MOUY tou op noא

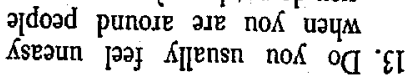

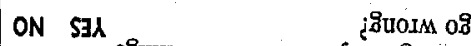

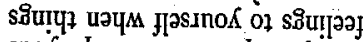

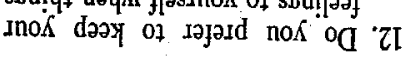

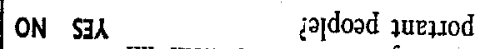

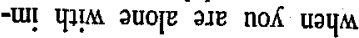

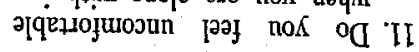

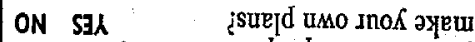
of ury asodord spuau Ino

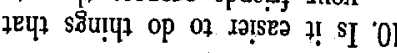

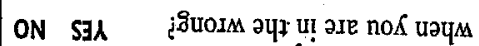

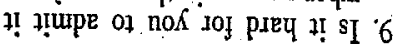

ON SAג

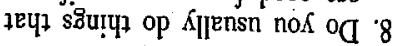

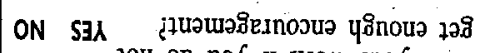
tou op noא J! YHOM INOK पIIM uo os oi noא dof prey

ON SFג

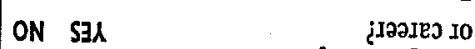

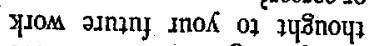
ә

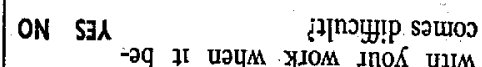

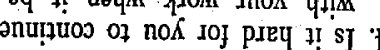

ON SIA दəवdoəd $K q$ passoq sulaq worj

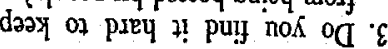

ON SER tadoad ol pasnponatu aq 10

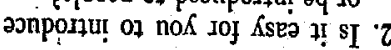

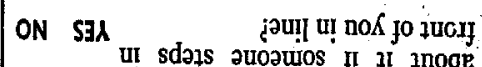

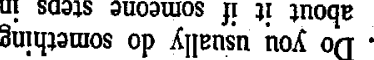

Y I NOILJAS

$-z$

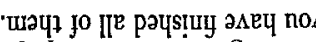

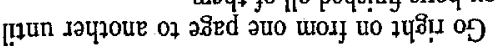

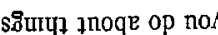

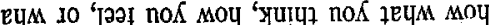

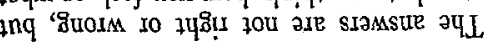

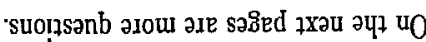

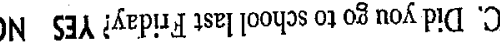

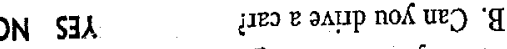

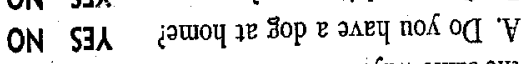
KeM әures วџฺ

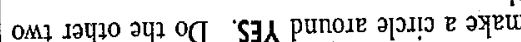

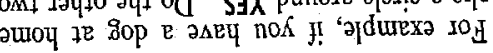

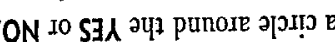

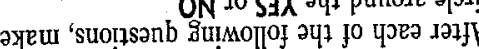

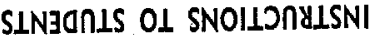

\section{INTERESTS AND ACTIVITIES}

First look at each thing in this test. Make a circle around the $L$ for each thing that you like or would very much like to do. Then make a circle around the $D$ for things you really do.

\section{L D Play the radio \\ 2 LD Read stories \\ 3. LD Go to movies \\ 4. LD Read comic strips \\ 5. LD Work problems \\ 6. LD Study history \\ 7. LD Study science \\ 8. LD Study literature \\ 9. LD Do cross-word puzzles}

10. LD Study trees

11. L D Study birds

12. LD Study animals

13. LD Study butterflies

14. LD Draw or paint

15. LD Work in laboratory

16. LD Model or design

17. LD Do housework

18. LD Sing

19. LD Play piano

20. LD Make a scrapbook

21. LD Keep a diary

22. L D Write poems

23. LD Speak pieces

24. LD Play an instrument

25. LD Visit museums

26. L D Collects stamps
27. L D Collect coins

28. LD Collect autograph

29. LD Collect pictures

30. LD Use a camera

31. LD Sew or knit

32. LD Repair things

33. LD Make boats

34. LD Make airplanes

35. LD Make a radio

36. LD Work with tools

37. LD Have a garden

38. LD Drive an automobile

39. LD Play with pets

40. LD Raise animals

41. LD Go fishing

42. L. D Climb or hike

43. LD Skate

44. L D Ride a bicycle

45. LD Ride a horse

46. LD Practice first aid

47. L D Play cards

48. LD Play dominoes

49. LD Play checkers

50. LD Play chess
51. LD Go to church

52. LD Go to Sunday School

53. LD Belong to a club 54. LD Belong to YMCA or YWCA

55. LD Go to parks

56. LD Engage in sports

57. LD Go to a circus

5. LD Sing in a chorus

59. LD Sing in a glee club

60. LD Belong to a gang

61. LD Play ping pong

62. LD Play croquet

63. LD Play baseball

64. LD Play tennis

65. LD Go hunting

66. LD Go riding with others

67. LD Play in band

68. L. D Play in an orchestra

69. LD Go to church socials

70. LD So to parties

71. LD Go to dances

72. LD Be an officer of a club

73. LD Be a class officer

74. LD Go camping 


\section{SECTION I C}

31. Do you have enough time for play or recreation?

32. Do you have to do what other people tell you to do most of the time?

33. Do you work to earn part or all of your spending money? YES NO

34. Do your folks give you a reasonable amount of spending money?

35. Are you scolded for many little things that do not amount to much?

36. Do you feel that you are given enough liberty in doing what you want to do?

37. Do you sometimes go out with members of the opposite sex?

38. Are you allowed to say what you believe about things?

39. Do your folks often try to stop you from going around with your friends?

Do your parents cause you embarrassment when you associate with the opposite sex?

46. Do you feel that you are an important part of your school? YES NO

47. Do your teachers seem to want you in their classes? as those of your friends?

49. Do your friends and acquaintances seem to have a better time at home than you do? YES NO

50 Do the people at home make you feel that you are an important part of the family?.

51. Are you regarded as being as healthy and strong as most of your friends and classmates?

52. Have you often wished that you had different parents than you have?

53. If you are a young man, are you liked by the young women? If you are a young woman, do the young men like you?

YES NO 54. Have you found it difficult to make as many friends as you wish?

41. Do you feel that you are bossed around too much by your folks?

42. Are you usually allowed freedom to attend the socials or shows that you like?

43. Are you usually allowed to bring your friends to your home when you wish?

44. Are you encouraged to help plan your future vocation or career?

45. Are you free to go to interesting places during your spare time?

55. Are you well enough liked at home so that you feel happy there?

56. Are you invited to groups in which both young men and women are present?

57. Do you have enough friends to make you feel good?

58. Do you feel that you fit well into the community in which you live?

59. Do you feel that your classmates are glad to have you as member of their school?

60. Do you feel that people usually think well of you?
48. Do you feel that your relatives are as attractive and successful

-67. Do you often feel lonesome
Somenestion $1 \mathrm{C}$

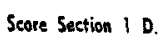

61. Are certain people so unreasonable that you can't help but hate them?

62. Do you find it more pleasant to think about desired successes than to work for them? YES NO

63. Do you find that many people seem perfectly willing to take advantage of you?

64. Do you have many problems that cause you a great deal of worry?

65. Do you find it hard to meet people at social affairs?

66. Are your responsibilities and problems often such that you cannot help but get discouraged? even when you are with peo ple?

68. Do you think that most people are out to cheat or "put it over" their associates?

69. Do you find many people inclined to say and do things that hurt your feelings?

76. Are you likely to stutter when you get worried or excited? YES NO

77. Do your muscles twitch some of the time?

YES NO

78. Do you have the habit of biting your fingernails often?

79. Do you sometimes have nightmares?

80. Do you sometimes walk or talk in your sleep?

81. Do you suffer often from annoying eyestrain?

82. Is it hard for you to sit still? YES NO

83. Are you more restless than most people?

84. Are you inclined to drum restlessly with your fingers on tables, desks, and chairs? YES NO . Are you sorry that you are continually growing odder?

85. Do people frequently speak so indistinctly that you have to ask them to repeat their questions?

71. Do you find it difficult to overcome the feeling that you are inferior to others?

86. Do you frequently find that you read several sentences without realizing what they are about? $\quad$ YES NO

72. Do you find it difficult to associate with the opposite sex?

73. Does it seem to you that younger persons have an easier and more enjoyable life than you do?

87. Do you find that you are tired a great deal of the time? YES NO

88. Do you often have considerable difficulty in going to sleep? YES ND

74. Do you often feel that people do not appreciate you or treat you as they should?

75. Are people frequently so unkind or unfair to you that you feel like crying?

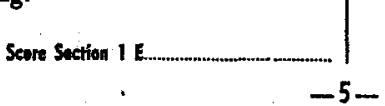

89. Do you have frequent headaches for which there seems to be no cause?

90. Are you bothered by periodic dizzy spells? 
91. Is it right to create a scene in order to get your own way? YES NO

92. Is it all right to avoid responsibility or work if you are not required to do it?

93. Is it necessary to be especially friendly to new students?

94. If they look funny enough, is it all right to laugh at peopl who are in trouble?

95. Should students follow their parents' instructions even though their friends advise differently?

96. Is it always necessary to express appreciation for help or parors?

97. Does finding an article give a person the right to keep or sell

98. Is it all right to ignore teachers' requests if they appear to be unfair?

YES NO

99. If you need something badly enough and cannot buy it, are there times when it is all right to take it?

100. Is it all right to cheat in a game when you will not get caught?

101. Do rich people deserve better treatment than poor ones?

102. Should a person be courteous to disagreeable people?

Are the beliefs of some people so absurd that it is all right to make fun of them?

Do older or elderly people deserve any special help not given others?

Is it necessary to obey "No Trespassing" signs?
106. Do you often introduce people to each other?

107. Is it hard for you to lead in enlivening a dull party?

108. Is it easy for you to talk with people as soon as you meet

109. Is it difficult for you to compliment people when they do something well?

110. Do you often assist in planning parties?

111. Do you usually remember the names of people you meet? YES NO

112. Do you keep from letting people know when they irritate you?

113. Do you frequently find it necessary to interrupt a conversation?

114. Do you find that it causes you trouble when you help others? YES NO

115. Do you attempt new games at parties even when you haven't played them before?

116. Do you have many friends rather than just a few?

117. Do you find that members of the opposite sex appear at ease when chatting with you? YES NO

118. Do you like to have parties at your home?

119. Do you find it hard to help others have a good time at parties?

120. Do you find that many people are easily offended by you? " YES NO
121. Are you justified in taking things that are denied you by unreasonable people?

122. Do you have to stand up for your rights?

123. Are you often forced to show some temper in order to what is coming to you?

124. Do you often have to make your classmates do things that they don't want to do?

125. Are people often so stubborn that you have to call them bad names?

126. Do you find it easy to get out of troubles by telling "white fibs"?

127. Do you sometimes think that it serves the school right if you break a few of their things?

128. Do you have to talk about yourself and your abilities in order to get recognition?

129. Are things frequently so bad at school that you just naturally stay away?

130. Are teachers and other people often so unfair that you do not obey thein?

131. Do you often have to fight or quarrel in order to get your rights?

132. Are people often so thoughtless of you that you have right to be spiteful to them?

133. Do little "kids" often get in your way so that you have to push or frighten them?

134. Are people at home or at school always bothering you so that you just have to quarrel? YES NO

135. Have things been so bad at home that you have had to run away?
SECTION 20

136. Are you troubled because your parents are not congenial?

Yes

137. Do the members of your family frequently have good times together?

138. Do your folks seem to believe that you are not thoughtful of them?

139. Are there things about one or both of your folks that annoy you? because your folks are usually short of money?

YES No 141. Are you troubled because your folks differ from you regarding the things you like? ${ }^{\text {YES NO }}$

YES NO 142. Do your folks appear to doubt whether you will be successful? YES NO

143. Does someone at your home quarrel with you too much of the time?

YES NO 144. Do you like your parents about equally?

145. Do the members of your family seem to criticize you a lot?

146. Do you usually like to be somewhere else than at home?

147. Do you avoid inviting others to your home because it is not as nice as theirs?

148. Do some of those at home seem to think they are better than you?

149. Are your folks reasonable to you when they demand obedience?

150. Do you sometimes feel like leaving your home for good? YES NO
YES NO 140. Are things difficult for you
Score Section $2 \mathrm{C}$ 
difficult that you may be in. danger of failing?

bility for the welfare or safety

of children or old persons? YES NO

152. Do you find that you can confide in at least one of your teachers?

167. Do you like to take care of your own or some neighbor's pets?

153. Would you like to be chosen more often to take part in games and other activities?

168. Are there any attractive members of the opposite sex in your neighborhood? YES NO

154. If it were right would you stay away from school as often as possible?

169. Do you know people who are so annoying that you would like to molest them?

155. Would you and your classmates like school better if teachers were not so strict?

156. Would you be happier if your classmates liked you better? YES NO

157. Does it seem to you that many of your teachers are nervous? YES No

170. Do you often play games with friends in your neighborhood? YES NO

171. Does it make you happy to know that your neighbors are getting along well?

172. Are there people of certain races that one should not be expected to tolerate?

158. Do many of the teachers seem to be unfair or unreasonable to their students?

159. Do you like to go to school affairs with members of the opposite sex?

160. Do you find that classmates of the opposite sex are as nice as those of your own sex?

161. Do you enjoy being alone more than being with your classmates?

173. Do you live in a rather uninteresting neighborhood?

174. Are the police officers of such a character that you would like to help them?

175. Do you visit with several young men and women in your neighborhood?

176. Do you sometimes go to neighborhood affairs with members of the opposite sex?

162. Are your classmates usually friendly to you?

YES NO 17. Do you ever do anything to your home surroundings? YES NO

163. Do your classmates seem to approve of the way you treat them?

178. Are many of your neighbors the kind of people you dislike? YES NO

164. Are many of your classmates so unkind or unfriendly that you avoid them?

179. Do you usually speak to both young men and young women in your neighborhood?

180. Are most of the people in your community the kind you refrain from visiting young men and women from enjoying each other's company? YES NO

Score Section $2 F$ 


\section{MANUAL OF DIRECTIONS \\ CALIFORNIA TEST OF PERSONALITY_SECONDARY SERIES}

A Profile of Personal and Social Adjustment

Devised by Ernest W. Tiegs, Willis W. Clark, and Louis P. Thorpe'

CONTENTS

I. PURPOSE of THE TEST $\ldots \ldots 1$

II. NATURE of the TEST $\ldots \ldots, 2$

III. RELLABLITY . . . . . . . 4

IV. $\nabla_{\text {ALDTIY }} \ldots \ldots \ldots \ldots$

V. The ImTterritzd Presowaltry . . : 5

VI. Directions gor Administerning . . . 5

VII. Dirkctions for Sconnas . . . . : 5

VIII. Directions gor Recording AND

Canating Scores and Percentules 6

IX. DirkCtions FOR INTERPRETTSG

Proflies and Gudnag Adjustmant 6

$X$ Dirgctions for Cagertwa Divergent

Profles . . . . . . . . 12

XI. INTERRSTS AND ACTVITIES . . . . 13

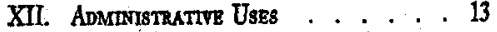

XIII. Percentme Nokms . . . . . . 14

THE AUTHORS

ERNSST W. MEGS, PhD, (Minnesota). Edititor-in-Chiet,

Calitomina Test Burrean Formerly: Dean of Universt

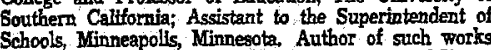

is Tests and Meesuruements for Teachers; Tests and Meass wrements in the limprovement of Leanuming Progressive Acli
Mental Maturlty.

WTLLUS W. CLARK, EdD. (Southern Califormia). Director of Research and Technical Services, California Te

search and Guidane, Los Angeles City Schools. Autho

and co-author of pamerous researces studies and such

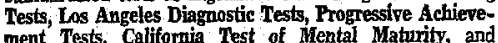

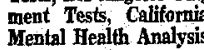

LOUIS P. THORPE, PhD. (Northwestern). Professor of Eduction and Psychology, and formerly Director of the fornia. Author of Psychological Foundations of Pessonalty and Life; author of numerous articles on

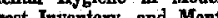
Health Analysis
Port I. Purpose of the Test

The California Test of Personality has been designd to identify and reveal the status of certain highly mportant factors in personality and social adjustment

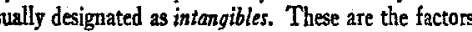
that defy appraisal or diagnosis by means of ordinary ability and achievement tests. Measurements of capacity, skill, and achievement, important as they are, do not constitute a complete picture of a functioning personality. When the teacher has, in addition to the above, in a variety of situations which vitally affect him as an individual or as a member of a group, he can use this more complete picture to guide him to better personal and social adjustment.

From one standpoint, use of the term personality is unfortunate. Personality is not something separate and apart from ability or achievement but includes them it refers rather to the manner and effectiveness with which the whole individual meets his personal and social prob. his fellows. The individual's ability and past achievements are always an inevitable part of his current attempts to deal with his problems intelligently. Since tests of ability and achievement are already available, the term personality test (measure, inventory, of profile) has become attached to instruments for identifying and evaluating the more intanglbe elements of total complex patterns of feeling, thinking, and acting.

Insistence on respect for the "wholeness" of the adjusting organism, or guidance of the whole student, represents a major contribution of the moderm movement in education. This personality test is an more easily and effectively approach this desirable goal.

Some of the distinctive features of the California Test of Personality may be stated as follows:

1. The major purpose of the test is to reveal the extent to which the student is adjusting to the problems and cond tons which confont him and is develop. ing a normal, happy, and socill efactive persona 2. The test is divided into two sections. The

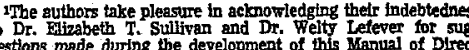

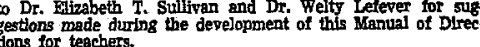

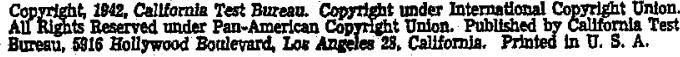


purpose of Section 1 is to indicate how the student feels and thinks about himself, his self-reliance, his o timate of his own worth, his sense of personal freedom, and his teeling of belonging. In this section the studen also reveals certain withdrawing and nervous tendencies which be may possess. Section 2 consists of social adjustment components. Its purpose is to show how th student functions as a social being, his knowledge of social standards, his social skills, his freedom from antisocial tendencies, and his family, school, and commun ity relationships.

An evaluation of these components discloses whether or not the student's basic needs are being met in a amosphere of security and whether he is developing

3. possible to compare and contrast the adjustment pat terns and habits of each student with the characteristic modes of response of large representative groups of simIlar students. The profile thus reveals graphically the points at which a particular student differs from pro sumably desirable patterns of adjustment and which constitute the point of departure for guidance. No computations are necessary on the part of the teacher in completing the profile.

4. This test is based upon a study of over 1000 specific adjustment patterns or modes of response to secific situations which confront students of these ated by other workers. The items finally included in the two sections of the test were selected on the basis of:

a. Judgments of teachers and principals regarding their relative validity and significance.

b. The reactions of students, expressing the extent to which they felt competent and willin to give correct responses.

c. A study of the extent to which student sponses and teacher appraisals agreed.

d. A study of the relative significance of items by means of the bi-serial $r$ technique.

5. In harmony with the generally recognized importance of a well balanced personality, the profile so devised as to in various situations satisfactory significantly, and when chancteristic patron so far from trpical adjustment that ther indieste sible or actual danger.

Part II. Noture of the Test

The California Test of Personality is a teachingleaming or developmental instrument primarily. Its purpose is to provide the data for aiding students to maintain or develop a sane balance between self and social adjustment. Student reactions to items are obtained, not primarily for the usefulness of total of section scores, but to detect the areas and speacific types of tendencies to thinh, feel, and act which rse
veal undesirable individual adjustments.' Each group of related unsatisfactory responses becomes in a sense, therefore, a major objective of etudent guidance Part IX of this Manual presents methods of classifying and treating such adjustment difficulties. This is a unique festure of the test.

The fact that exactly six sub-tests appear in each of the two sections of the test may erroneously sug the with least partially ralidated by other workers. Three of

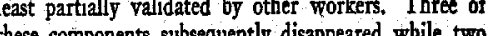
these components sibsequntly disappeared while two therer treated as a single

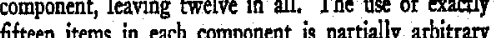
fitten liens in each component is partially arbitrary iod instrument. However, the final selection of items iod instrument. However, the final selection of items of each component was based upou the relative sizes tro, and omitted responses which they received in the tho, and omited resp

Although factor analysis studies of the data so cured though the use of this test have been in prom gress for many months, the factors extracted represent a grouping of tendencies to act which vary considerably from the concepts which abound in the likerature on personality and with which teachers are

From a practical operational standpoint arrived at through experimental tryouts of the test, it has seemed wise to retain familiar terminology in an organization of components based on logical analysis, experience, the judgments of workers in this field and a considerable number of statistical studies.

Factor analysis and other statistical studies are continuing in the hope that as the nature of these personality factors becomes better known to investigators and teachers alike, their component designacions and profile organization may increasingly approach the realities which they seek to represent. The differentiation of personality and social adjustment into twelve more or less well defined compo(Contizued on page four)

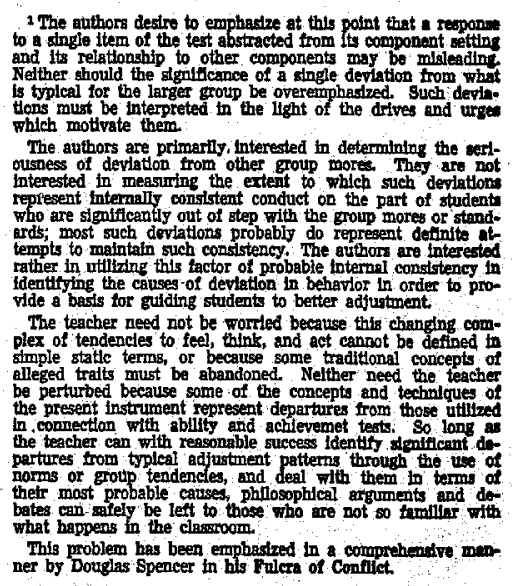

\section{SECONDARY SERIES}

SCORING KEY_FORM A

\section{CALIFORNIA TEST OF PERSONALITY}

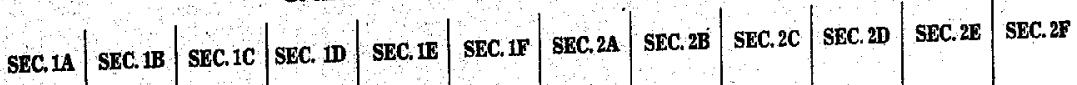
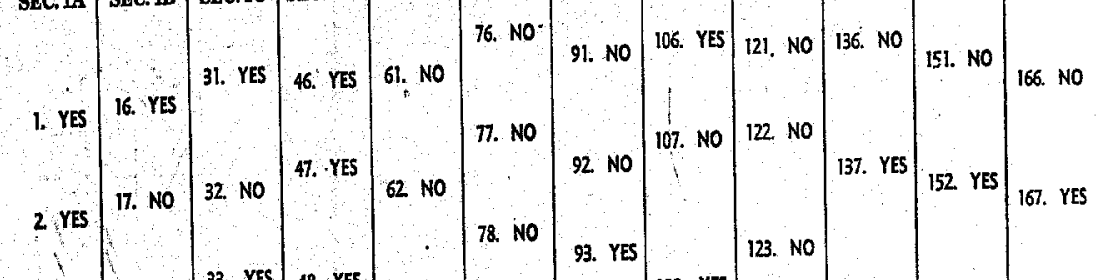

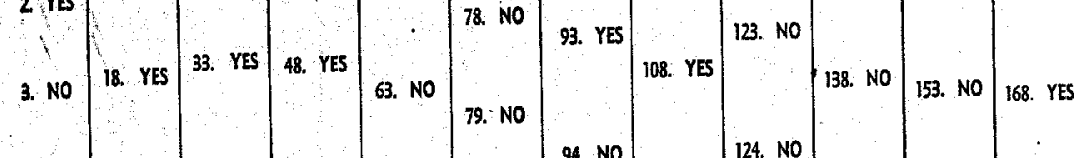

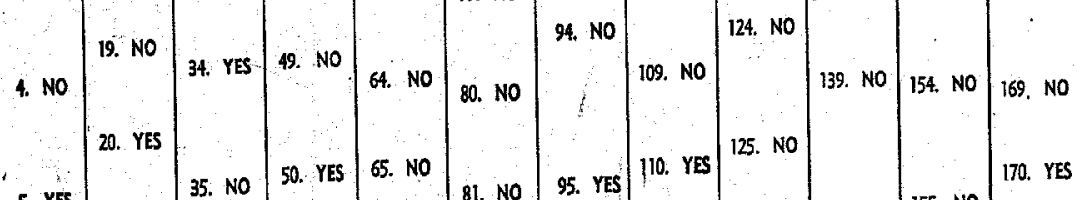

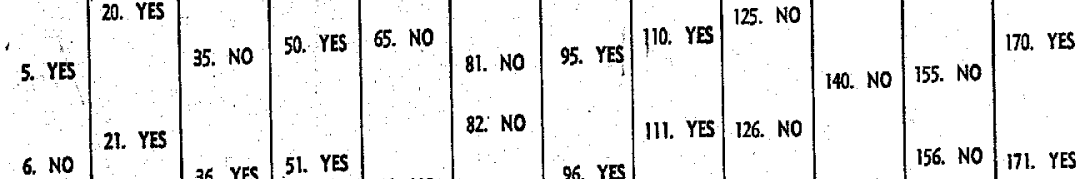

6. NO ${ }^{21 .}$ YES
36. YES

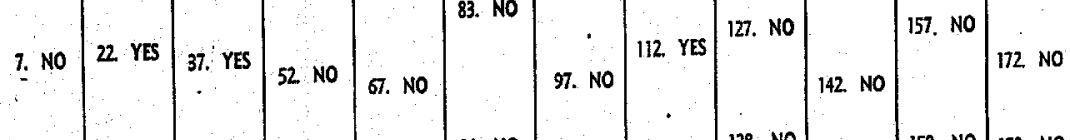

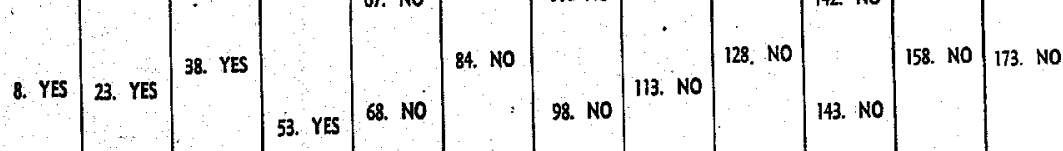

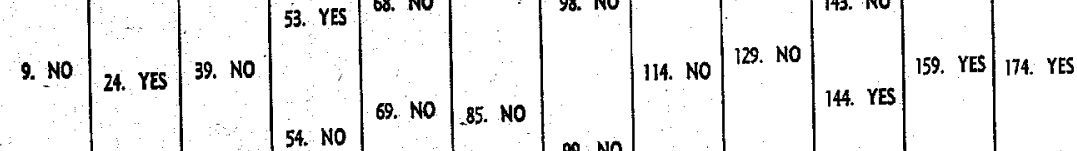

10. NO 25. YES 40 NO

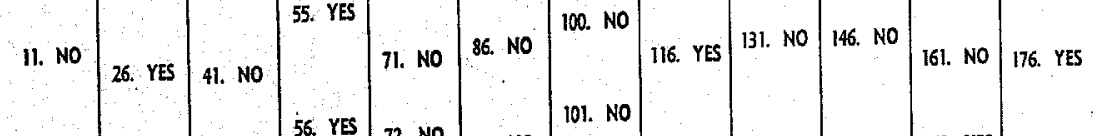

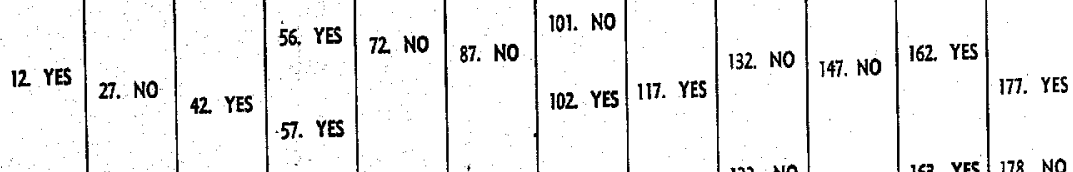

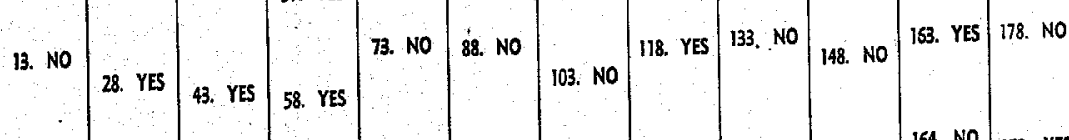

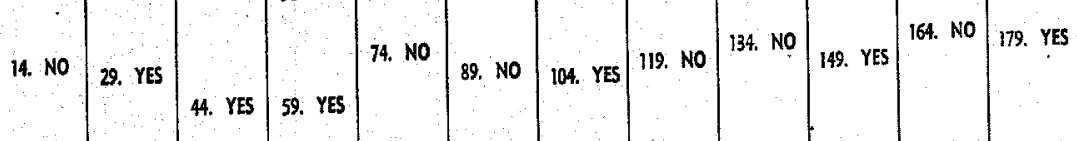

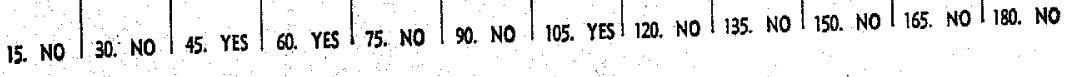

Publlshed by Callfomla Test Burean
5916 Bollywood Bouleverd, Los Angeles 28, Calliomia 
ORGANIZATION OF THE CALIFORNIA TEST OF PERSONALITY

\begin{tabular}{|c|c|c|}
\hline $\begin{array}{l}\text { E ADJUSTMENT: } \\
\text { A balance } \\
\text { Ween self and } \\
\text { ial adjustment }\end{array}$ & $\begin{array}{l}2 \text { Social Adjustment: Based on } \\
\text { feelings of social security }\end{array}$ & $\begin{array}{l}\text { A. Self-reliance } \\
\text { B. Sense of Personal Worth } \\
\text { C. Sense of Personal Freedom } \\
\text { D. Feeling of Belonging } \\
\text { E. Freedom from Withdrowing Tendencies } \\
\text { F. Freedom from Nerrous Symptoms } \\
\text { A. Social Standards } \\
\text { B. Social Skills } \\
\text { C. Freedom from Anti-social Tendencies } \\
\text { D. Family Relations } \\
\text { E. School Relations } \\
\text { F. Community Relations }\end{array}$ \\
\hline
\end{tabular}

BRIEF DEFINITIONS OF THE VARIOUS COMPONENTS

1A. Self-reliance-A student may be said to be selfreliant when his actual actions indicate that he can do things independently of others, depend upon himself in

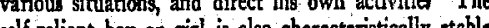
reli-reliant boy or girl is also characteristictly

1B. Sense of Personal Worth-A student poseases a sense of being worthy when be feels he is well regardsense of being worthy when the Feels he is well regarded by others, when he feels that others have faith in his future success, and when he belicves that he has average teel capable and reasonably. To ted

1C. Sense of Personal Freedom-A student enjoys a sense of freedom when he is permitted to have a rezsonable share in the determination of his conduct and in setting the general policies that shall govern his life. Desirable freedom includes permission to choose one's own friends and to have at least a little spending money.

ID. Feeling of Belonging-A student feels that he belongs when he enjoys the love of his family, the well-wishes of good triends; and a cordial relationship with peple in gereal. Such a student will as a rele get along well with

IE. Withdrawing Tendencies-The student who is said to withdraw is the one who substitutes the joys of a fantasy world for actual successes in real life Such a person is characteristically sensitive lonely, and ouch to self-concern. Normal adjustment is characterized by reasonable freedom from these tendencies

IF. Nervous Symptoms - The student who is ulassified as having nervous symptoms is the one who suffers from one or more of a yariety of physical symptoms such as loss of appetite, frequent ere strain, inability to seep, or a tendency to be chronically tired. Persons of his kind may be

2A. Sociol Stondards-The student who recoguizes desirable sacial standards is the one who bas come to understand the rights of others and who apprecintes the necessity of subordinating certain desires to the

needs of the group. Such a person understands what is regarded as being right or wrong.

2B. Social Skills-A student may be said to be socially skillul or effective when he shows 2 liking for people, when he inconveniences himself to be of assistance to them, and when he is diplomatic in his dealings with both irends and strangers. The socially skillful student subordinates his egoistic tendencies in favor of interest in the problems and activities of his associates.

2C. Anti-social Tendencies-A student would normally be regarded as anti-social when he is given to bullying, frequent quarreling, disobedience, and do structiveness to property. The anti-social person who endeavors to get his satisfaction from these tendencies.

20. Family Relations-The student who exhibits desirable family relationships is the one who feels that he is lored and well-treated at home, and who has a sense of security and self-respect in connection with the parious members of his family. Superior family relation also include parental control that is neither too strict nor too lenient. 2E. School Relations-The student who is satisfacteachers like him who enjoys other students, and who finds the school work adapted to his level of interest and maturity. Good school relations involve the feding on the part of the individual that he counts for some thing in the life of the institution.

2F. Community Relations-The student who may be said to be making good adjustments in his community is the one who mingles happily with his neighbors, who takes pride in community improvements, and who is tolerant in dealing with both strangers and foreign ers. Satisfactory community relations include as well the disposition to be respectful of laws and of regula tions pertaining to the general welfare.

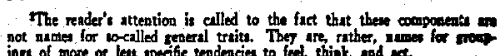


nents as a basis for diagnosis and guidance represents, in itself, a wide departure as well as a significant challenge for teachers. Such a treatment should result in an
increasingly sympathetic and intelligent handling of adjustment problems.

\section{Part III. Reliability}

Certain outcomes such as knowledges, understandings, and skills, once attained, remain relatively stabl and tests designed to reveal their presence may possess dent, on the dent, on the other hand, is a growing organism whose integration mast be presed a ance with his experiences Some of the items of this ance with his experiences. Some of the items of this areas and such soupont attitudes areas, and such student attitudes mas change in a reatively short otime. For these and other reasons, the will sometimes appear to be somewhat lower then will sometimes appear to be somewhat lower

However, the reliability of the Califormia Test of Personality does not suffer by comparison with man widely used tests of mertal ability and school achievement. The following correlations were obtained with 558 cases by the split-halves method corrected by the Spearnan-Brown formula:

S.D. dist. P.E. est

Total Adjustment $\quad \begin{array}{lll}r & \text { score } & \text { scare } \\ -\ldots . . . & 19.9 & 3.5\end{array}$

Sec. 1. Self Adjustment. $904 \cdot 11.5 \quad 24$

Sec. 2. Social Adjustm't .908 $\quad 10.0 \quad 2.0$

The correlation between Section 1 and Section 2 54, is sufficiently low to emphasize the desirability of studying the student from the standpoint of both self adjustment and social adjustment. The reliabilities of the component tests vary from .60 to .87 and are thus oufficientily hight to locate more restricted areas of personality difficulty. After these areas have been located, the teacher may proceed to identify specific adjustment difficulties as indicated in Part IX.

Part IV. Validity The validity of any instrument is dependent not only
upon its intrinsic nature but also upon the manner in upon its intrinsic nature but also upon the manner in
which it is to be used. The latter point is an important consideration in the validation of instruments in the personality feld. Among the factors of that are related to the validity of the present test are the following:
A. Selection of Items
B. The Personality Components
C. Test Item Disguise
D. Limitations

Each of these factors will receive brief consideration.
A. Selection of Itoms

Adequate selection of test items is, in general, the best guarantee of the validity of any testing instrument. Attention has already been called to the manner in which reactions of stidents, teachers, and principals other tests, and statistical techniques were utilized in the process of validation of the California Test of Personality.

B. The Personality Components

The twelve components mentioned in Part I and presented in Part II of this Manual represent functionally related groups of crucial, specific evidences of passonal or social adjustment, heir names correspond ality adjust rew ad and development. The items of each com powth and development. The items of each component represent fundamental action patterns. The the unity or "wholeness". of normal individuals the unity or "wholeness" of normal individuals ase not mutually exclusire.

\section{c. Test Item Disguise}

The authors have been sensitive to the tendency of some students to paint self-portraits which are better than the originals. They have attempted to nullif the effects of these tendences in two ways; namely, by disguising as many items as possible which might conflict with the student's tendency to protect himself an by providing outaide checting devices as indicated in Part $\mathbf{X}$.

The authors do not ask, "Do you play truant?" but rather, "Are things frequently so bad at school that you just naturally stay away?" They do not ask, "Do you quarrel or are you quarressome?" but, "Does some one at your home quarrel with you too much of the time?. Such disguised itema do not tempt the student to detect their purpose by asking, "Are you too sersitive "but instead ast, "Do rou find many people in-

In many such instances the facts about a student's djustment are not as important as the way he feels and what he believes concerning them, since such be liefs and feelings are frequently the keys to his intimate ality status, as well as to his possible improve-

D. Limitations

Practical considerations have limited the test to one hundred and eighty iems. Many others might have been used to obtain a more complete sampling. How ever, it is possible that a carefur selection of items has produced a relatively short instrument which is as reliable and useful as one of greater length.

Language difficulties may affect the usefulness of tests and personality profiles. In spite of the safeguards used, the present test probably has not escaped the inluence pot will, no doubt, result in interpretations somewhat at variance from those intended. The varying languag abilities of students may also produce discrepancies in understanding and response, Changing attitudes an a lack of self-knowledge are other problems which must be faced. However, the authors have exaluated the langiage of these tests by means of the Leweren Vocabulary Grade Placenent Formula, teacher reactions, and student responses, and bave, in general, kep the language diffculties at or below the seventh grade level of difficulty.

Part V. The Integrated Personality The authors wish to re-emphasize the desirabilit of interpreting and aiding the student in terms of an of interpreting and aiding the strdent in terms of an essecticts or this reason, interpretations of profle data should be made and plans for personalify improvement should be projected, not only in tems of the testimony of the test ing to defeat adequate adjustment.

Mental deficiency or mental immaturity may be productive of many types of difficulties. Inability to read or to succeed in some other type of school activit may create conflicts which encourase the development of various kinds of defense mechanisms. These diffculties frequently first come to the attention of the teacher in such forms of misbehavior as negativism, day-dreaming ego-centrism, ot other unsatisfactor detours around the problems of a too complex educa tional environment. Many of the apparently physica difficulties of students have no observable physical basis. whatsoever but may result from unsatisfactor efforts to solve conflicts which arise because school activities are not in harmony with their interests, needs and capacities.

It is desirable, therefore, that after the test has revealed specific evidences of difficulty; the teacher viev the whole individual in his total environment, as far a possible, before selecting and using the types of remepossible, before selecting and using the types of reme-
dial activities described in Part IX of this Manual.

Part VI. Directions for Administering

The student responses secured in this test are designed to furnish diagnostic information regarding various elements of personality and socjal adjustment. It will be noted that, beginning on page 3 , there are twelve sections with a total of 180 questions. A list of interests and activities is presented on page 2 of the

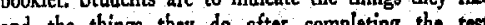
and the thing

There is no time limit for the responses and students should be permitted to answer all items. Ordinarily the responses may be given in one class period of 45 minutes.

Students should have lead pencils and a test booklet. Directions to be given strdents are in black type.
After identifying data are recorded on the front page, state: Open your bookiet and fold back the page to pase 2 (I the prope found page 2.)

Now look at the bottom where it says: "Intructions to Students" After each of the follow ing questions, put a circle around the YES or NO. (Illustrate circle on blackboard if necessary.) Do you have a dog at home? Put a circle around the YES or the NO. Now answer the other questions by putting a circle around the YES or NO.

On the next pages are more questions. The answers are not right or wrong, but show what you think, how you feel, or what you do about things

Go right on from one page to another until yor bave finished them all

An Interests and Activities questionnaire is provided on page 2 . This may be given immediately fo lowing completion of the test or at a later time, if desired. The instructions are: The examiner is to read the directions aloud and explain that student are to draw a circle around " $L$ " for things they like or would like to do. They are to draw a circlo around " $D$ " for the things they really do.

For use of the Interests and Activities questionnaire ee Part XI of this Manual.

Instructions for giving the Test when the Specied Machine Scoring Anwever Sheet is to be used. Read the instructions given on this answer sheet. Do no read the instructions on page 2 of the test booklet

Part VII. Directions for Scoring

Use the answer key which is furnished with the test determine desirable responses in each section of the test. There are fifteen items in each sub-section and the score for each column is the number of student desirable responses with a $\mathrm{C}$.

If erasures or changes are made, consider the intent of the student.

If both YES and NO are marked, or if the answer is omitted, no credit is given.

Needless to say, the scoret should be careful to ux he correct column of the answer key for column

Count the desirable student responses (number of $C^{\prime}$ s) and secord the number on the dotted line at the bottom of each column. 
Part VIII. Directions for Recording and Charting Scores and Percentiles

The steps in recording and summarizing date on the front page of the booklet are as follows:

1. Transfer the section scores of each of the twelve sections to the right of the 15 's in the column headéd "Student's Score."

2. Add the scores of Section I, A-F, to obtain the Self Adjustment Score.

3. Add the scores of Sections II, A-F, to obtain the Social Adjustment Score.

4. Add the Self Adjustment and the Social Adjustment Scores to obtain the Total Adjustment Scote.

5. To determine percentile ranks for each section and for total adjustment refer to the table of percentile tion on page 7).

6. To prepare the chart on the right half of the page, mark with an $x$ the percentile rank for each section and connect these $x$ 's with lines in Sec. 1 and for total a djustment.

Directions for interpretation of these data and for student guidance are given in Part IX. Briefly, it may be stated that maladjustment in the various components is indicated when the student's score is among the lower percentiles, or when the percentile graph tends to the left.

In the event that the examiner believes there are serious divergencies in the profile from observed bebavior, read the comments in Part X.

Part IX. Directions for Interpreting Profiles and Guiding Adjustment Activities

A. Student Adjustment o Problem for All Teachers

Examination of the completed profles for the students of $a$ class will usually reveal the fact that the need for assistance in improving peroonality and social adjustment is not restricted to a limited number of "problem" students; instead, the impact and interaction of environmental factors with individual needs and of environmental factors with individual needs

These adjustment problems vary in complexity. The great majority of them are probably unfortunate babit patterns of feeling and action which must be changed. Others have their origin in physical diffeculties which must be relieved or corrected before re-education is possible. Actual or virtual mental deficiency may account for others. An appreciable number of problems undoubtedly arise from deep-seated canlics which

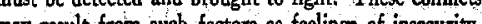
may rest re real or lanced anjury to the indichad or to other, af of school. In some histances lack of adjus inent be he the In the past we have emphasized the achieremen of such more or less academic outcomes as knowledges, appreciations, attitudes, and salls for all students in proportion to their capacities and needs. $A$ better un derstanding of the nature of the student and his problems now leads us in a similar manner to recognize and to meet his needs for assistance in personality develop ment and sacial adjustment. Just as the teacher periodically combines the results of informal observation and tests to evaluate academic achievement, she may now combine informal observation, the testimony of the profile, and other types of evidence to determine individual success or need for assistance in personality problems and social adjustment difficulties

\section{Studying the Profil}

The profile (personality picture) has been divided into twelve aspects or components because these seem to represent the most important identifiable personality and social adyustment areas, An attempt has been made to give these components names which corre 1 a d

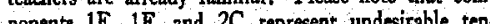

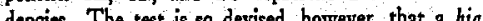

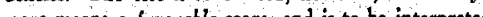
sere toms, and anti-social tendencies.

Each component (self-reliance, for instance) is composed of fifteen personal questions rielding evidences of the presence or absence of an adjustment probiem of its kind. From the profile the teacber first disdeviates seriously from young people in general, Such components may next be examined to discover specific answers which reveal lack of adjustment.

In general, study of the profile results may consist of the following steps:

1. Determining the number of students who deviate seriously in each component. This information will reveal what component areas constitute adjustment problems for the group as a whole.

2. Determining the specific items of each of the above components which are giving diffeulty. These specific difficulties may then be treated as specific clase adjustment problems.

3. Studying the individual profiles which deviate markediy from the general class problems and determining the specific difficulties of each such student.

4. Studying the students' records of interests and activities, both for possible causes of difficultr and for clues to appropriate remedial treatment.

\section{Ganesal Principts of Mathod}

In the past it has been a too common practice, in giving various personality inventorios and interest blanks, to note total or partial scores and then to file these results for future action, which rarely materialized. It has been the purpose of the authors of the

$$
\text { (Gontined on peqp (righ) }
$$

Name 2 telen lonsth

Grade $11-A$

School Lincoln F/gh Age 17 Last Birthday May 14

Teacher.Mos Yrown Date May $19 \% 939$ ex: $M-B$

COMPONENTS

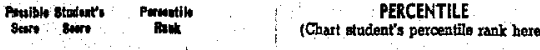

1. Self Adjustmen

A. Self-reliance

90

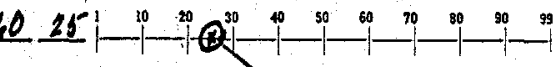

C. Sense of Personal Freedom $151210 \quad 12 \ldots+\ldots$

D. Feeling of Belonging

11120

E. Withdrawing Tendencies

151

$201 \ldots$

Ferrous Symptoms

$15 \frac{9}{11}$

15

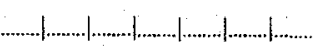

1511

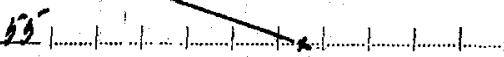

2. Social Adjustment

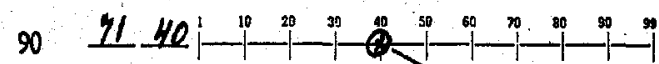

Social Standards

$$
1514.20
$$

B. Social Skills

15 ?

$\frac{20}{10}$

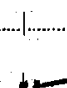

$1 \ldots+\ldots$

C. Anti-social Tendencies -

$15 \frac{13}{1}$

D. Fomily Relations

1512

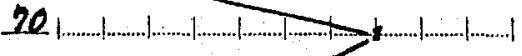

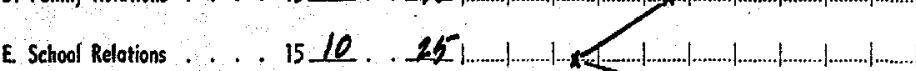

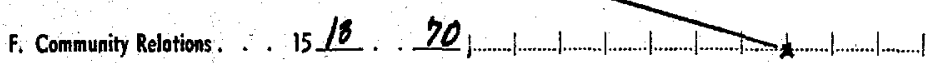

TOTAL ADJUSTMENT . . 180

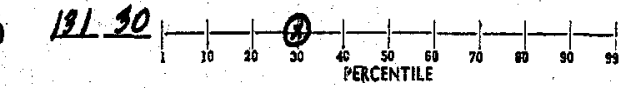

The above profile of Helen Smith reveals that she The above profile of Helen Smith reveals that she This means that she surpasses about one-fourth and is surfassed by three-fourths of the students on whom the percentue norms of this test are based. Her social adjustment is shghtly below average (40 ard. Helen appears to have an adequate knowledge of social standards and is reasonably gell adjusted in jamily and community relationshups. She is also relatively free from anti-social tendencies and from nervous symptoms

On the other hand, Helen is decidedly lacking in On the conch hand, Helen is dectledy lacking in social skils and in thy den is decidedy helationships.An inspeclion of the particular situations in these components in which she reports jeelings and clues to her difficulity. On the self-adjustment side,

Helen is also very low in her sense of personal worth and feeling of belonging. These difficultios ore oc companied by a serious tendency to withdrow from reality and to secure personal satisfactions throu the substitution of fantases for succosses in roal life

The profile as a whole suggests decided lack of success in attaining security and favorable recognithet special attention to the development of sociel shills and the provision of opportunity for sacial might reddily remedy a situation which if success quately met may lead to more werious diffict ade An examinetion of the stecitic item answers particularty in those areas in which the percents, patis low will reseal the restonses the percentile rank is low, will teveal the responses which resulted in the unsatisfactory ratings secured. These responses to the recommendyed and interpreted in relation $7-$ 
California Test of Personality to create an instrument which will implement the desire of teachers to direct leaming and adjustment in hasmony with the major objectipes of modern education. In othes words, the test represents a means by which teachers can more easily.
and effectively translate their desires to aid students into actual accomplishmen

The modern curriculum emphasizes the democratic ideal of learning and adjustment through freedom and direction. Since it is often the only part of the person's environment which may be specifically planned to meet his interests and needs in the light of capacities, the curriculum may well be regarded as a crucial factor in the dereopment of spmmetrical, effective and wellbalaneed personalities.

In general, the improvement of personality and social adjustment consists of learning to substitute better responses for unsatisfactory or inadequate reactions in the concrete types. of situations in which the student experiences adjustment difficulties. This means. that the point of departure in aiding students to make better adjustments should be by way of an attack on the particular difficulties revealed by the test.

There are two major approaches, with their many variations, in the matter of student adjustment methodology. These contrasting approaches may, as a matter of convenience, be called the direct and the indirect. In the former the student is informed and understands the purpose of the activities in which he engages and may thus be led to cooperate voluntarily. By the latter method, the student is led to engage in or refrain from activities and to clarify errors of feeling or thinking which will improve his outlook wothout bentg made conscious of the process itsell. This technique is somewhat analogous to that of obtaining correct expression in English by asking appropriate questions. Whese the cause or contributing factor in maladjustment hat been the teacher or a parent, care must be exercised in the use of the direct method. In such an instance, both the teacher and the parent should take a less evident part in remedial measures.

Teachers should exercise the greatest care in distinguishing between symptoms and causes of personality diffculty. In identifying types of maladjustment and planning remedial activity, the teacher must not lose sight of the danger of regarding symptoms as basic causes of personality disturbance and of attempting to remedy these difficulties by the mere elimination of symptoms. Causes of malad justment frequently lie deeply imbedded in the emotional life of the student and can be identified only by careful and painstaking diagnostic study.

Remedial activity or treatment may for convenience be classified into six types, as follows:

1. Personality exercises and practice. This type of treatment is particularly useful for changing unde sirable habit patterns. Examples of such patterns abound in the

2. Correcting erroneous beliefs and attitudes. Such attitudes occur in components dealing with thowledge of social standards, sense of worth, feeling of belonging sense of freedom, and in many family, school and community relationships.

3. Dealing with unfavorable enoironmental conditions. Frequently the student could adjust satistac torily except for certain factors in bis home, school, or community environment. A change in attitude or activity on the part of teachers, parents, or neighbo
frequently aids in the solution of a difficult problem.

4. Modifying undesirable forms of attempted adjustment. The treatment in this form of disturbance constitutes a different type of procedure. The mal adjustments in question are illustrated in the anti-socia and withdrawing tendency components.

5. Elimination of physical and nervous difficulties. These difficulties are fairly objective and easily recognized. They are sampled in the neroous tendency con ponent. They may require medical attention and

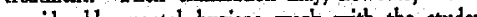
afflicted.

6. The recognition and recording of apparent mental disorders. Many students, at one time or another, appear to be egoistic and conceited; often they give evidence of being unduly suspicious. But when these and other more or less common, yet undesirable, adjustment tendencies become babitual or extreme they may lead to serious mental disorders.

It is apparent that no one component of the tost should be treated as a completely independent unit personality. Neither shourd re-education sctivities be planned without reference to all other componens. In addition, such sources of information as schoo records of ability, interests, and achievement, as well as other facts regarding home, out-of-school activitie and the like, should be investigated in difficult cases.

There are two basic principles which must be observed regardless of what method of treatment is indicated.

1. The maladjusted student must of ten have something defnite done for him before he can help himself. self-confidence and feelings of personal security are stored. Thus it is important that teachers attempt determine the underlying causes of observed diffiptie

2. Adjustment problems should be broken into their simpler clements in order that improvement activitios may be chosen with due regard to the needs and progress of the student. When the student does not seen sufficiently challenged by the methods utilized, the teacher may safely suggest more stimulating activities but if the student fails in his efforts it may be necessar for the teacher to retrace her steps and break down the problem into its simpler phases.

The teacher should show the student that learning to deal with one's self and with others in an intelligen sympatietic, and many-sided manner is one of the moss important ways to attain happiness and sucecs in life.
Space will not permit a separate illustration for each these sit approact

D. Illastrative Exomples and Suggestions for Treotment

1. Struations Alded by Practice

Component 1A: Developing Self-reliance

Form A Item 4: Is it hard for you to continue with your work when it becomes difficult?

A student is self-reliant if he performs many acts in a way that indicates an inner feeling of assurance and a way that in dicates an inner feeling of assurance and manner be is said to lack self-reliance. The basic principle of improvement, therefore, consists of creating confidence and effecting improvement through spmconfence and intelligent planning of definite situations pat practice purposes

If the student deviates sufficiently in this component (as revealed by the profile) to warrant special attention, each evidence of difficulty should be noted.

In general, a successful attack consists of five steps:

1. The student must be sure of the teacher's sympathy and respect.

2. The student must feel sure that the teacher indertands his diffeulty.

3. Consideration of the problem must develop a foeling of security and a desire to improve on the paitt
of the student. The seriousness of difficulties should not be overemphasized.

4. In the light of available knowledge about the student and of the seriousness of his adjustment diffculties, the teacher must break down his problems into their appropriate dements.

5. The teacher must guide the student in a gradu ated series (from easy to more difficult) of adjustment activities which challenge but do not defeat him.

Assume for example that a student finds it diffeult to talk in class. Some or all of the following steps may be used to aid him. The extent to which these need to be utilized depends on the seriousness of his disability

a. Before the class hour begins, tell the student that be will be asked a question, the correct answer to which is "Yes." Ast the question and have him answer it.

b. Repeat step a utilizing single word answers (or short answers) given him beforehand until he responds confidently and until the nembers of the class expect him to answer.

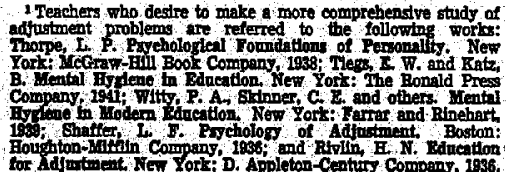

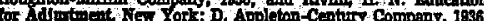

c. Tell the student before class what questions he will be asked. Be sure that the questions are simple, that they require little talking and that

d. Without previous arrangement, ask the student questions which it is certain he can answer.

c. Ask the student to make a simple report from notes.

f. Ask for a simple report without notes.

g. Continue to increase the complexity of the taske until the student does as well as can be expected.

b. If the student fails at any point, ignore the failure, and repeat the previous step or steps until he appears ready to progress

The following is another example: Assume that the student finds it very difficult to meet or introduce people. Among the steps which will aid him are the fol wing procedure:

2. The teacher (or someone else) telis the student the name, as well as same interesting fact, about the person who is to be introdnced. The teacher has him repeat the name and suggests i question or comment for him to make in starting the conversation. The student meets the stranger and starts the conversation.

b. The teacher emphasizes the desirability of giving attention to the other person's name when being introduced. The student is told several things about a new person, but not his name. The student uses the name of the person when acknowledging the introduction and begins
conversation.

c. The teacher informs the student that he is to meet another teacher, student, barker, or some other person. She requests him to think of some. student repeats the name of the other person and starts a conversation.

d. The teacher asks the student to make a list of things which different people might be interest ed in at various social functions. She ssts such questions as, "If you met Mr. Black, oditor of one of our local newspapers and parent of another student in this school, what would you talk about?"

e. Continue planning and practice until the student adjusts as well as appears possible.

\section{Errongous Bhurffs and AtTrtudgs}

Component 1D: Feeling of Belongin

Form A, Item 60: Do you feel that people usually think well of you?

Assume that a student answered "No" to this question. The fact that be may be wrong as shown by 
later investigation does not change the unfavorable in Anience of his beliof or attitude. It is necessary in some way, through explanation or evidence actually to change the attitude of this student before the An approach characterized by sympathetic interest and anderstending on the part of the teacher, and is often eliminate the problem.

The general method of approach in handling thes erroneous beliefs and attitudes which are responsible for another large proportion of adjustment difficultie may be stated as follows:

1 Determine whether or not the student is right in this beliefs or attitudes.

2. If it is found that be is mistaken, explain his difficulties and show him his errors.

3. If the student is not convinced ast him to keep a record of his specific "weaknesses and illnessess" (o The mere keping of a record will often convince him of his error.

4. If the student keeps a record of actual instances of weaknesees and illnesses and they appear to uphold his belief, the teacher must often readjust her first judg ment: If, howerer, she is still convinced that the student is wrong, it is advisable to gather similar evidence re garding the extent to which other otudents face and meet the same problem. In the present instance it would be a record of the extent to which other students $e x$ hibited the same wearnesses and ilresses. If this evr dence shows that the status of the student in question is typical, he no longer has any justification for his at titude.

5. If the student still persists in his belief, it may be based on other factors. Search should be made for evidence of conficts in ather componen to tor excessive feelings of inferiority, for difficulties in his record of ability and achievement.

6. If investigation proves that the student was right to begin with and that the evidence he gathered ssems an requin the modfoction of his activitios to sut pem requires the modification of his activites to suit bis with the procedures outlined in our next remedial sec.

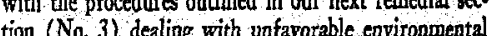
conditions.

It is rarely necessary to go into such detail with single evidenos of difficulty and then usually only in question from the general pattern of most persons

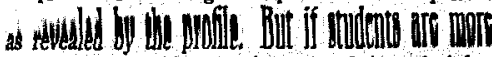
important than subjects, equipment, and time schedules,
the wise teacher will be willing to go into this detain in order that ther mar be properly oriented and as sisted in their efforts to make successful adjustments.

The same approach with apptopriate modifications may be used in other similar types of difficulty.
3. DBAIING WITH UNPAVORABL EnVTRoNMBnTal Conditons

Component 2E: School Relations

Form A, Item 151: Are some of rour subjects so diffeult that you may be in danger of failing?

Component 2D: Family Relations

Form A, Item 145: Do the members of your family seem to criticize you a lot?

Assume that the student angiters "Yes" to both of chese and similar questions and that he is right in bis beliets. In both these nastances something should be done. In the first case, the school has the major responsibility, and in the second, the problem is one for the home.

The school has long been aware of the first problem but only recently has it been possible to approach the solution for it with a rational and decensible plan. The veals of failure neither does it rereal the which his perolity is being ubiecte on the culties, given some reduction in a

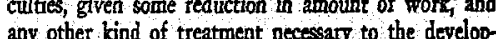
any other tind of treatment necessary to the development of a teeling of security, He must be put on a basis of equality with those who happen to te so constituted short, the school program should fit his maturity level. Sometimes this ideal requires a distinct change in teacher attitudes and prooedures.

The second problem is more time consuming but just as important. It ustually involves contact with individual parents and great tact is sometimes recessary to make them understand how they are defeating thej own purposes and faling as parents when they destroy the feeling of security and the hope necessary for personal growth and adjustment on the part of thelr children.

After the problems for a schoolroom or for a whole school have been tabulated from the profile answers, the most general difficulties can be handled by principal and teachers in informal talks to students. These problems may also be made the subject of parent-teachers' and mothers club meetings. Frequently outside speaters can be used to advantage after they have been in-
formed of the major adjustment problems which exist in a particular group.

In addition to this general approach, the following
technique will be found nacful in handling individual Parfnipi

1. Meet parents casually and "size hen up " $T_{Y}$ hibit.

2 If they appear to be intelligent, underntanding and cooperative, begin at onee explaning the strdento diffculties and asking for their cooperation. Suggest definite things for them to do in changing the student's attifude.

3. If the parents are unfriendly, indifferent, or conditions are otherwise unfavorable, they must be influenced through P. T. A or other meetings and through personal contacts before the erroneous attitude is mentioned.

4. If the family is cooperative but unconvinced, at tempt to have the parents keep a record for a short time of actial instances in which they exhibit the attitude which is so discouraging to the student

5. It is not necessart that the parent admit his errot, if the is in error, or that the student be made 2dmit bis error in case the parent is right. Merel raising the question, dealing with it objectively so as the facts of the casc inl permit, and aiscal difficulties and their implications is as far as the teacher can usually go. This procedure will, however, often improve the situation considerably, if not entirely elim inate the dififictly. Furthermore, the teacher frequenI can compensate for the ill effects of the parents' treat ment by giving the student the feeling of self-respect and security which be so much needs.

The specific difficulties mentioned above are repreentative of a large class for which the same genera type of remedial procedures may be used.

4. Deaswg yith ANTt-soctal AND

Wrmbrawnig Tandeacies

Component 2C: Anti-social Tendencies

Forn A, Item 131: Do you often bave to quarrel or fight in order to get your rights?

Component IE: Withdrawing Teadencies

Forno A, Item 69: Do you find many people inclined to sey and do things to hurt your feelings?

For the most part, individuals tond to scare, push, bully, dominate, and otherwise mistreat younger or eriority or lack of ego recognition. The sufferer tries convince himself that he is not inferior to others. His bullying is an anti-social way of attempting to compensate for his feeling of weakness.

Students withdraw from their problems and are characteristically shy, timid, sensitive, suspicious, and given same reasons Such persons tend to give up the bat-
tle of life- their day-dreams are but Ile of life; their day-dreams are butt substiuce aveworthy The withdrawing tendency is considered just to real people and to society in general.

Some students will give a large number of "yes". answers. Sich responses are indicative of the need for a decper feeling of security
In general, the following treatment is recommended

1. Develop the best teacherstudent relationship possible. Let the teacher lose no opportunity to con-

2. Whenever possible, give the student ego-satisfying responsibilities such as policing school halls, acting as club or group leader, or assisting in other school responsibilities, Care must be observed to assign responsilities which the maladjusted student can and will carry successfully and which will not be resented by

3. Adjust regular school tasks and activities to the needs and capacities of the student. Mate a complete and detailed antalysis of his diffeculties and work with him until he wins success, with its attendant satisfastion, within the limits of his possibilities.

4. The major objective in this instance is adjustment and sucess within the studeat's own limitation and not conformity to standards, some of which his limitations will prevent him from attaining. The teachez must find a sufficieat number of activities in which the student can thus be successful if she is to provide the necessary feelings of secunty and relieve him of the necessity of maintaining his ego by anti-social or withdrawing behavior.

5. Draung With Narvous Symptoms Component 1F: Nervous Symptom

Form A, Item 78: Do you bave the habit of biting your fingernails often?

Form A, Item 81: Do you suffer often from annoying eye strain?

Form A, Item 82: Is it hard for you to sit still?

Some of these spmptoms, such as lack of appetite, ege strain, dizzy spells, beadaches, and chronic fatigue mas be due to physical disorders, and should thus be dragnosed and treated by an authonzed physician. Many physical symptoms of this kind, however, are y felings of insecurity and by emotional conficts.

Students suffering from these nervous difficulties are usually unhappy in their homes, without good friends, ize their enero in self-concern and self-pits. Po utillogically, the chief difficulty with such unfor. Psychoand girls is that their attention is centered upon their own troubles rather than upon the intersing

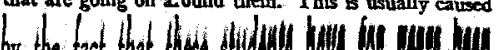
frustrated in their efforts to secure the response and
recognition from parents and others that provides the much coveted feeling of being wanted, of being considered worthy and successful. Thus these seurotic individuals are maladjusted in both the self and the social phases of life. 
The following methods of handling diffculties of this kind are recommended:

1. Examine the student's health record in the nurse's or physician's file. If the record is old or otherwise unsatisfactory, or no record of a physical examina tion is araila

2. If the examination record appears to reveal an evidence of a physical basis for nerrous tendencies the stadent should be referred to a physician for treatment.

3. If the physician reports no physical basis for adjustment difficulties the most probable cause of these nervous symptoms is similar to the major cause of antsocial behavior and withorawing tendencies; namely the lack and need of a feeling of adequate persona security.

4. Povide the appreciation, approval, and ego satisfactions that the individual craves as recommended for the anti-social behavior and withdrawing tendencies, but with the following modification: endeavor to re store bope and confidence before attemping to delegate responsibilities. This may be done by setting up con-
ditions which tend to guarantee recognized success in school and elsewhere.

5. Students exhibiting nervous symptoms are aided by phrsiological as well as psychalogical relaxation Teachers should avoid putting them in tension-produce ing situations. Excessive self-concern must gradually ous tensions are to be relieved

6. The Beta hypothesis (negative practice) tochnique, as developed by Dunlap, is good for nervous tics. In other words, actually practicing a periodic closing of the eyes, muscle tremor, or other nervous ic ads in ganing coscos control orer it and thus

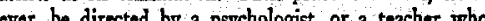
ever, be directed by a psychold
has been specially trained.

6. Daalnag With Mantal Disordgrs

In general, mental disorders may be considered extreme and persistent deriations from normal adjustment. From the standpoint of the teacher there would be reason to suspect such a case hen logg and persistment trpes was ine treatment types was insuccessu. However, the lack of to circumstances should on menter of such a disorder. The should first of all cooperation of the parents. If the student is refered the cooperation of the palis the teecher actively as possible the data which she has and the treatment which she has atterinted, and then cooperate with the psychiatrist or agency which is theing over the treatment of the case

It should be recognized, howerer, that some students disolay the early symptoms of what is in called "ines under the very of thal terms Many of these unhappy youths ase no doubt disinte- grating in their emotional life due to excessive frustration and the constant presence of hostility. Certain an appreciable fraction of this group could be assiste and treated in time

At any rate, there is danger that teachers untraine in mental hygiene matters will overlook symptoms of grave significance in the behavior of their charges. A a prominent psschologist recently commented, it is a matter of no small import that some teachers, as well as parents, permit children to manifest symptoms of psychosis (insanity) that may later become decidedy serious, without doing anything about them until it is too late. As an example, the student who is conceited and egoistic, who displays a superficial attitude in his relations to other people, and who is markedly suspiciow may be developing the form of insanity called paranoi (a psychosis characterized by attitudes of conceit and grandeur and by spstematic delusions of persecution)

E Conclusions on Student Adjustment

Finally, the teacher should realize that students do not group themselves into personality trpes and the pafterns of malajustment often include disturbances in several of the components that have been induded in the profile. A student may, and probably usually will, need assistance in several of the areas of posstible dis. turbance $A$ student who lacks self-reliance may have erroneouss attitudes, may be out of harmony with school and home requlations, and may be decided $y$ inclined to be antitocial in his relations to others. Malajustmento are not contined to types; they present a variety of symptoms that may pervade many areas of both self adjust ment and social adjustment.

Because all aspects of personality are closely interlocked or integrated remedial treatient taly interself-reliance may also eliminate anti-social behavior. And a change in environment that stimulates the with drawing person to attack his problems may bring about a reduction in nervous spmptoms as well. In short, sympathetic help that enables an unhappy student to find self-realization and to develop generous socdal attitudes will tend to hedp him achieve that balanoe of personality that makes for good life adjustment.

\section{Part X. Directions for Checking Profiles Which Appear to Diverge from Observed Student Adjustment}

If a student appeared ill or dsturbed when responding to the questions of the test he should be given an opportunity to repeat the exercise at a more giver an opporte time.

If lack of reading ability was a disturbing factor the teacher may give and interpret orally such parts of the test as appear to be in confict with her obserrations. If it appears that the student has consciously migrepresented himself, a number of checks are possible with most of the items:

1. Other teachers familiar with the student may be asked to respond to the items in question
2 A tew students may be asted to complete profiles for each other including the sudent under examination.

3. After the parents have been appraised of the nature and objectives of the test, they may be asked to complete the items in question.

4. The student may be requested to repeat his performance at another time.

5. The teacher may keep a record of careful, systematic observation over a sufficiently extended period of time to obtain an adden

It should be remembered that not wany such problem cases a The detect the actual or major purpose of the test is to roun people in order to aid them in masing normal justments But when apparent discrepanciester tween student responses and teacher observations it important to determine the facts in order that remedin activities mar be intellipently directed. The teacher should not trust her informal opinions too far; evidence from the test will ustally be much more valid. Furthermore, it must be remembered that teachers sometimes stimulate unnecessary malad justment by their unjustifable unfarorable atti tudes toward both individual students and whol classes.

\section{Part XI. Interests and Activities}

The Interests and Activities questionnaire (page 2 of test booklet) is not a part of the test proper an in not sconed or charted on the first page profile as we the twe ve adjustment components. The teacher ing

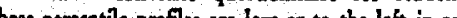
fose percantie profles are low or to the lefe in any additional information is desired. The questionnaire yields four types of information
about different interests and activities: (1) The things about different interests and activities: (1) The things the studeat likes, or would like very much to do, but
does not do; (2) The things the student likes, or would like to do, and actually does; (3) The things which like to do, and actually does; (3) The things which
the student does not like, or does not wish to do, but the student does not like, or does not wish tro do, bu nor does.

The interest and activity items are divided into (a) those of a primarily individual nature (Items 1-46) and (b) those that are predominantly social (Items 47-74). Within each of these two groups the items are arranged in the general order of the amount of acthe more passive or sedentary types and adraneng to th

After the teacher has identified the component or components in which a student appears to be experiencing discules, and has reviewed such other data as she can obtain regarding such factors as health, ati t ablits Activities questionnaire
A study of the questionnaire will still further enlarge the teacher's modesstanding of a student's personality, lend additional assistance in determining the cause or carses of his diffeculty, and provide clues for planning remedial work Among other facts the dent fails to do things that he would enjoy doing dent fails to do things that he would enjoy doing
but does not do, why he does not like some of the thins bes chings he coes do, and whether or not anything the interests and activities field.

In general, a wide range of interests and activities is evidence of rood adjustment; a narror range in this respect may be indicative of actual or potential maladjustment. Therefore, a basic principle in dealing with most adjustment diffeulties of this type is that of stimulating individual and social interests, and encouraging the student to become more active in such interests and activities 39 mag be suited to his degree of physical, 50 . cial, and mental maturity.

\section{Past XII. Administrative Uses}

Although this test has been designed primarily to aid teachers in detecting and dealing with adjustment probems, its usefulness is not confined to the individual classroom.

The normative data, or scores on the various sections of the test, should be summarized on the blanks provided in order that they may supply administrative officers with information regarding the adequacy of per-
sonal and social adjustment in:

\section{Single classes in a given school \\ 2. Individual schools \\ 3. The whole school system}

If the majority of self adjustment scores for a school or school system are low, it may indicate that the eduational procedures in vogue are too formal or tradihonal and that more informal activities should be undertaken. If scores on freedom from withdrawing tendencies, freedom from nerrous ssmptoms, and freedom from anti-social tendencies are low, it may indicate that the course of study materials are too difficult for student capacities. Such a situation might well be skills suggest the desirability of more emphasis on as pects of social training, etiquette, and attitude building which, in some school systems, are not regarded as being a part of the regular curriculum. Low scores on the conmunity relations section of the test may indicate too little stress on school-community relations and suggest more emphasis on interpreting the activities and needs of the community in terms that students can comprehend.

Unsatisfactory school and school district trends rerealed by percentile summaries are to be regarded as the points of departure for investigating the need or 
desirability of modification in the objectives, materinls, and procedures of the curriculum.

Teachers, supervisors, and administrators should be lert to the opportunities which are provided in the chool tarironment for setting up stimulating situr of the jo Tul cil inter cion a

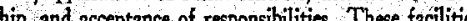

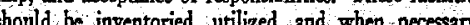
modifed to harmonize with ouch objection codures 20 are requiste to the derelopment of prelladjusted and effective personalities.

A careful analysis of the arailable opportunities for personality derelopment and their constructive utiliza tion in the problem of student adjustment is the privilege and opportunity of all who are engaged in cor ducting the Nation's educational progtam.

\section{Pat XIII. Percentile Norms}

The percentile norms provided on the last page of this Manual were derived from test data for student in grades nine to fourteen inclusive in different school in and near Los Angeles, Calitornia. A percentile mas be described as a point on a 100 point scale which give the per cent of scores which fall below that particula percentile. For example, a student whose score falls at the 35 percentile point exceeds 35 per cent of the students on whom a score may also be interpreted to mean that this trudent is lower than 65 per cent of the students in the standardization group.

\section{Examiner's Memoranda:}


CALIFORNIA TEST OF PERSONALITY_SECONDARY SERIES

PERCENTILE NORMS

\begin{tabular}{|c|c|c|c|c|c|c|c|c|c|c|c|c|c|c|c|c|c|c|c|c|c|c|}
\hline & & Percentile: & 1 & 5 & 10 & 15 & 20 & 25 & 30 & 35 & 40 & 45 & 50 & 55 & 60 & 65 & 70 & 75 & 80 & 85 & 90 & 95 \\
\hline Sec. 1 & 1. Self Adjust & ent__._Score: 3 & & $\begin{array}{l}37- \\
45\end{array}$ & $\begin{array}{l}46- \\
52\end{array}$ & $\begin{array}{l}53- \\
55\end{array}$ & $\begin{array}{l}56- \\
58\end{array}$ & $\begin{array}{l}59 . \\
61\end{array}$ & $\begin{array}{l}62- \\
64\end{array}$ & $\begin{array}{l}65- \\
66\end{array}$ & $\begin{array}{l}67- \\
68\end{array}$ & $\begin{array}{l}69 . \\
70\end{array}$ & 71 & 72 & 73 & 74 & 75 & 76 & $\begin{array}{l}77 . \\
78\end{array}$ & $\begin{array}{l}79- \\
80\end{array}$ & $\begin{array}{l}81- \\
82\end{array}$ & $\begin{array}{l}83- \\
88\end{array}$ \\
\hline Sec. 2 & 2. Social Adjus & ment..Score: 3 & & $\begin{array}{l}39- \\
54\end{array}$ & $\begin{array}{l}55- \\
57\end{array}$ & $\begin{array}{l}58- \\
61\end{array}$ & $\begin{array}{l}62- \\
64\end{array}$ & $\begin{array}{l}65- \\
66\end{array}$ & $\begin{array}{l}67- \\
68\end{array}$ & $\begin{array}{l}69- \\
70\end{array}$ & $\begin{array}{l}71- \\
72\end{array}$ & 73 & 74 & 75 & 76 & 77 & 78 & 79 & 80 & 81 & $\begin{array}{l}82- \\
83\end{array}$ & $\begin{array}{l}84 \\
88\end{array}$ \\
\hline \multirow[t]{2}{*}{ Total } & Adjustment & ........Score: 7 & & $\begin{array}{l}75- \\
99\end{array}$ & $\begin{array}{l}100- \\
109\end{array}$ & $\begin{array}{l}110- \\
116\end{array}$ & $\begin{array}{l}117- \\
122\end{array}$ & $\begin{array}{l}123- \\
127\end{array}$ & $\begin{array}{l}128- \\
132\end{array}$ & $\begin{array}{l}133- \\
136\end{array}$ & $\begin{array}{l}137- \\
140\end{array}$ & $\begin{array}{l}141- \\
143\end{array}$ & $\begin{array}{l}144- \\
145\end{array}$ & $\begin{array}{l}146- \\
147\end{array}$ & $\begin{array}{l}148- \\
149\end{array}$ & $\begin{array}{l}150- \\
151\end{array}$ & $\begin{array}{l}152- \\
153\end{array}$ & $\begin{array}{l}154- \\
155\end{array}$ & $\begin{array}{l}156- \\
158\end{array}$ & $\begin{array}{l}159- \\
161\end{array}$ & $\begin{array}{l}162- \\
165\end{array}$ & $\begin{array}{l}166- \\
177\end{array}$ \\
\hline & & Percentile: & 1 & 5 & 10 & 15 & 20 & 25 & 30 & 35 & 40 & 45 & 50 & 55 & 60 & 65 & 70 & 75 & 80 & 85 & 90 & 95 \\
\hline
\end{tabular}

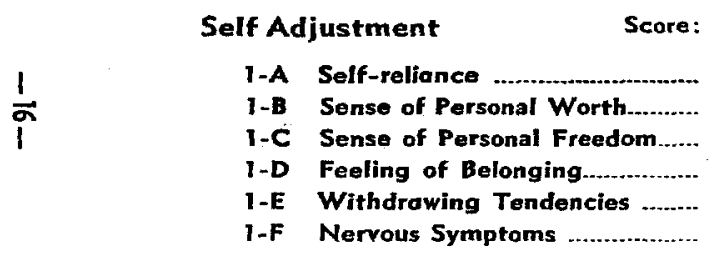

\begin{tabular}{|c|c|c|c|c|c|c|c|c|c|c|c|c|c|c|}
\hline \multirow{7}{*}{ 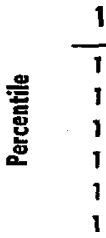 } & 2 & 3 & 4 & 5 & 6 & 7 & 8 & 9 & 10 & 11 & 12 & 13 & 14 & 15 \\
\hline & 1 & 1 & 1 & 5 & 15 & 25 & 35 & 45 & 60 & 70 & 80 & 90 & 95 & 99 \\
\hline & $i$ & 1 & 1 & 1 & 1 & 5 & 5 & 10 & 20 & 35 & 50 & 65 & 80 & 95 \\
\hline & 1 & 1 & 1 & 1 & 5 & 5 & 5 & 5 & 10 & 20 & 30 & 45 & 70 & 90 \\
\hline & 1 & 1 & 1 & 5 & 5 & 5 & 5 & 10 & 15 & 20 & 30 & 45 & 70 & 90 \\
\hline & 1 & 1 & 1 & I & 5 & 5 & 10 & 15 & 25 & 35 & 50 & 65 & 80 & 95 \\
\hline & 1 & 1 & 1 & 1 & 5 & -10 & 15 & 30 & 45 & 55 & 65 & 75 & 85 & 5 \\
\hline
\end{tabular}

Social Adjustment

2-A Social Standards

2-B Social Skills

2-C Anti-social Tendencies

2-D Family Relations

2-E School Relations ...

2-F Community Relations

\begin{tabular}{|c|c|c|c|c|c|c|c|c|c|c|c|c|c|c|}
\hline \multirow{7}{*}{ 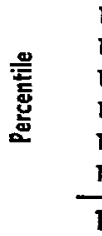 } & 1 & 1 & 1 & I & 1 & 1 & 1 & 1 & 5 & 10 & 25 & 45 & 70 & 90 \\
\hline & 1 & 1 & 1 & $\mathbf{I}$ & 5 & 5 & 5 & 10 & 20 & 40 & 55 & 75 & 90 & 99 \\
\hline & 1 & $\mathbf{I}$ & 1 & 1 & 5 & 5 & 5 & 10 & 20 & 30 & 50 & 70 & 90 & 99 \\
\hline & 1 & 1 & 1 & 1 & 1 & 5 & 5 & 10 & 20 & 30 & 45 & 60 & 80 & 95 \\
\hline & 1 & 1 & 1 & 1 & 5 & 5 & 10 & 15 & 25 & 45 & 60 & 75 & 90 & 99 \\
\hline & 1 & 1 & 1 & 1 & 5 & 5 & 5 & 10 & 20 & 35 & 50 & 70 & 85 & 99 \\
\hline & 2 & 3 & 4 & 5 & 6 & 7 & 8 & 9 & 10 & 11 & 12 & 13 & 14 & 15 \\
\hline
\end{tabular}

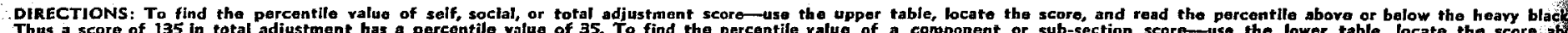

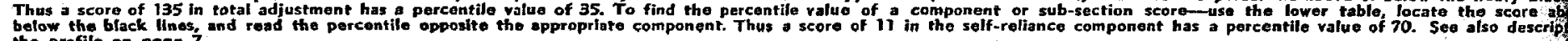
the profilo on poge 7 . 


\section{HESTON \\ PERSONAL ADJUSTMENT INVENTORY}

By Joseph C. Heston, Ph.D.

Director of Buteau of Testing and Research and Associate Professor of Psychology

De Pauw University, Greencastle, Indizna

\section{INVENTORY}

There are no right or wrong answers to the questions on the following pages; each person differs in the way he feels about them. We are attempting to study certain aspects of personality that are important factors in one's adjustment to life, school, or work in general. You can help by answering each question thoughtfully and honestly. Your sincere cooperation in this will prove beneficial to you and your counselors. Think carefully, but do not spend too much time on any one question. Let your own personal experience or opinion guide you and record the way you feel about each question.

For each question, decide whether your answer is "Yes" or "No." If your answer is "Yes," blacken the "Yes" space on the answer sheet. If your answer is "No," blacken the "No" space. For instance, if your answers to questions 76, 77, 78, 79, and 80 were "Yes," "No," "No," "Yes," "No," respectively, you would fill in the answer spaces as follows:

$$
\begin{aligned}
& \text { (26) } \\
& \text { (B) ㄹes } \\
& \text { (20) } \text { IES }
\end{aligned}
$$

If you think the answer to a particular question is "Yes" under some circumstances and "No" under others, decide which is more often the appropriate answer and mark the corresponding space.

- You should be able to decide fon every question, or for almost every question, whether the true answer would usually be "Yes" or "No" If, however, there are a small number of questions for which you are absolutely unable to decide whether "Yes" or "No" is the better answer, fill in the circles containing the question numbers. For instance, if you could not choose between "Yes" and "No" for question 281, you would fill in the circle as follows:

$$
0 \quad \text { yss }: \cdots
$$

However, in nearly every case you should decide which answer is more commonly characteristic of you, thus keeping the number of omitted statements down to an absolute minimum:

In filling in answer spaces, be sure to make your marks heavy and black.

This inventory is copyrighted. The reproduction of any part of it thy mimeggraph, hectlograph, or in any other way, whether the reproductions are sold or furnished free for use, is a violation of the cotyright law.

Published by World Book Company, Yonkers-on-Hudson, New York, and Chicaga, Illinois Copyright rgqu by World Book Company. Copyright in Great Brizain. All rights reserered 


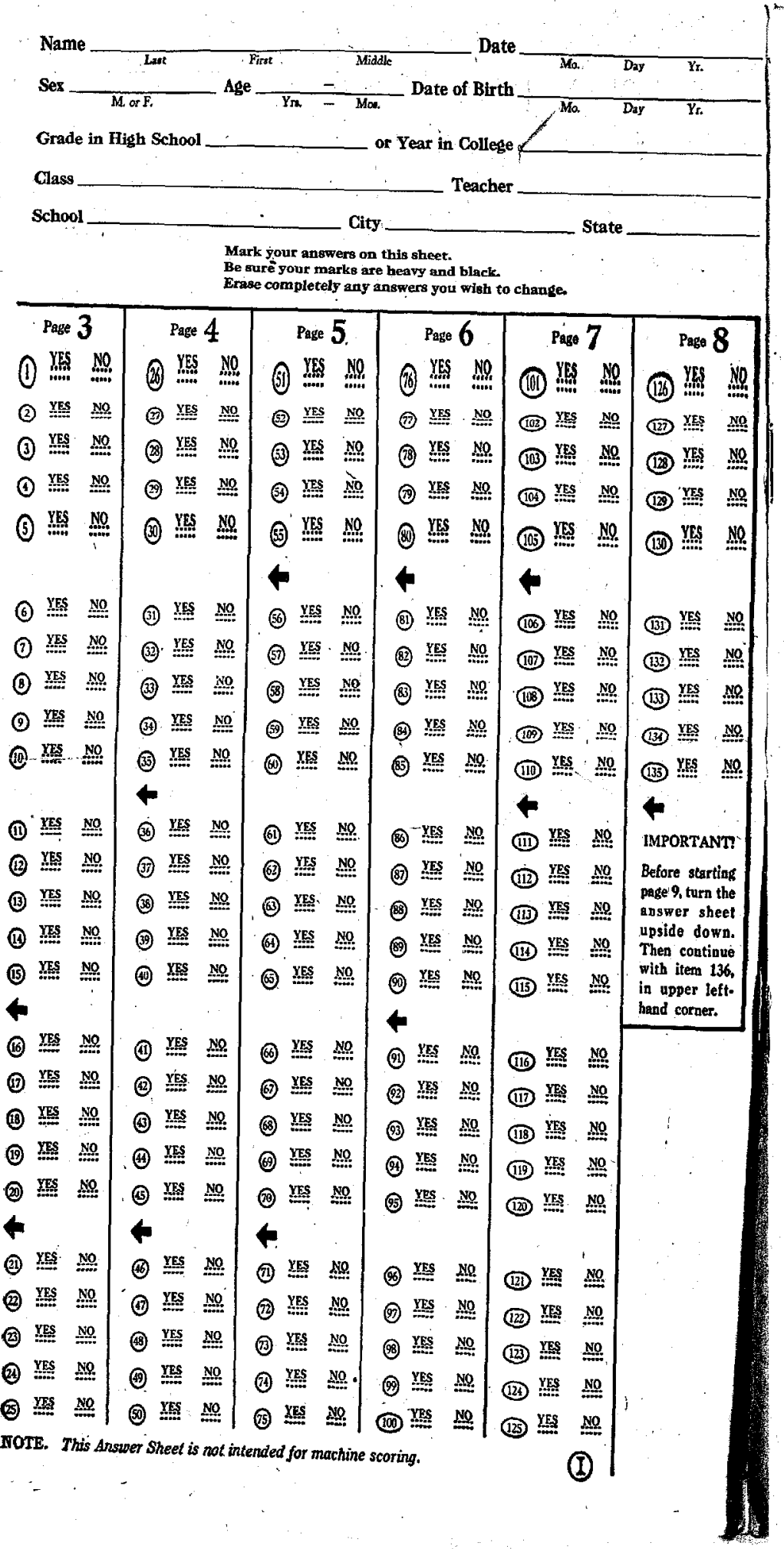

\section{Heston Personal Adjustment INVEntory}

Indicate your answers by marking them on the separate answer sheet. Do not mark this booklet at all. Remember to make your marks in the spaces on the anThe heavy and dark. Try to answer "Yes" of "No" to every question.

The answer sheet should be slipped under the right-hand edge of page 3 (or whatever page you are workg on) next to each other. When the answer sheet is placed correctly, the arrow tips on it next to each other. Whenld point directly to the arrow tips on the booklet, and the answer spaces (and on it should point directly to the arrow tips on the booklet, and the answer spaces (and quesbooklet to which they correspond (and the question numbers).

1. Are you disturbed because some of your family differ from your stańd- Pase 3 ards or beliefs? .

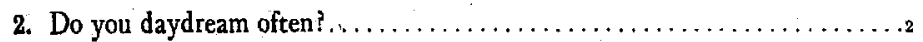

3. Are you most contented when at home? .......................

4. Are you less readily upset or frustrated than most people? ..............

6. Has your association with your father generally been pleasant?..........

6. Can you keep at a monotonous task for a long time without urging or encouragement?..............., ........................

7. Are you often absent-minded? . . . . . . . . . . . . . . . . . . . . . . .

8. Do you like to analyze your thoughts and feelings? .................

9. Do you frèquently feel self-conscious about your appearance? . . ............

10. Do you evaluate new ideas to see if they fit your point of view?.........10

11. Have you any nervous habits, such as twitching your face or futtering your eyelids?..........................................1

12. Do you avoid asking friends home because it is unattractive?..........12

13. Have you often been lost in thought?........................13

14. Does either of your parents become angry readily? $3 \ldots \ldots \ldots \ldots \ldots \ldots$ is

15. Does it embarrass you greatly to make an error in a social group?........15

16. If you lose something, are you apt to suspect someone of taking or misplacing it? ............................................6 17. Are you a happy-go-lucky person? .......................17

18. Do you enjoy speaking in public?.........................

19. Do you become angry readily?............................

20. Do you like to introduce yourself to strangers at social affairs? , ......, 20

21. Do you often think of smart things to say when it is too late to say them? ..21

22. Do others generally credit you with good judgment? ...............22

23. Can you face a difficult task without worry? .....................

24. Do you thoughtfully question the statements and ideas of teachers?.......24

25. Do you ever wish you were more attractive?..................... 
26. Does either of your parents insist on obedience, regardless of whether Page 4 the request is reasonable? . . ..................................

27. Do you become tense under competition, as in tennis, debating, etc.? . . . .27

28. Is it hard for you to maintain a pleasant disposition at home? ..........28

29. Are you readily bothered by distractions when doing mental work? . . . . 29

30. Do you feel your parents, have set too high goals for you? ...............

31. Do you tend to be unconcerned about your work - that is, take it in, routine manner?

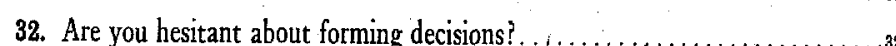

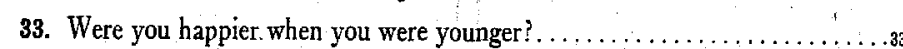

34. Do you do much thinking more than that needed by your work? . . ........34

35. Have you often felt there are really few things worth living for?. $\ldots \ldots \ldots, 35$

36. Are you ever disturbed by useless thoughts coming into your mind persistently?........................................,

37. Do you find less appreciation at home than elsewhere? ..............37

38. Do you dread seeing a snake? . . . . . . . . . . . . . . . . . . . . . . . 88

39. Does your family feel you are not considerate of them? ...............

40. Do you tend to worry over possible troubles? ................., 40

41. Are you often left out of things (maybe unwittingly) in group activities?...41

42. Do you usually keep out of the limelight on social occasions? . . . . . . .

43. Do you feel life hàs a great deal more happiness than trouble?.......... 43

44. Do you enjoy having numerous social engagements? . . . . . . . . . . . .44

45. Do you ever feel sorry for all the other people on earth?............

46. Do you enjoy assignments forcing you to derive your own conclusions from a body of facts or data?

47. Have you ever had a queer feeling you were not your old self? . ..........4

48. Do you usually plan and think things through before acting? . . . . . . .

49. Can you tackle new situations with a reasonable degree of assurance? ......4s

50. Are you challenged by a problem until you reach a satisfactory answer?... 50 (Go right on to page 5 .
51. Does either of your parents make you resentful by criticizing your Page $\mathbf{5}$ appearance?..........................................5

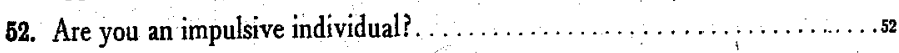

53. Do your friends have more fun at home than you do? .............53

54. Have there been frequent quarrels within your immediate family? . . . . . . 54

55. Do you sometimes feel just miserable, even if there is no good reason? $3 . .55$

56. Do you sometimes tackle work as though it were a matter of life or death?. . 56

67. Do you ever feel too self-conscious? .......................57

58. Do you frequently theorize about the reasons for human behavior?......58

59. Are you often unable to reach a decision until too late for action? . . . . . .59

60. Does conversation help you more than reading in formulating your ideas? . .60

61. Can you regain a state of calm easily after an exciting situation is over? $\ldots \ldots 61$

62. Do some of your family generally neglect to repay favors? . . . . . . . .62

63. Do you become easily rattled at critical times?.$\ldots_{1} \ldots \ldots \ldots \ldots \ldots \ldots \ldots$

64. Do you feel your parents have dominated you too much? . . . . . . . . . .64

65. Are your table manners less correct at home than when out in company? ...65

66. Would you be very disappointed if prevented from having numerous social contacts? .........................................6

67. Do you hesitate to accept new acquaintances as real friends? ..........67

68. Is it hard for you to make new friends?. . .......................68

69. Do you sometimes become angry? .........................

70. Do you tend to restrict your acquaintances to a chosen few? ...........

71. Does it seem you never do things in a manner to gain notice and praise from others? ...........................................

72. Do you often philosophize concerning the purpose of life?............72

73. Does it disturb you for others to watch you while you work? ...........73

74. Have you more interest in athletics than in intellectual activities? . . . . . . 74

75. Do you tend to be quick and certain in your actions?.............

(Go right on to page 6.) 
78. Do you become more nervous when at home? .................. 78

79. Are your nerves ever raw or on edge? ....................... 79

80. Do you disagree with your parents about your choice of a vocation?......80

81. Do you like discussions of the more serious questions of life with other

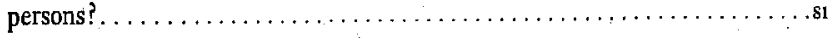

82. Do you ever wish that you could change your height? ............82

83. When in a new city, do you like to visit museums? . . . . . . . . . . . 83

84. Do you always feel that you can achieve the things you wish? .........84

85. Are you frequently restless when attending a lecture?.............85

86. Do you become upset when you have to consult a physician for your illness? 86 87. Do your ever wish you had been born in a different family?..........87 88. Would you rather watch sports or contests than participate in them? . . . 88 89. Does either of your parents often find fault with your actions? . . . . . . . . 88

90. Do you often feel blocked because you are unable to do as you desire? . . , 90

91. Are there many jobs you would not accept because they are beneath you? . .91

92. Can you generally have a really hilarious time at a gay party? . . . . . .92

93. Is the other fellow usually at fault when you have an argument?.......93

94. Do you converse much with clerks who wait on you? . . . . . . . . . . .94

95. Do you become impatient if waiting for other persons?.............95

96. Do you feel few obstacles can hinder you from achieving your final goal?. a a

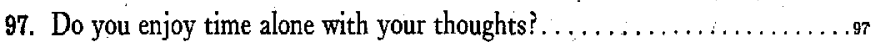

98. Do you often have the blues? .......................... 98

99. Do you have philosophical leanings? ... . . . . . . . . . . . . . . .99

100. Are you generally confident of your own ability? ...............

101. Do you ever have contradictory moods of love and hate for one of Page 7

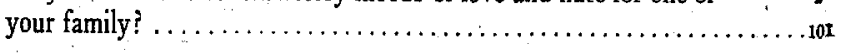

102. Are you often.in a meditative state?........................

103. Is your greatest obligation to your own family? ................ 103

104. Do you have to alter your body position frequently while sitting? . . . . . . 105. Is (was) your mother dominant in the family? .................

106. Do you ever. feel that in life's competition you are generally the loser?... 107. Do you enjoy solving brain teasers? . . . . . . . . . . . . . . . . . 107 108. Do you frequently feel unworthy?......................... 109. Do you critically evaluate the structure of novels and movies? . . . . . . . 100 110. Do you worry over humiliating situations more than most persons? . . . . 110

111. Are you embarrassed if you arrive too early or too late at a social engagement?.

112. Have the actions of one of your parents ever caused you great fear? . . . . 112 113. Do you often feel listless and fatigued for no apparent reason?........13 114. Does your family have as much fun together as you would like?.........114 115. Do you think you are a tense person? . . . . . . . . . . . . . . . . . .115

116. Are you willing to permit others to hesitate or consider before they act?...116 117. Do others judge you a lively individual? ....................117 118. Do you usually find it easy to form new acquaintances?............. iis 119. Are there times when everything seems to go against you?............119 120. Are you usually pleased to be in the limelight at social affairs? ..........120

121. If you could go into a theater without paying and be undetected, would

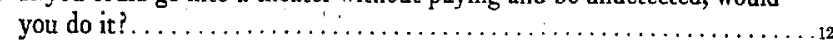

122. Are you frequently troubled by thoughts of self-guilt? .............122

123. Do you enjoy discussing an ideal society or Utopia? ...............23 124. Does it disturb you to be "different" or unusual? ................124 125. Do you prefer biographical movies to those of the musical comedy type? . .125 (Go right on to page 8 .) 
126. Do others ever whisper or exchange knowing glances when you seem Page 8

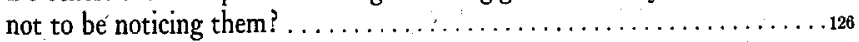

127. Do you often hesitate about meeting important persons?: $\ldots \ldots \ldots \ldots \ldots$

128. Do you tend to be shy with the opposite sex?.................. 128

129. Do others deliberately seek to annoy you? . . . . . . . . . . . . . . 129 ,

130. Would you prefer to be a scientist rather than a politician? . . . . . . . t30

131. Do you find it hard to continue work when you do not get enough encouragement?.

132. Are you more of a practical individual than a theorist?..............

133. Are you bothered by inferiority feelings? . . . . . . . . . . . . . .

134. Would you rather have a theory explained than study it out yourself?.....134

135. Are you inclined to let people dominate you too much?.

..135

Important! Before starting page 9, turn the answer sheet upside down. Then continue with item No. 136 , which will be in the upper left-hand corner of the answer sheet.
136. Do your parents too frequently expect you to obey, though you are " Page 9 grown up?.......................................

137. Do you often tell your troubles to others? . . . . . . . . . . . . . .

138. Do you talk over important plans with your family?...............

139. Are you frightened to be alone in the dark? . ..................139

140. Have you ever had an urgent desire to run away from home? . . . . . . . . 140

141. Is the application of principles more interesting than the theoretical

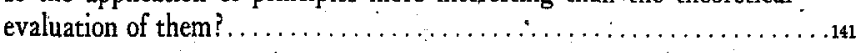

142. Are there some people you dislike? ........................

143. At a party is it easy for you to be natural? . . . . . . . . . . . . . .

144. Does it ever seem that everyone is working against you? . . . . . . . . . 144

145. Do you converse much with strangers when on a journey? .............145

146. When disturbed or upset, do you tend to suffer from indigestion or other distress?.

147. Do you have more love for your mother than for your father?........147

148. Are your feelings rather easily hurt? ......................148

149. Are your parents too old-fashioned in their beliefs and ideas?..........149

150. Can you relax yourself easily? . ..........................

151. Do you like using leisure time in creative writing (poetry, stories, etc.)? ...151

152. Have you often wished that your appearance were different? .......... 152

153. Would you rather work outdoors than indoors? . . . . . . . . . . . .

154. Do you often pause just to meditate about things in general? . . . . . . . 154

155. Do you frequently show yourself up disadvantageously? . . . . . . . . . 155

156. Do you usually let others have their own way, even at the expense of your own satisfaction?.

157. Are your friendships limited primarily to members of your sex? . . . . . 157

158. Do you often get into difficulties which you did not seek to cause?........158

169. Do you like to be in a crowd just to be with other people?.............159

160. Are thère many persons who do not care to associate with you?........160

(Go right on to page 10. .) 
161. Are there certain things about some of your family which definitely ${ }^{\text {Pare }} \mathbf{1 0}$ annoy you? ..........................................101

162. Are your spirits usually on a rather even keel? . .................182

163. Would you be, willing to give up everything for your family? ............163.

164. Do you sometimes think the world is distant and dreamlike?..........164

165. Are there some rather serious handicaps in family life? ..............165

166. Can you become so enthusiastic your spirit generates enthusiasm in others? ..........................................168

167. Do you feel people frequently misunderstand what you mean? $\ldots \ldots \ldots \ldots$. 167

168. Are you hesitant to seek assistance from others? ...................188

169. Do you dislike being kidded about your little oddities? . .............169

170. Can you express yourself better in speech than in writing? .............170

171. Is your mood easily governed by your associates - i.e., by others who

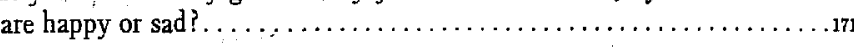

172. Have your parents been too strict with you? . . . . . . . . . . . . . . 172

173. Do you ever laugh at a dirty joke? ........................ 173

174. Does a sudden stimulus startle you easily? .....................174

175. Do you think there have been too little affection and love in your home?. .175

176. Do you like to read criticisms of articles or books you have previously

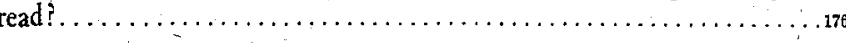

177. Does your family believe you are as much a success as you could be?.....177

178. Do you find pleasure in solving intellectual problems? ................178

' 179. Is it generally hard for you to reach decisions? . . . . . . . . . . . . . . .179

180. Do you enjoy work that needs very little thought after it is learned? ...... 180

181. When driving, does it bother you considerably to get caught in slow traffic?..............................................

182. Do you generally take the lead in making new friends? ...............188

183. Do others often try to get credit for things you have achieved?..........183

184. Do you enjoy mixing socially with others? . . . . . . . . . . . . . . . 184

185. Are you constantly comparing yourself with others? . . . . . . . . . . . 185

(Go right an to page 11 .)
186. Do you and your parents exist in different worlds, as far as ideas Page $\mathbf{1 1}$ are involved? .............................................

187. Do you tend to deliberate over your past? ...................187

188. Do you like all the persons in your family just about equally well?......188

189. Do yoü blush readily? ...................................189

190. Are your relatives as likable and attractive as those of your friends? .....190

191. When traveling, are you more interested in new things and places than in new people?.......................................

192. Are you frequently irritated by minor annoyances?................182

193. Do you ever need to conquer bashfulness? . . . . . . . . . . . . . . . . . 198

194. Do you ever feel flattered because you know an important person?....... 194

195. Have you ever been the life of the party? .....................195

196. Have you often had to remain quiet or leave the house to have peace at home? ............................................

197. Do thunder and lightning make you frightened?.................197

198. Do you usually have better times at places' away from your home?

199. When upset emotionally, do you take much time to recover composure? ....199

200. Is your father your ideal of manhood?

201. Can you play your best in a contest against an opponent much better than you?........................................., 201

202. Are you usually carefree? . . . . . . . . . . . . . . . . . . .

203. Do you sometimes feel isolated and alone when in a group of people?.....203

204. Do you tend to be introspective - that is, self-analytical?...........204

205. Are you always ready to decide what your next step should be? . . . . ...205

206. Do others sometimes offend you unwittingly because you cover your feelings?. . . . . . . . . . . . . . . . . . . . . . . . . . . . . . .

207. Do others often tell you about their personal family problems? ........207.

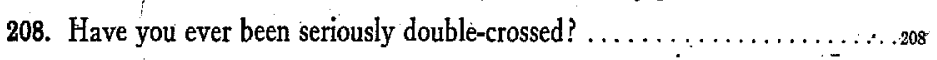

209. Do you tend to remain quiet in a social group? . . . . . . . . . . . . 209

210. Do you sometimes become irritable when not feeling well? . ..........210

(Go right on to page 12.) 
211. Have you ever observed a vague feeling of uneasiness without

Page 12 knowing why?

212. Do you feel you have been bossed too much?...................212

213. Do you ever feel like swearing?............................213

214. Do you ever have thoughts too bad to tell others?................214

215. Has either of your parents any personal traits that annoy you?

216. If a person goes out of his way to be nice, do you look for his real reasons? . .216 217. Have you learned to pay compliments readily when they are deserved? . .217 218. Do others frequently blame you for things unjustly?..............218 219. Have you been concerned about being shy? ................. 220. Are you inclined to be radical in your religious or social attitudes?......220

221. Have you often argued with your parents about how to do work around home?...........................................221

222. Do you often find difficulty in sleeping even though tired? . . . . . . . . .222

223. Have your parents often objected to the companions you choose? . ......223

224. Are you readily moved to tears? ...........................224

225. Is your family too curious about your private affairs? . . . . . . . . . . 225

226. Would you rather keep your radio on a symphony than turn to popular music?.........................................226

227. Can you adjust yourself readily to new conditions or situations? .........227

228. Do you like work involving a great amount of attention to details? . . . . 2228

229. Do you often feel rather awkward? . . . . . . . . . . . . . . . . . . . 228

230. Do you prefer one long complex problem to several simpler ones? . . . . . 2230

231. Are some persons so bossy you like to do just the opposite of what they ask? .............................................

232. Would you rather visit with only one person than with a group? . . . . .232

233. Has lack of money robbed you of opportunities for real success?........233

234. Are people generally interested in your activities? . . . . . . . . . . . . .234

235. In group activity are you often forced to take an insignificant role? . . . . . .2255

(Go right on to page. 13.)
236. When a critical situation is past, do you often think what you Page 13 should have done but didn't? . ........................286 237. Is either of your parents a very nervous person? . . . . . . . . . . . 238. Are you often in a mood of excitement? . . . . . . . . . . . . . . . . . . 238 239. Is either of your parents easily upset? . . . . . . . . . . . . . . . . . 239 240. Are you often too conscientious? . . . . . . . . . . . . . . . . . .

241. Do you become uneasy when waiting for a slow person to finish a task? . . 241 242. Do you like to entertain people?...........................248

243. Have some persons unfairly criticized you to others? ..............243

244. Do you frequently feel ill at ease with others? . . . . . . . . . . . . . 244

245. Do other persons often misunderstand your real intentions? . . . . . . . 245

246. Do your parents fail to recognize your maturity and still treat you as a child?.

247. Does the idea of a fire or an earthquake frighten you?..............

248. Do you often think your parents misunderstand you? . . . . . . . . . . . 248

249. Are you so frequently on the go that you keep yourself worn out? . . . . .249

250. Have you had many unpleasant disputes with your brothers or sisters? . . 250

251. Could you become so absorbed in creative activity that you would not need close friends?................................

252. Do you often fear other persons will dislike you? ................252

253. Can you enjoy an evening alone? . . . . . . . . . . . . . . . . . . . . 253

254. Do you frequently feel conspicuous in a group? .................

255. Do you often analyze other persons' motives? . . . . . . . . . . . . .

266. In social conversation, are you customarily more of a listener than a talker?.............................................

257. Are there some personal things about which you are rather touchy? . . . 257

258. Do you like to take charge of group activities?. ..................258

259. Are you considered critical of others?. . . . . . . . . . . . . . . . . 259

260. Can you usually find a ready answer for remarks made to you? . . . . . . 260

(Go right on to page 14. 


\begin{tabular}{|c|c|c|c|c|c|}
\hline $\mathrm{A}$ & $=$ & $\mathbf{s}$ & - & E & - \\
\hline C & - & $\mathbf{P}$ & - & $\mathbf{H}$ & - \\
\hline
\end{tabular}

\section{HESTON PERSONAL ADJUSTMENT INVENTORY}

261. At a banquet, would you do without something rather than ask to Page 14 have it passed? ...

262. Do you tune the radio away from quiz programs?......

they should be done a o...........282 263. Do you ever put things of when they should be done at once?......... 263 264. Are you generally rot concerned about the future?..................264 265. Have most persons made a better life adjustment than you? ...........265 266. Do you ever wish to move elsewhere because of too few congenial people where you are?. .

267. Are you usually indifferent to the opposite sex?..................267

268. Do you find it hard to start conversations with strangers? .............268

269. Do you often feel people are watching you on the street? .............269

270. Do you think social affaírs are often a waste of time? .270

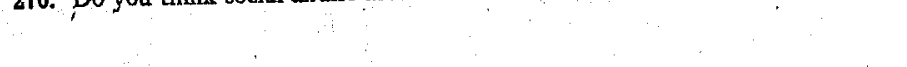

\begin{tabular}{|c|c|c|c|c|c|}
\hline & & & $\Rightarrow$ & $\Rightarrow$ & \\
\hline & 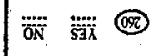 & 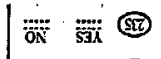 & 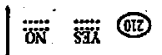 & | $\overline{\mathrm{oN}} \overline{\overline{3 x}}$ & | \\
\hline & 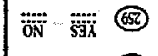 & क्ष & क्ष & 前菏 & 形 臸 \\
\hline & 洴 & $\overline{\mathrm{ON}}$ 前入 & 要 倠 & 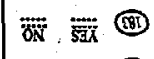 & $\overline{\overline{O N}} \quad \overline{\mathrm{S} I \bar{X}}$ \\
\hline & 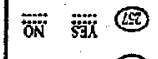 & 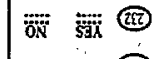 & 养 $\overline{\overline{s i \lambda}} @$ & 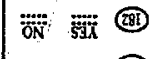 & 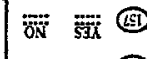 \\
\hline & Ö & $\overline{\text { oN }}$ & 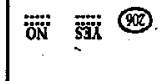 & 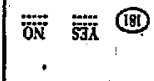 & ӧ \\
\hline & 浱焉 @ & 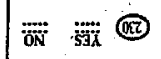 & 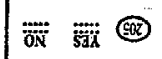 & 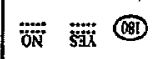 & 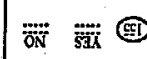 \\
\hline & $\overline{\mathrm{ON}} \overline{\mathrm{Fi \textrm {A }}}$ & 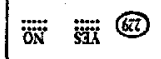 & 前 $\overline{\overline{s i n}}$ & 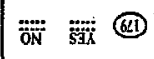 & $\overline{O F} \quad \cdots$ \\
\hline & 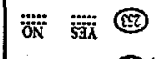 & 器 芌 @ & 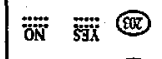 & 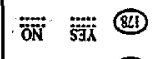 & 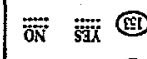 \\
\hline & 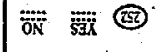 & 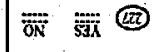 & 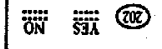 & 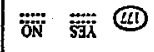 & 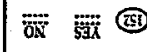 \\
\hline & 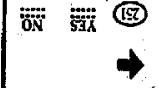 & ON 觔 & 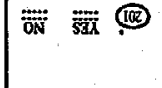 & 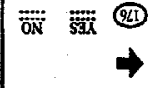 & 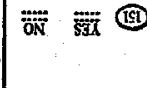 \\
\hline & 菏 菏 & 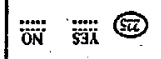 & 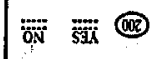 & 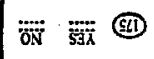 & 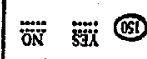 \\
\hline & 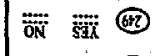 & 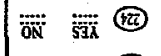 & 竞 泳 & 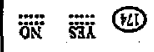 & . \\
\hline & 前 䆑票 & 获 器 @ & 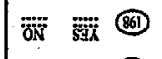 & 渠 器 @ & 榙 萠 \\
\hline & 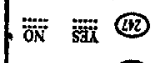 & 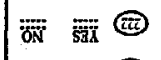 & $\overline{\overline{\partial N}} \overline{\overline{s i x}}$ （@i & 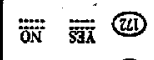 & 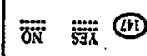 \\
\hline & 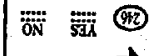 & 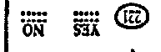 & 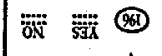 & 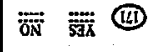 & 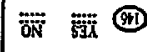 \\
\hline 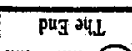 & & & & & \\
\hline 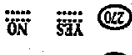 & Ōं & $\overline{\overline{\partial N}}$ 猖 & 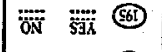 & 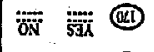 & 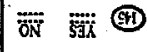 \\
\hline$\overline{\text { oN }}$ & क्ष & 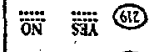 & ŌN $\overline{\mathrm{SAT}}$ & 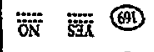 & 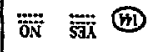 \\
\hline 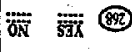 & 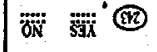 & पूत & 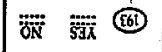 & 跧 & 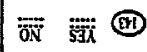 \\
\hline 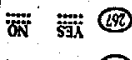 & 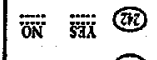 & 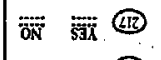 & 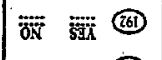 & 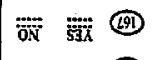 & 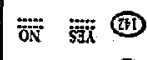 \\
\hline 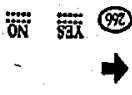 & 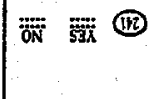 & 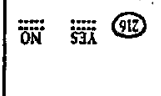 & 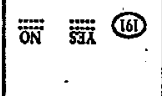 & 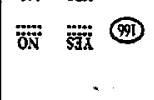 & 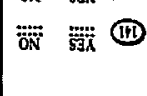 \\
\hline 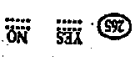 & 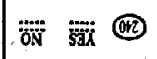 & 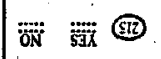 & 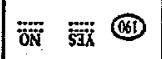 & 프 & 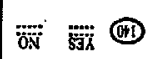 \\
\hline Ō & 㛃 器 & 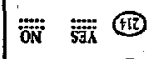 & 获 & 前 唯 & 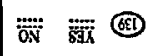 \\
\hline 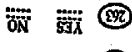 & ö इंत्र & 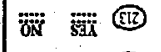 & 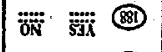 & 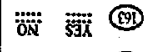 & 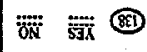 \\
\hline 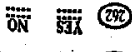 & $\overline{\overline{O N}} \overline{\text { जुर }}$ & 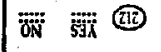 & 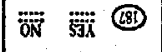 & 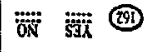 & 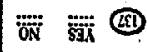 \\
\hline 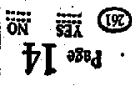 & 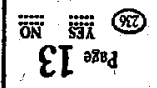 & 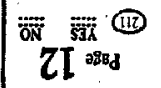 & 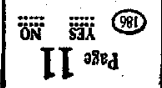 & $\begin{array}{c}\text { OI } \\
\text { OI }\end{array}$ & 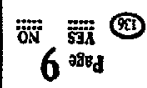 \\
\hline
\end{tabular}




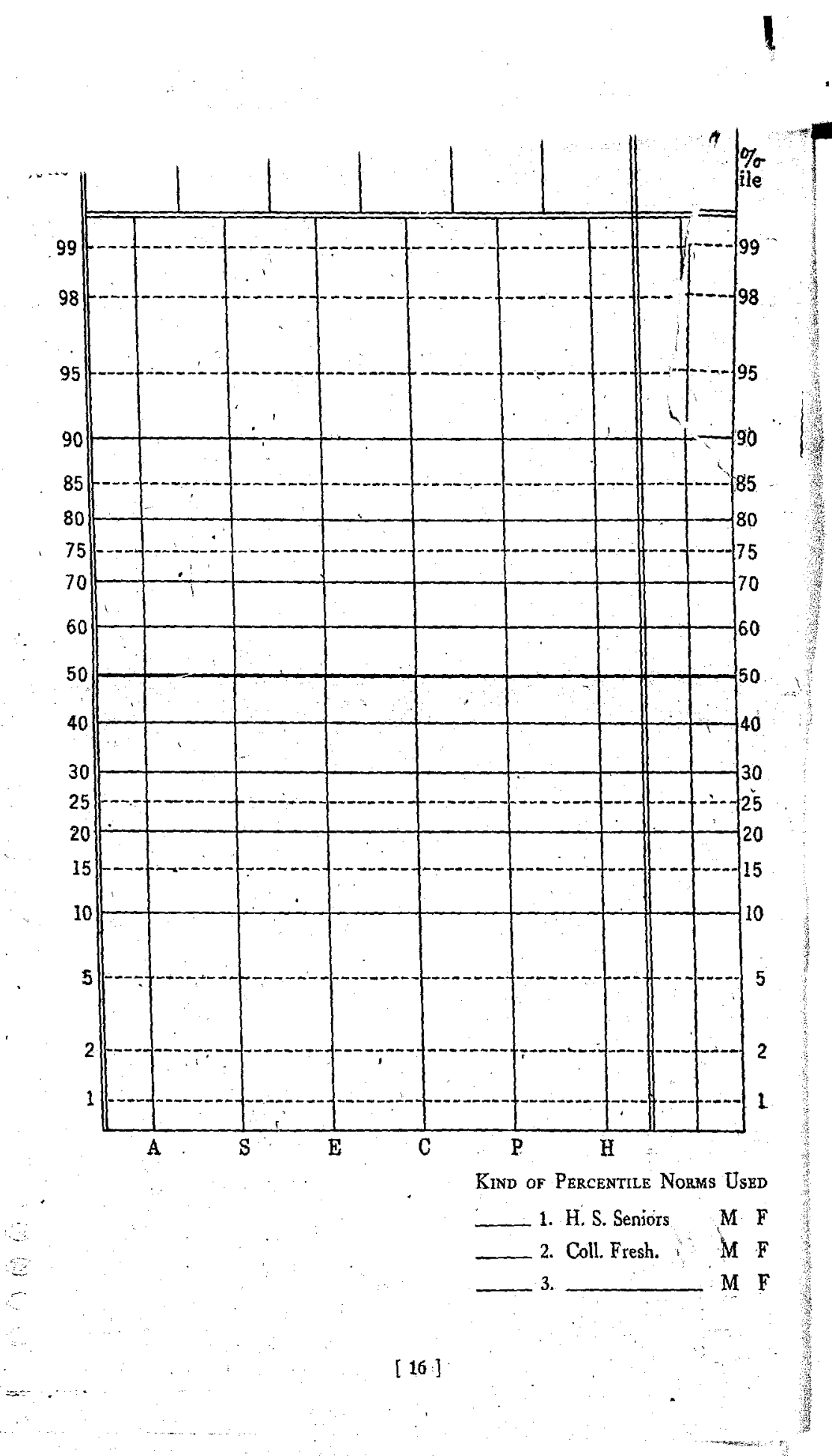


HESTON

PERSONAL ADJUSTMENT INVENTORY

PERSONAL ADISTMENT INVENTORY

Manual

By

Joseph C. Heston, Ph.D.

Director of Bureau of Testing and Research

and Associate Professor of Psychology

DePauw University, Grẹencastle, Indiana

WORLD BOOK COMPANY

Yonkers-on-Hudson, New York 
Copyright I949 by World Boot Comper. Coprenthe-2 any. Copyright in Great Britain. All rights reserved

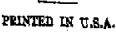

\section{CONTENTS}

PURPOSE OF THE INVENTORY

NATURE OF THE INVENTORY

Content 2

Nature of the Scores 2

\section{General Features}

Answer Sheets

Articulation of Test Booklets and Answer Sheets 3 Time Required for Test 3

Keys 3

Machine Scoring 3

Simplicity of Scoring

Directions for AdMINIŚTERING

Recommended Procedure 4

For administration with separate answer sheet 4

For administration with detachable answer sheet 5

General Directions for the Examiner 6

DIRECTIONS FOR SCORINo

General Directions for Scoring ?

Obtaining and Recording Raw Scores

Machine scoring of separate answer sheet $?$

Hand scoring of separate answer sheet 9

Hand scoring of detachable answer sheet 9

Conversion to Percentiles 10

Use of the Proflle Chart

10

Filling out the Profile Chart 10

Interpreting the Profile Chart' 11

Sample Profiles 11

The Inyentory Scales
(A) Analytical Thinking 14
(S) Sociability 15
(E) Emotional Stability 15
(C) Confidence 16
(P) Personal Relations 16
(H) Home Satisfaction 16

INTERPRETATION OF SCORES
2 
Basic Technical Data

Source of Items 19

Reliability 25

Validity 25

Additional Studies 29

Scale Intercorrelations 31

Spectal Researçh Scales

ACKNOWLEDGMENT

BIBLLOGRAPHY

College Freshmen - Men 20

College Freshmen - Women 21

High School Seniors - Men 22

High School Seniors - Women 23

5. Number and Sources of Cases Used in PrePARING NORMS

6 Reliability of the Inventory Scales

7-10 VALIDITY DaTA

7 Degree of Agreement between Counselors' Judgments and Inventory Scores 27

8 Correlation between Inventory Scores and Mean Trait-Ratings by Acquaintances 27

9 Correlation between Inventory Scores and SelfRating on These Traits 28

10 Correlation between Self-Rating and Mean Ratings by Acquaintances on the Six Inventory Traits 28

11-12 Mean Raw Scores and Critical Ratios of the Difference in Means, for Selected Groups 29-30

11 College Women "Leaders" vs. "Non-Leaders" 29

12 College Men vs. Male Reformatory Inmates 30

13 Correlations between the Invevitory Scales and Academic Aptitude and Acrievement 31

14 Inter-Tratt Correlations for the INVENTORY Scales 


\section{Heston Personal Adjustment Inventory}

\section{Manual}

\section{PURPOSE OF THE INVENTORY}

The busy professional counselor and the guidance-minded classroom teacher have indisputable need for assistance in evaluating the various facets in the personalities of their counselees and students. Knowledge of the counselee's ability level and interest pattern alone will not explain al the complex ramifications of individual behavior. The-way the student feels about himself, the reaction tendencies he follows in dealing with others, his capacity to meet emotional stress - these are all essential components in the modification of his total behavior and achievement. Fully to appraise the complete individual, therefore, one must of necessity include the pertinent personality factors in the equation. The Personal Adjustment Inventory has been designed to assist in this process. It does not purport to give a inal or irrevocable solution to the assessment of personality, but it does provide in convenient, accessible form a significant preliminary summarization of certain traits, thus giving the counselor or teacher a basis for further personalized evaluation of the individual.

The author is well aware of many of the criticisms often leveled against personality questionnaires. Ellis $(8)^{1}$ has performed a useful service in collating many of these objections. The present Inventory meets many of the more fundamental criticisms and is thus freer of basic faults than many of its predecessors in this field of measurement. While no instrument can overcome all the possible errors with which personality inventories have been charged, it is the writer's firm persuasion that such tests do have valuable practical utility and that most forward-looking counselors would rather use a tool with some admitted difficulties than rely solely on subjective judgment, rationalizing the process by refusing the available instruments on the grounds that they are not yet perfected.

This Personal Adjustment Inventory is, therefore, offered as an objective means of getting at six basic components of an individual's adjustment. It is usable with students from high school freshman age to mature adults. Norms are provided for both high school and college groups. Separate adult norms, of non-college type, are not available, but trends observed in the standardization data suggest that this may be unnecessary. All the norms have been built on unselected student groups, presumed typically normal in adjustment; hence all scores are in terms of comparison to high school and college populations in general. Three years of research, involving three successive item-validation studies and the analysis of over 4200 different test papers, supply appreciable evidence of the methodological care used in construction of the Inventory. Clinical experience with many individual cases during the last three years has demonstrated the value of the Inventory approach, both to the author and to numerous visiting counselors on the staff of DePauw's Educational Guidance Clinic, held annually each June.

${ }^{1}$ Italic numbers in parentheses, as in this case, refer to entries in the Bibliography at the end of the Manual. 
To summarize and also to anticipate material to be amplified later, we feel the present Inventory will prove useful in student personnel work for the following specific reasons:

(1) It measures six important traits of personal adjustment.

(2) These traits are well established and easily interpreted.

(3) It was constructed through a continuous long-term research program.

(4) It affords adequate statistical reliability of measurement.

(5) Validation has been carried out by several methods. The Inventory has been validated both statistically and in actual clinical use.

(6) It is usable at either college or high school level:

(7) Stable and representative norms are provided.

(8) It is simple to administer and convenient to score.

\section{NATURE OF THE INVENTORY}

Content

The Inventory comprises a list of 270 questions, to which the person tested is asked to answer "Yes" or "No." He is permitted to indicate those questions to which he is unable to settle on a "Yes" or "No" answer. The questions deal with six aspects of adjustment, designated as follows:

$$
\begin{aligned}
& \text { A-Analytical Thinking } \\
& \text { S-Sociability } \\
& \text { E-Emotional Stability } \\
& \text { C-Confidence } \\
& \text { P-Personal Relations } \\
& \text { H- Home Satisfaction }
\end{aligned}
$$

These six traits are described in detail in succeeding paragraphs. (See section on "The Inventory Scales," on pages 14-17.)

\section{Nature of The Score}

The scoring is on a simple unweighted basis, with ready conversion into adequate percentile-norm equivalents. High scores indicate possession of much of the trait measured and are, in general, preferable, since high scores tend to represent good adjustment and low scores poor adjustment. No item contributes to more than one trait scale; hence any observed relationships between the various scores are genuine in so far as they are derived from separate measures. The items from the various scales are systematically scattered throughout the test to help conceal the identity of the basic traits being investigated. The item arrangement, however, still permits convenient grouping of questions to facilitate scoring.

\section{GENERAL FEATURES}

\section{ANSWER SHEETS}

Separate answer sheets are available on which the individual being tested indicates his responses to the questions. These answer sheets may
be scored either by hand or by the use of the International Business Machines scoring machine. An alternative procedure is to detach and use the answer sheet which is provided in the test booklet. These detachable answer sheets, however, are suitable for hand scoring only. They cannot be scored by machine, and even when the inventories are to be scored by hand, use of the separate answer sheet is recommended in preference to the answer sheet in the booklet, since the former is slightly more convenient to use and score.

The answer sheet contains, for every question, a row consisting of the question number and two spaces (one for answering "Yes" and one for answering "No"). For instance, for question 61 the row would appear as follows:

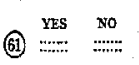

If the student wished to answer "Yes" to this question, he would mark the "Yes" space, thus:

$$
\text { (112) }
$$

Articulation of Test Booklets añd Answer Shetrs

The test booklet and the answer sheet are so organized that each question in the booklet is lined up directly with the answer spaces in which the student is to mark his response. This device insures that the student will not mark his answer in the wrong row.

\section{Time Required for Test}

The test is administered without time limits. This makes it very simple to administer and has the further advantage of insuring that everyone will be able to finish. In the average situation, where students proceed at a fair rate, the majority will finish in forty to fifty minutes.

Separate keys are provided for hand scoring and for machine scoring. The keys for hand scoring are included in the test package. If the answer sheets are to be scored by machine, two keys (a Rights Key and an ItemElimination Key) must be purchased separately, since the keys included in the test package are not suitable for machine scoring.

\section{MAchine SCORING}

As indicated above, the Inventory may be scored by the International Test Scoring Machine. 'For this purpose the separate answer sheet and special machine-scoring keys must be used. It is also necessary when the answer sheets are to be machine scored that they be marked with pencils containing a special kind of very soft lead. These special pencils, containing the electrographic lead, may be procured from International Business Machines Corporation, 590 Madison Avenue, New York 22, N. Y.

\section{SIMPLICITY OF SCORING}

The test is extremely easy to score, either by hand or by machine. The keys are of the convenient stencil type. This means that for hand scoring it is only necessary to place the key over the answer sheet and count the number of marks that can be seen through the holes of the key. The two hand-scoring keys each give scores on three different scales. Scoring by machine is even quicker, since all six scores are obtained at the same time 
(by a single insertion of the answer sheet in the machine). It is worth noting that this simplicity of scoring has been achieved without any sacrifice of validity. In other words, it was considered desirable in the interests of validity to intermingle the items from the various scales, so as to conceal more completely the identity of the traits being measured, and it was possible to set up an efficient scoring system (i.e., all six scores at one insertion) without departing from this principle.

\section{DIRECTIONS FOR ADMINISTERING}

Recommended Procedure

(For administration with separate answer sheet)

1. Distribute the booklets and answer sheets to the students.

2. Each student should have a pencil and an eraser. If it is planned to score the tests by machine, each student should be given a special pencil containing electrographic lead. (See first paragraph on "Machine scoring of separate answer sheet," page 7 .)

3. Say to the students:

"This questionnaire is not like the ordinary test in which you are asked to show what you know. We are interested here in how you feel lou to show what you hnow. Weare interested here in how you jeet about many questions in everyday life. As we read together the directions on the first page of the booklet, you will understand this more fully."

4. Read all the directions on the title page aloud with the class.

5. Then say:

"Now notice the separate answer sheet that has been given you. You are to place all your answers on this answer sheet; do not mark the questionnaire booklet in any way. Now fill in all the blanks at the top of the answer sheet giring Print this information and the back of the acter and the back of the answer sheet. Do not proceed with the questions in the questionnaire until I tell you to do so."

6. Allow time to fill in the blanks. Then say:

"After you have filled out all the blanks on both sides of the answer sheet, be sure it is turned with the answer space side face up."

7. Demonstrate how to place the answer sheet. Then say

"Turn to page 3 of the booklet. Fold the cover page back underneath the rest of the booklet, so that only page 3 shows. Slip the answer sheet under the edge of page 3 so that the column of spaces marked 'Page 3' is alongside page 3 , like this."

8. Demonstrate how to place the answer sheet. Then say:

"Notice that the arrow tips on the answer sheet point directly toward the arrow tips on page 3. When you have finished page 3 , turn to page 4 and fold the page back under the rest of the booklet, so that page 4 is the only page showing. Then slip the answer sheet under the booklet in such a way that the column of answer spaces for page 4 matches the questions for page 4. Again adjust the position of the answer sheet so that the arrow tips on it are lined up with those on page 4 of the booklet Do each succeeding pare in the same way. Note that when jou hare Do each succering it inished page 8 you will have to turn the answer sheet upside down before starting page 9."

9. If the tests are to be machine scored, read the following paragraph. Do not read it if the tests will be scored by hand.

"Mark all, answers with the special pencil which you have been given. Use solid black marks to indicate your answers, and be sure your marks are the same length as the pair of dotted lines. In order to be sure that your pencil marks are sufficiently heavy and black, it is well to ro back and forth orer each mark two or three times, pressing firmly wo the with the pencil. Be sure not to make any unecessary stray pencil marks on the answer sheet - mo matter how light and inconspicuous these marks may be. It is especially important that no stray marks be put on or near the answer spaces."

10. Continue here, regardless of whether the tests are to be machine scored or hand scored:

- "If you should wish to change an answer after you have recorded it, be sure to erase it completely; do not ever try to cross out an answer There is no time limit, but we do want you to work rather rapidly. Read The is arestion and decide upon an answer without much hesitation or each quetion and decide upon an anwer whth deliberition Dossibl help; it will be better to answer every one, if you can. Remember that if you feel you can't possibly answer ' Yes' or "No' to a question, you should fill in the circle which surrounds the question number. Now review the summarized directions at the top of page 3 and proceed with the test."

\section{(For administration with detachable answer sheet)}

1. Distribute the booklets to the students. Each student should also have a pencil and an eraser.

2. Say to the students:

"This questionnaire is not like the ordinary test in which you are asked to show what you know. We are interested here in how you feel about many questions in everyday life. As we read together the directions on the first page of the booklet, you will understand this more fully."

3. 'Read all the directions on the title page aloud with the class.

4. Then say:

"Now notice that the answer sheet for this questionnaire has been printed as pages 2 and 15 of the booklet."

5. While reading the next sentence, demonstrate the way to detach the answer sheet from the booklet.

" Grasp these front and back pages together in one hand and, holding the rest of the booklet in your other hand, carefully pull the answer sheet pages off the booklet, being careful to keep the answer sheet in one piece." 
6. Continue reading:

"You are to place all your answers on this answer sheet; do not mark the test booklet in any way. Now fill in the blanks in the upper left corner of the answer sheet, giving your name, today's date, your age, etc. Print this information accurately and clearly. Do not proceed with the questions in the questionnaire until I tell you to do so."

7. Allow time to fill in the blanks. Then say:

"Slip the answer sheet under the edge of page 3 so that the column of spaces marked 'Page 3 ' is alongside page 3 , like this."

8. Demonstrate how to place the answer sheet. Then say:

"Notice that the arrow tips on the answer sheet point directly toward the arrow tips on page 3 . When you have finished page 3 , turn to page 4 and fold the page back under the rest of the booklet, so that page 4 is the only page showing. Then slip the answer sheet under the booklet in such a way that the column of answer spaces for page 4 matches the in such a way that the column of answer spaces for page 4 matches the
questions for page 4 . Again adjust the position of the answer sheet so questions for page 4. Again adjust the position of the answer sheet so
that the arrow tips on it are lined up with those on page 4 of the booklet. Do each succeeding page in the same way. Note that when you have finished page 8 you will have to turn the answer sheet upside down before starting page 9."

9. Make certain that everyone has understood the directions. Then say

"If you should wish to change an answer after you have recorded it, be sure to erase it completely; do not ever try to cross out an answer. There is no time limit, but we do want you to work rather rapidly. Read each question and decide upon an answer without much hesitation or each question and decide upon an answer without much hesitation or
deliberation. Do not omit any more questions than you can possibly help; it will bo better to answer every one, if you can. Remember that if you feel you can't possibly answer ' Yes ' or 'No' to a question, you should fill in the circle which surrounds the question number. Now review the summarized directions at the top of page 3 and proceed with the test."

\section{General Directions for the Examiner}

Since this is not a "knowledge test" the examiner may, if necessary, help interpret the meaning of a question to a student who requests it. However, the vocabulary has been kept as simple and clear as possible so that this is usually not necessary. The examiner may find that if he encourages students to request much further clarification of questions, they will require an unduly long period to take the test. As has been indicated, in the average situation the majority of students will fnish in forty to fifty minutes.

\section{DIRECTIONS FOR SCORING}

General Directions for Scoring

The separate answer sheet may be scored either by hand or by use of the International Test Scoring Machine: The attached answer sheet can be scored only by hand. Different scoring keys are necessary for the machine and hand methods, but the general principle is the same and the raw scores derived by the two methods are identical. Under either method an answer to any item is scored as one point on its appropriate scale if it agrees with the answer ("Yes" or "No") descriptive of that scale's characteristics. Answers which are the opposite of the scored responses and omitted questions are not counted in the scoring. For instance, if " $\mathrm{No}_{0}$ " is the key response to a particular question, an individual who answers that question "No" is credited with one point; an individual who omits the question or answers "Yes" receives no credit for it.

Before any scoring is done the answer sheets should be inspected to determine the number of omitted items and/or double-marked items. If any double-marked items (i.e., items which have been answered both "Yes", and "No") are found, both answers should be erased and the item counted as omitted.

The count of omitted items should include both unanswered items for which the item number circles have been flled in and items which were couble-marked. If there are more than twenty omitred items in all, the student should either retake the test or reconsider the omitted questions and reach definite answers on most of them. Otherwise the scores on all scales will be artificially lowered and thereby invalidated.

Of the 270 items, 261 are used in obtaining the scores on the six Scales A SECPH. The remaining nine items are not used on the keys for these scales; most of these nine items, however, enter into the scores on the special research scales discussed on pages 32-33 of this Manual.

Obtaining and Récording Raw Scores

The scores obtained from the keys are raw scores. They should be recorded on the answer sheet in the left halves of the boxes which appear in the upper right corner of the answer sheet. (The right halves of the score boxes are to be reserved for the recording of percentile scores.)

The order in which the scores for the various scales are obtained is as follows:

For machine scoring: A CS P E H

For hand scoring (with either answer sheet): A S E C P H

\section{(Machine scoring of separate answer sheet)}

Before they are scored, all answer sheets should be scanned for stray pencil marks (which should be erased) and for answer marks which are not sufficientity long or dark (these should be darkened with an electrographic pencil). It will be found convenient to do this preliminary inspection at the same time the answer sheets are inspected for double-marked items and omitted items (as recommended under "General Directions for Scoring" above). 
To score the test on the International Test Scoring Machine, two keys are necessary - a Rights Key and an Item-Elimination Key. These keys must be purchased separately, since the keys which are included in the test package are not suitable for machine scoring.

The scores on all six scales may be obtained with only one insertion of the answer sheet in the machine. The method of setting up the machine, the steps for checking its operation, and the actual mechanics of operation are not discussed in this Manual, since it is assumed that anyone who scores the Inventory by machine will be familiar with the machine and its operation.

The field holes punched on the Item-Elimination Key for each of the six scales are as follows:

\begin{tabular}{c|c|c}
\hline Conrrots & $\mathrm{R}$ & $\mathrm{W}$ \\
\hline A & Scale A & Scale C \\
B & Scale S & Scale P \\
C & Scale E & Scale H \\
\hline
\end{tabular}

The procedure recommended for setting switches so as to obtain all six scores by machine with optimum efficiency, in the order A C S.P E H, is as follows:

1. To obtain score on Scale A (Analytical Thinking): Set Master Control Switch at $A$; set the three Formula Switches at $\mathrm{R}$.

2. To obtain score on Scale $\mathrm{C}$ (Confidence):

Change A Formula Switch setting from $\mathrm{R}$ to $\mathrm{W}$.

3. To obtain score on Scale S (Sociability):

Change Master Control Switch setting from A to B.

4. To obtain score on Scale P (Personal Relations):

Change $B$ Formula Switch setting from $R$ to $W$

5. To obtain score on Scale $\mathrm{E}$ (Emotional Stability):

Change Master Control Switch setting from B to C.

6. To obtain score on Scale 1 (Home Satisfaction):

Change C Formula Switch setting from $\mathrm{R}$ to $\mathrm{W}$.

The recommended switch settings may be summarized as follows:

\begin{tabular}{|c|c|c|c|c|c|}
\hline \multirow{3}{*}{ SCALE } & \multirow{3}{*}{ Name of Scale } & \multicolumn{4}{|c|}{ Switch Settings } \\
\hline & & \multirow[b]{2}{*}{$\begin{array}{l}\text { MASTER } \\
\text { CONTROL } \\
\text { SWITCH }\end{array}$} & \multicolumn{3}{|c|}{ FORMULA SWITCHES } \\
\hline & & & $\begin{array}{c}\text { A } \\
\text { Formula } \\
\text { Switch }\end{array}$ & $\begin{array}{c}\text { B } \\
\text { Formula } \\
\text { Switch }\end{array}$ & $\begin{array}{c}\text { C } \\
\text { Formula } \\
\text { Switch }\end{array}$ \\
\hline A & Analytical Thinking & A & $\mathrm{R}$ & (R) & (R) \\
\hline C & Confidence & A & $\mathrm{W}$ & (R) & (R) \\
\hline $\mathrm{S}$ & Sociability & B & (W) & $\mathrm{R}$ & (R) \\
\hline $\mathrm{P}$ & Personal Relations & B & (W) & $\mathrm{W}$ & (R) \\
\hline $\mathrm{E}$ & Emotional Stability & C & (W) & (W) & $\mathrm{R}$ \\
\hline $\mathrm{H}$ & Home Satisfaction & $\mathrm{C}$ & (W) & (W) & $\mathrm{W}$ \\
\hline
\end{tabular}

The raw scores obtained on the machine should be recorded in the appropriate spaces in the upper right corner of the answer sheet:

\section{(Hand scoring of separate answer sheet)}

Two hand-scoring keys (Key 1 and Key 2) are included in each test package. These keys are stencils perforated in such a way that when they are superimposed on the answer sheets the scorable responses for each scale show through and may thus be counted.

Key 1 yields scores for Scales A, S, and E, while Key 2 is used to obtain scores on Scales C, P, and $\mathrm{H}$.

Notice the two circles with plus signs in them $(\Theta)$ on the answer sheet. One of these symbols" is near the upper right corner of the answer sheet; the other is near the center of the bottom edge. To obtain the scores for Scales A, S, and E, superimpose Key 1 over the answer sheet in such a way that the two $\bigoplus$ symbols show through the corresponding index holes on the key; the key will then be adjusted so that all the holes and answer spaces are correctly aligned. To obtain the score on Scale A, count the number of answer marks that show through the scoring stencil in the sections marked "A." Likewise obtain the scores on Scales $S$ and $E$, using the appropriately labeled sections of the scoring stencil. Note that on the key all the sections for a given trait have the same crosshatching. The scores for Scales C, P, and $\mathrm{H}$ are obtained in the same way, using Key 2 instead of Key 1. These raw scores should be recorded in the appropriate spaces in the upper right corner of the answer sheet.

A second counting is always advisable to verify the accuracy of the originally recorded scores.

\section{(Hand scoring of detachable answer sheet)}

The same keys are used for hand scoring the answer sheets detached from the test booklet as for the separate answer sheet. The procedure for the detachable answer sheet is the same as for the separate answer sheet except for the method of adjusting the key over the answer sheet.

Notice the two circled I's and the two circled II's on the detachable answer sheets. Notice also that the.left halves of the two keys are marked "When detachable answer sheet is used, place key so that I's show, to score this half." Likewise the right halves of the key are marked "When detachable answer sheet is used, place key so that II's show, to score this half."

This means, for instance, that to obtain the score on Scale A; Key 1 should first be adjusted so that the I's show through the two index holes the answer marks that show through on the two sections marked " $A$ " on the left half of the key should then be counted; then move the key about $1 \frac{1}{2}$ inches to the right so that the II's show through and continue the count of answer marks, this time counting only the marks on the section in the right half marked "A." This method, of course, yields the final score on Scale $A$ (the sum of the scores on the left and right halves of the answer sheet). Scores on Scales $S$ and $E$ are obtained in the same way, using the appropriate sections of Key 1; likewise the $\mathrm{C}, \mathrm{P}$, and $\mathrm{H}$ scores are obtained from Key 2

These raw scores should be recorded in the appropriate spaces in the upper right corner of the answer sheet.

A second counting is always advisable to verify the accuracy of the originally recorded scores. 


\section{Conversion to Percentiles}

After a paper has been scored, the raw scores thus obtained must be converted into their percentile equivalents" before interpretation. The appropriate norm table should be selected from among Tables 1-4.(pages 20-23 of this Manual), according to the student's sex and the type of school (college or high school). When this norm table is entered with the given raw score (found in either margin of the table), the percentile value will be indicated in the body of the table under the appropriate scale column. For example, a college man who has a raw score of 27 on Scale A has, according to Table 1, a 61 percentile rank on $A$. Or, as another sample, it will be seen that a high school girl whose raw score on $\mathrm{C}$ is 31 will have a percentile rank of 88 on C, according to Table 4 .

The percentile equivalents for each scale should be entered in the designated spaces in the scoring box in the upper right corner of the answer sheet, preferably in a different color from the raw scores. If a profile chart is to be filled out, the raw scores should be transferred to the appropriate boxes at the top of the profile chart and the percentile equivalents recorded directly below them. In this event it is not necessary to record the percentiles on the answer space side of the sheet.

It is desirable to check all transfers of score and all percentile conversions, in order to insure accuracy.

\section{USE OF THE PROFILE CHART}

Counselors often find it advantageous to be able to depict test scores graphically as a visual aid in interpretation. This procedure may prove desirable either to permit the counselor himself to see the student's adjustment pattern more clearly or to enable the counselor to utilize this technique in discussing the results with the student. To meet this requirement, a Profile Chart has been prepared for this Inventory and printed on the reverse side of each separate answer sheet. It also appears on the last page of the test booklet, for the benefit of those who use the detachable answer sheet in the baoklet. The six scales (ASECPH) have been identified on this profile by their initial letters only, to prevent the examinees from realizing in advance the nature of the traits covered by the inventory. Spaces have been provided for the recording of raw scores and percentiles on the profile. The Profile Chart is illustrated in Figures 1, 2, and 3 (pages 12-14).

\section{Fillivig Out the Profile Chart}

To prepare the Profile Chart for an individual student, one should first enter the raw scores in the appropriate boxes at the top of the chart, and then convert them to their percentile equivalents, which should also be recorded. Table 1, 2, 3, or 4 (whichever one is the most appropriate) should be used for this conversion. The type of norms used should be indicated at the bottom. For instance, if the riorms for college men are used, a check mark $(\sqrt{ })$ should be put on the line at the left of the words "Coll. Fresh.," and the letter " $M$ " to the right of it should be encircled to indicate that the norms used are those for men. Next, plot the percentile value on each scale by placing a small dot on each of the vertical lines (for the separate scales) at the height corresponding to the indicated percentile rank as calibrated along the margin of the chart. The profile is then completed by drawing a line connecting all the dots for the six scales.

\section{Interpreting the Profile Chart}

Two things should be noted in the interpretation of the Profile Chart in addition to the principles discussed in the "Interpretation of Scores" section of this Manual (pages 17-18). First, it will be observed that the percentile calibrations along the margins of the chart are not equally spaced. The reason for this is that our marginal scale has been drawn in such a way as to take account of the fact that in traits which are normally distributed, small variations around the average are much more common and less significant than variations of the same magnitude at the extremes. For instance, the real difference between the 90th and 95 th percentiles is actually more significant than the difference between the $50 \mathrm{th}$ and 60 th percentiles, even though the latter difference seems twice as large numerically (in terms of percentile points). The scale in the Profile Chart is designed to give a truer representation of the relative degree of variation indicated by the various percentile scores than would be obtained if the percentiles were spaced at equal distances.

The second factor to note is the order used in grouping the traits. In a later section of this Manual (see Table 14) it is pointed out that scales " $\mathrm{E}$," "C," and "P" are often closely related. A lesser positive relation exists between " $\mathrm{P}$ " and " $\mathrm{H}$," and another minor relation appears between " $S$ " and "E." Scale " $A$ " shows little relation to any of the other five scales. The traits are therefore arranged on the Profile Chart so that the ones most often positively related to each other are portrayed side by side. This placing of appropriate traits adjacent to each other enables the counselor to see at a glance whether a particular individual's adjustment pattern follows the group trend or whether there are some noticeable unusual fluctuations in his profile.

\section{Sample Profiles}

Use of the profiles can best be exemplified by presentation of three case histories taken from the author's files. These cases have been selected to illustrate the potential sensitivity of the Inventory in a wide variety of situations.

Miss X, Mr. Y, and Miss Z entered DePauw University as freshmen in September, 1947, and went through the usual comprehensive testing and counseling services of the Bureau of Testing and Research. In each case the writer had considerable personal contact with both the students and theic parents, as well as a great deal of biographical information about the students' backgrounds. One year later it was possible to check in terms of actual college performance the validity of the prognoses one would have derived from the Inventory at the time of these students' admittance to the University.' 


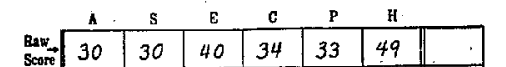

$\cdot$

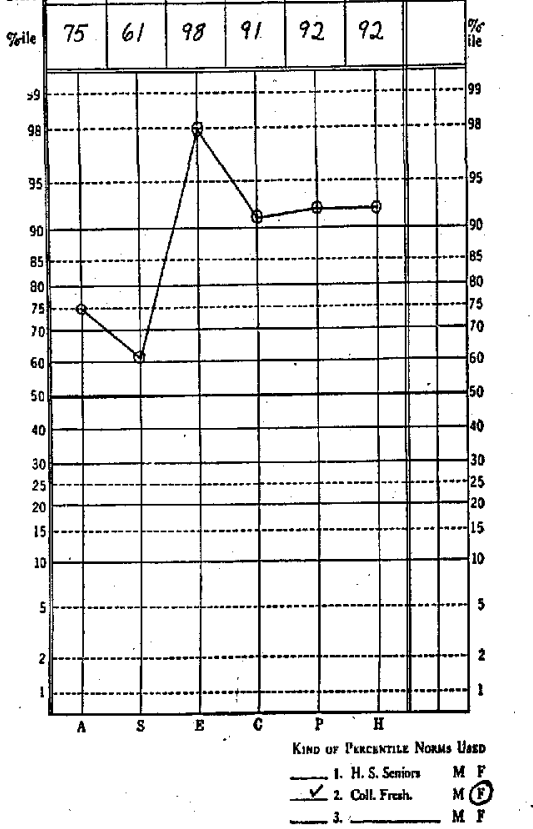

Fic. 1. Profile of Miss $X$

Miss $\mathrm{X}$, whose profile is shown in Figure 1, presents a picture of excellent adjustment on all scales of the Inventory. She came from a good, comfortable home, with moderate income and intellectually superior parents. Her Ability Index (a commoderate income and intellectually superior parents. Her Ability Index (a com-
posite score based on five hours of ability and achievement tests) placed her at the posite score based on five hours of ability and achievement tests) placed her at the background, and ability all indicated that the outlook for her college career was favorable. Miss X made a good social adjustment on the campus; she joined a congenial sorority and entered into a moderate number of campus activities. In her freshman year she had almost a perfect "A" grade-record, and she was elected as one of the outstanding members of the freshman scholastic honorary society. There is little doubt that Miss X will continue to display the same fine adjustment and achieve a similar excellent record in the next three years of college.

Mr. Y (see profile, Figure 2), on the other hand, illustrates one of the worst prognoses from the standpoint of personality adjustment, although home background and ability are relatively favorable. The Inventory diagnosis of multiple maladjustment trends was confirmed later by similar results on the Minnesota Multiphasic Personality Inventory, on which the student's scores denoted serious maladjustment on more than half the scales. Mr. $\breve{Y}$ 's parents were both college graduates and in fairly satisfactory financial circumstances. One of his parents, however, did exhibit distinct symptoms of poor personal adjustment. Academically Mr.Y appeared a safe enough risk, since his "Ability Index"was at the 55th percentile rank and he had been in the top fifth of his high school class. Although not socially inclined, Mr. Y was inducted into the fraternity which members of his family. had usually joined. Within two weeks after college started, he began to
Manual

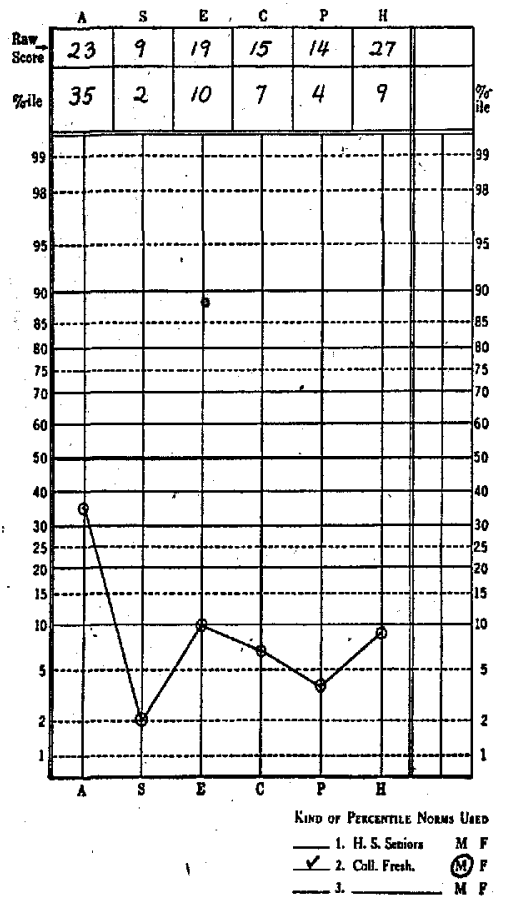

F1G. 2. Profile of Mr. Y

exhibit definite overt manifestations of serious personality maladjustment. He was unduly irascible with his housemates, very erratic in class attendance and preparation, extremely gloomy and despondent, and desperately desirous of dropping tion, extremely gloomy and despondent, and desperately desirous of dropping
college and either joining the army or simply going off on a hobo tour. His family college and either joining the army or simply going of on a hobo tour. His family
and his fraternity brothers put pressure on him to settle down, but this mierely aggravated his instability. Psychiatric assistance became necessary, and upon recommendation of college officials and the consulting psychiatrist he was withdrawn from school for more thorough psychotherapy. At this time it seems questionable that $\mathrm{Mr}_{\mathrm{r}} \mathrm{Y}$. will ever overcome his persona Aty handicaps suffiently to succeed in college or in life to the extent that would be commensurate with his other capacities.

Miss Z's profile (Figure 3) displays minor fluctuations, coupled with one potentially serious area of maladjustment (i.e., Home Satisfaction). Her low rating in this area has since been demonstrated by clinical follow-up to be a factor which this area has since been demonstrated by clinical follow-up to be a factor which has handicapped her markedly in her college work. Her parents are wealthy and
both have college training. Miss Z's "Ability Index" at the 98th percentile together with high school rank at the 95 th percentile seemed to predict a brilliant academic year for her. However, at the close of the year Miss $\mathrm{Z}$ had earned a mediocre low " $\mathrm{C}$ " grade average; she had been given a " $\mathrm{D}$ " in the subject-matter area she had chosen as her probable major field. The contributory significance of the home factor was amply revealed in some half donen conferences with $M$ and several long-distance telephone conversations with her father, who also made two personal visits to the counselor's office. Miss Z's mother, highly dissatisfied by the daughter's failure to join a sorority and by early grade reports of only average 


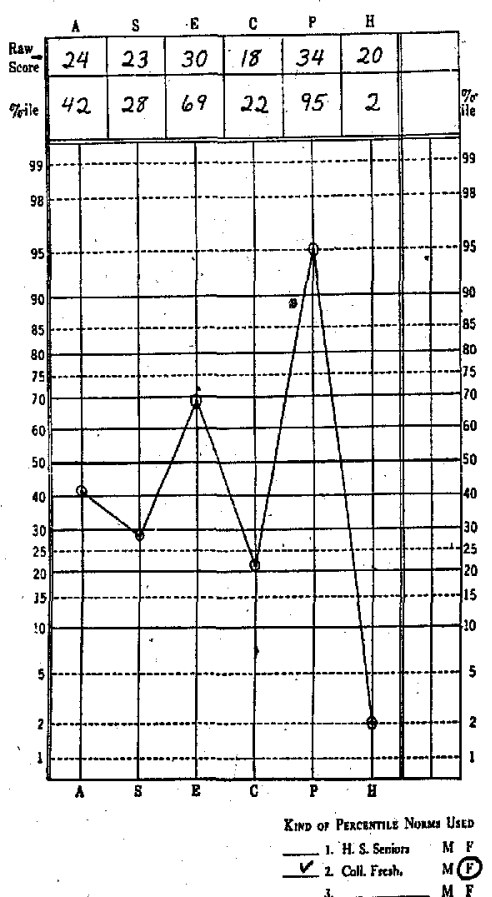

Fic. 3. Profile of Miss $Z$

work, began putting more or less continuous pressure on her. The more the mother complained and urged, the more rebellious and disturbed the daughter mother grew. The father seend to have to spend much of his tine trying to smooth over the mother-daughter controversy. This home situation, indicated at the outset by the Inventory, is to a large extent the underlying reason for Miss $Z$ 's level of achievement failing to be commensurate with her potentially exceptional ability Since home friction is often a factor beyond the effective scope of college counselors, it is likely to continue to hamper Miss Z's further college career. She can and should graduate, but will neither enjoy college as much as she should nor attain the academic success that she might if the home adjustment were better.

\section{THE INVENTORY SCALES}

(A) Analytical Thinking

This scale, which was originally labeled "Intellectuality," parallels what has often been termed "Thinking Introversion." Scores on this scale are not synonymous with intelligence; hence "Analytical Thinking" has been selected as a more accurate designation. A study cited later does show "A" much more closely related to college aptitude and achievement than any of the other scales. A person high on " $A$ " likes to be intellectually independent, thinks for himself, analyzes and theorizes a great deal, enjoys solving problems, likes carefully planned and detailed work, is persistent at tasks, and is serious (as opposed to casual). Low scores suggest an un- critical acceptance of others' ideas, a willingness to avoid planning and thinking, and a dislike for creative or intellectual activities. " $A$ " bears practically no relationship to any of the other five scales; it is a very independent measure. The following samples illustrate " $A$," with the scored answer indicated in parentheses:

60. Does conversation help you more than reading in formulating your ideas?

262. Do you tune the radio away from quiz programs?

109. Do you critically evaluate the structure of novels and movies?

178. Do you find pleasure in solving intellectual problems?

34. Do you do much thinking more than that needed by your work

\section{(S) Sociability}

High degrees of this trait indicate extroversion in the social sense. A person with a high " $S$ " score is more interested in people than in things, he makes friends easily, converses readily and freely, feels he is a "lively" individual, enjoys social mixing, and fiequently takes the lead in social participation. The low person is self-conscious, shy, and socially timid, has only a limited number of friends, and seeks the background on social occasions. He is the "introvert" who is lacking in social skills and/or inclinations. " $\mathrm{S}$ " is more nearly related to " $\mathrm{C}$ " than to any of the other scales. It is least related to "A." Sample " $S$ " questions and answers are:

219. Have you been concerned about being shy?

(No)

168. Are you hesitant to seek assistance from others?

209. Do you tend to remain quiet in a social group?

143. At a party is it easy for you to be natural?

182. Do you generally take the lead in making new friends?

\section{(E) Emotional Stability}

High scores here typify persons who can remain in stable and uniform spirits, are not subject to apprehensive fears or worries, are not easily upset or frustrated, can relax and avoid tension, and see life in reality rather than through daydreams and uneasy retrospection. People low on " $E$ " are easily disrupted by minor crises, are readily embarrassed, often feel tired and listless, are too impulsive and jittery, frequently feel thwarted, and suffer often from tension, worry, and uneasiness. Extremely low scores may indicate the traditional "neurotic." Both " $\mathrm{C}$ " and " $\mathrm{P}$ " appear highly correlated with "E." There is good reason to believe this is a genuine association, since the items of each scale comprise relatively discrete varieties of behavior. "Some sample " $E$ " questions are:

187. Do you tend to deliberate over your past?

62. Are you an impulsive individual?

150. Can you relax yourself easily?

2. Do you daydream often?

61. Can.you regain a state of calm easily after an exciting situation is over? 


\section{(C) Confidence}

Persons scoring high on "C" make decisions readily; feel sure of- the value of their own judgment, adjust easily to new or difficult situations, feel they enjoy the approval and favor of their associates, face the present and future optimistically rather than linger regretfully over the past, lack inferiority feelings, and are not dissatisfied with their physique and appearance. A high positive relationship has been observed here between " $C$ " and " $E$ " (Emotional Stability), as shown in Table 14. People low on " $C$ " distrust their ability, cannot make decisions satisfactorily, and display the traditional "inferiority complex." The following samples illustrate " $\mathrm{C}$," with the scored answer indicated in parentheses:

162. Have you often wished that your appearance were different? (No)

177. Does your family believe you are as much a success as you could be?

229. Do you often feel rather awkward?

32. Are you hesitant about forming decisions?

23. Can you face a difficult task without worry?

\section{(P) Personal Relations}

High scores on " $P$ " indicate two basic attitudes: (1) feeling that other people are trustworthy and congenial and (2) ability to refrain from annoyance and irritation at others' behavior. Thus one who is high on " $P$ " does not feel slighted by others, does not feel they misunderstand him or cast him in an inferior role, is not too critical of others, does not lose patience readily, and is not angered too frequently or too easily. He can see things fairly and impersonally. Persons low on this scale are touchý, suspicious, and easily irked by other people. A very low score might be partially indicative of "paranoid" trends. Caution is needed in the interpretation of an individual's "P?" score, because it has the lowest reliability ${ }^{1}(.80)$ of any of the six scales. Some sample questions, with the high " $P$ " answer shown, are:

257. Are there some personal things about which you are rather touchy?

235. In group activity are you often forced to take an insignificant role?

95. Do you become impatient if waiting for other persons?

67. Do you hesitate to accept new acquaintances as real friends? (No)

167. Do you feel people frequently misunderstand what you mean?

\section{(H) Home Satisfaction}

On " $\mathrm{H}$ " a high score denotes pleasant family relations, an appreciation of desirable home conditions, a feeling of mutual understanding and respect, freedom from emotion-breeding home conflicts, and a healthy recognition of one's obligation to home and family. At the low extreme we find admissions or complaints of such difficulties as wishing for a different home,

$$
\text { 'See "Reliability," page } 25 .
$$

feeling that enjoyment can be found only away from home, conflicts with parents' ideas, family not considerate, parents too strict, domineering, or unsympathetic, or parents overly irritated or emotional. Although composed of items correctly classifiable into a separate category, the " $\mathrm{H}$ " scale exhibits some positive correlation with all the other scales except "A." Sample " $\mathrm{H}$ " statements are:

37. Do you find less appreciation at home than elsewhere? (No)

163. Would you be willing to give up everything for your family? (Yes)

248. Do you often think your parents misunderstand you? (No)

239. Is either of your parents easily upset? (No)

138. Do you talk over important plans with your family? (Yes)

\section{INTERPRETATION OF SCORES}

In evaluating scores on the scales just described. one must observe three limitations to safeguard against certain pitfalls in interpretation. To use these personality scores wisely and appropriately, thes factors should be remembered:

(1) The norms used are based on so-called "normal" individuals - i.e., students who as a group are not expected to include many seriously abnormal folk. Within such groups there are definite and considerable variations and only a few persons are ever exactly average. Even considerable variation should not be construed as seriously unusual, because the norms simply reflect existing variation within typical representative samples of students. Hence one must set the critical scores well out to the extremes of the scales. Only the lowest (and, in certain cases, also the highest) two or three per' centiles are far enough from the average to suggest possibly serious adjustment difficulties.

(2) The scores depend on what the individual says (and is willing to say) about himself. By and large our experience has proved that most persons answer these questions in sincere and consistent fashion. Clinical interviews support the accuracy of tendencies revealed by these trait scores in a surprisingly large majority of instances. However, faked answers and careless answers also have been uncovered. In some cases exceptionally high scores may result when a student chooses the flattering answers, in an attempt to make himself appear much better than he really feels. The validity studies cited later indicate that in general the answers are measuring the tendencies claimed; yet in individual cases the counselor should seek corroboration of extreme scores and not accept the test results uncritically as complete and positive evidence.

(3) In the scoring procedure only answers favorable to each scale description are scored. Thus, high scores mean the definite existence of a given pattern of answers. Low scores customarily mean the absence of this pattern and imply that opposite answers were selected. However, the omission of too many items will automatically tend to lower all trait scores. For this-reason the counselor should not accept as valid any test paper where there are more than 
about twenty questions which have not been answered "Yes" or "No" In such cases the student should retake the test and make a definite "Yes" or "No" choice for nearly all the questions. Answer sheets with an excessive number of unanswered questions can be spotted quite readily, since the instructions require the person tested to fill in the circle surrounding the question number whenever be cannot answer "Yes" or "No." Thus, in the case of any paper which appears to have an excessive number of filled-in question numbers, the scores should be considered of dubious validity.

\section{THE NORMS}

Developmint of the Norms

It is axiomatic that raw scores on any test have little or no interpretative significance. A well-chosen set of norms is the essential background against which one must evaluate the relative meaning of the scores of a given individual. The percentile norms now available for this Inventory (see Tables 1-4 on pages 20-23) afford reasonably stable standards for student popula-

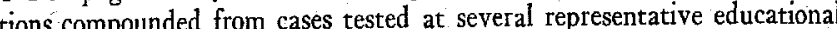
institurions. The composition of the groups on which these norms ar based is described in Table 5 (on page 24). In addition to the number of cases utilized in the preparation of the present norm tables, the author carried out earlier normative analyses of over 2300 additional test papers collected in the preliminary item-analysis research prior to the publication of the current edition of the Inventory.

In the task of compiling data from various schools to secure a representative cross section for each norm population, the author has enjoyed the coöperation of the several educational personnel officials gratefully acknowledged below. 1 : At the college level the entire freshman class (September, 1947) was tested at each school shown in Table 5, except the University of Kentucky. This group of schools is representative of liberal arts colleges chosen to supply students of varying socioeconomic status and academic-aptitude levels. Shortridge High School is the only high school in Table 5 where the entire senior class $(1947-48)$ was not tested; the Shortridge sample was composed of an alphabetically designated sample of seniors. Additional data for evaluation of upper-class college students (not used in the norms) were obtained both from DePauw University and the University of Kentucky. Further data on high school students (Grades 9, 10, and 11) were obtained from the Greencastle (Indiana) Higl School, where all students were tested at each grade level, the Mitchell (Indiana) High School, where all of Grades 11 and 12 were tested, and the Arsena Technical Schools (Indianapolis), where some seniors were volunteer candidates for the test.

${ }^{1}$ The following persons generously coöperated in collecting the norm data: Dr. Carl Kardatzke, Anderson College; Dean Allen B. Kellogg, Indiana Central College; Dean Cora I. Orr and Dean Charles W. McCracken, Muskingum College; Dr. Lysle W. Croft; University of Kentucky; Dr. Fred W. Totten, Wabash College; Miss Elizabeth Daggy and Mr. Glenn Kkelton, Greencastle (Indiana) High School; Dr. Austin A. Cole, Ruchmond (Indiana) Ternich
INTERPRETATION OF THE NORMS

Certain generalizations about the Inventory norms appear to be suggested by the statistical data:

(1) Small but persistent sex differences exist in the score distributions for each scale, particularly in scales "C," " $\mathrm{S}$," and "E." Separate norms for the two sex groups have therefore been prepared.

(2) More difference exists between college students (regardless of yea of study) and high school students (regardless of grade) than between the grade levels within either college or high school. In other words, the difference between freshmen and seniors in high school, or freshmen and seniors in college, is smaller on the average than the difference between high school seniors and college freshmen. This is probably a function of the increase in selectivity of the college population in general. It has therefore seemed necessary to provide separate norms for college and high school. Since the fluctuations of distribution patterns within these two educational brackets are relatively small, it seems feasible to use college freshman norms for any year in college, and high school senior norms for any high school grade.

(3) The college and high school norms are both based upon total distributions obtained from several schools. Some significant differences have been observed among the various schools contributing data. Therefore, while these norms may be taken as representative of college or high school students as a whole, yet it would appear wise for any school using the Inventory for a large group-testing program to check its own distributions for possible significant variations from the general norms.

\section{BASIC TECHNICAL DATA}

SOURCE OF ITEMS

The professionally trained counselor is well aware that most of the various published personality inventories contain a common core of items and areas that keep continuously reappearing. Many of these items are replicas or variations of questions first appearing in the original Woodworth Personal Data Sheet (20), prepared for use with soldiers in World War I. Many factor analyses and validation studies of personality test items have been reported in the literature by Bell, Guilford, Thurstone, McConnell and Evans, Darley and McNamara, Flanagan, and others. The primary difference among many of the current personality inventories (including the present one) lies in the scoring, weighting, and validity of the items and traits being measured. Other important differences involve type and size of norm groups and the degree of caution with which authors have approached the crucial problems of interpretation and verification.

The present author has in the past six years carried out several interinventory correlational studies and factor analyses of existing tests in order further to identify traits measured in common by two or more of these published inventories. All of this research was designed to combine in one instrument the measurement of the several traits judged most useful in the evaluation of students' adjustment. From these analyses of the various 


$$
\text { TABLE } 1
$$

Percentile Norms for the Heston Personal Adjustment Inpentory COLLEGE FRESHMEN - ME

(Norms based on 884 men from five colleges; tested in 1947) Percentile Values

\begin{tabular}{|c|c|c|c|c|c|c|c|}
\hline & & & & & & & \\
\hline $\begin{array}{l}\text { Risw } \\
\text { ScoRE }\end{array}$ & A & $S$ & $i E$ & C & $P$ & $\mathrm{H}$ & $\begin{array}{l}\text { RAw } \\
\text { SCORB }\end{array}$ \\
\hline $\begin{array}{l}51 \\
50\end{array}$ & & & & & & $\begin{array}{l}99 \\
98\end{array}$ & $\begin{array}{l}51 \\
50\end{array}$ \\
\hline 49 & & & & & & 93 & 49 \\
\hline 48 & & & & & & $88^{\circ}$ & 48 \\
\hline 47 & & & & & & 83 & 47 \\
\hline 46 & & & & & & $\begin{array}{l}77 \\
71\end{array}$ & $\begin{array}{l}46 \\
45\end{array}$ \\
\hline 44 & & & & & & 64 & 44 \\
\hline 43 & & . & 99 & & & 59 & 43 \\
\hline 42 & & & 98 & & & 54 & 42 \\
\hline 41 & & 99 & 97 & 99 & & 50 & 41 \\
\hline 40 & & 98 & 96 & 98 & & .46 & 40 \\
\hline 39 & & 97 & 93. & 97 & & 42 & 39 \\
\hline 38 & 99 & 95 & 90 & 95 & 99 & 36 & \\
\hline 37 & 98 & 92 & 87 & 92 & 98 & 32 & 37 \\
\hline 36 & 97 & 89 & 83 & 88 & 97 & 29 & 36 \\
\hline $\begin{array}{l}00 \\
35\end{array}$ & 95 & 85 & $79^{\prime}$ & 84 & 96 & 26 & 35 \\
\hline 34 & 92 & 81 & 74 & 80 & 94 & .24 & 34 \\
\hline 84 & $\begin{array}{l}72 \\
87\end{array}$ & $\begin{array}{l}\text { o1 } \\
78\end{array}$ & $\begin{array}{l}69 \\
69\end{array}$ & 74 & 90 & 22 & 33 \\
\hline 32 & 84 & 73 & 64 & 69 & 88. & 19 & 32 \\
\hline 31 & 80 & 68 & 60 & 63 & 83 & 17 & 31. \\
\hline 30 & 75 & 63 & 54 & 58 & 79 & 15 & 30 \\
\hline 29 & 70 & 58 & 51 & 54 & 74 & 14 & 29 \\
\hline 28 & 65 & 54 & 45 & 49 & 65 & 12 & 28 \\
\hline 27 & 61 & 49 & 40 & 44 & 59 & 9 & 27 \\
\hline 26 & 55 & 45 & 34 & 40 & 52 & 8 & 26 \\
\hline 25 & 48 & 41 & 29 & 37 & 46 & 7 & 25. \\
\hline 24 & 41 & 36 & 25 & 32 & 41 & 5 & 24 \\
\hline 23 & 35 & 32 & 22 & 28 & 34 & 4 & 23 \\
\hline 22 & 30 & 28 & 18 & 24 & 29 & 4 & 22 \\
\hline 21 & 25 & 25 & 16 & 21 & 24 & 3 & ר \\
\hline 20 & 20 & 22 & 12 & 18 & 19 & 2 & 20 \\
\hline 18 & 16 & 18 & 10 & 15 & 16 & 2 & 19 \\
\hline 18 & 13 & 14 & 8 & 12 & 12 & 2 & 18 \\
\hline $\begin{array}{l}100 \\
17\end{array}$ & $\begin{array}{l}10 \\
10\end{array}$ & $\begin{array}{l}14 \\
12\end{array}$ & 7 & 10 & 9 & 2 & 17 \\
\hline 16 & 8 & 9 & 5 & 9 & 8 & 1 & 16 \\
\hline 15 & 6 & 8 & 4 & 7 & 6 & 1 & 15 \\
\hline 14 & 4 & 7 & 3 & 5 & 4 & 1 & 14 \\
\hline $\begin{array}{l}14 \\
13\end{array}$ & $\begin{array}{l}4 \\
3\end{array}$ & 6 & 2 & 5 & 3 & 1 & 13 \\
\hline 12 & 3 & 5 & 1 & 3 & 2 & 0 & 12 \\
\hline 11 & 2 & 3 & 1 & 3 & 1 & & 11 \\
\hline 10 & 2 & 3 & 1 & 2 & 1 & & 10 \\
\hline 9 & 1 & 2 & 0 & 2 & 1. & & 9 \\
\hline 8 & 0 & 1 & & 1 & 0 & & 8 \\
\hline 7 & & 1 & & 1 & - & & 7 \\
\hline 6 & & 0 & & 1 & & & 6 \\
\hline 5 & & & & 0 & & & 6 \\
\hline
\end{tabular}

TABLE 2

Percentule Norms for the Heston Personat Adjustment Inventory COLLEGE FRESHMEN - WOMEN

(Norms based on 597 women from five colleges; tested in 1947) Percentile Values:

\begin{tabular}{|c|c|c|c|c|c|c|c|}
\hline $\begin{array}{c}\text { RAW } \\
\text { ScoRE }\end{array}$ & A & S & E & C & $P$ & $\mathrm{H}$ & \begin{tabular}{|l} 
RAw \\
Scorf
\end{tabular} \\
\hline $\begin{array}{l}51 \\
50\end{array}$ & & & & & & $\begin{array}{l}99 \\
96\end{array}$ & $\begin{array}{l}51 \\
50\end{array}$ \\
\hline 49 & & & & & & 92 & 49 \\
\hline 48 & & & & & & 87. & 48 \\
\hline 47 & & & & & & 81 & 47 \\
\hline $\begin{array}{l}46 \\
45\end{array}$ & & & & & & $\begin{array}{l}75 \\
68\end{array}$ & $\begin{array}{l}46 \\
45\end{array}$ \\
\hline 44 & & & & & & 61 & 44 \\
\hline 43 & V. & & & & & 55 & 43 \\
\hline 42 & & & & & & 49 & $\begin{array}{l}42 \\
41\end{array}$ \\
\hline $\begin{array}{ll}41 \\
40\end{array}$ & & 99 & 99 & & & $\begin{array}{l}44 \\
40\end{array}$ & $\begin{array}{l}41 \\
40\end{array}$ \\
\hline $39^{\circ}$ & & 97 & 97 & 99 & & 35 & 39 \\
\hline 38 & 99 & 95 & 95 & 98 & & 32 & 38 \\
\hline 37 & 98 & 92 & 93 & 96 & 99 & 28 & 37 \\
\hline 36 & 97 & 89 & 91 & 95 & 98 & 25 & 36 \\
\hline 35 & 95 & 86 & 89 & 94 & 97 & 23 & 35 \\
\hline 34 & 92 & 81 & 85 & 91 & 95 & 20 & 34 \\
\hline 33 & 89 & 76 & 83 & 88 & 92 & 17 & 33 \\
\hline 32 & 85 & 72 & 79 & 84 & 87 & 15 & 32 \\
\hline 31 & 80 & 66 & 73 & 79 & 84 & 14 & 31 \\
\hline $30^{\prime}$ & 75 & 61 & 69 & 75 & 79 & 12 & 30 \\
\hline 29 & 70 & 57 & 63 & 71 & 72 & 10 & 29 \\
\hline 28 & 65 & 52 & 58 & 67 & 64 & 9 & 28 \\
\hline 27 & 58 & 48 & 53 & 62 & 57 & 7 & 27 \\
\hline 26 & 53 & 44 & 48 & 57 & 49 & 6 & 26 \\
\hline 25 & 46 & 39 & 43 & 52 & 41 & 5 & 25 \\
\hline 24 & .42 & 33 & 38 & 48 & 36 & 4 & 24 \\
\hline 23 & 35 & 28 & 33 & 42 & 29 & 4 & 23 \\
\hline 22 & -30 & 26 & 29 & 38 & 24 & 3 & 22 \\
\hline 21 & 24 & 23 & 25 & 34 & 19 & 3 & $\overline{21}$ \\
\hline 20 & 18 & 20 & 22 & 30 & 15 & 2 & 20 \\
\hline 19 & $15^{\prime}$ & 18 & 18 & 25 & 12 & 1 & 19 \\
\hline 18 & 13 & 16 & 16 & 22 & 10 & 1. & 18 \\
\hline 17 & 8 & 14 & 14 & 18 & 7 & 1 & 17 \\
\hline 16 & 6 & 12 & 12 & 15 & 5 & 0 & 16 \\
\hline 15 & 5 & 9 & 9 & 12 & 3 & & 15 \\
\hline 14 & 3 & 7 & 6 & 9 & 2 & & 14 \\
\hline 13 & 2 & 6 & 5 & 8 & 2 & & 13 \\
\hline 12 & 2 & 5 & 4 & 7 & 1 & & 12 \\
\hline 11 & 1 & 4 & 2 & 4 & 1 & & 11 \\
\hline 10 & 1 & 3 & 2 & 3 & 1 & & 10 \\
\hline & 0 & 2 & 1 & 2 & 0 & & \\
\hline 8 & & 1 & 1 & 1 & & & 8 \\
\hline 7 & & 1 & 1 & 1 & & & 7 \\
\hline 6 & & 0 & 0 & 0 & & & 6 \\
\hline
\end{tabular}


TABLE 3

Percentile Norms for the Heston Personal Adjustment Inventory HIGH SCHOOL SENTORS-MEN

\begin{tabular}{|c|c|c|c|c|c|c|c|}
\hline \multirow[b]{2}{*}{$\begin{array}{c}\text { Raw } \\
\text { Score }\end{array}$} & \multicolumn{6}{|c|}{ Percentile Values } & \multirow[b]{2}{*}{$\mid \begin{array}{l}\text { RaW } \\
\text { ScoorE }\end{array}$} \\
\hline & $A$ & $\mathrm{~s}$ & E & C & $P$ & $\mathrm{H}$ & \\
\hline $\begin{array}{l}49 \\
48 \\
47 \\
46 \\
45\end{array}$ & & & 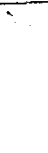 & & & $\begin{array}{l}99 \\
96 \\
94 \\
91 \\
87\end{array}$ & $\begin{array}{l}49 \\
48 \\
47 \\
46 \\
45\end{array}$ \\
\hline $\begin{array}{r}-44 \\
43 \\
42 \\
41 \\
40\end{array}$ & & & $\begin{array}{l}99 \\
98 \\
97 \\
96\end{array}$ & & & $\begin{array}{l}80 \\
75 \\
70 \\
65 \\
63\end{array}$ & $\begin{array}{l}44 \\
43 \\
42 \\
41 \\
40\end{array}$ \\
\hline $\begin{array}{l}39 \\
38 \\
37 \\
36 \\
35\end{array}$ & $\begin{array}{l}99 \\
98\end{array}$ & $\begin{array}{l}99 \\
96 \\
95 \\
92 \\
91\end{array}$ & $\begin{array}{l}94 \\
93 \\
91 \\
91 \\
85\end{array}$ & $\begin{array}{l}99 \\
97 \\
96 \\
93 \\
89\end{array}$ & $\begin{array}{l}99 \\
98 \\
98\end{array}$ & $\begin{array}{c}57 \\
52 \\
48 \\
44 \\
42\end{array}$ & $\begin{array}{l}39 \\
38 \\
37 \\
36 \\
35\end{array}$ \\
\hline $\begin{array}{l}34 \\
33 \\
32 \\
31 \\
30\end{array}$ & $\begin{array}{l}96 \\
94 \\
92 \\
90 \\
88\end{array}$ & $\begin{array}{l}88 \\
83 \\
80 \\
78 \\
74\end{array}$ & $\begin{array}{l}83 \\
79 \\
71 \\
67 \\
60\end{array}$ & $\begin{array}{l}84 \\
82 \\
78 \\
73 \\
66\end{array}$ & $\begin{array}{l}96 \\
95 \\
93 \\
89 \\
88\end{array}$ & $\begin{array}{l}38 \\
34 \\
30 \\
29 \\
27\end{array}$ & $\begin{array}{l}34 \\
33 \\
32 \\
31 \\
30\end{array}$ \\
\hline $\begin{array}{l}29 \\
28 \\
27 \\
26 \\
25\end{array}$ & $\begin{array}{l}86 \\
85 \\
81 \\
73 \\
67\end{array}$ & $\begin{array}{l}69 \\
65 \\
60 \\
57 \\
53\end{array}$ & $\begin{array}{l}53 \\
46 \\
44 \\
41 \\
34\end{array}$ & $\begin{array}{l}60 \\
53 \\
50 \\
45 \\
42\end{array}$ & $\begin{array}{l}84 \\
80 \\
75 \\
70 \\
64\end{array}$ & $\begin{array}{l}24 \\
23 \\
19 \\
17 \\
14\end{array}$ & $\begin{array}{l}28 \\
27 \\
26 \\
25\end{array}$ \\
\hline $\begin{array}{l}24 \\
23 \\
22 \\
21 \\
20\end{array}$ & $\begin{array}{l}61 \\
49 \\
44 \\
38 \\
33\end{array}$ & $\begin{array}{l}48 \\
44 \\
40 \\
33 \\
31\end{array}$ & $\begin{array}{l}24 \\
20 \\
20 \\
15\end{array}$ & $\begin{array}{l}51 \\
32 \\
29 \\
26\end{array}$ & $\begin{array}{l}57 \\
52 \\
44 \\
38 \\
30\end{array}$ & $\begin{array}{l}13 \\
13 \\
11 \\
10 \\
10\end{array}$ & $\begin{array}{l}22 \\
21 \\
20\end{array}$ \\
\hline $\begin{array}{l}19 \\
18 \\
17 \\
16 \\
16\end{array}$ & $\begin{array}{l}29 \\
26 \\
21 \\
18 \\
14\end{array}$ & $\begin{array}{l}26 \\
23 \\
21 \\
17 \\
14\end{array}$ & $\begin{array}{r}13 \\
12 \\
18 \\
7 \\
5\end{array}$ & $\begin{array}{l}14 \\
12\end{array}$ & $\begin{array}{l}26 \\
22 \\
18 \\
15 \\
14\end{array}$ & $\begin{array}{l}8 \\
7 \\
6 \\
4 \\
3\end{array}$ & $\begin{array}{l}16 \\
16\end{array}$ \\
\hline $\begin{array}{l}14 \\
13 \\
12 \\
11 \\
10\end{array}$ & $\begin{array}{r}11 \\
8 \\
6 \\
4 \\
3\end{array}$ & $\begin{array}{r}11 \\
8 \\
7 \\
6 \\
4\end{array}$ & $\begin{array}{l}2 \\
1 \\
1 \\
0\end{array}$ & $\begin{array}{r}11 \\
9 \\
7 \\
6 \\
5\end{array}$ & $\begin{array}{r}11 \\
9 \\
8 \\
7 \\
6\end{array}$ & $\begin{array}{l}3 \\
2 \\
1 \\
0\end{array}$ & $\begin{array}{l}14 \\
13 \\
12 \\
11 \\
10\end{array}$ \\
\hline $\begin{array}{l}9 \\
8 \\
7 \\
6 \\
6\end{array}$ & $\begin{array}{l}2 \\
1 \\
1 \\
1 \\
0\end{array}$ & $\begin{array}{l}4 \\
3 \\
2 \\
1 \\
0\end{array}$ & & $\begin{array}{l}4 \\
3 \\
1 \\
1 \\
1\end{array}$ & $\begin{array}{l}3 \\
1 \\
1 \\
0\end{array}$ & & $\begin{array}{l}6 \\
5\end{array}$ \\
\hline 4 & & & & 9 & & & 4 \\
\hline
\end{tabular}

TABLE 4

Percentile Norms for the Heston Personal Adjustment Inyentory HIGH SCHOOL SEMORS - WOMEN

(Norms based on 251 women from three high schools; tested. in 1947) Percentile Values

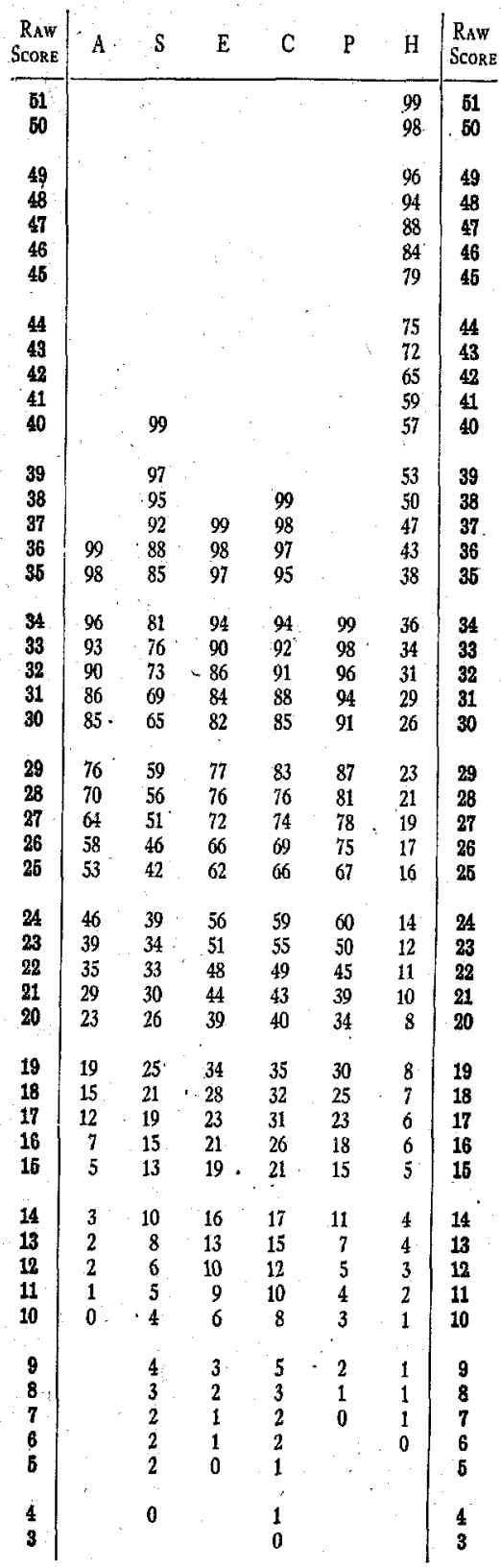


TABLE 5

Number and Sources of Cases Used in Preparing Norms, TABLES 1-4

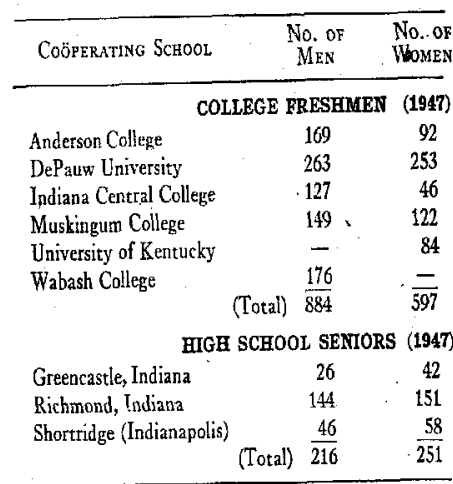

separate personality components that are apparently validly measurable, it has seemed both desirable and feasible to construct this test of traits "A S E C P H."

Many of the items in this Inventory have been modeled after questions found valid for similar traits in preceding inventories. Specifically the author wishes to acknowledge with grateful appreciation the kind permission of the following authors and their publishers to use certain modified and rephras in their own respeccepred (For comple citation parentheses.) It is through the coöperation of these investigators that we were able to approach the construction of the present Inventory with much very valuable background research and experience already available. While the items have all been revised in their wording to clarify their connotations for present purposes, our indebtedness to these earlier authors is still very great:

Bell's Adjustment Inventory (4)

Darley and McNamara's Minnesota Personality Scale (6)

Guilford's Inventory of Factors STDCR (11)

Guilford and Martin's Inientory of Factors GAMIN (12)

Evans. and McConnell's Minnesota T-S-E Inventory (10)

Thurstones' Personality Schedule (19)

These items plus many others constructed originally for this study were then tentatively sorted for experimental analysis and verification into the six trait categories (A S E C P H) now measured by this Inventory. Three item-validation studies, described below, were then carried out with the entire freshman classes entering DePauw University in 1945 and 1946 and in six colleges in 1947. During this experimental observation and statistical refinement more than 450 items were tried out in ultimately selecting the 270 items now included in the Inventory. Throughout this preliminary work and in the present form of the Inventory, no single item has ever been allocated to more than one of the scales. Thus the degree of overlapping between traits (as shown in the scale intercorrelations) is genuine and not an artifact resulting from the practice of counting one item on several scales.

\section{ReLiabilit}

The reliabilities of the six scales in the present edition have been determined by the split-half method applied to a sample of 100 students (50 of each sex) from the 1947 freshman class at Anderson College. The raw correlations thus obtained were treated by the Spearman-Brown Prophecy formula for estimating reliability from two comparable halves of a test. Table 6 presents these corrected reliability coefficients, which are all large enough for very satisfactory use in group situations. In individual cases one should observe some caution,particularly in traits " $\mathrm{C}$ " and " $\mathrm{P}$," where the coefficients are lower and hence the scores are less stable. All of these reliability coefficients are very similar in magnitude to those obtained in two earlier studies - a study based on 200 DePauw University freshman women tested in 1946 (split-half method) and a test-retest (April-September) reliability study done in 1947 with 56 men candidates for scholarships at DePauw University. The close agreement among the three separate studies gives us added confidence that the reliability coefficients reported in Table 6 represent a stable trend.

TABLE 6

ReltabiltTy of the Inventory Scales, as Determined by the

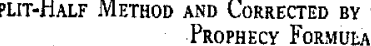

$N=100$ (50 Men and 50 Women, Anderson College, 1947)

\begin{tabular}{lc}
\hline \multicolumn{1}{c}{ SCALE } & RELIABLILTY \\
\hline COEFFCIENT \\
\hline A-Analytical Thinking & .855 \\
S-Sociability & .910 \\
E-Emotional Stability & .862 \\
C-Confdence & .835 \\
P-Personal Relacions & .800 \\
H-Home Satisfaction & .867 \\
\hline
\end{tabular}

The problem of validity of the several scales has been approached in a threefold fashion: (1) the method of internal consistency, (2) the psychological meaningfulness of the component items, and (3) the method of validation against independent criteria. Admittedly none of these methods alone is adequate, for personality tests are by the very nature of their content extremely difficult to validate. As Stagner (17) has so aptly put it, one cannot "surgically lay bare the "inner personality' and compare its organization with results of the test. Only indirect inferences are possible."

No item has been retained in any of our final scales unless it first meets the test of internal consistency. This technique, used successfully by the Thurstones (18), has been utilized in several inventories since. To satisfy this criterion, an item must successfully differentiate between "High" and "Low" criterion groups on the scale in question. In selecting items for this Inventory the criterion groups on any given scale were the highest 27 per cent of the sample (scored by the predetermined answer key) and the lowest 27 per cent. Use was then made of the "Discrimination Index" suggested by Davis (7). 
Three internal-consistency studies have been performed, involving espectively trat-riterion oroups chosen from the 1945 DePauw University freshme the $1946 \mathrm{D}$ aun University freshmen, and in 1947 from all the papers (from six colleges) used in final preparation of the present norms. Following each analysis, items were then assigned (or changed, if necessary) to the scale for which they earned the highest discrimination index. In these successive steps of statistical refinement many items were eliminated and some ultimately became attached to scales other than the ones for which they were originally formulated in 1945 . A minimum Discrimination Index of 30 was used for retention of an item, and a mean Discrimination Index of 45 or higher was obtained for the items in each scale.

Separate item-analyses were run for each sex in the 1947 population obtained from the six coöperating colleges. This procedure was designed to determine if separate scoring keys should be used for the two sexes. The obtained validities were su nearly parallel for the two sexes on every scale that we are definitely warranted in concluding that separate scoring keys are not justified for the two sexes. Even though separate norms are needed, the traits, measured in each case appear based on the same item patternș.

The hasty critic will freely point out that use of the method of internal consistency in item-validation is unfortunately analogous to "lifting oneself by one's bootstraps." This methodological difficulty is recognized, but one cannot overlook the fact that item-relationships assessed in this manner must exist in the thinking and attitudes of the examinees who have taken the tests. Otherwise items chosen as "valid" for one population would not show repeated consistency when transferred to other groups. The surviving items now used in our Inventory must have some meaningful stability, since they have demonstrated continued significance in three separate analyses, even when involving students from six different college populations. Factor analysis, sometimes suggested as a substitute method of item selection, is essentially not so different, for it depends upon correlations obtained from inter-item relations and hence is an "internal" method, too.

The second method utilized in seeking to improve validity was the insistence that in connotation each statement must be psychologically meaning ful for the trait under consideration. An item was not assigned to a scale, no matter how high its statistical discrimination index, unless in its customary connotation it made "sense" for that scale. In part the author was helped here by the judgment of the earlier authors previously acknowledged and in part by the judgment of the various counselors working with him in the DePauw University Bureau of Testing and Research.

In the third approach to evaluation of validity we have utilized a series of studies seeking to demonstrate the relation of test scores to specified independent criteria. ${ }^{1}$ The goal in these studies has been to observe how the Inventory's assessment of personality components agrees with some of the methods frequently used in student personnel programs. One does not expect validity coefficients here equal to those obtainable in intelligence or achievement measurement.

In one study 34: DePauw faculty members were given the Inventory percentile scores of each of their student counselees and asked to express

'All these investigations were carried out at. DePauw under the author's supervision raphy, or by the staff of the Bureau of Testing and Research their judgment on each score in one of three possible ways: (1) Agree with score within 15 percentile points, (2) Disagree by more than 15 percentiles, or (3) Refuse to judge because of too little basis. (The counselors were given more than one futl semester to become acquainted with their students before they were given their scores and asked to express their judgments.) These 34 professors passed judgment on the "validity" of the scores for a total of 269 counselees, as shown in Table 7. With the exception of trait " $\mathrm{H}$ " (refused judgment in half the cases) the counselors agreed about 65 per cent of the times and disagreed about 10 per cent, refusing 25 per cent of the judgments. It is apparent that the Inventory traits size up a student in somewhat the same manner as the faculty counselor knows him.

TABLE 7

The Degree of Agremment between Counsrlors JUDGMENTS AND INVENTORY SCOREs

(Based on 34 Counselors and 269 DePaury Freshmen)

\begin{tabular}{lccc}
\hline \multirow{2}{*}{ Inventory Tratt } & \multicolumn{3}{c}{ (Per Cent of Counselor Judgaemts) } \\
\cline { 2 - 4 } & AGregd & Disagreed & Refused \\
\hline A-Analycical Thinking & 64 & 10 & 26 \\
S-Sociability & .66 & 8 & 26 \\
E-Emotional Stability & 69 & 6 & 25 \\
C-Confdence & 65 & 12 & 23 \\
P-Personal Relations & 61 & 12 & 27 \\
H- Home Satisfaction & 47 & 4 & 49 \\
\hline
\end{tabular}

Armstrong (2) compared trait scores earned by 95 DePauw upperclass men with ratings on these same traits. Each subject was rated by seren close acquaintances on a graphic rating scale showing five steps or degrees per trait. 'In scoring the ratings, however, a ten-step "ruler" was used to measure the strength of each rating, thus permitting more refinement of the data. The raw correlation between each trait score and its respective mean rating was determined. These coefficients were then corrected for the unreliability of the criterion, using the formula suggested by Adkins (1), designed to predict validity if the criterion was perfectly reliable. This method is superior to the customary correction for attenuation that corrects for unreliability of the test, too. The corrected coefficients shown in Table 8 indicate significantly positive correlations in each comparison. Some of these are as high as those often secured between college aptitude tests and college grades.

TABLE 8

Correlation between INventory SCores and Mean Trait-Ratings by Acquantances $N=95$ (DePaw Upper-Class Students)

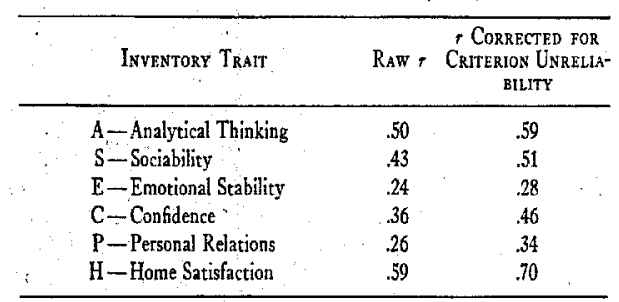


The Armstrong study raised the question as to how test scores would be related to self-ratings. In Table 9 are presented the raw validity coefficients thus obtained in a sample of 92 DePauw University freshmen in 1947. These parallel the raw correlation coefficients in Table 8 to a certain extent.

TABLE 9

CoRrelation betweEn InVENToRy Scores and Self-Rating on These Traits

$N=92 \quad$ (DePauw Freshmen)

\begin{tabular}{|c|c|}
\hline Inventory TRATT & t \\
\hline A - Analytical Thinking & .31 \\
\hline S-Sociability & .45 \\
\hline E-Emotional Srablity & 46 \\
\hline C-Confidence & .34 \\
\hline $\mathrm{P}-$ Personal Relarions & .35 \\
\hline H-Home Satisfartion & .62 \\
\hline
\end{tabular}

To complete the cycle of appraisal of such rating as criteria of validity, Eloe (9), using 81 of the same students involved in Table 9, correlated their self-ratings with their mean ratings by five acquaintances. His data, in Table 10, show on the average somewhat less agreement between the two types of ratings than between Inventory scores and either set of ratings. We may conclude that the Inventory scores are in the main more consistent than either of the types of rating used as criteria in Tables 8 and 9 . The Sociability and Home Satisfaction scales seem the most valid when judged by rating criteria.

$$
\text { TABLE } 10
$$

Corpelation between Self-Rating and Man Rating by Acouaintances on tHe Six InVEntory Traits

\begin{tabular}{lr}
\multicolumn{1}{c}{$N=81$ (DePauw Freshmen) } \\
\hline \multicolumn{1}{c}{ TRATT } & \multicolumn{1}{c}{} \\
\hline A-Analytical Thinking & .13 \\
S-Sociability & .38 \\
E-Emotional Stability & .27 \\
C-Confdence & .44 \\
P-Personal Relations & .27 \\
H-Home Satisfaction & .43
\end{tabular}

In a small study involving only $37 \mathrm{DePauw}$ University freshmen, Longley (16) computed all the intercorrelations between this Inventory and the Minnesota Multiphasic Personality Inventory (13). High scores on the MMPI signify maladjustment; hence negative correlations would be anticipated for those scales on the two tests that exhibit agreement. Because of the small sample we shall summarize here only correlation coefficients of .50 or more, as suggesting significant relationship. None of the MMPI scales revealed coefficients of this magnitude with our scales for Analytical Thinking, Sociability, or Home Satisfaction; these results were as one would expect. Confidence correlated -.50 with Depression and -.64 with Psychasthenia. Personal Relations correlated -.75 with Depression,

\section{Manual}

-.53 with Psychasthenia, and -.52 with Schizophrenia. Emotional Stability correlated -.55 with Psychasthenia and -.59 with Schizophrenia. All these coefficients indicate positive agreoment that people low on our "C," "P," and "E" scales are prone to show relatively poor adjustment as far as the MMPI scales for Depression, Psychasthenia, and Schizophrenia are concerned. This corroborates the conclusions one might draw from a comparison of the trait descriptions for the two tests.

Henry (14) has recently devised a 22-item questionnaire with quantitative answers to measure Sociability among college students. Each item is so phrased that the respondent gives a numerical answer to a question asking "How many?" or its equivalent. Scores ranging from 35 to 105 (with a median at 76) have been obtained; thus his test affords a wide possible variability. Using this as his criterion of Sociability, he found the following (raw) coefficients of correlation, in a sample of 49 DePauw University upperclass men, between his test and our Inventory scales: Confidence .44, Personal Relations .08, Analytical Thinking .08, Sociability .71, Home Satisfaction .26, and Emotional Stability .12. Since the correlation of our Sociability scale with Henry's quantitative measure of the same trait is so high even when not corrected for criterion unreliability, it is evident that both scales are arriving independently at the same sort of measurement.

\section{Additional Studies}

There are several further analyses which can be used to help clarify some of the significance of Inventory scores, even though these researches are not cited as validity measures. Bauerschmidt and Kennedy (3) used the Inventory in a study contrasting "leaders" and "non-leaders" among the senior women at DePauw in 1948. Their objective criterion of leadership was the "activity-point" system customarily used on the campus in controlling the number of extracurricular activities participated in by any one student. These investigators selected from the 195 women of the senior class the 20 with the highest point total for four years and the 20 with the lowest total. The leaders had an average of 64 points, ranging from 42 to 85 , and the non-leaders an average of 8 , with a range of 2 to 16 . The data in Table 11 give the means and critical ratios for differences in means. None of the critical ratios reach the "certainty" level of 3.0 , but the ones for Analytical Thinking and Emotional Stability are high enough to predict that in about 98 out of 100 cases leaders will be higher than non-leaders on

TABLE 11

Mean Raw Scores and Critical Ratros of the Difference in Means on the Hegton Personal Adjustment Inventory for 20 Collegge Women "Leaders"
vs. 20 "Non-Liaders"

\begin{tabular}{|c|c|c|c|c|c|}
\hline INvENTORY SCAIE & $\begin{array}{c}\text { LEADER,' } \\
\text { MEAY }\end{array}$ & $\begin{array}{c}\text { NoN- } \\
\text { LEADERs } \\
\text { MEAN }\end{array}$ & $\begin{array}{c}\text { DifFer- } \\
\text { ENCE }\end{array}$ & $\begin{array}{l}\text { STANDARD } \\
\text { ERROR OF } \\
\text { THE DIF- } \\
\text { FEREACE }\end{array}$ & $\begin{array}{l}\text { CRTticai Ratio } \\
\text { OF THE Difter- } \\
\text { eNCE in Means }\end{array}$ \\
\hline A-Analytical Think & 26.8 & 23.2 & 3.6 & 1.7 & 2.06 \\
\hline S-Sociability & 29.5 & 28.5 & 1.0 & 1.8 & 0.56 \\
\hline E-Emotional Stability & 28.3 & 24.0 & 4.3 & 2.2 & 2.16 \\
\hline C-Confidence & 28.8 & 24.7 & 4.1 & 6.3 & 0.64 \\
\hline P-Personal Relations & 26.2 & 22.4 & 3.8 & 4.2 & 0.89 \\
\hline H - Home Satisfaction & 39,0 & 38.6 & 0.4 & 12.6 & 0.03 \\
\hline
\end{tabular}


While the other differences are less significant, it is evident that leaders have a tendency to score higher on all the scales except Home Satisfaction. Examination of the individual scores reveals the following interesting generalization, that while some non-leaders may be high on Invery any scale.

Cook (5) used the Inventory with 73 men just being admitted to the Indiana Reformatory at Pendleton. The age distribution of these male prisoners approximated that of college men. The offenses for which they were committed were not of the type to justify penitentiary sentences. Seeking to determine what differences in adjustment the Inventory would reveal, Cook compared the 73 reformatory inmates' score distributions with the sample of 884 college freshman men used in our norm group. The data in Table 12 reveal that in every scale the college men exhibited superior

TABLE 12

Mean Raw Scores and Crittcal Ratros of the Difference in Means on the Heston InveNToRy for 884. College Men vs. 73 Male REFORMATORY INMATES

\begin{tabular}{|c|c|c|c|c|}
\hline INvENTORY SCALE & $\begin{array}{c}\text { COLLEGE } \\
\text { MEN'S MEAN }\end{array}$ & $\begin{array}{l}\text { REFORMATORY } \\
\text { MEAN }\end{array}$ & $\begin{array}{c}\text { STANDARD } \\
\text { ERROR OF } \\
\text { THE DrFERERACE }\end{array}$ & $\begin{array}{l}\text { CRItical Ratio } \\
\text { OF THE Dirft:- } \\
\text { ENCE IN MEans }\end{array}$ \\
\hline A-Analytical Thinking & 24.7 & $21: 2$ & .32 & 10.94 \\
\hline S-Sociability & 26.1 & $24,0^{\circ}-1-3$ & .91 & $2.31^{\circ}$ \\
\hline E-Emotional Stability & 30.1. & 26.4 & .94 & 3.94 \\
\hline C-Confidence: & 26.8 & 24.7 & .87 & 2.41 \\
\hline $\mathrm{P}-$ Personal Relations & 24.7 & 23.0 & .72 & 2.36 \\
\hline H-Home Satisfaction & 38.8 & 34.2 & 1:13: & 4.07 \\
\hline
\end{tabular}

adjustment scores, for all the critical ratios either reach or approach signifcance. The Inventory can evidently make successful group discrimination between these two widely divergent samples of men. The critical ratio for "A" is very high, which is not surprising. In a second phase of the study Cook did not succeed in finding significant differentiation between our norm group of high school boys and a group of 98 boys of comparable age at the Indiana Boys' School at Plainfield, a juvenile correctional institution. Apparently the divergence (in educational and socioeconomic status as well as in antisocial inclinations) is less pronounced here than between the older men in the college and adult criminal groups sampled.

Since the Inventory will be used in educational institutions, there will be considerable interest in its relation to those two familiar variables frequently used in academic research - i.e., scholastic aptitude and scholastic ächievement. Accordingly we have carried out a study of a sample of 100 DePauw 1947 freshmen (50 men and 50 women), using the American Council on Education Psychological Examination (total raw score) as our criterion of scholastic aptitude, and first-semester grade-average as our measure of achievement. The raw correlation coefficients are given in Table 13. Only two of the coefficients are significant, indicating some small positive relation between Analytical Thinking and both variables. This is an interesting trend, but should not necessarily be construed as evidence of validity for our scale "A." The negative correlation between " $E$ " and grade-average is not quite significant, but it does confirm a similar trend we have observed in various earlier studies.
TABLE 13

Correlations between the Inventory Scales and ACAdemic A ATITUde aNd Achievement

$N=100 \quad$ (50 Men and 50 Women, DePauw University, 1947)

\begin{tabular}{|c|c|c|}
\hline SCALE: & $\begin{array}{l}\text { CORRELATHON WITH } \\
\text { ACADEMIC APTITUDE A } \\
\text { (ACE PSYCHOLGCALA } \\
\text { EXAMINATION) }\end{array}$ & $\begin{array}{l}\text { CoRRELATION WITH } \\
\text { ACADEMICACHIEVEMENT } \\
\text { (FrRST SEMESTER } \\
\text { GRADE AVERGGES) }\end{array}$ \\
\hline$A-A$ Analytical Thinking & .307 & .358 \\
\hline S-Sociability & -.039 & -.051 \\
\hline E-Emotional Stability & -.087 & -.243 \\
\hline $\mathrm{C}$-Confidence & -.021 & -.126 \\
\hline P-Personal Relations & -.096 & .041 \\
\hline $\mathrm{H}-$ Home Satisfaction & -.032 & -.084 \\
\hline
\end{tabular}

\section{SCALE INTERCORR ELATION}

Whenever one is confronted with a series of labeled scores, each supposedly measuring a different trait, an appropriate question to ask is "Are these traits really separate and independently measured, or are the test elements which compose one score the same as those which enter into another score, thus causing a spuriously high correlation between the different scores?". In too many personality inventories the latter is the case The same items enter into several different scores so that even if the trait measured were independent, the scores obtained would necessarily be correlated at least to a certain extent, since a change in one response would change several scores simultaneously; furthermore, if there were a genuine correlation between two of the traits measured, the correlation between the obtained scores would be unduly high, since it would reflect not only the true correlation but also the spurious relation arising from the failure to obtain independent measures of the traits.

In the Heston Personal Adjustment Inventory; each of the six traits is measured entirely independently, by a separate set of items. The items in each set have demonstrated that, in light of both logical and statistical considerations, they belong in that set alone. Since this is the case, we may feel confident that whatever correlations are found between scales represent true relationships and are not artifacts resulting from the scoring method employed.

Examination of the intercorrelations among the scales shows that the degrees of relationship between pairs of traits assessed by the Inventory vary rather widely; some of the correlations are in the vicinity of zero while others are definitely significant in magnitude, as seen in Table 14 These data, based on a combined sample of 50 men and 50 women from the 1947 DePauw freshman class, are very much like others we have previously obtained with earlier groups. The congruent results found with successive samples indicate adequate stability for the present data. In 1946 we calculated separate intercorrelation tables for a sample of 100 men and another of 100 women. The two sets of coefficients were so nearly parallel that we were justified in using a combined sample for the 1947 analysis.

From the evidence in Table 14 it seems obvious that scales " $C$," " $P$," and " $E$ " form a significantly related triad. This association is both logical and genuine. The items do not overlap from one scale to another. Although 
TABLE 14

Inter-Trait Corgelations for the Inventory Scales

$\hat{N}=100 \quad$ (50 Men and 50 Women, DePáuw University, 1947)

\begin{tabular}{|c|c|c|c|c|c|c|}
\hline Scale & $\Lambda$ & $S$ & $E$ & C & $P$ & $\mathrm{H}$ \\
\hline $\begin{array}{l}\text { A-Analytical Thinking } \\
\text { S-Sociability } \\
\text { E-Emotional Stability } \\
\text { C-Confidence } \\
\text { P-Personal Relations } \\
\text { H- Home Sacisfaction }\end{array}$ & & $\begin{array}{c}-.076 ! \\
\vdots\end{array}$ & $\begin{array}{r}-.183 \\
.325\end{array}$ & $\begin{array}{l}.011 \\
.438 \\
.726 \\
. \\
-\end{array}$ & $\begin{array}{r}-.169 \\
.378 \\
.641 \\
.580 \\
1\end{array}$ & $\begin{array}{l}.033 \\
.262 \\
.382 \\
.312 \\
.393\end{array}$ \\
\hline
\end{tabular}

they involye categories of behavior independently describable, it is easy to see how the three characteristics can coexist to similar degree in many persons. This raises the pertinent question as to whether it is necessary to measure the three traits separately, when perhaps one scale would suffice To meet this query, the data for a random sample of 50 men were examined. The procedure followed was to determine how frequently a man's score on one trait fell in the same quarter of the norms on the other trait. Thus, if he had a percentile of 98 on " $\mathrm{C}$ " anid a percentile of 76 on " $\mathrm{P}$," he was in the same (top) quarter of the norms. In the ensuing comparisons we found " $\mathrm{C}$ " and " $\mathrm{P}$ " coincided in the same quarter in 36 per cent of the cases, " $C$ " and " $E$ " in 52 per cent of the cases, and " $P$ " and " $E$ " in 48 per cent of the cases. We can conclude, then, in spite of the high correlations observed among these three traits, that in at least half the cases the score on one trait will probably vary, 25 or more percentile points from the other two scores. This seems to justify continued use of all three scales to get at separate factors in adjustment.

Scales " $\mathrm{S}$ " and " $\mathrm{H}$ " show some positive association with " $\mathrm{C}$," " $\mathrm{P}$," and " $E$ " and also with each other. These correlations, however, are smaller and of less consequence than those in the "C P E" triad just discussed. Again we stress that since there is no item overlapping, all associations observed are legitimate phenomena and not spurious artifacts. It seems reasonable to assume some positive relations would be found among traits of supposed good personal adjustment

Scale "A," our measure of Analytical Thinking, seems very much divorced from the other five scales. It is certainly the most independent scale of the entire Inventory. Not only does it correlate to a negligible degree with the other five, but it will be recalled that "A" was the only one appreciably related to our academic measures of aptitude and achievement. The description of the scale itself perhaps provides sufficient explanation as to why " $A$ " shows so little relation to the other scales.

\section{SPECIAL RESEARCH SCALES}

The author has developed from this Inventory another scale, "Masculinity-Femininity," for use in psychological research projects. This "MF" scale, described elsewhere (15), is not being made generally available with the Inventory, because it is not only more tentative, but also much more difficult to interpret clearly to the average examinee.

\section{Manual}

Bauerschmidt and Kennedy (3), in 33 study, have begun the development of a "Leadership" with their leadership item-analysis procedure similar to that used for the "MF", based on an

Qualified professional workers who usish for the "MF" scale.

scales in new research projects are invited to use either of these tentative author. Scoring keys and an pertited to communicate directly with the properly supervised research purposes norms will be made available for

\section{ACKNOWLEDGMENT}

Genuine indebtedness has already been indicated to the various authors items. An even greater contres for their permission to use modified test Vivian Pickett and University Bureau of Testing and R. These two assistants in the DePaur the many details of test scoring Research have been associated with all the various station test scoring, compilation of norms, item-analyses, and the various statistical studies involved since the project was initiated in task could not have been accomplished. 


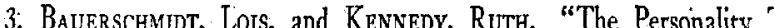
College Women Leaders." Seminar Thesis, DePauw University; 1948.

4. BerL, Hucr M. The Adjusiment Inventory. The Stanford University. Press; 1934.

5. Cook, C. DALE. "A Comparison of the Personal Adjustment Inventory Scores of Criminal and Normal Male Subjects." Seminar Thesis, DePauw University; 1948.

6. Darley, John G., and McNamara, Watter J. Minnesota Personaility Scale. New York: The Psychological Corporation; 1941.

7. DAVIs, FREDERICK B. Item-Analysis Data - Their Computation, Interpretation, and Use in Test Construction. Harvard Education Papers, No. 2 Cambridge: Harvard University Graduate School of Education; 1946.

8. Eluss, Albert. "The Validity of Personality Questionnaires." Psychological Bulletin, 1946, 43, 385-440.

9. Eloe, Howard W. "Study of the Relationship between a Self-Rating Scale and an Acquaintance Rating Scale." Seminar Thesis, DePauw University; 1948.

10. Evans, Catharine, and McConneli, T. R. Minnesota T-S-E Inventory. Chicago: Science Research Associates; 1942.

11. Guilford, J. P. Inventory of Factors ST D C R. Beverly Hills, California: The Sheridan Supply Company; 1940.

12. Guilford, J. P., and Martin, Howard G. Inventory of Factors $G$ A M I N. Beverly Hills, California: The Sheridan Supply Company; 1943.

13. Hateatway, S. R., and McKrnsey, J. C. Minnesota Multiphasit Personality Inventory. New York: The Psychological Corporation; 1943.

14. Henry, Rtchard L. "An Objective Criterion of Sociability." Seminar Thesis, DePauw University; 1948.

15. Heston, Joseph C. "A Comparison of Four Masculinity-Femininity Scales." Educational and Psychological Measurement, 1948, 8, 375-387.

16. Longley, Patricia. "A Study of the Interrelationship of the Minnesota Multiphasic Personality Inventory and the Heston Personal Adjustment Inventory." Seminar Thesis, DePauw University; 1948.

17. Stagner, Ross. ' Psychology of Personality. New York: McGraw-Hill Book Company; 1937.

18. Thurstone, L. L., and Thurstone, Thelma G. "A Neurotic Inventory." Journal of Social Psychology, 1930, 1, 3-30.

19. Thurstone, L. L., and Thurstone, Theima G. Personality Schedule. Chicago: The University of Chicago Press; 1929.

20. Woodworth, Robert S. Personal Data Sheet. Chicago: C. H. Stoelting Company; 1918.

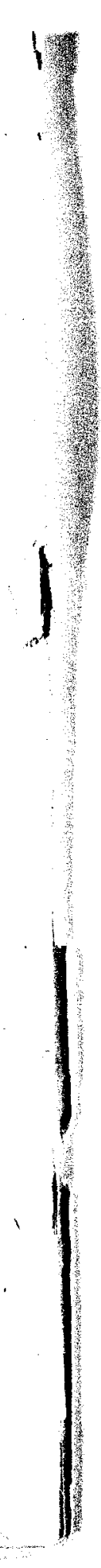


Student Adjusiment Reting Sheet

Iituber. Grace

Date ô̂ Birth

Instructions:

After reciliz the nenul considor each sspoct of adjustient hat is cefince in tho left hand colum one at time. Checis in the risht hend colun the closcrintion that nost neerir fits the individu$\therefore$ under consideration. After a.j. aspects have boen checlicd, reviev

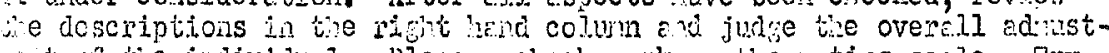
wit of tise jindividul. place a ciecle rerle on the pating sca?e. Try

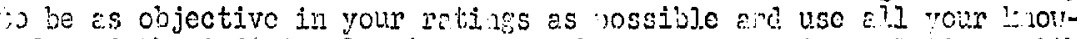
ore of the individuet meined through your dey to dey rejetions it th 1....

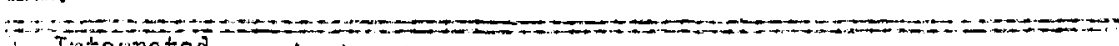

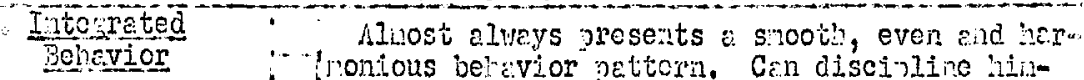
Tonious belavior petterin. Gon discijline hin-

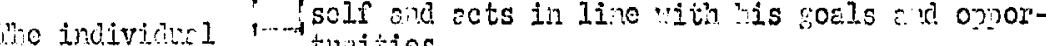
noserts a thil thies.

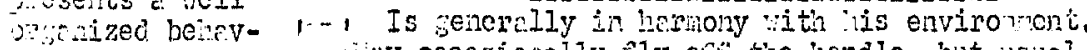

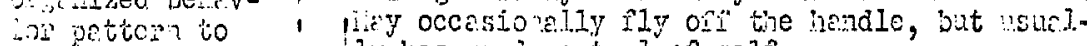
twe rold. Te , lity hes jood_control. of selí.

a.s reconcilod a. iatnteins a fairly oveir bellavior pattern. oc-

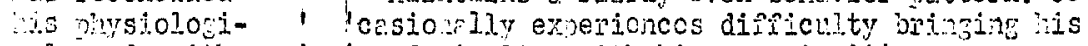

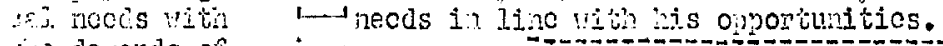

$\therefore$ de dends of ; ; Is froche tity emretic in is behevior. 3onder

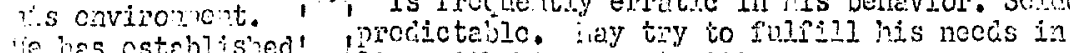
te hes esteblis'ed! , line ith his oportunties.

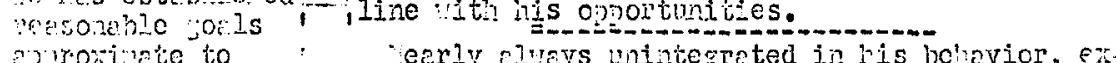
aronite to

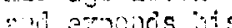
enche in. totend the cessively tonse, or continue?ly roing ofi on?

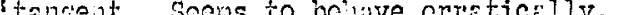

1 loje an excessive weed or affection, dutentico

1 'oraise, ets., trrowh exayereted behevior-

1 sterling, arcossive soxval activity, inirizilism, $\therefore$ ictic.

2. Sociel Conorinity

eeds the derands of socictr

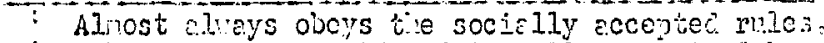

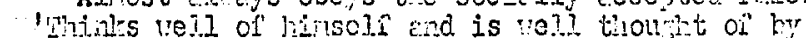
1 tothers. Is sonsitive to $t$ e pigits end heelings lot otions.

" Pries to comîn to socieñy accented resula-

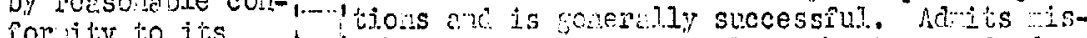

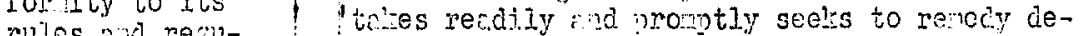

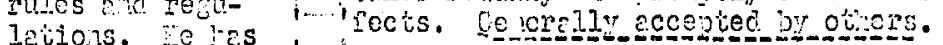

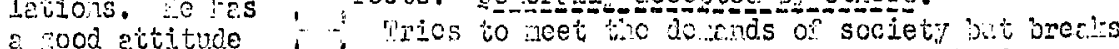
tomard jeojle and its rtles occrsionily. See.s to prosit iron ex neonle hevo a - herience.

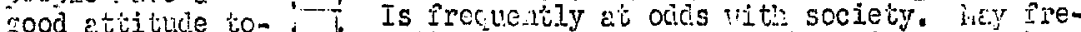

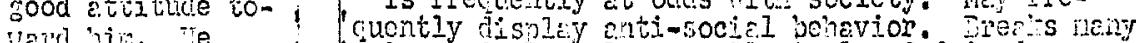

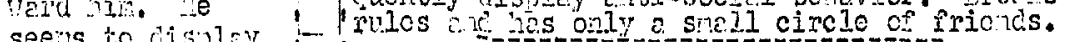

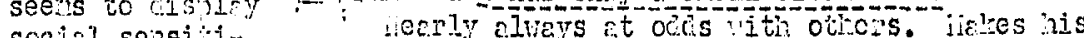

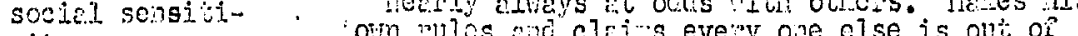
vity.

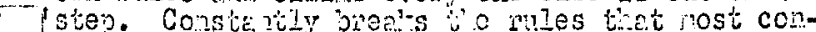

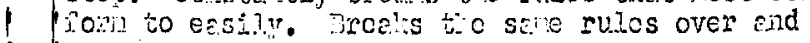

oveis. 
Student Adjustment Rating Sheet(cont.)

3. Adaptation to

Can profit from

past experiences

find consequentiy

sets goals that are

conmensurable with

his abjilty, can

strenoths and weak-

nesses and capital

izes on them. Is

izes on them. Is
able to nut off in-

mediate jatioaknesses rather than adjusting to them. Can

Leldom refrain from inmediate pleasure seening.

or the more last-

that comes with the

attainment of long

range goals.

i $-2-$

ITearly always sets goals that are realistic. Can nearly always put of $\mathrm{f}$ immediate satisfactions in favor of efforts toward long range go

Usually faces things realistically. Occasion-

ally permits infledate satisfactions to distract

efforts toward a distant goal. Recovers quickly.

Sometimes behaves realistacaly but at other

times is very unrealistic. Can put off inne-

diate satisfactions and does so about half the time

Mntaining

unistency

orer a reason-

Sets unreal goals for hinself. Alnost always

'

Wants to have the reward, but can almost never

make himself do the day to day tasiss that will bring the reward.

able period of time - Behavior can cenerally be predicted. Occasionhis actions are con-l- ally his reactions are surprioing.

sistent with the

standards he sets 1 one misses being able to predict his behavior for himself. Know-

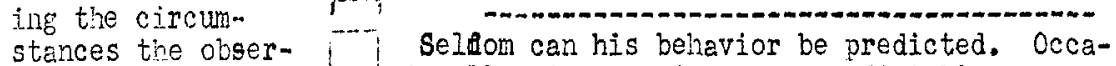
ver can usually yre-lsionally his reactions are predictable.

dict what course - n

his behavior will a...t Behavior is almost never predictable, one can take.

never be sure just what course of action he

5. Maturing vith $\begin{aligned} & \text { A steady progression can be noted from child- } \\ & \text { like behavior to more mature forms. Fery little }\end{aligned}$

ingly responsible , 1 progression identifiable but moves forward in for his own becasionally reverts to childish forms as he grozs older. L of behavior but recovers quickly.

Infantile forms of

behavior, $i, e, e x-\rightarrow$ Progression is occuriting but there are frequent cessive bids for at- setbocks and sometimes one feels as if gains in tention of an adult Lone area are offset by losses in another. drop out and he becomes more interest- $\longrightarrow$ Frequently reverts to childish behavior. Aded in status with vitow ve overage mates. Seems 1 to occasional to be growing up in trums, etc.

tudes, and reactions.

Seems to react live a child of a much young

er age. Can't be trusted. Bither extremely

dependent on adult direction or verr defiant

toward all direction. 
Student Adjustzent Retins Shoet(cont.)

6. Ootingl Is usuc1ly checrful and outinistic. Can take

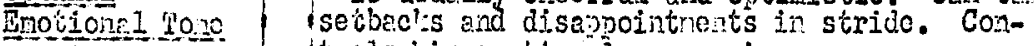
Docsin't react cx- itrols his cwotione I expressions.

cossively to t'e

drily tricls ald int Maintains adequate control over enotionel exconventences, $3 x-\mid$ pressions. hay occasionelly perit an ezasgcrpresses assurnce - - ated displey but recuperates cuickly.

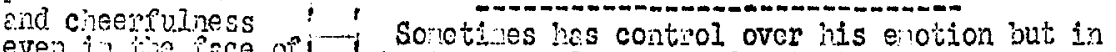

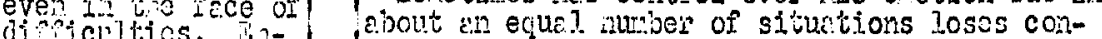

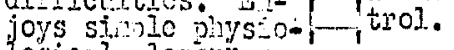

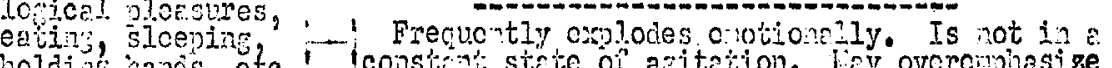

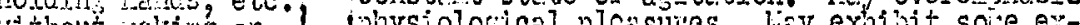

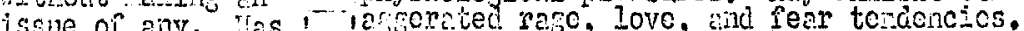

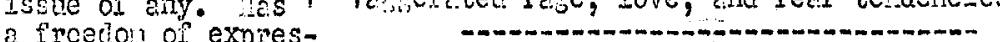
a rcedon of expression of ention, but pson. Waibits violent races loves, feors, control. _letc. Tes little or no coittrol over his reactions,

\section{Iñereasin i Production is comensurate vith his ebility.} Erifectivciness Does thins erfectively ond efficiently. ConBecones increas- tributes to gron through entective scif-acin ly errective in itivity. A sele starter.

oling contribu- i-; Generally vorl-s w to ability levol but sonetions to the group. tiwes uses inerificjentit nethods. Doesn't nalie Resolvcient on un- as much coitcribution as he could.

due tensions leaves

hif free to nale ef: Usually mintoins a feinly even minor dis-

flcient use on his crepancy botveen coflity ond effectivenoss icvol.

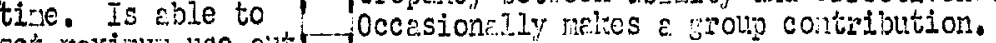

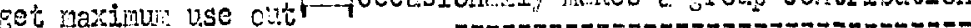

of his obilities no' ' Somewhet of $\varepsilon .18 \mathrm{~g}$ botween erficioncy level and matcer hat level, ability. Rerely thates cay cortribution 60

isoun. lictrocs are inefoctive but he does not

Y01: 0.2.

1 - deliberctcly veste onjort.

1.1 An extre lar betien abijity and joduction.

- An extre c la betieen abiju cid moduction.

- veliy proddec. Jethods of vorting are vesteful.

-........ Dote

itome of person gakins netin. Position

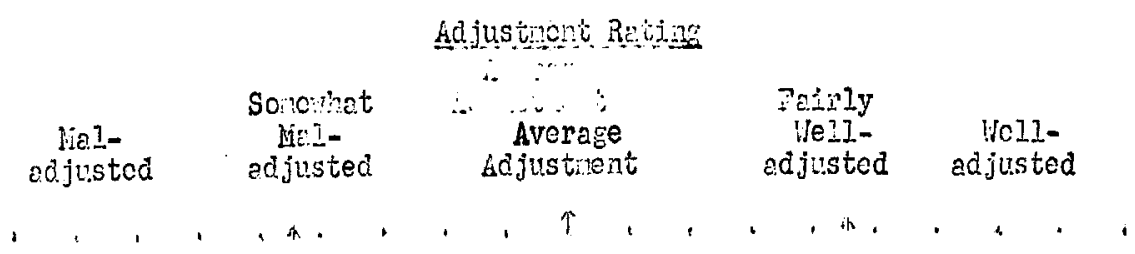




\section{THPOMEP}

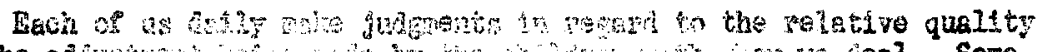

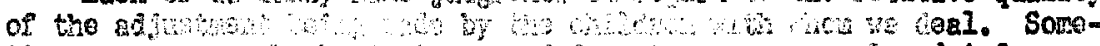

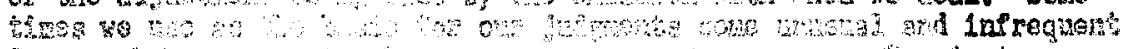

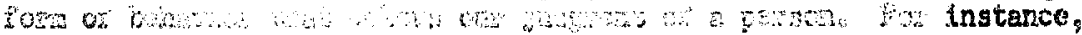

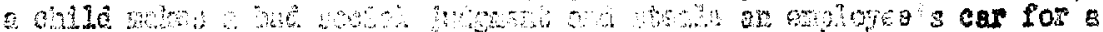

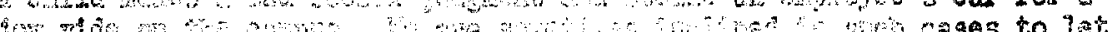

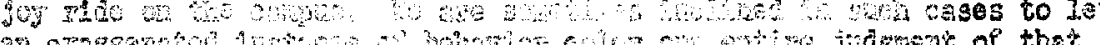

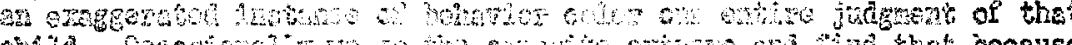

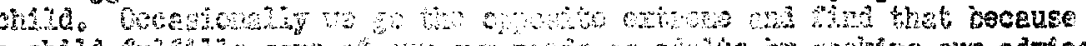

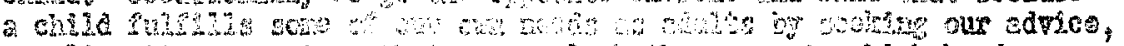

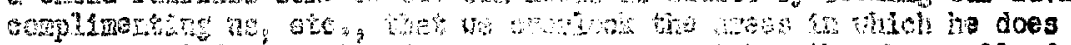

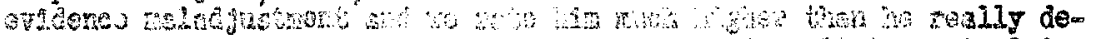

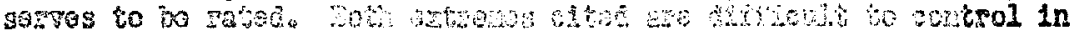
Donen 0 f

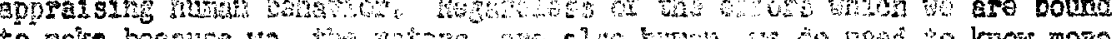

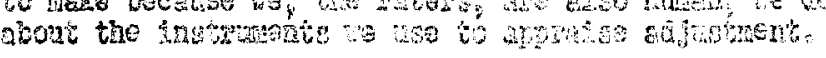

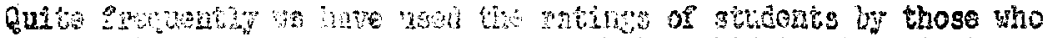

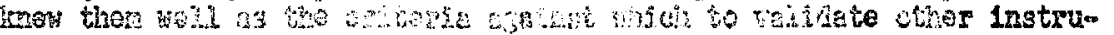

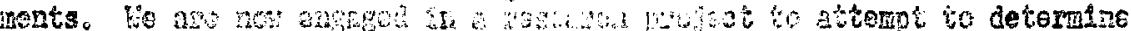
the folotsonit.

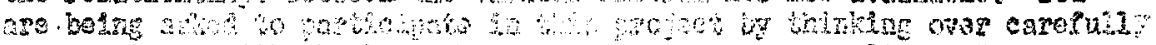

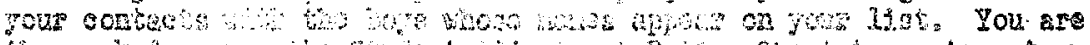

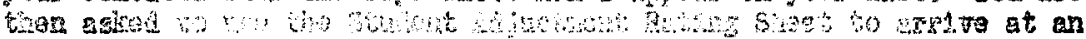

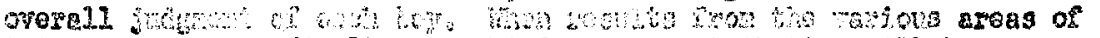

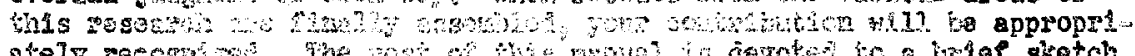

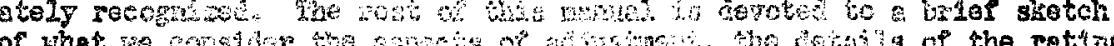

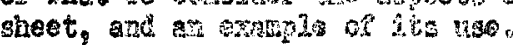

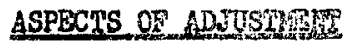

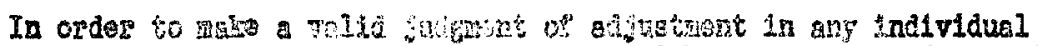

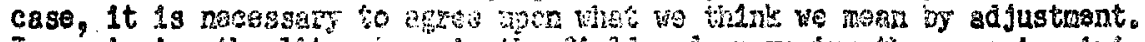

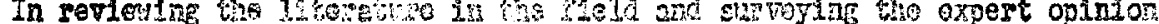

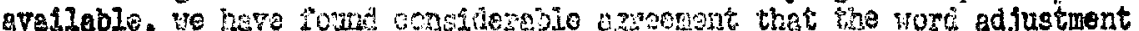
pertsins to a proess not a strte renelisa on to bo sesched. However, for convend,

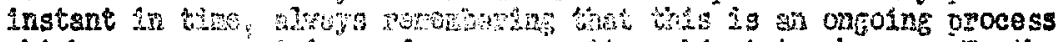

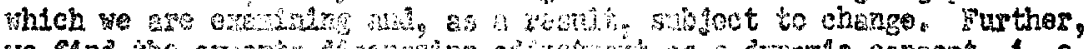

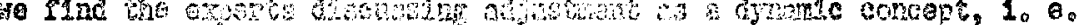

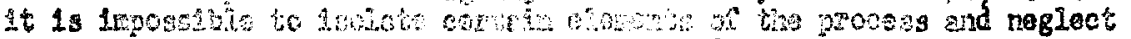

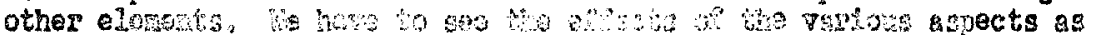

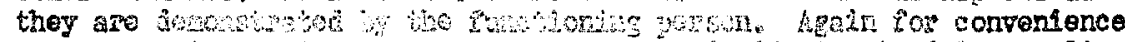

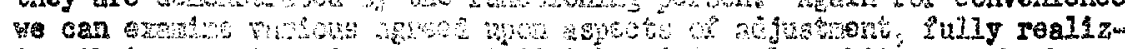

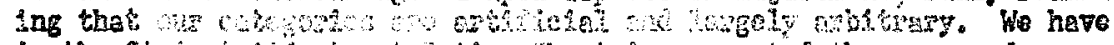

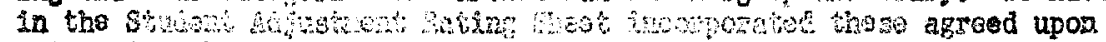

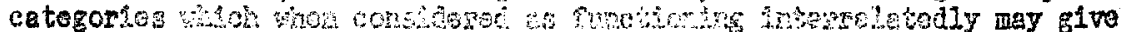

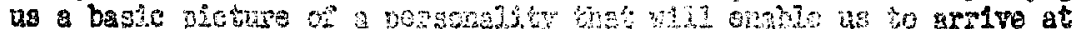

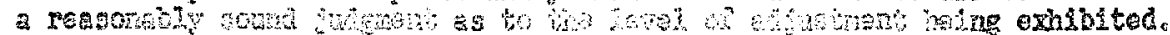

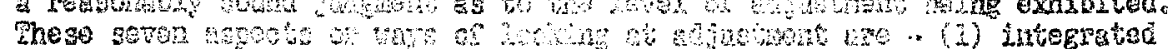

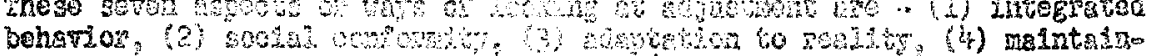

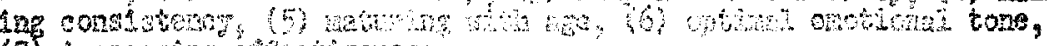

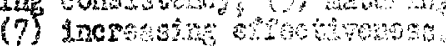




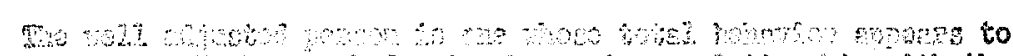

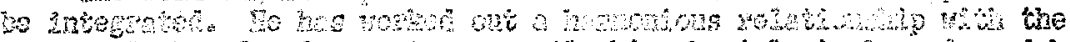

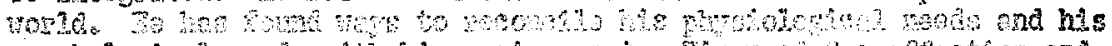

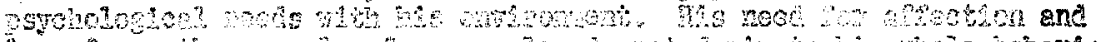

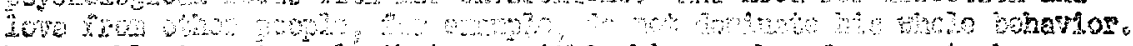

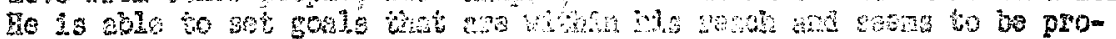

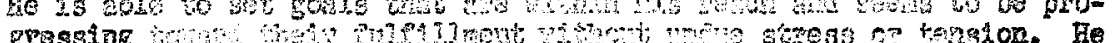
gressing

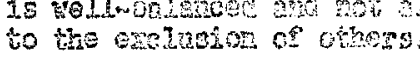

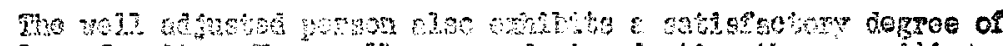

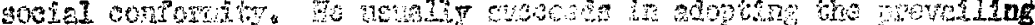

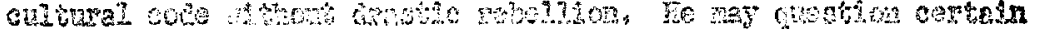

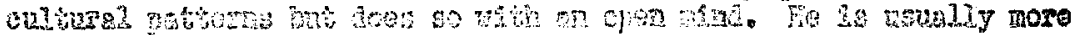

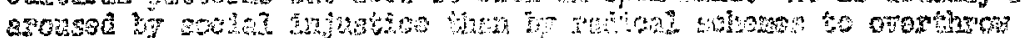

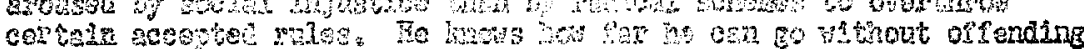
contala ses.

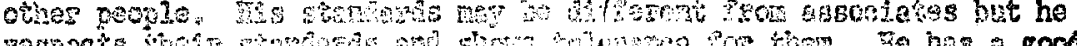

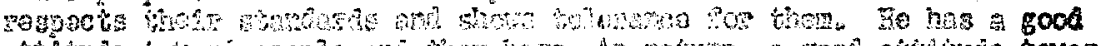

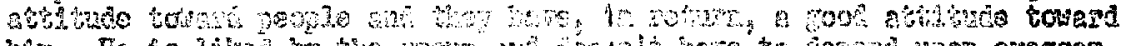

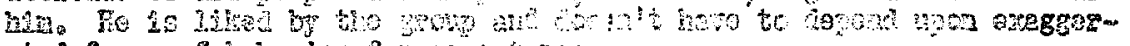

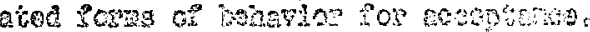

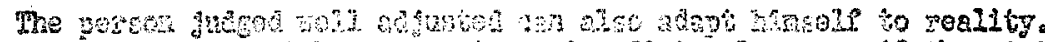

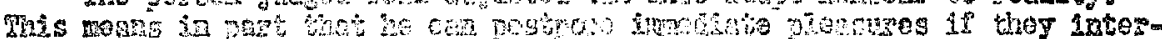

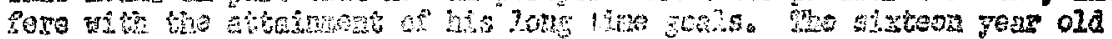

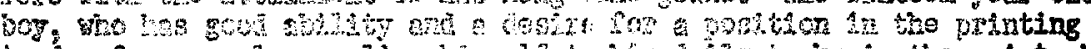

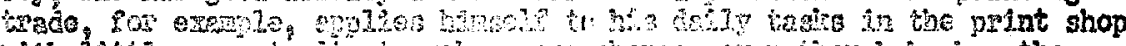

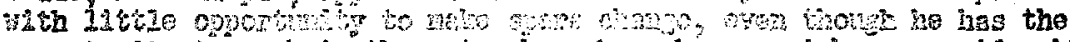

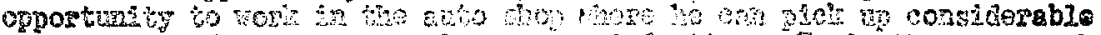

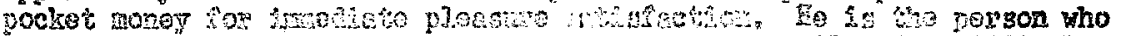

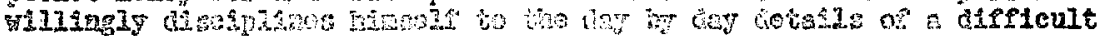

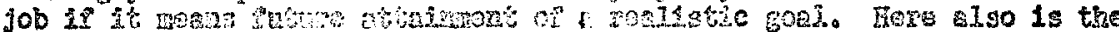

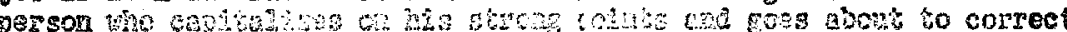
his Th

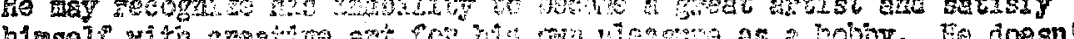
hilise

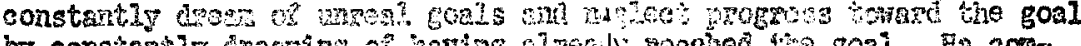

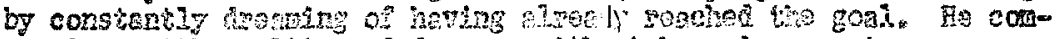

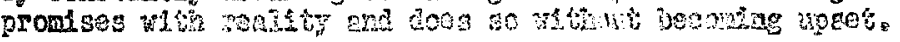

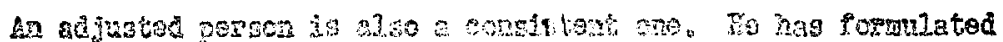

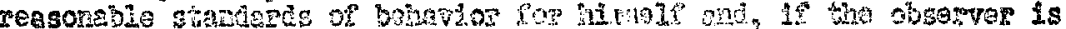

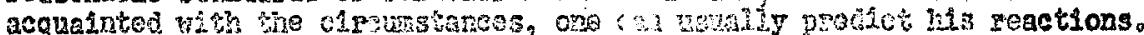

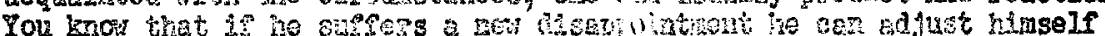

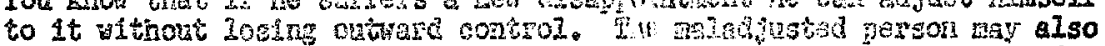

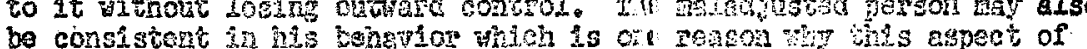

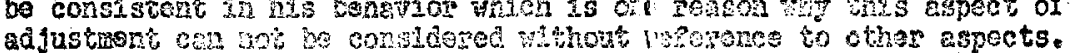

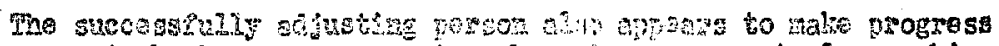

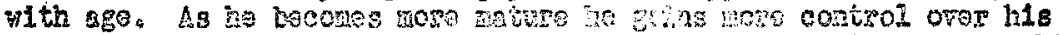

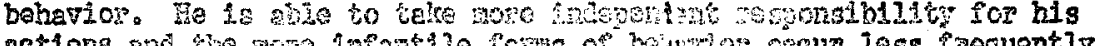

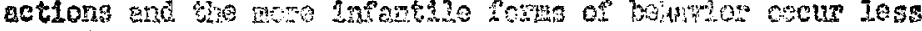

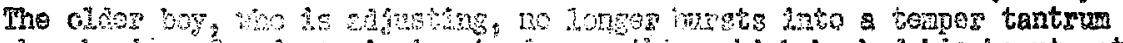

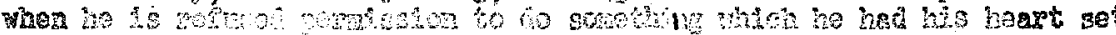

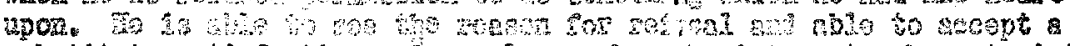

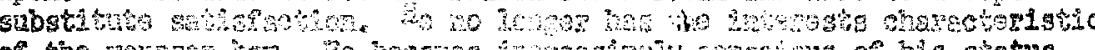

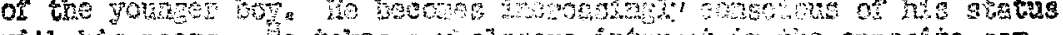

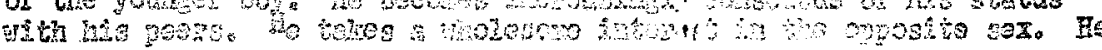




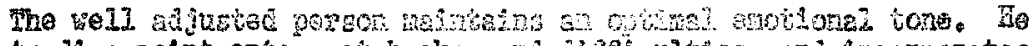

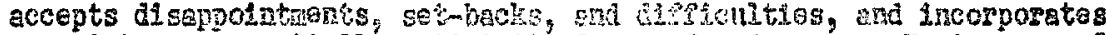

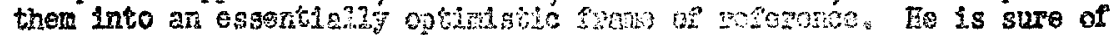

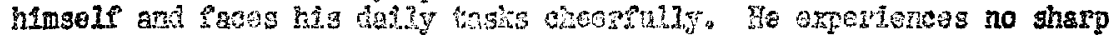

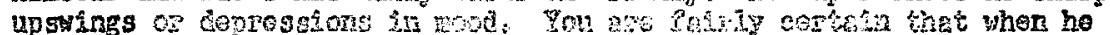

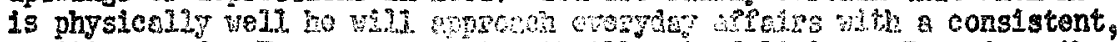

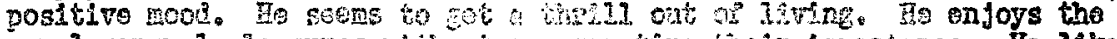

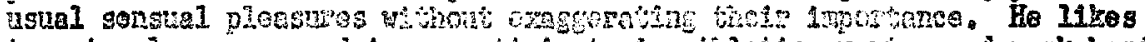

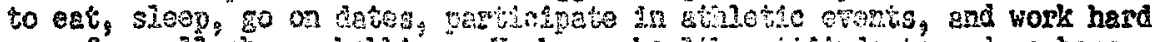

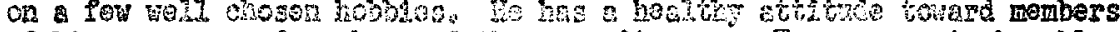

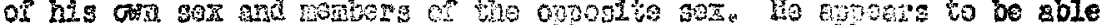
and

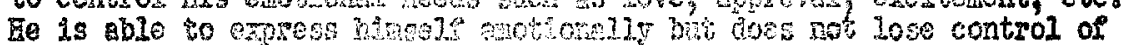
nimsels.

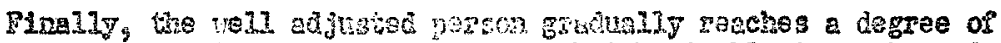

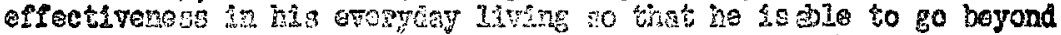

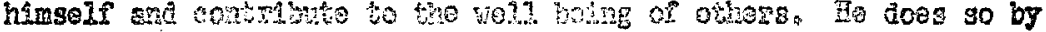

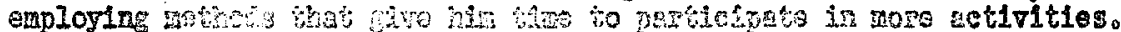

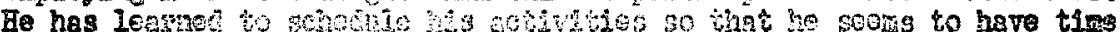

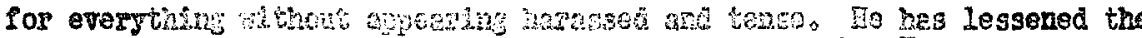

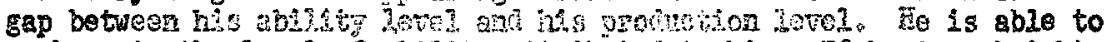

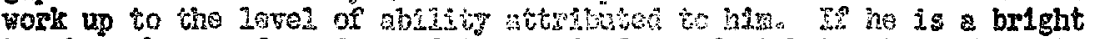
boy he makes good gredes and is parad of tho faot but not to the extent

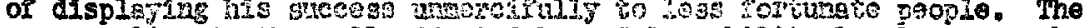
sate applies to the nell adjester boy or low ablinty lovol. Ho vorks

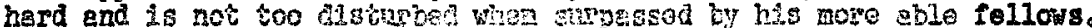

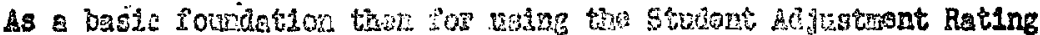

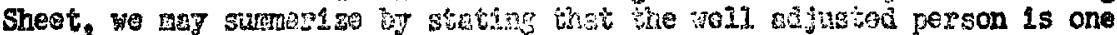
who is characterized by an inberiated bohctiom pattern, who as conscious of the domends of soctetr, and peiros ar ofrost to conton to those domands, who can adest to seality who is ecnsfstent in his day to day behavior, who grous paychojogisaly wh the who walntains a healthy omotional tone, and who through incpenging orfortiveness makes increasing contributsons for the velfare of the same ha naladystod porson

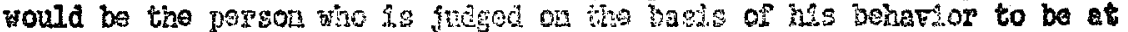

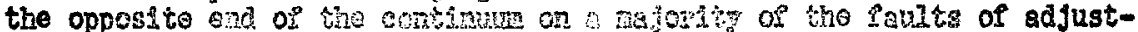
nent deseribed.

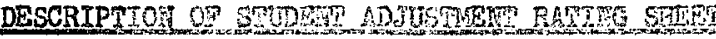

This rating shoet is based mon the seren Paootg of edjustinent as described in the last section. whe naze of enoh boy to be pated is

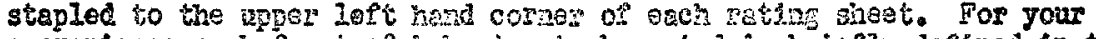

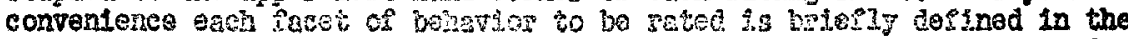

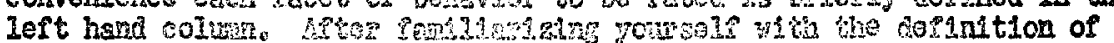

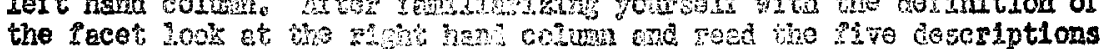

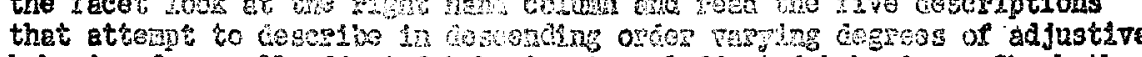

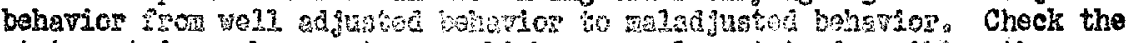

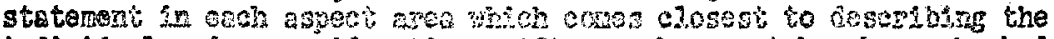

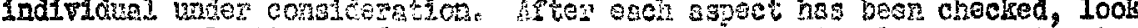

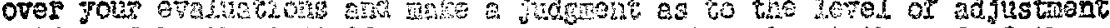

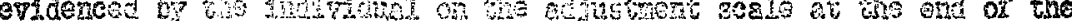

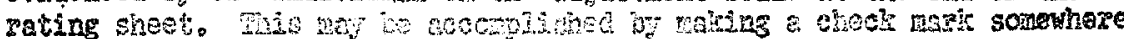


along the seale provised.

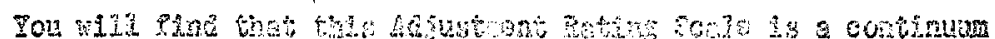

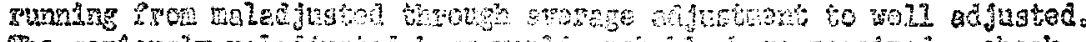

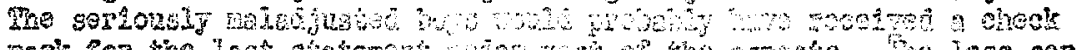

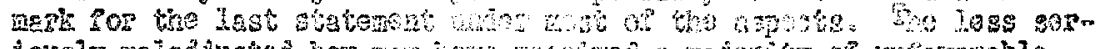
tored ma

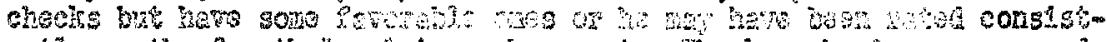

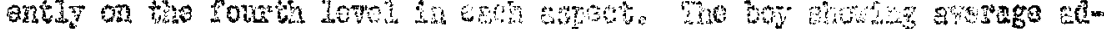

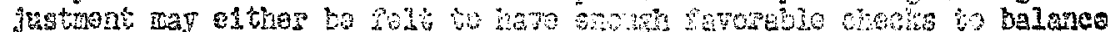

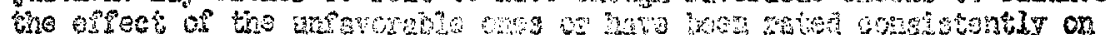

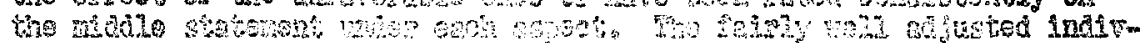

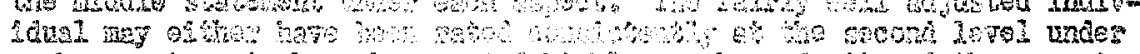

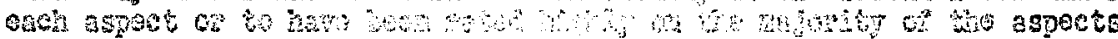

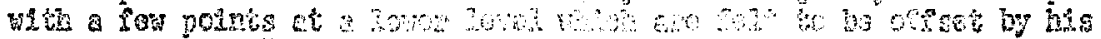

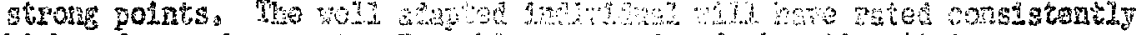

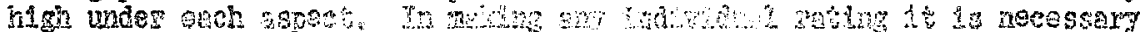

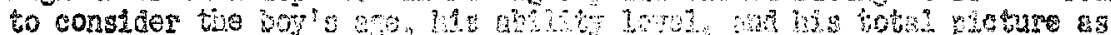

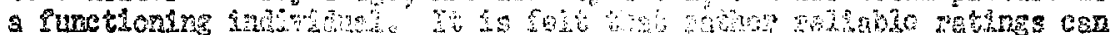

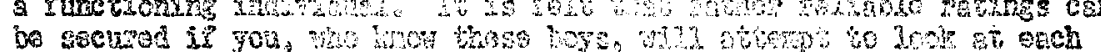

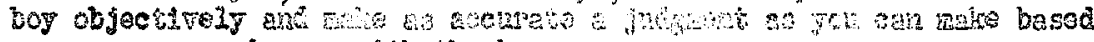
upon you axperienec nith the boy

\section{EXAHPIS RADTE}

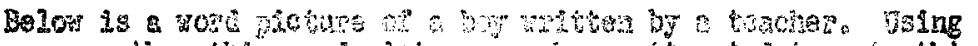

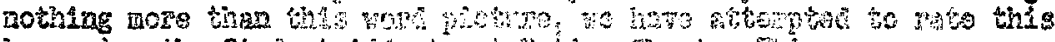

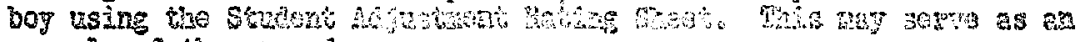
granplo or the prosederts.

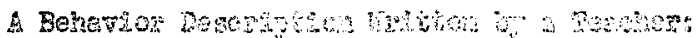

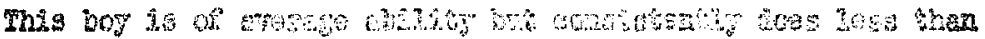

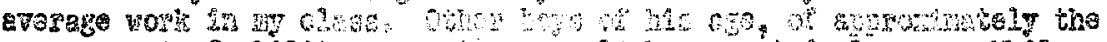

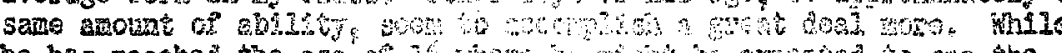

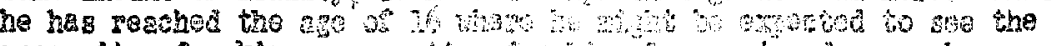
aecessthy of und

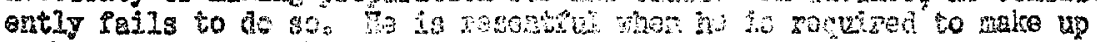

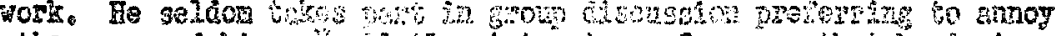

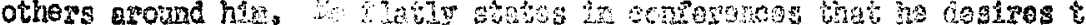

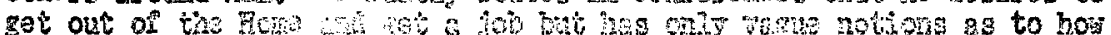

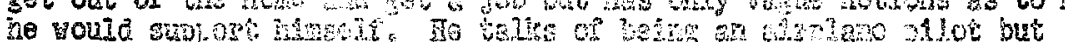

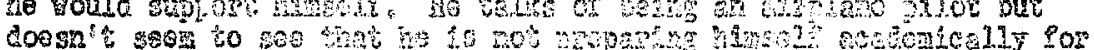

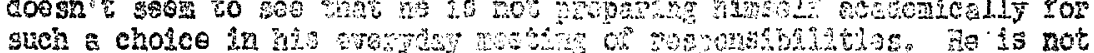

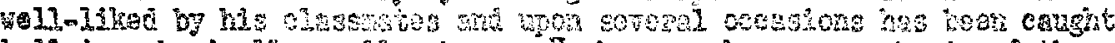
bul2ying physteally sno?

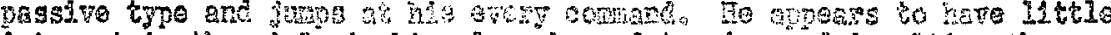

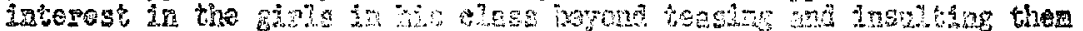

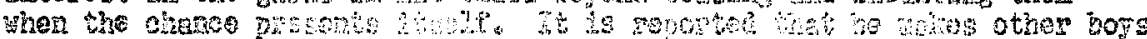
do his night wow and $\mathrm{H}$.

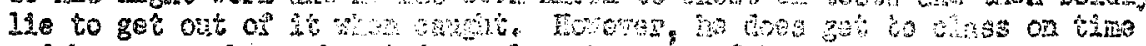

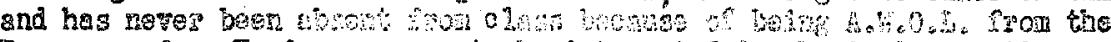

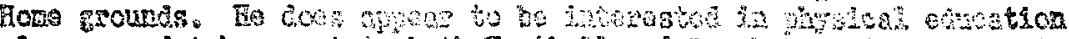

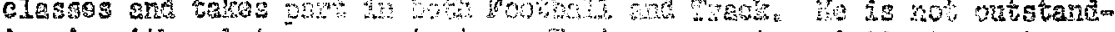

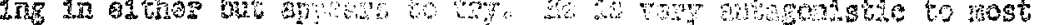

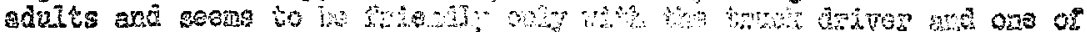
the Parkerg. 
iltuber Grade Date of Birth

Instructions:

Ufter reatig the munal consider eac: espect of edjust ent then is defined in tho left hend colum one at a time. Chect in the right hend colimn the description the ast neerly fits the individuII under consideration. After a.3. asjects have been checlicd, review be doscriptions in the right hend colum equ judge the overell adust-

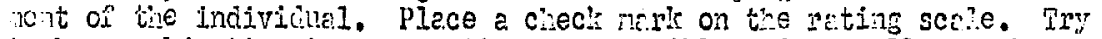

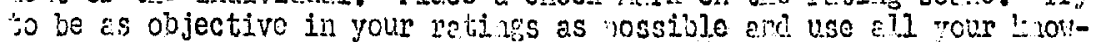

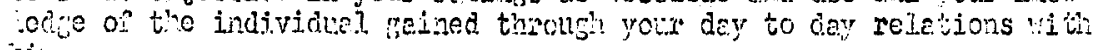
inis...

7 Titorated Behevior alcost alvays jresents a snoot?, even aidd her i ronious belvior pettorn. Con discipline hillwe indivitul 1 - tulities.

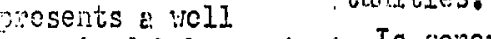

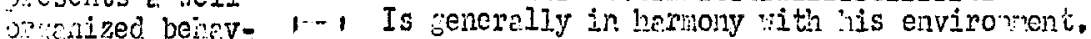

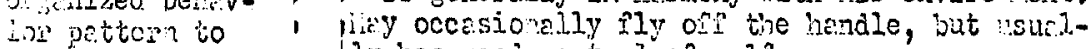

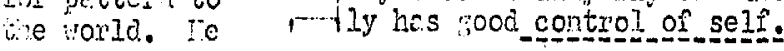

nes reconcilod $\quad$ i binteins a foirly ovei benavior pattern. $0 c-$ as norjolosi- i casionlly experionces dificulty jinging his $\therefore=$ incecs vitin

te dewends of : $;$ Is frocue triy errotic in is behavior. seldon $\longrightarrow$ necds in lino vith his oportunities.

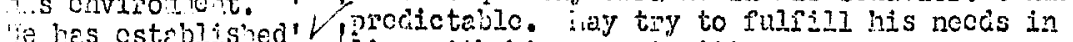

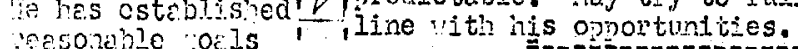

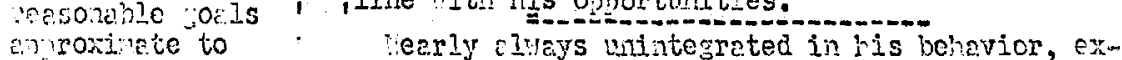
Iis aco level cessively tonsc, or continumliy going off on a

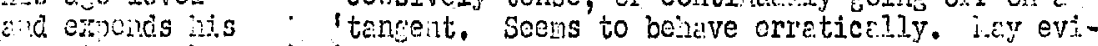

enorics yor!:- ! lonce an excessive heed for affection, edtentton,

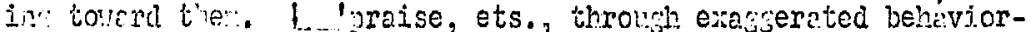

1 stecling, oxcossive scrual activity, iniriatilss, 10 tc.

2. Social Alnost alvays obcys ite socicily accentec rule.

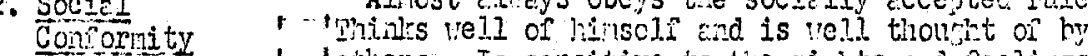
eeds the de- "ochers. Is sorsitive to the rights and feelings ands of society 1 'of ot'ers.

nands of society inies to conion to socinily eccented recula-

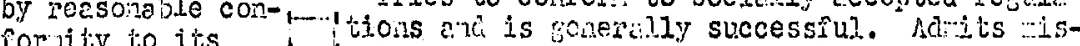
rorilit to its | tries recdily md rompty seelns to remoly de-

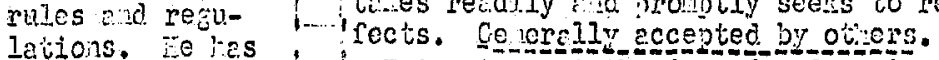

a cood attitude Trios to jeet to docinds of society but breciss tovard neojle and its rules occosionally. Seens to prosit froul exneople heve a - perience, Accepted by otiers part of tixo tine. peode Is recuenty at ode wits society. icy ire-

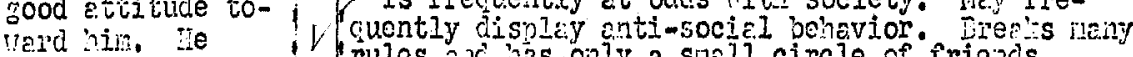

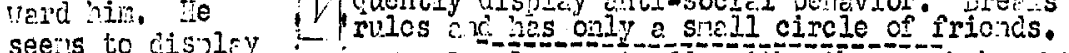

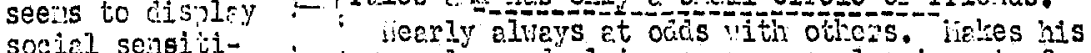
soeicl sensiti- , orn wulos ond clei.s every one else is out or

vity. $\quad$ step. Consterty bientis ito pules tite nost con-

f fow to exs.t.y. Broals tie seine rules over and : : over. 
Student sdjustment Rating sheet(cont.) 3. Adaptation to

Can profit from past experiences and consequently sets goals that are commensurable with his abjlity, Can recognize his own strengths and veakresses and capitalizes on them. Is 1 Goals are frequently unrealistic. Justifies his able to put off lin- weaknesses rather than adjusting to them. Can thediate satisfaction L seldom felrain lrom inmedate pleasure soeng. for the more sasting satisfaction that cones with the attainment of lon: range goals. Sets unreal goals for hinself. Ainost ratifies the inmediate Wants to have the revard, but can almost never make himself do the day to day tasis that vill oring the revard,

Mantaining
Ovisistency
over a reason-
able period of time Behavior can generally be predicted. Occasionhis actions are con-l ally his reactions are surprising. ststent with the staidards he sets $\square$ one misses being able to predict his behavior for himself. Know- about half the time.

ing the circum- Selom can his behavior be predicted ver can usually pre-1.... sionally his reactions are predictable.

dict what course his behavior will a...t Behavior is almost never predictable. One can take. never be sure just what course of action he

5. Naturing with $\begin{aligned} & \text { A steady progression can be noted from child- } \\ & \text { Age behavior to more mature forms. Very little }\end{aligned}$

Becomes increas ingly responsible for his own behavior as he grows older Infantile forms of behavior, i. e. ex- $1-1$ Progression is ocuswing but there are frequent cessive bids for at- setbaks and sometimes one feels as if gains in tention of an adult $\_$one area are offset by losses in another. comes more interest- Frequently reverts to childish behavior. Aded in status with. $\quad$ vences if made at all are slow. May be overage mates. Seems 1 dependent, defiant, and stubborn, Mag resort to be growing up in to occasional

tudes, and reactions. Seems to react like a child of a mugh youngdependent on adult direction or very defiant toward all direction. 
Student Ldjustuent Riting Shoet(co.nt.)

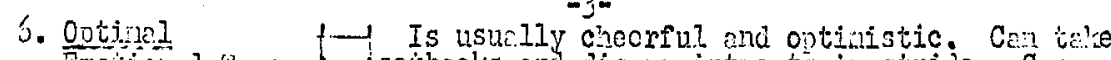

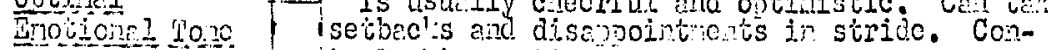

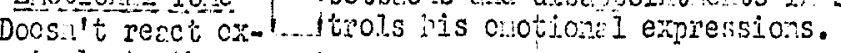

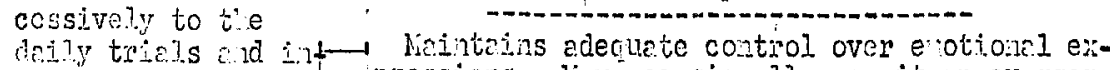
converences, ix- prossions, hay occosionclly perit an exajocr-

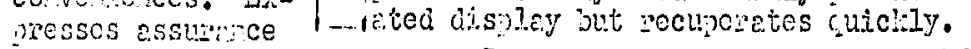

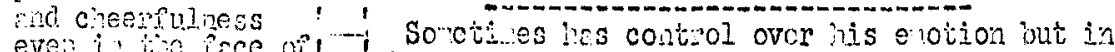

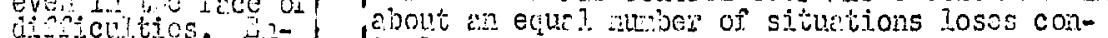
joys shito bys - trol.

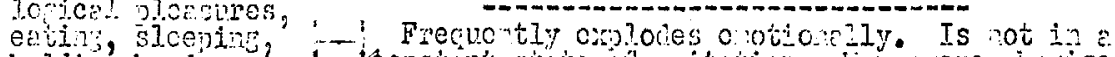

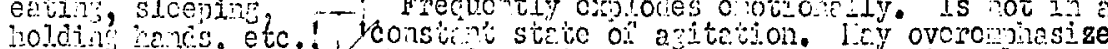

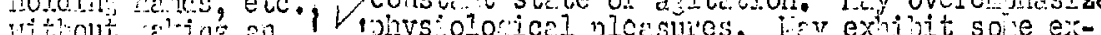

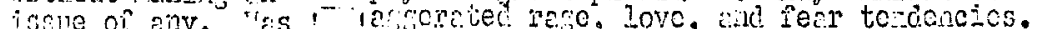
iscle oi enty. as sjor of eiption, but $\rightarrow$ Gitros vat to exomcreted enotioncl expression of enotion, but sion. Woibits violent renes, loves, Peors, rinl maintins
contro?.

7. Increasia - Production is comensurete vith his aliitu Brfectivoness, Doos ting enfectively and esficientiy. ConBecones incress- itributes to ro? through entective sclis-acinjly effective in itivity. A sele starter.

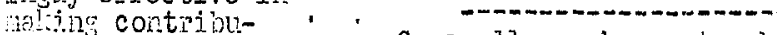

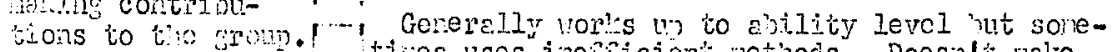

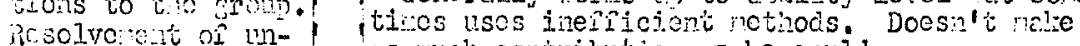
die tersions lervost-ias meh coitribution as he could.

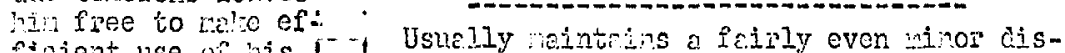

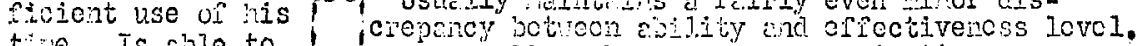

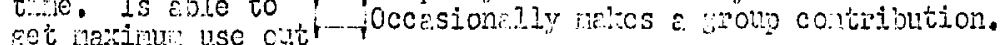

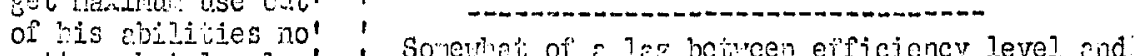
retter hat lovel

he is ionced to

"ont: on.

1 i

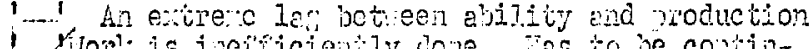

Yijorl: is ineiticienty cone. Tes to be contin-

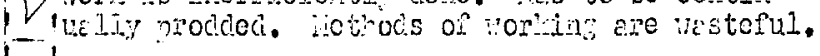

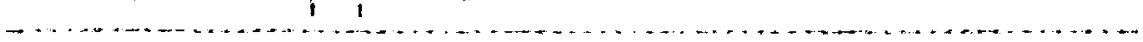

niver? Dete

itomo or ferson bleting netin: Posjition

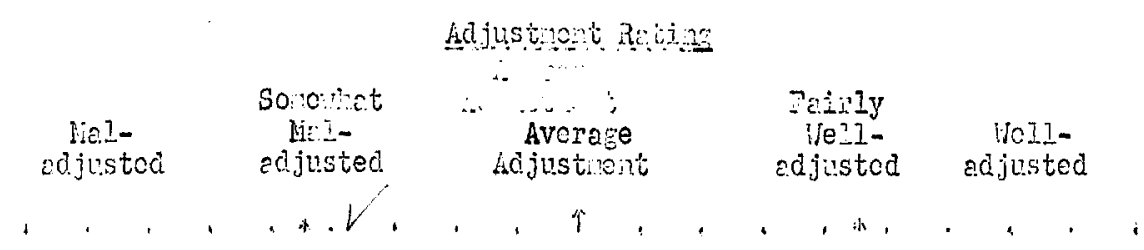




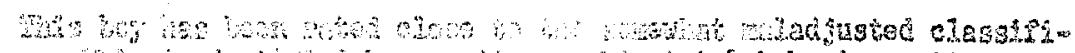

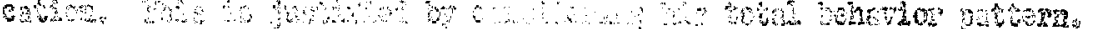

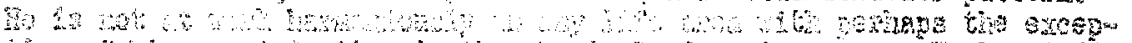

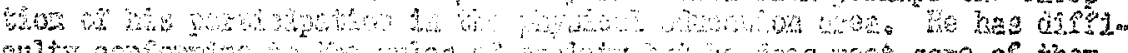

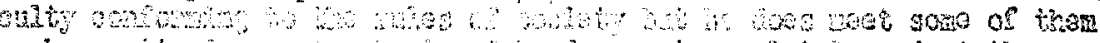

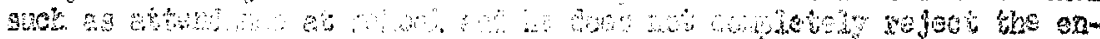

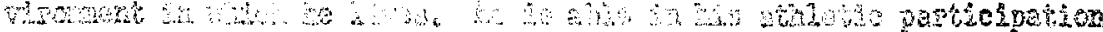

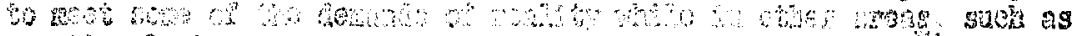

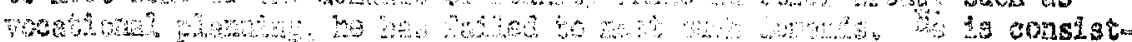

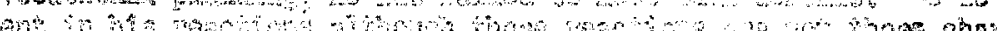

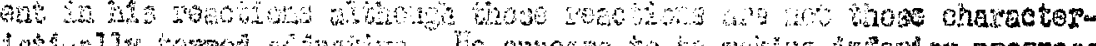

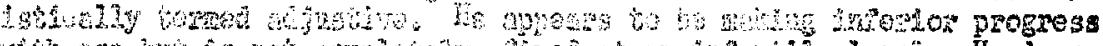

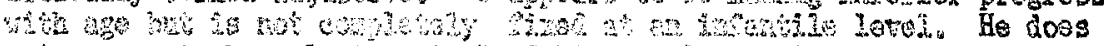

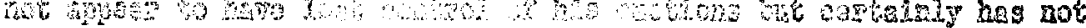

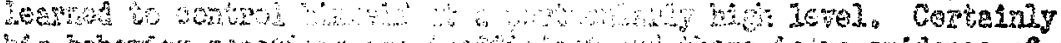

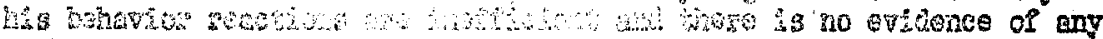
rogl cont real.

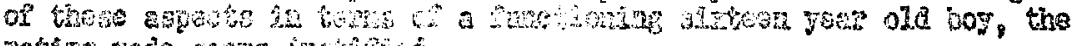

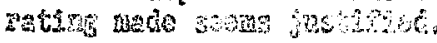

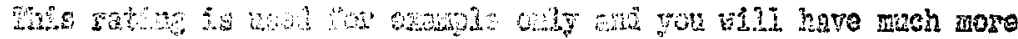

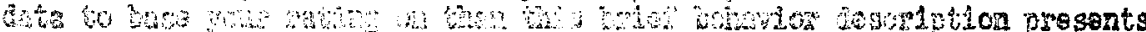

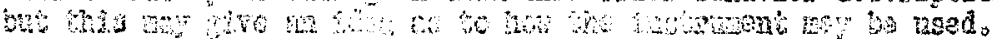




\section{HAGGERTY-OLSON-WICKMAN BEHAVIOR RATING SCHEDULES}

By M. E. Haggerty, Ph.D.

Dean of the College of Education, University of Minnesota

W. C. Ozson, Pr.D.

Director of Research in Child Development, University of Michigan

and E. R. WrCKMAN

The Commonwealth Fund, New York City

Publisned by World Book Company, Yonkers-on-Hudson, New York, and Chicago, Illinois Copyright 1930 by the American Council on Education. Copyright in Great Britain All rights reserved. Bow: BRS-10

$$
\text { PerNIID IN US.A. }
$$


SCHEDULE A: BEHAVIOR PROBLEM RECORD

Score__

Name School

Rating by Date 19 Grade

\section{DIRECTIONS FOR USING}

\section{Schedule A}

Below is a list of behavior problems sometimes found in children. Put a cross $(X)$ in the appropriate column after each item to designate how frequently such behavior has occurred in your experience with this child. A cross should appear in some column after each item. The numbers are to be disregarded in making your record. They are for use in scoring.

\begin{tabular}{|c|c|c|c|c|c|}
\hline \multirow[b]{2}{*}{ Behavior Problem } & \multicolumn{4}{|c|}{ FREQUENCY OF OCCURRENCE } & \multirow[b]{2}{*}{ SCORE } \\
\hline & $\begin{array}{l}\text { Has never } \\
\text { occurfed }\end{array}$ & \begin{tabular}{l|} 
Has occurred \\
once or twice \\
but no more
\end{tabular} & $\begin{array}{l}\text { Occasional } \\
\text { occurrence }\end{array}$ & \begin{tabular}{|c} 
Frequent \\
occurrence
\end{tabular} & \\
\hline Disinterest in School Work & 0 & 4 & 6 & 7 & \\
\hline Cheating & 0 & 4 & 6 & 7 & \\
\hline Unnecessary Tardiness & 0 & 4 & 6 & 7 & \\
\hline Lying & 0 & 4 & 6 & $?$ & \\
\hline Defiance to Discipline & 0 & 4 & 6 & 7 & \\
\hline Marked Overactivity & 0 & 8 & 12 & 14. & $\therefore$ \\
\hline Unpopular with Children & 0 & 8 & 12 & 14 & \\
\hline Temper Outbursts & 0 & 8 & 12 & 14 & \\
\hline Bullying & 0 & 8 & 12 & 14 & \\
\hline Speech Difficulties & 0 & 8 & 12 & 14 & \\
\hline Imaginative Lying & 0 & 12 & 18 & 21 & \\
\hline Sex Offensés & 0 & 12 & 18 & 21 & \\
\hline Stealing & 0 & 12 & 18 & 21 & \\
\hline Truancy & 0 & 12 & 18 & 21 & \\
\hline Obscene Notes, Talk, or Pictures & 0 & 12 & 18 & 21 & \\
\hline
\end{tabular}

Directions for scoring. Transfer the numbers you have marked for the different items to the right-hand column, headed "Score." Add the numbers to secure the total score, and record the total in the upper right-hand corner of this sheet.

$$
\text { [2] }
$$

\section{DIVISION III}

18. Is he quiet or talkative

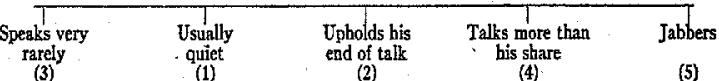

16. Is his behavior (honesty, morals, etc.) generally acceptable to ordinary socia standards?

\begin{tabular}{|c|c|c|c|}
\hline $\begin{array}{l}\text { Unacceptable, } \\
\text { - Extreme } \\
\text { violations } \\
\text { (5) }\end{array}$ & $\begin{array}{l}\text { Occasional } \\
\text { violations }\end{array}$ & $\begin{array}{l}\text { Ordidarily } \\
\text { acceptable }\end{array}$ & $\begin{array}{l}\text { Aiways } \\
\text { acceptable } \\
\text { (1) }\end{array}$ \\
\hline
\end{tabular}

17. What are his social habits?

\begin{tabular}{|c|c|c|c|}
\hline $\begin{array}{l}\text { Lives almost } \\
\text { entierly to } \\
\text { himself. } \\
(4)\end{array}$ & $\begin{array}{c}\text { Follows few } \\
\text { social } \\
\text { activities } \\
\text { (3) }\end{array}$ & $\begin{array}{l}\text { Pursules usual } \\
\text { social activities } \\
\text { and customs } \\
\text { (1) }\end{array}$ & $\begin{array}{c}\text { Actively } \\
\text { setks social } \\
\text { pleasures } \\
\text { (2) }\end{array}$ \\
\hline
\end{tabular}

18. Is he shy or bold in socialırelationships?

\begin{tabular}{|c|c|c|c|c|}
\hline $\begin{array}{c}\text { Painfully } \\
\text { sell-consciou }\end{array}$ & $\begin{array}{c}\text { Timid, } \\
\text { Frequently } \\
\text { embarrassed }\end{array}$ & $\begin{array}{l}\text { Self-conscious } \\
\text { of orccasions }\end{array}$ & $\begin{array}{l}\text { Conhident } \\
\text { in himself }\end{array}$ & $\begin{array}{c}\text { Bold, } \\
\text { Insensitive } \\
\text { social fieetili }\end{array}$ \\
\hline (4) & & (1) & (3) & \\
\hline \multicolumn{5}{|c|}{ tav } \\
\hline Repuls & Disagreable & $\begin{array}{l}\text { Unnoticed, } \\
\text { Colorlesse }\end{array}$ & Colorful & Magnetic \\
\hline (5 & 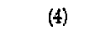 & 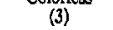 & (2) & \\
\hline
\end{tabular}

20. How does he accept authority?

$\begin{array}{ccccc}\text { Defiant } & \begin{array}{c}\text { Cititical of } \\ \text { authority }\end{array} & \begin{array}{c}\text { Ordinarily } \\ \text { obedient }\end{array} & \begin{array}{c}\text { Respectful, } \\ \text { Complies } \\ \text { by habit } \\ \text { (1) }\end{array} & \begin{array}{c}\text { Entirely resigned, } \\ \text { Accerts all } \\ \text { authority } \\ (5)\end{array} \\ \text { (5) } & \text { (4) } & (3) & & \end{array}$

21. How flexible is he?

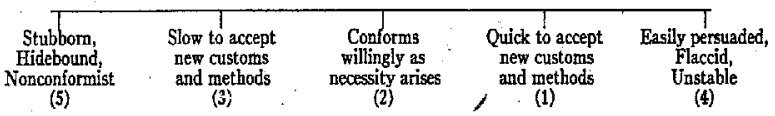

22. Is he rude or courteous?

\begin{tabular}{|c|c|c|c|}
\hline 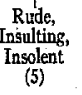 & $\begin{array}{l}\text { Sometimes } \\
\text { unmagnnerly, } \\
\text { Seucy } \\
(4)\end{array}$ & $\begin{array}{l}\text { Observes general } \\
\text { conventions of } \\
\text { civility and respect } \\
\text { (3) }\end{array}$ & $\begin{array}{l}\text { Courteous, } \\
\text { Gracious } \\
\text { (I) }\end{array}$ \\
\hline
\end{tabular}

23. Does he give in to others or does he assert himself ?

$\begin{array}{ccccc}\begin{array}{c}\text { Never assets } \\ \text { sele, } \\ \text { Servile } \\ \text { (5) }\end{array} & \begin{array}{c}\text { Generally } \\ \text { yields }\end{array} & \begin{array}{c}\text { Holds his own, } \\ \text { Yields when } \\ \text { necessary }\end{array} & \text { Assertive } & \begin{array}{c}\text { Insistent, } \\ \text { Obstinate }\end{array} \\ \text { (4) } & \text { (1) } & \text { (1) } & \text { (2) } & \text { (3) }\end{array}$

24. What tendency has he to criticize others?

\begin{tabular}{|c|c|c|c|c|}
\hline $\begin{array}{c}\text { Never } \\
\text { criticizes } \\
\text { (3) }\end{array}$ & $\begin{array}{l}\text { Rarely } \\
\text { criticizes } \\
\text { (1) }\end{array}$ & $\begin{array}{l}\text { Comments on } \\
\text { outstanding weak- } \\
\text { nesses of faults. } \\
\text { (2) }\end{array}$ & $\begin{array}{c}\text { Has a } \\
\text { critical } \\
\text { attitude } \\
\text { at }\end{array}$ & $\begin{array}{c}\text { Extremely } \\
\text { critical, } \\
\text { Rarely approves } \\
\text { (5) }\end{array}$ \\
\hline
\end{tabular}


SCHEDULE B: BEHAVIOR RATING SCALE

Scare

Name $\quad$ Schooi Grade_L

Division I

Division II -

Division $I I I$

Division $I V$

Rating by

\section{DIRECTIONS FOR USING}

\section{Schedule B}

1. Do not consult anyone in making your judgments

2. In rating a person on a particular trait, disregard every other trait but that one. Many ratings are rendered valueless because the rater allows himself to be influenced by a general favorable or unfavorable impression that he has formed of the person.

3. When you have satisfied yourself as to the standing of this person in the trait on which you are rating him, indicate your rating by placing a cross (X) immediately above the most appropriate descriptive phrase.

4. If you are rating a child, try to make your ratings by comparing him with children of his own age.

5. The masculine pronoun (he) has been used throughout for convenience. It applies whether the person whom you are rating is male or female.

6. In making your ratings, disregard the small numbers which appear below the descriptive phrases. They are for use in scoring.

\section{DIVISION I}

1. How intelligent is he?

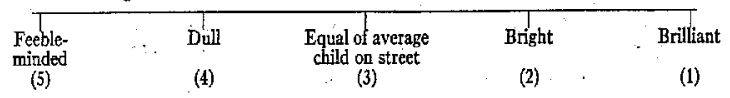

2. Is he abstracted or wide awake?

$$
\begin{gathered}
\text { Continually } \\
\begin{array}{c}
\text { absorbed in } \\
\text { himself } \\
(5)
\end{array}
\end{gathered} \quad \begin{gathered}
\text { Frequently } \\
\text { becomes } \\
\text { abstracted }
\end{gathered}
$$

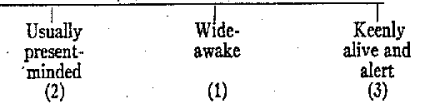

3. Is his attention sustained?

\begin{tabular}{|c|c|c|c|}
\hline $\begin{array}{l}\text { Distracted: Jumps } \\
\text { rapidly from one } \\
\text { thing to another. }\end{array}$ & $\begin{array}{c}\text { Difficult to } \\
\text { keep at task } \\
\text { until completed } \\
\text { (4) }\end{array}$ & $\begin{array}{l}\text { Attends } \\
\text { adequately }\end{array}$ & $\begin{array}{l}\text { Is absorbed } \\
\text { in what.the } \\
\text { does } \\
\text { (1) }\end{array}$ \\
\hline
\end{tabular}

4. Is he slow or quick in thinking?

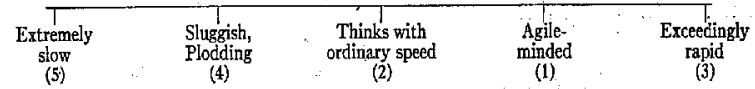

5. Is he slovenly or careful in his thinking?

$\begin{array}{ccccc}\begin{array}{c}\text { Very sovenly } \\ \text { and iliogical } \\ \text { (5) }\end{array} & \begin{array}{c}\text { Inexact, } \\ \text { A dabbler } \\ (4)\end{array} & \begin{array}{c}\text { Moderately } \\ \text { careful } \\ (2)\end{array} & \begin{array}{c}\text { Consistent } \\ \text { and logical } \\ \text { (1) }\end{array} & \text { Precise } \\ \text { (1) } & \text { (3) }\end{array}$

6. Is he mentally lazy or active?

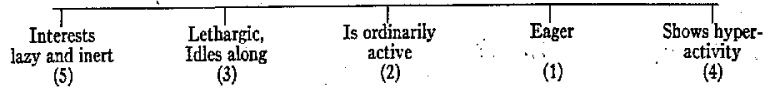

7. Is he indifferent or does he take interest in things?

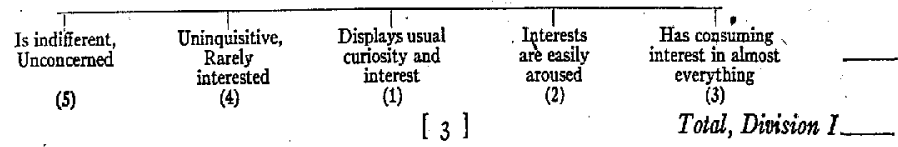

\section{DIVISION II}

8. Is he slovenly or neat in personal appearance?

\begin{tabular}{|c|c|c|}
\hline $\begin{array}{l}\text { Unkempt, } \\
\text { Very glapenly } \\
(5)\end{array}$ & $\begin{array}{c}\text { Rather } \\
\text { negligen } \\
(4)\end{array}$ & Inconspicuous \\
\hline
\end{tabular}

9. How does he impress people with his physique and bearing?

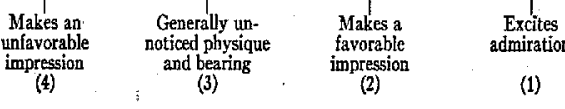

\begin{tabular}{|c|c|c|c|c|}
\hline $\begin{array}{c}\text { Weal and } \\
\text { handicapped } \\
(5)\rangle\end{array}$ & $\begin{array}{l}\text { Has some physical } \\
\text { difficulties } \\
\text { (3) }\end{array}$ & $\begin{array}{l}\text { Can hold } \\
\text { his orm } \\
\text { (2) }\end{array}$ & $\begin{array}{l}\text { Is stronger } \\
\text { than most } \\
\text { (1) }\end{array}$ & $\begin{array}{l}\text { Has excep- } \\
\text { tional strength } \\
\text { (4) }\end{array}$ \\
\hline
\end{tabular}

10. Can he compete with others on a physical basis?

11. What is his physical output of energy?

$\begin{array}{ccccc}\begin{array}{c}\text { Extremely } \\ \text { sluggish }\end{array} & \begin{array}{c}\text { Slow in } \\ \text { action }\end{array} & \begin{array}{c}\text { Moves with } \\ \text { required speed }\end{array} & \begin{array}{c}\text { Energetic, } \\ \text { Vivacious }\end{array} & \begin{array}{c}\text { Over-action } \\ \text { Hyperkinetich } \\ \text { Merdding }\end{array} \\ \text { (5) } & \text { (3) } & \text { (2) } & \text { (1) } & \text { (4) }\end{array}$

\begin{tabular}{|c|c|c|c|}
\hline $\begin{array}{l}\text { Shows quick } \\
\text { exhaution }\end{array}$ & $\begin{array}{l}\text { Does not have } \\
\text { ordinary } \\
\text { endurance } \\
\text { (3) }\end{array}$ & $\begin{array}{l}\text { Endures } \\
\text { satisfactorily }\end{array}$ & $\begin{array}{l}\text { Rately shows } \\
\text { fatigue }\end{array}$ \\
\hline
\end{tabular}

12. Is he easily fatigued?

13. How does he impress you with regard to masculine or feminine traits? - (NoTE. If subject is male, rate on first line; if female, use second line.)

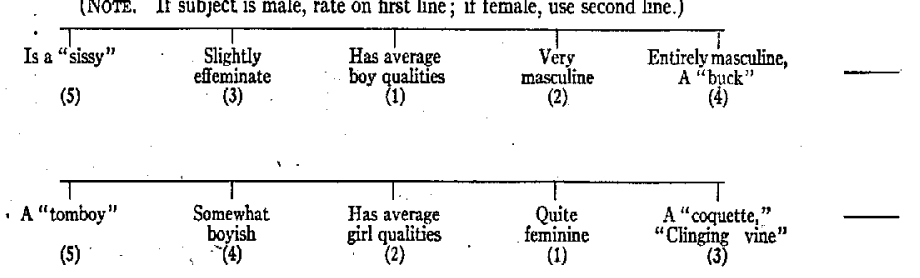

14. Does he lack nerre, or is he courageous?

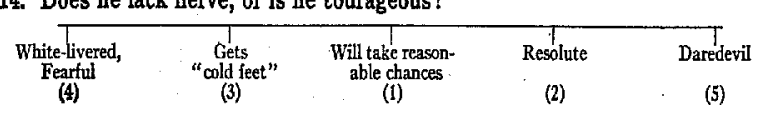

[ 4$]$ 
DIVISION III

15. Is he quiet or talkative?

Speaks very Usually

D

sarely
$(3)$

upholds his
end of talk
(2)

Talks more
his shan
$(4)$

Score

16. Is his behavior (honesty, morals, etc.) generally acceptable to ordinary social standards?

$\begin{array}{ccccc}\begin{array}{c}\text { Unacceptable, } \\ \text { Bxtreme } \\ \text { violations } \\ \text { (5) }\end{array} & \begin{array}{c}\text { Occasional } \\ \text { violations }\end{array} & \begin{array}{c}\text { Oddinarily } \\ \text { scceptable }\end{array} & \begin{array}{c}\text { Always } \\ \text { accoptable }\end{array} & \begin{array}{c}\text { Bends backmard, } \\ \text { Very rigid } \\ \text { standards }\end{array} \\ \text { (4) } & \text { (3) } & \text { (3) } & \text { (1) } & \text { (2) }\end{array}$

17. What are his social habits?

\begin{tabular}{|c|c|c|c|}
\hline $\begin{array}{l}\text { Lives almost } \\
\text { entiecly to } \\
\text { himself } \\
\text { (4) }\end{array}$ & $\begin{array}{l}\text { Follows few } \\
\text { social } \\
\text { activities } \\
(3)\end{array}$ & $\begin{array}{l}\text { Pursues usual } \\
\text { social activities } \\
\text { and customs } \\
\text { (1) }\end{array}$ & $\begin{array}{c}\text { Actively } \\
\text { seetss social } \\
\text { pleasures } \\
\text { (2) }\end{array}$ \\
\hline
\end{tabular}

18. Is he shy or bold in socialrelationships?

\begin{tabular}{|c|c|c|c|c|}
\hline $\begin{array}{l}\text { Painfully } \\
\text { self-conscious } \\
\text { (4) }\end{array}$ & $\begin{array}{c}\text { Timidid } \\
\text { Frequently } \\
\text { emblarassed } \\
\text { (2) }\end{array}$ & $\begin{array}{c}\text { Self-conscious } \\
\text { on o,casions } \\
\text { (1) }\end{array}$ & $\begin{array}{l}\text { Confident } \\
\text { in himsel } \\
\text { (3) }\end{array}$ & $\begin{array}{l}\text { Bold, } \\
\text { Insensitive to } \\
\text { social feelinga } \\
\text { (5) }\end{array}$ \\
\hline
\end{tabular}

19. Is his personality attractive?

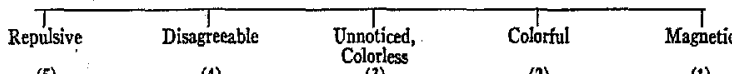

(5)

20. How does he accept authority?

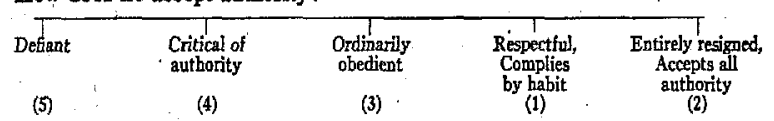

21. How flexible is he?

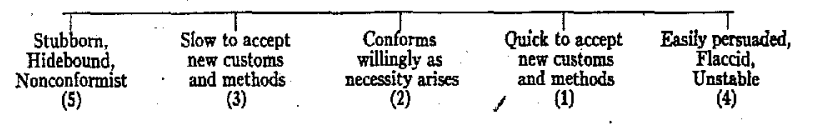

22. Is he tude or courteous?

\begin{tabular}{|c|c|c|c|c|}
\hline 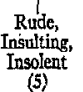 & $\begin{array}{l}\text { Sometimes } \\
\text {-unmannerly, } \\
\text { Saucy } \\
\text { (4) }\end{array}$ & $\begin{array}{l}\text { Observes general } \\
\text { conventions of } \\
\text { civility and respect } \\
\text { (3) }\end{array}$ & $\begin{array}{c}\text { Courteous, } \\
\text { Gracious } \\
\text { (1) }\end{array}$ & Elegant \\
\hline
\end{tabular}

23. Does he give in to others or does he assert himself

\begin{tabular}{|c|c|c|c|c|}
\hline $\begin{array}{c}T \\
\text { Never asserts } \\
\text { self. } \\
\text { Servile } \\
\text { (5) }\end{array}$ & $\begin{array}{c}\text { Generally } \\
\text { yields } \\
\text { (4) }\end{array}$ & $\begin{array}{l}\text { Holds his own, } \\
\text { Yields when } \\
\text { necessary } \\
\text { (t) }\end{array}$ & $\begin{array}{l}\text { Assertive } \\
\because \\
\text { (2) }\end{array}$ & $\begin{array}{c}\text { Insistent, } \\
\text { Obstinate } \\
\text { (3) }\end{array}$ \\
\hline \multicolumn{3}{|c|}{ What tendency has he to criticize others? } & - & \\
\hline $\begin{array}{c}\begin{array}{c}\text { Never } \\
\text { criticizes } \\
\text { (3) }\end{array} \\
. \text { (3) }\end{array}$ & $\begin{array}{l}\text { Rarely } \\
\text { criticizes } \\
\text { (1) - }\end{array}$ & $\begin{array}{c}\text { Comments on } \\
\text { outstanding weak- } \\
\text { nessess or faults . } \\
\text { (2) }\end{array}$ & $\begin{array}{c}\text { Has a } \\
\text { citical } \\
\text { attitude. } \\
\text { (4) }\end{array}$ & $\begin{array}{l}\text { Extremely } \\
\text { critical, } \\
\text { Rerelely papproves } \\
(5)\end{array}$ \\
\hline
\end{tabular}




\section{HAGGERTY-OLSON-WICKMAN BEHAVIOR RATING SCHEDULES}

Scales for the Study of Behavior Problems and Problem Tendencies in Children

By M. E. HAGGERTY, PB.D.

Dean of the College of Education, University of Minnesota

W. C. OlsoN, Ph.D.

Director of Research in Child Development, Oniversity of Michigan

and E. K. WiскамAN

The Commonmealth Fund, New Yort City

\section{MANUAL OF DIRECTIONS}

\section{- Measures of MaLadjustMeNi}

THE NEED POR RATING SCALES

The authors, in making available for general use two measures of maladjustment in children, are keenly aware of the limitations of these two instruments which are described in this manual. - Unwise and untrained persons may use the scales 50 that they increase maladjustment rather than correct the conditions that the resultant scores reveal. Such possibilities, however, inhere in many of our methods of dealing with children, with intelligence tests, with ordinary school examinations, and with the curriculum. No one of these means of directing the development of children can in any sense be used as a substitute for more dependable knowiledge of children or for good judgment of teachers or of others who may essay to use these instruments. The scale should be employed with the same responsibility that an intelligent physician assumes when prescribing medical treatment for a patient.

The need is very great for a better understanding of child behavior, particularly undesirable behavior. Any instrument that furthers such understanding should be available to all who can make intelligent use of it. The scales should primarily help to stimulate, direct, and improve research in the behavior problems of children. The chief argument for publishing the scales in their present form is to help accomplish this purpose. Under wise guidance the reşults obtained from the use of the scales reveal more objectively the factors in a particular behavior problem. The result may be used to correct the behavior problems of individual children. Thus the scales give a clearer picture of both the weaknesses and the assets of the individual, which may be used as a basis for a program of reconstructive education. A knowledge of the limitations of the scales should be possessed by all who use them. These limitations are discussed in the following paragraphs.

Published by World Book Company, Yonkers-on-Fudson, New York, and Chicago, Illinos Copyright 1930 by World Book Company. Copyright in Creat Britain All rights reservel. How wRs: som-3

$$
\text { PenTre Di 0.S.A. }
$$


CADTIONS

1. Reliability of measures. Although the reliability of the scales s far from perfect, it compares favorably with the reliability of many widely used intelligence tests. An intensive study of reliability and validity was made only of the Behavior Rating Scale, Schedule B. ${ }^{1}$ In general, when the total scores of Schedule B are obtained from repeated ratings by the same teacher, the reliability of the total scores is 86 for elementary school children. With an abbreviated scale the corresponding correlation is .66 for preschool children. The reliability of a single rating is .92 as Qbtained from the correlation between halves of the scale, with a prediction for the total. Ratings of the same pupils, when made by different judges under somewhat different conditions, commonly correlated about .60 for elementary school children. With an abbreviated scale the corresponding correlation is .60 for preschool children. The correlation is .70 between the scores assigned by a typical rater in a nursery school and the averages of the scores assigned by three or four other teachers.

2. Validity of measures. Thevalidity of the Behavior Rating Scale has been studied by means of ratings, clinical cases, and the subsequent histories of children. Scores on Schedule B correlate 60 with ratings from the direct approach followed in Schedule A. Fifty per cent of a group of Child Guidance Clinic cases include children who, according to teachers' ratings, fall in the highest ${ }^{2}$ ten per cent of the school population. The subsequent history of pupils who have been rated by the Behavior Rating Scale indicates that the devices have validity for the prediction of later conduct disorders in the school and community. A composite score on Schedules A and B correlated .76 with the frequency with which a group of children were referred by teachers and monitors to the office of an elementary school principal.

3. Bias of the rater. The bias of the persons making the ratings may result in tendencies for ratings to deviate from a genuinely objective record. Since teachers are subject to such bias to a greater or less degree, a child's score may reflect the teacher's attitude quite as truly as it does a fact about the child.

4. Emphasis upon aggressive behavior. An analysis of results of the use of the scales reveals a tendency to emphasize behavior of an aggressive type, and to miss certain non-aggressive types of nervous or emotional disorder the correction of which may be as important for the mental hygiene of the child as the correction of aggressive behavior which is more apparent. Other methods should be used to locate disorders in children which are of the less aggressive type. There is a possibility, although it is not certain, that this defect in the scales accounts for the fact that boys receive higher scores than girls.

5. Significance of scores a relative matter. The significance of a score is not clearly revealed by its actual size. Its interpretation is relative to the mean score of the group studied. For this reason it is not easy to use the individual scores to measure improvement unless their relative character is recognized.

6. Need for supplemental data. For individual diagnosis, the pupil's rating on th scale should be used together with all available supplemental data, such as his school rec. ord, intelligence test scores, chronological age, home conditions, health conditions, etc.

${ }^{1}$ For a detailed report of the reliability of Schedule B, the reader is referted to 0lson, Willard C., Probleth Tendencies in Children. University of Minnesota Press, Minneapolis; 1930.

"A high score implies undesirable tendencies.
It should also be stressed that the computation of behavior scores for a single child or for a group of children should always be considered the beginning of a program of amelioration. One is never warranted in regarding the score as a final act, that may pin a noxious label upon an individual, giving him an inescapable classification or justifying the influence of the environment in which he lives. In the school situation the rating may not infrequently point to the need for some adjustment of school conditions, for changes in the behavior of teachers, for modifications of the curriculum, or for the adjustment of other disturbing environmental factors.

Used within the limitations indicated above, these measuring devices, which have already proved valuable in the quantitative study of behavior problems in normal children, will also be useful to research agencies, clinics, school administrators, teachers, and others qualified by training and discretion to employ them. The construction, use, and significance of the schedules bave been discussed in considerable detail in a series of publications. ${ }^{1}$. Therefore the details of technique, materials, and methods involved in their development are not presented in this manual. Instead, only a brief statement is given concerning the construction, significance, reliability, and use of the schedules.

DEFnITIONS

Since there is no satisfactory standardized terminology, it will be necessary to define certain terms used in discussing the schedules. The term behavior problem will be used to represent the discrepancy betweeen the capacities of the individual to adjust himself, and the demands of his environment. It follows from the definition that the question of what constitutes a behavior problem depends upon the environmental demands as well as upon the reaction possibilities - innate and acquired - of the individual. For a workable definition a behavior problem may be any activity that is objectionable to a social group - home, school, or community. A child who manifests one or more behavior problems is a problem child. By means of the Behavior Rating Schedules the behavior status of a problem child may be designated in quantitative terms on the basis of his relative position on a distribution of problem tendencies in the general school population. The use of the schedules assumes that all children are problem children, but that they are so in varying amounts.

\section{CONSTRDCTION}

The Behavior Problem Record, Schedule A, is a list of behavior problems which have been listed on the schedule in order of their frequency, as reported for a group of elementary school children. To use the schedule, the teacher records on it the problems manifested during her experience with each child. The frequency of occurrence of each problem determines the rating assigned. Each problem and each level of occurrence have been assigned a statistical weighting based on seriousness and frequency. The score for a child is the sum of the weightings for the problems recorded. High scores indicate the presence of numerous and serious problems, while low scores indicate the presence of few and less serious problems.

${ }^{1}$ Haggerty, Melvin E., "The Incidence of Undesirable Behavior in Public School Children," Journal of

Wickman, E. K., Children's Betavior and Teachers' Atuitudes. Commonwealth Fund, Division of Publications, New York; 1928.

Olson, Willard C., Prodiem Tendencies in Children. University of Minnesota Press, Minneapolis; 1930 
The Behavior Rating Scale, Schedule B, consists of a graphic rating scale for each of thirty-five intellectual, physical, social, and emotional traits. Below the scale for each trait appear five descriptive phrases to assist the rater in making a quantitative judgment. Schedule $A$ is designed to locate problem children through a record of overt behavior problems, while Schedule B covers personal characteristics on a variety of traits, regardless of whether or not the behavior described would be called a behavior problem. The amount of each trait in Schedule B bas been assigned a weighting in terms of its relationship to Schedule A. The method may be illustrated by reference to Trait No. 11, Division II, "What is his physical output of energy?"

11. What is his physical output of energy?

$\begin{array}{lccccc} & \begin{array}{c}\text { Extremely } \\ \text { sluggish }\end{array} & \begin{array}{c}\text { Slow in } \\ \text { action }\end{array} & \begin{array}{c}\text { Moves mith } \\ \text { required speted }\end{array} & \begin{array}{c}\text { Energetic, } \\ \text { Vivacious }\end{array} & \begin{array}{c}\text { Overactive, } \\ \text { Hyperdinetic, } \\ \text { Meddling }\end{array} \\ \text { N } & 15 & 161 & 457 & 139 & 18 \\ \text { Mean } & 44.9 & 15.5 & 8.8 & 8.4 & 27.1 \\ \text { Weight } & 5 & 3 & 2 & 1 & 4\end{array}$

The data for this trait have been interpreted as follows: Of 790 pupils, 15 who were rated as being "extremely sluggish" had an average behavior score of 44.9 on Schedule A. This is the highest average score for any of the five subdivisions of this particular trait, and therefore receives a weighting of 5 . Eighteen pupils who were rated as overactive, hyperkinetic, and meddling had an average behavior score of 27.1 . This, being the next to the highest average score for the five divisions, received a weighting of 4. In a similar manner the average belavior score for each remaining division was computed and a weighting assigned. It is interesting that by this weighting method personal traits may be diagnostic of a condition that is not apparent in the nature of the trait itself. The sum of the weights for the different traits is called a problem tendency score for the child. Taking into account the relative nature of the measures, high scores represent undesirable deviations, and low scores desirable deviations from the typical behavior of a group of children.

OTHER RELATIONSHIPS

Age and grade differences in scores on the Behavior Rating Scale are negligible, but boys show significantly greater problem tendencies than girls. The data for obtaining norms need be differentiated only according to sex. The abbreviated form of the scale used with preschool children requires, of course, a different set of norms. The majority of teachers do not differ significantly in the mean composite score of the ratings they assign on Schedule B when rating comparable groups, or when different raters judge the same group. Mean ratings on Schedule A tend to fluctuate more widely. Scores on Schedule B may be expected to correlate with achievement in school subjects to about the same extent as the usual intelligence test does, or perhaps to a slightly greater extent. An intensive analysis of the relationships among achievement, intelligence, and behavior indicates that a score in problem tendencies gives a somewhat unique contribution to the prediction of achievement.

$\checkmark$

SUGGESTED USES

The instruments lend themselves to use in a variety of experimental projects which cannot be detailed here. The two devices may be used separately or in conjunction but when only one is used Schedule B is recommended. Under supervision they bave been used profitably in one normal school by students preparing to be teachers, and in an institute for child welfare. They provide one method of training observers in the individual study of children. Guidance clinics will find the devices useful for securing from teachers standardized reports concerning the behavior of children who are being studied. The extent to which the teacher's attitude and the child's behavior are components of the situation should be taken into account in each instance. The quantitative scores obtained should prove useful in analyzing other types of clinical data. The norms given separately for intellectual, physical, social, and emotional traits indicate roughly the major fields of maladjustment, as seen through the eyes of persons closely acquainted with the child. School principals and counselors should find the information recorded on the schedules of value in their work with individual children, and also as a suryey technique to aid in choosing the children who should have the services of child guidance. The teacher herself should gain a further understanding of child behavior by using the devices in the classroom. In so doing she may also ask herself the questions, "To what extent is my own attitude a factor in the behavior reported?" and "To what extent will a change in my attitude ameliorate the undesirable condition?"

\section{SURVEY TECHNTOUE}

It is necessary for those who use these schedules to become familiar with their nature, their purpose, and their technique. In collecting a portion of the data upon which the norms are based the following elaborate procedure was employed. The problem was the rating of first-grade pupils in a large city school system. The administrative officials, supervisors, representatives of child-guidance clinics, and principals of the schools included first met with the surveyors for a general discussion of the project. . A second meeting was held with the teachers who were to do the rating. At this meeting each teacher was supplied with a manual of directions for using the schedules. They were asked to rate two of their children prior to a personal consultation with the persons in charge of the investigation. This personal interview, which dealt with the details of rating, was held with the teacher in her own school, sometime during the two weeks following the general meeting. The chief purpose of the interview was to interest the teacher in the project, secure her careful coöperation, and make clear the exact procedure. After this she made the ratings of all her pupils. The completed scales and class record sheets were returned to the central office. The data were then compiled to obtain norms for interpreting the ratings.

Variations in the method of securing the records are described in the publications listed in the footnote on page 3.

\section{DiRections For MakTng Ratings}

\section{SCHEDULE A. THE BEHAVIOR PROBLEM RECORD}

On the Behavirr Problem Record you will find ffteen items that indicate undesirable behavior, varying in seriousness. You are to review your entire experience with each child as it is related to each item of behavior listed on the record. If the item of behavior has never occurred, make a check in the first column. If it has occurred 
only once or twice, make a check in the second column. If it has occurred more than twice, but is not a constant problem, make a check in the third column. If it occurs quite regularly in the child's behavior, make a check in the fourth column. The numbers in the body of the sheet are to be disregarded in making your record. They are for use in scoring. In order to make clearer to you the meaning of each item of behavior, the following statements are given to suggest the general nature of each problem:

1. Disinterest in School Work. Under this heading include any action of the child that you interpret as showing lack of interest in school work.

2. Chealing. Consider all forms of cheating in reference to school work.

3. Unnecessary Tardiness. Consider his tardiness record. If the tardiness is unexcused and due to his own failures, it should be interpreted as unnecessary. Consider also the promptness with which he returns from recess periods.

4. Lying. Include under this head all misrepresentations of facts.

5. Defiance to Discipline. Consider how well he accepts authority and obeys the rules of the school.

6. Marked Overactivity. Consider under thishead the child'sphysical output of energy Marked overactivity is characterized by a general restlessness, by an inability to sit or stand still, by playing constantly with objects, by uncontrolled activity about the school and playground, by involuntary movements of the hands, feet or other parts of the body.

7. Unpopular with Children. Under this head consider how well he is liked by other children.

8. Temper Outbursis. Consider the child's reactions to unpleasant situations and to frustrations of his behavior. Temper outbursts may be manifested by crying. by violent physical reactions, or by abusive language.

9. Bullying. Consider whether the child attempts to dominate his playmates by physical force and abusive language and whether he picks quarrels with smaller children. If a girl, the activity may be somewhat different. Consider whether she delights in tormenting, teasing, or making fun of other girls.

10. Speech Diffculties. Under this heading include stuttering or stammering, the substitution of one sound for another, and aural inactivity, as indicated by pronouncing letters or sounds incorrectly or by slurring letters or sounds.

11. Imaginative Lying. Under this head consider the child's tendency to tell tales not based on fact. Such lying might include claims of unusual prowess or posses sions, air castles, tales of extraordinary happenings, of being pursued by animals or persons, of being persecuted, etc.

12. Sex Offenses. Under this head consider all acts relating to sex behavior which are objected to by conventional standards of health and morals.

13. Stealing. Consider the child's honesty with regard to the property of bthers.

14. Truancy. Consider unexcused (illegal) absences from school, wherein the child absents himself on his own responsibility.

15. Obscene Notes, Talk, or Pictures. Under this head consider whether the child circulates notes, pictures, or stories of a suggestive nature among members of the class and whether he uses filthy or profane language about the school or play. ground.
- PROCEDURE

(1) First read carefully the directions which appear at the top of the Behavio Problem Record:

Below is a list of behavior problems sometimes found in children. Put a cross $(X)$ in the appropriate column after each item to designate how frequently such behavior has occurred in your experience with this child. A cross should appear in some column after each item. The numbers are to be disregarded in making your record. They are for use in scoring.

(2) Next make out a record for each child in your room.

(3) When all the records have been made, score each one according to the directions at the bottom of the sheet:

Directions for scoring. Transfer the numbers you checked for the different items to the right-hand column, headed "Score." Add the numbers to secure the total score, arid record the total in the upper right-hand comer of this sheet.

SCHEDULE B. THE BEHAVIOR RATING SCALE

The following instructions appear on the first page of each copy of the rating scale. Read them carefully and reread them occasionally to keep them in mind.

1. Do not consult anyone in making your judgments.

2. In rating a person on a particular trait, disregard every other trait but that one. Many ratings are rendered valueless because the rater allows himself to be influenced by a general favorable or unfavorable impression that he has formed of the person.

3. When you have satisfed yourself as to the standing of this person in the trait on which you are rating him, indicate your rating by placing a cross (X) immediately above the most appropriate descriptive phrase.

4. If you are rating a child, try to make your ratings by comparing him with children of his own age.

5. The masculine pronoun (he) has been used throughout for convenience. It applies whether the person whom you are rating is male or female.

6. In making your rating, disregard the small numbers which appear below the descriptive phrases. They are for use in scoring.

It is suggested that you make your ratings in pencil so that a change can be made easily in case of error. Your first rating may best be done in consultation with someone familiar with the method and should be in the nature of a practice exercise. When you actually start rating the entire class, it is recommended that you first rate each child on the traits in Division I, then rate each child on Division II, then on Division III, and finally on Division $N$. This will enable you to concentrate your attention on fewer items at one time, and should result in greater accuracy in your judgments. Refer any questions concerning the method to someone who understands the procedure.

\section{DIRECTIONS FOR SCORING SCHEDULE B}

After all members of the class have been rated on each trait in the Behavior Rating Scale, the papers should be scored. A small number appears in parentheses under each descriptive phrase. Transfer the number you have checked for each trait to the column at the right of the page under the heading Score. Add the scores separately 


\section{Haggerty-Olson-Wickman Beharior Rating Schedules}

for Division I, Division II, Division III, and Division IV. Record the scores for each division in the upper right-hand comer of the first page and add to obtain the total score. A pupil's score is the sum of the numbers under the phrases which were marked - in rating the pupil. When all papers have been scored, record the results on the Class Record.

$$
\text { NORMS }
$$

Tables 1,2,3, and 4, derived from the use of the schedules, will be useful in interpreting pupils' scores obtained on the schedules.

TABLE 1

Distribution or Scores on tefe Bebamor Probiem Record, Schedute a

\begin{tabular}{|c|c|c|c|c|c|c|}
\hline \multirow{2}{*}{ SCORES } & \multicolumn{2}{|c|}{ Bors } & \multicolumn{2}{|c|}{ GiRIS } & \multicolumn{2}{|c|}{ TOTAI } \\
\hline & TRIREENCY & $\underset{\mathbb{R A N I}}{\text { PERCERTII }}$ & FREQUENCY & $\begin{array}{c}\text { PERCENTLE } \\
\text { RANK }\end{array}$ & RREQUENCY & $\underset{\text { PERRTIL }}{\text { PERCER }}$ \\
\hline $\begin{array}{l}120-23 \\
116-19\end{array}$ & & & $1 \%$ & 100.0 & 1 & 100.0 \\
\hline $112-15$ & 1 & 1000 & & 99.9 & 1 & 99.9 \\
\hline $108-11$ & 1 & 99.9 & & & 1. & $\begin{array}{l}99.9 \\
908\end{array}$ \\
\hline $104-07$ & 1 & 99.8 & & & 1 & 99.8 \\
\hline $100-03$ & 1 & 99.7 & & & $i$ & 99.7 \\
\hline $96-99$ & 3 & 99.5 & & & 3 & 99.7 \\
\hline $92-95$ & & & 2 & 99.7 & 2 & 99.5 \\
\hline $88-91$ & 2 & 99 & & & 2 & 99 \\
\hline $\begin{array}{l}84-87 \\
80-83\end{array}$ & $\frac{1}{2}$ & 99 & 1 & 99.6 & 2 & 99 \\
\hline $76-7$ & 6 & $\infty$ & 1 & $\infty$ & & \\
\hline $72-75$ & 3 & 98 & 3 & 99 & 6 & 99 \\
\hline $68-71$ & 12 & 98 & 3 & 99 & 15 & 98 \\
\hline $64-67$ & 13 & 96 & 3 & 99 & 16 & 98 \\
\hline $60-63$ & 11 & .95 & 5 & 98 & 16 & 97 \\
\hline $36-59$ & 9 & 94 & 3 & 98 & 12 & 96. \\
\hline $52-55$ & 12 & 93 & 5 & 98 & 17 & 95 \\
\hline $48-51$ & 17 & 92 & 5 & 97 & 22 & 95 \\
\hline $44-47$ & 13 & 91 & 11 & 96 & 24 & 94 \\
\hline $40-43$ & 31 & 89 & 12 & 95 & 43 & 92 \\
\hline $36-39$ & 32 & 86 & 16 & 94 & 48 & 90 \\
\hline $32-35$ & 37. & 83 & 14 & 93 & 51 & 88 \\
\hline $28-31$ & 46 & 79 & 25 & 91 & 71 & 85 \\
\hline $24-27$ & 67 & 74 & 37 & 88 & 104 & 81 \\
\hline $20-23$ & 81 & 67 & 39 & 84 & 120 & 76 \\
\hline $16-19$ & 71 & 60 & 65 & 79 & 136 & 70 \\
\hline $12-15$ & 111 & 52 & 108 & 71 & 219 & 61 \\
\hline 8-11 & 83 & 43 & 80 & 66 & 163 & 53 \\
\hline 47 & 170 & 32 & 195 & 29 & 365 & 40 \\
\hline 0 & 261 & 12 & 430 & 20 & 691 & 16 \\
\hline $\begin{array}{c}\mathrm{N} \\
\text { Median }\end{array}$ & $\begin{array}{c}1098 . \\
13.2\end{array}$ & & $\begin{array}{c}1065 \\
\quad 6.1\end{array}$ & & $\begin{array}{c}2163 \\
8.6\end{array}$ & \\
\hline
\end{tabular}

Manual of Directions

TABLE 2

Distabution of Total Scores on the Behator Rating Scale, Schedule B

\begin{tabular}{|c|c|c|c|c|c|c|}
\hline \multirow{2}{*}{ SCORE } & \multicolumn{2}{|c|}{ Boys } & \multicolumn{2}{|c|}{ Girks } & \multicolumn{2}{|c|}{ TOTAL } \\
\hline & FREQUENCY & $\begin{array}{c}\text { PERCENTLIE } \\
\text { RANKS }\end{array}$ & FREQUENCY & $\underset{\text { RANT }}{\text { PERCENTIR }}$ & TREQUEXCY & $\begin{array}{l}\text { PIRCENTILE } \\
\text { RANI }\end{array}$ \\
\hline $135-139$ & 2 & 99.9 & & & 2 & 99.9 \\
\hline $130-134$ & 3 & 99.8 & & & 3 & 99.9 \\
\hline $123-129$ & 6 & 99.5 & 2 & 99.9 & 8 & 99.7 \\
\hline $120-124$ & 10 & 99 & 2 & 99.8 & 12 & 99 \\
\hline $115-119$ & 19 & 98 & 9 & 99.4 & 28 & 99 \\
\hline $110-114$ & 21 & 97 & 10 & 99 & 31. & 98 \\
\hline $105-109$ & 25 & 95 & 18 & 98 & 43 & 96 \\
\hline $100-104$ & 40 & 93 & 15 & 97 & 55 & 95 \\
\hline $95-59$ & 70 & 89 & 30 & 93 & 100 & 92 \\
\hline $90-94$ & 61 & 85 & 39 & 92 & 100 & 88 \\
\hline $85-89$ & 96 & 79 & 58 & 89 & 154 & 84 \\
\hline $80-84$ & 90 & 73 & $\lceil 4$ & 84 & 164 & 78 \\
\hline $75-79$ & 120 & 60 & 98 & 78 & 218 & 72 \\
\hline $70-74$ & $\begin{array}{l}132 \\
132\end{array}$ & 57 & 95 & 71 & 227 & 64 \\
\hline $65-69$ & 172 & 47 & 141 & 63 & 313 & 55 \\
\hline $60-64$ & 187 & 35 & 215 & 50 & 402 & 42 \\
\hline $55-59$ & 180 & 22 & 202 & 35 & 382 & 28 \\
\hline $50-54$ & 136 & 12 & 194 & 21 & 330 & 14 \\
\hline $45-49$ & 68 & 5 & 122 & 9 & 190 & 7 \\
\hline $40-44$ & 26 & $i$ & 58 & 3 & 84 & 2 \\
\hline $35-39$ & 9 & .3 & 12 & & 21 & .4 \\
\hline $\mathrm{N}$ & 1473 & & 1394 & & 2867 & \\
\hline Median & 68.8 & & 62.5 & & 65.4 & \\
\hline Mean & 72.4 & & 65.9 & & 69.2 & \\
\hline $\mathrm{S}, \mathrm{D}_{\mathrm{did}}$ & 18.4 & & 16.3 & & 17.7 & \\
\hline
\end{tabular}


TABLE 3

Distribution or Scores on the Behavior Ratng Scale, Schadue B, ay Divistons

\begin{tabular}{|c|c|c|c|c|c|c|c|c|}
\hline \multirow{3}{*}{ CORE } & \multicolumn{2}{|c|}{ 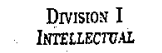 } & \multicolumn{2}{|c|}{$\begin{array}{c}\text { Drvisiron II } \\
\text { PHYSICAL }\end{array}$} & \multicolumn{2}{|c|}{$\begin{array}{c}\text { Drwistor III } \\
\text { SOCCLIL }\end{array}$} & \multicolumn{2}{|c|}{$\begin{array}{l}\text { Drrsstron IV } \\
\text { EMOOTIONAL }\end{array}$} \\
\hline & Boys & GrRIS & Boys & GIRLS & Bors & GIRYS & Boys & GIRTS \\
\hline & PREQ. PR. & PREQ, PR. & FREQ. PR. & RREQ. PR. & RREQ, pR, & SRRQ. PR. & FREQ, RR. & RREQ. PR. \\
\hline 45 & & & $\ldots .$. & & 199.8 & $\ldots$ & & \\
\hline 44 & & $\begin{array}{ll}\ldots & \ldots \\
\therefore\end{array}$ &.... & $\ldots$ & $\ldots$ & & 199.8 & \\
\hline 43 & .. & .. $\ldots$. & .. $\quad \ldots$ & $\cdot \ldots$ & & & 1. 99.5 & .. \\
\hline 42 & . & $\because \quad \ldots$ & $\begin{array}{lll}. . & \ldots\end{array}$ & $\begin{array}{ll}. . & \ldots .\end{array}$ & 199.5 & $\therefore \quad \ldots$ & & 1098 \\
\hline 41 & .. & $\therefore \quad \ldots$ &..$\quad \cdots$ & $\begin{array}{lll}\cdot \cdots & \cdots\end{array}$ & & $\begin{array}{lll}. & \cdots\end{array}$ & $\begin{array}{l}399 \\
\end{array}$ & 199.8 \\
\hline 40 & & $\ldots$ & .. $\quad \ldots$ & $\begin{array}{lll}. . & \ldots\end{array}$ & 299 & 199.8 & 199 & 199.5 \\
\hline 39 & .. & $\ldots$ & $\begin{array}{lll}. & \ldots\end{array}$ & $\begin{array}{ll}. . & \ldots\end{array}$ & &.$\therefore \cdots$ & 198 & \\
\hline 38 & .. $\ldots$ & $\ldots$ & $\begin{array}{ll}. . & \ldots\end{array}$ & $\begin{array}{ll}. . & \ldots\end{array}$ & 1 & . $\quad \ldots$ & $\begin{array}{lll}. \quad & \cdots\end{array}$ & $\begin{array}{l}1.99 \\
198\end{array}$ \\
\hline 37 &.$\quad$. & $\ldots$ &..$\quad \ldots$ & $\begin{array}{ll}. . & \ldots\end{array}$ & $\begin{array}{l}497 \\
296\end{array}$ & 199.5 & 907 & 198 \\
\hline 36 & .. & $\ldots$ &..$\quad \cdots$ & $\cdots$ & & 1 s9.0. & 297 & 198 \\
\hline 35 & .. & & & $\ldots$ & 395 & 299 & 596 & 298 \\
\hline 34 & & & $\begin{array}{ll}. . & \ldots \\
. & \ldots\end{array}$ & $\ldots$ & & 298, & & \\
\hline 3. & & 199.8 & .. $\quad \ldots$ & $\ldots$ & $394^{\circ}$ & & 4 & 296 \\
\hline 32 & 699 & & $\begin{array}{ll}\therefore \quad \ldots \\
\end{array}$ & $\begin{array}{lll}. . & \ldots\end{array}$ & 6 & 88 & 2 & 395 \\
\hline 31 & 697 & 198 & .. $\quad \ldots$ & $\begin{array}{lll}. . & \ldots\end{array}$ & 491 & 397 & & 395 \\
\hline 30 & 795 & 298 & $\ldots$ & $\ldots$ & 10 & & 8 & 394 \\
\hline 29 & & & $\ldots \ldots$ & $\ldots$ & & & & \\
\hline 28 & 492 & 297 &.$\quad \ldots$ & $\therefore \quad \ldots$ & 8 & & & 492 \\
\hline & 6.90 & 796 & & & & & 88 & 291 \\
\hline 26 & 7. 88 & $793 \mathrm{r}$ & 199.8 & $\begin{array}{ll}1 & 99.8\end{array}$ & 1478 & 987 & 80 & 490 \\
\hline 2 & 1185 & '11 & 199.5 & 2. 99 & 14 & 8 & 5 & 5 \\
\hline 24 & $\begin{array}{ll}9 & 82\end{array}$ & 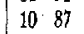 & & & & 15 & & \\
\hline 2 & 779 & 1584 & & 199 & 15 & 13 & 11 & 1684 \\
\hline 22 & 577 & 58 & & & 20 & 8 & 167 & 1180 \\
\hline 21 & $20 \quad 73$ & 1278 & 796 & 98 & $17 \quad 50$ & 21 & 1266 & 977 \\
\hline 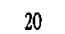 & 1165 & 7 & 4 & 1096 & 27 & 156 & $19 \quad 60$ & 74 \\
\hline & & & & & & & & 70 \\
\hline 18 & 961 & 176 & 10 & 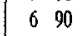 & & 10 & & \\
\hline 17 & 1655 & $22 \quad 62$ & 87 & 0 & 17 & 234 & 174 & 2161 \\
\hline 16 & 2349 & 1557 & 2481 & 1884 & 2018 & 2739 & 2438 & 2653 \\
\hline 15 & 43 & 5047 & & & 14 & 33 & 213 & \\
\hline is & & & & 32 & 14 & 20 & 2622 & 5031. \\
\hline 1. & $22 \quad 23$ & $27 \quad 27$ & & 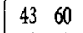 & 4 & 20. & $\begin{array}{ll}31 & 13\end{array}$ & $\begin{array}{lll}37 & 17\end{array}$ \\
\hline 12 & 1616 & 2519 & \begin{tabular}{|ll}
49 & 3
\end{tabular} & 384 & 53 & 229 & 126 & $2588^{\circ}$ \\
\hline 11 & 1811 & 1413. & 421 & 6332 & $\begin{array}{ll}5 & 1\end{array}$ & 163 & 82 & 122 \\
\hline 10 & 16 & 14 & & $44 \quad 15$ & 1.2 & 23 & $\begin{array}{ll}3 & 5\end{array}$ & 1 \\
\hline 9 & $\begin{array}{ll}6 & 1\end{array}$ & 174 & 123 & 225 & .. & $\begin{array}{ll}. . & \ldots\end{array}$ & $\begin{array}{lll}. . & \ldots\end{array}$ & $\begin{array}{ll}. . & \ldots\end{array}$ \\
\hline 8 & 1 & $\begin{array}{ll}4 & 1\end{array}$ & 2.3 & $\begin{array}{ll}6 & .9\end{array}$ & $\begin{array}{lll}. . & \ldots\end{array}$ & . $\quad \ldots$ & $\ldots \ldots$ &..$\quad \ldots$ \\
\hline 7 & & 2 & & & $\because$ & . $\ldots$. & $\begin{array}{lll}. & \ldots\end{array}$ & \\
\hline & & 326 & .30 & 326 & 300 & 326 & 300 & \\
\hline & & 15. & & & & & 18 & \\
\hline & 18.2 & 17.1 & & 13 & 22 & 18 & 20 & 18.1 \\
\hline & & 5.5 & 3.3 & 3.3 & 6.3 & 4.9 & -7.0 & 5.8 \\
\hline
\end{tabular}

Manual of Directions

TABLE 4

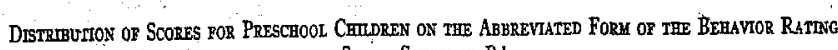
SCALE, SCBEDUIE B

\begin{tabular}{|c|c|c|c|c|c|c|}
\hline \multirow{2}{*}{ SCORE } & \multicolumn{2}{|c|}{ Boys } & \multicolumn{2}{|c|}{ GrRss } & \multicolumn{2}{|c|}{ Total } \\
\hline & TREQUENCY & $\begin{array}{c}\text { PRRCENTLL } \\
\text { RUNI }\end{array}$ & FREQUENCY & $\begin{array}{c}\text { PERCENTLIE } \\
\text { RANI }\end{array}$ & IREQOENCY & 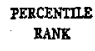 \\
\hline $80-82$ & & & 1 & 99 & 1 & 99 \\
\hline $77-79$ & 3 & 97 & & & 3 & 97 \\
\hline $74-76$ & 4 & 90 & 1 & 96 & 5 & 93 \\
\hline $71-73$ & & 82 & & & 3 & 88 \\
\hline $68-70$ & 3 & 76 & 1 & 94 & 4 & \\
\hline 65-67 & 1 & 72 & 1 & 92 & 2 & 81 \\
\hline $62-64$ & 3 & 68 & 3 & 87 & 6 & 77 \\
\hline $59-61$ & 3 & 61 & 3 & 80 & 6 & 70 \\
\hline $.56-58$ & 3 & 57 & 5 & 70 & 8 & 62 \\
\hline $53-55$ & 6 & 46 & 2 & 62 & 8 & 53 \\
\hline $50-52$ & 1 & 39 & 3 & 56 & 4 & 47 \\
\hline $47-49$ & 1 & 36 & 7 & 44 & 8 & 40 \\
\hline $44-45$ & 7 & 28 & 6 & 29 & 13 & 28 \\
\hline $41-43$ & 3 & 18 & 4 & 17 & 7 & 17 \\
\hline $38-40$ & 5 & 9 & 3 & 8 & 8 & 9 \\
\hline $35-37$ & 1 & 3 & 2 & $\dot{2}$ & 3 & 3 \\
\hline $32-34$ & 1 & 1 & & & 1 & .6 \\
\hline$\therefore N$ & 48 & $\therefore$ & & & 90 & \\
\hline Median & 55.5 & $i$ & 49.6 & & 53.4 & \\
\hline $\begin{array}{l}\text { Mean } \\
\text { S. D }\end{array}$ & 56.6 & & $\begin{array}{l}52.1 \\
10.0\end{array}$ & & $\begin{array}{l}54.5 \\
12.1\end{array}$ & ' \\
\hline
\end{tabular}

${ }^{2}$ The abbreviation consists in the omisision of Items $5,6,8,16,17,22,24,30,31$, and 32 of the complete form. The Minnespota and the Child Welfare Research Station of the University of Ioma. 


\section{HWEREVIEW OUTLING}

1. Number 2. Grade_Reg/Met/Acc 3. Date of Birth

4 Date of Admission 5. Intelligence Level

I. Interests

A. Sports and Games

B. Hobbies

C. Vocationel Ambitions and Plans

D. Activity ố orm choice

E. Reading Interests

Evaluation ( )Anti-sociel or Indifferent, ( ) lack of range, only slightly interested in fey things, ( ) clains no interests or plans, () has average number of interests, () vide range of Interests but some:hat llalted in depth, ( ) has some cone suming interests but vell balanced. Talks easily about thern.

() Vocational plans are concrete ald realistic.

II. School Adjustinent

A, Academic school likes or dislikes

B. Vocational school lites or dislikes

c. Progress setisfaction

D. Teacher-Pupil relationships

E. Further anbitions in way of formel training

Evaluations ( ) Hates all school rork, waiting on vorking certificate, ( ) Teachers e.ll pick on him, ( ) Only time he is happy is in the class room, ( ) I1kes some aspects of school, cen't see necessity, () average like of school, rather neutral, () thinks he's neking progress in school, () likes school but doesn't have clear notion of relationships, ( ) gets along vell with teachers, () sees school as part of his total plansmakes positive statements. 
III. Cottage and Campus Adjustment: Cottake Supervisor

A. Relationship with supervisor

B. Relationshin with cottage nates

c. Reaction to rules and disciplinary actions

D. Reactions to other adults

E. Reactions to food, clothing, vork responsibilities, etc.

Evaluations ( Desiring transfer, hates supervisor, cen't get along uith roormate, thinis place is terrible, () mildIy hostile to thole set-up, too compliant, ( ) gets elong frizly well-has average amount of disiltes, ( ) verbalizes reasons for rules-hos foir relation witi supervisor and other boys-expresses group loyalty, ( ) reacts vell to cottage end campus regulations, suggests inprovenents in constructive way, sees positive side.

IV. Fealth

A. Previous and present health evaluation

B. Visual, auditory difficuities

c. Appetite

D. Sleep, Dreams, Inuresis

E. Heelth Worrles

Evaluation ( Wiany worries in regard to health, ( ) sore complaints of sleeplessness, enuresis, frequent colds, con't hear, or see, etc. ( ) balance between compleints and positive foelings, ( ) predominantly positive feelings in regard to health uf th fov ninor irritations, () feels plgorously hoalthy, nothing wrong- acts and lools 1 t.

V. Social, Emotional, and Sexusl Adjustment

A. kaking Friends 
3. Prevalent nood (ctitical, happy, confldent,-emberrassed)

C. Heterosexual Interests (ibxed group activity)

$$
\text { (dating) (att1tude toviard) }
$$

D. Sexuel Information

(Feelling of aceouacy)

(Source)

(Peelings in regard to masturbetion, perversions, etc.)

E. Attitudes tonard Sociel Conventions

Evaluation:( ) feels friendless, embarrassed, hostile, critical, ( ) evidence of some sexual conflict and guilt, ( ) may be sonevhat embarrassed and feel somewhat friendless and ignorant of sexual knowledge, ( ) rather hesitaint to discuss but not too concerned, () feels nornal ond sees hiliself as falriy popular, ( ) frank, poised, not vorrled, confident.

VI. Fanily Relationships

A. Visitations and Vacctions

B. Attitude towerd being in Hone

C. Attitudes toward Siblings

D. Conceptions of Future Relationships

E. Real1ty Appra1sal

Evaluation: ( ) cen't discuss femily, hostile, places unreel halo eround family relations, ( ) emberrassed in regard to family, thinls he is rejected, ambivalent, ( ) fecis fanily let him dorn but he cen melie the best of it-doesn't get enough visits or vacations, ( ) interested in family velfare, admires successful meribers, ( ) looks at family realisticaliy, sees himself as a grouing, independent individual who cen stand on own feet. 
VII. Miscellaneous (any outstanding attitude, enotion, or behavior that occurred during interviev which does not fit other categories)s

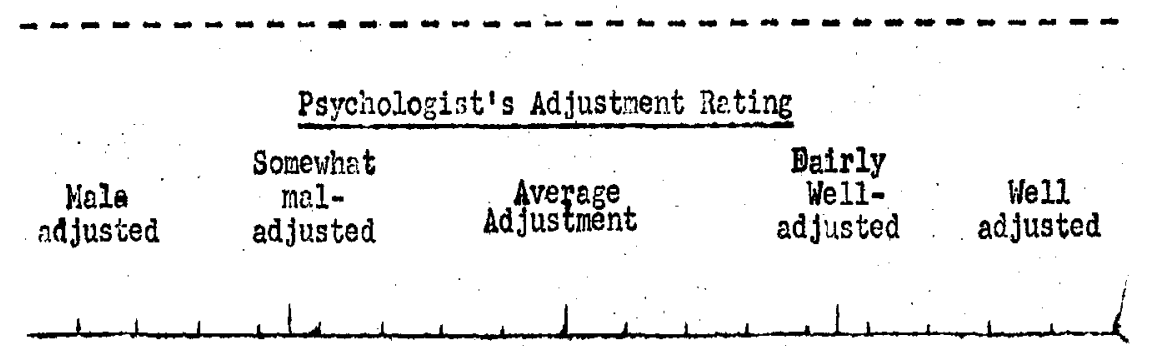


GUESS WIO?

1. Grade Date

1 Directions: Each of you has a list of nanes of the boys in the Fone in alphabeticel order. Fere is a list of short descriptions that vey describe cortain oî these boys. Hrite down one nare for each description. Be sure you trite both first and last hame. The boy naned by you should fit the description as nearly as possible, You nay urite in the waine of the sare boy for severci descriptions if you vish. No one but tre person giving this test and yourselî yill thon whon you nane so be as fronk as jossiblo.

A, Te is a popular fellow on the Campus. The fellows and giris all lite him.

1.

B. Fie is so honcly or so unatractive that othor pcople do not lilie to be around hin. iearly everyone finds hin unpleasent to loo:. at.

$$
\text { 2. }
$$

c. Ilere is a boy who talkes part in all zroup genos. It

seems like he is good in zearly all sports and really lites

to plisy tren,

3.

D. This boy cen't seez to tell a joke so that it's runny. Fo seldon laughs at folres and hes to be told the point of the jolse and heve it cxpleined to tin. 4.

E. He is afroid. He won't take a dare. He is always afrid he vill got hurt, liost guys say he is "chtclen".

5. 
F. This boy is a leeder. He knorss ho: to do a lot or things.

Te steris genes. Iie starts nev ideas that are good. The other fuys like to follow hir and do what he does.

6.

G. He is entiusiastic, pepy. Fe is almeys ready to tackle

a job. Docsn't very oitten get discouraged.

7.

11. This fellow never looks neat. IIis hair is unconbed. Ile doesn't cere hou he looks. Sozecines he even smells bedly.

3.

I. This fellow is good-100xing. "early ovoryone vishes to be as nice looking as he is,

9.

J. Fie cimeys has a ney jolie. The jolkes ho tells are really

furny. He :seeps the other guys laughing nearly everytine he starts in to telk.

20.

K. Itcre is a boy who scems to be very unhepoy. Ee seloion shiles, se seems to be vorried. Fe doesin't secn to enjoy anytining that other suys lilke.

11.

L. The rest of the fellows don't have auck to do with this boy. Fe is very unpomiar. Fe docs things that other suys don't live.

12. 
i. Pris fellon is fricicily. then sorene noecs hely, ie's pint there. He belkes other guy's perts then the crond is dom on tren. He's a sood fellon! to know.

23.

i. This wy vill so out oi his yey to set ont of a light.

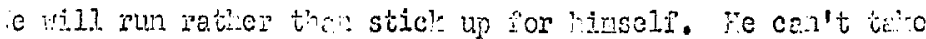
it.

It:

o. Iio is not. Wis hir is usunlly corbed. Te leons hilselî cloen. re teles plenty of s'overs and never smelis bedly.

15.

P. This boy has a good sense on lunor. Ho cen tole thiding vithout getting sore. Ie so etincs laughs at his om nistaler.

16.

Q. He spends much of his tine tellitin about sex. jie tries to get other boys to teve scruel reletions wh him. Te is frequently seen teteing part in sexvel activities in the coitege, 17.

R. This boy vilI try anyting that looks lile it cen be done, He vill dere to do difricult things such as nev dives thile svicuing or herd stunts. Fe will cone right ont and asl bople for thing ven otiers are afraid.

13. 
S. This folzon is 'ere to nelic rrienis with. Te seens to li'se to keep by hiraself. Ie ects as $i n$ he didn't vat to to ve eny firiends.

19.

T. Le is acver entiusicstic about anything. Ye seldon puts is wole heart in any activity. Fe rould retion tale it essy evor if it nerns losin for his side.

20.

J. Te alyoys follons and does just wht some other fellon tells hin. ro hever seens to have eny icos of his onk. 21.

V. This rellor nover telos pert in any active genes. Te sit.s around and roods a lot. Eo vould reter vetch then nlay.

$$
\text { 22. }
$$

W. This boys von't refuse a fight if the other fellov is

about his size sind age. Ie can tele uis orn pert.

$$
23 .
$$

x. STe cen't tole a jolte. Bvorytino tule suys got to cutting up and purling triclis on each otien, he gets sore. 24.

Y. Te is nost alvers cheorul. io metter whet hejous he

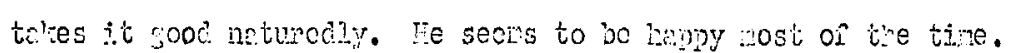
25.

le'se sure you have tried to urite in a nere for every blenk. 
Each person will be given a sheet containing the names of every boy in the study in alphabetical order. Each test blank will be passed out to the student whose name is stapled to the blank. The blank will also have the code number of the student on 1t. The test will be preceded by a brief discusstion of the purpose of the study - that we are interosted in finding out more about boys of this age, their likes, their dislikes and how well they can size each other up. They will be told that their replies will be confidential and will not be used ageinst any boy in any manner. They will be asked to attempt to make a guess for each question but will not be forced to.

sooring of the "Guess who" will be after the system used by Tryon. If a boy is mentioned for a positive charaoterization, he will receive a plus 1 credit. Positive descriptions are $A, C, F, G, I, J, M, O, P, R, W$, and $Y$. If a boy is mentioned for a negative description, he shall recelve for every mention a minus 1 . Negative descriptions are $B, D$, $E, H, K, I, N, Q, S, T, U, V$, and $X$. Total score will be the algebrato score for each boy. It will be urnecessary to divide by total opportunity to be mentioned as the members of the group are constant on all tests. 

2. You heve becn assigned a double roon and you nay choose anyone on the list that you wish for a roonate.

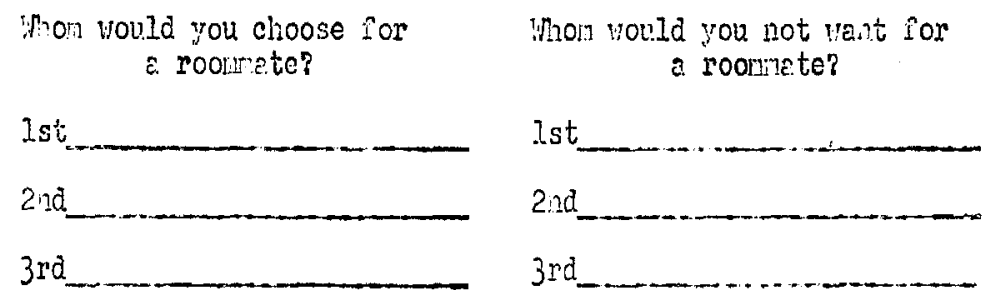

3. Sone very food friends have invitod you for a veeltend. They have asled you to bring a friend with you.

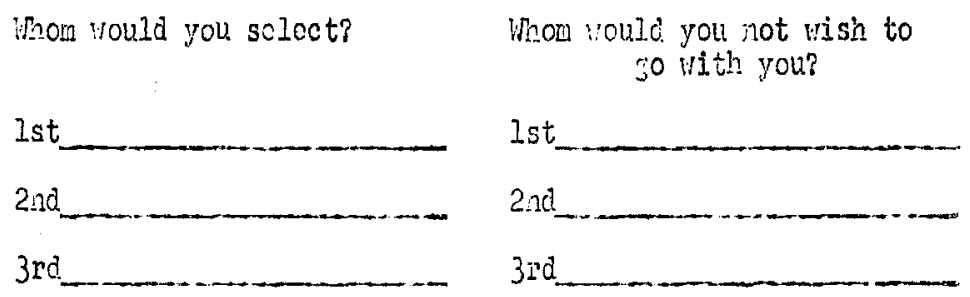

4. You are askod to wor's in the check roon at the zuditoriwn dur. ing a neeting of The Amorictin Legion. You wis? be remitted to keep all tile tips.

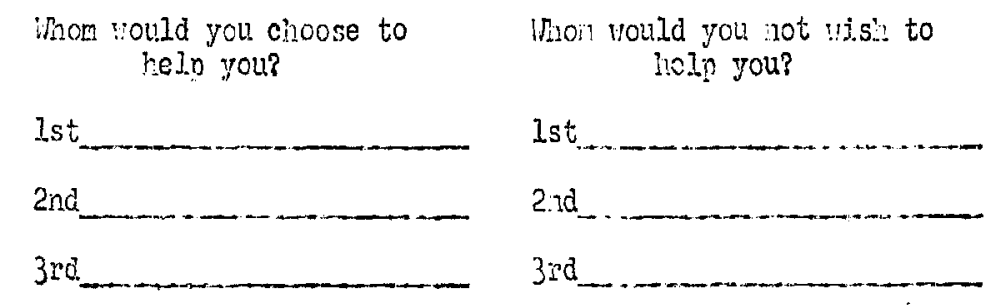

5. You are the vimer of e redio contest and have von en all-exponse tour to Washington D. C. for yourselî and a friend.
Whol yould you invite?
Whon would you not :ish to
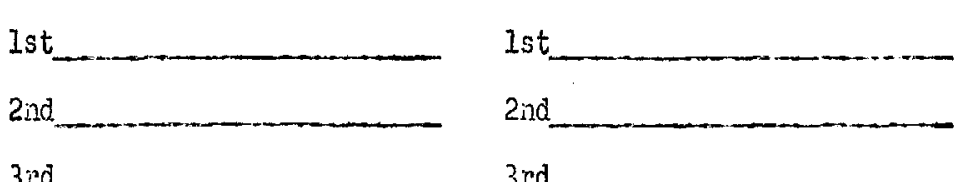
$3 r d$
$3 r d$ 

Instruction Sheet to Accompany
Companionship Choice Test

Each person will be given a sheet containing the names of every boy in the study in alphabetical order. The companship Choice Test will be given to students in accordance with the code number. The code number will be on the test form and the name stapled to the test. The persons filling out the test will tear off their names. They will be told that this exercise is a part of the larger study attempting to know more about boys' feelings, wishes, and cholces.

They will be requested for honest effort in helping to secure data as to patterns of cholces which will not be used by any other department at the Home. For the most part, good cooperation may be expected. The directions on the test will be read and any questions answered. As papers are fintshed, they will be taken up.

The Companionship Test will be scored on the basis of number of choices and rejections. Bronfenbrenner states that total choices using as many criteria as we are using is an adequate index of soclal acceptance which is all we are interested in. We are making the assumption that the chosen boy is socially accoptable, that the unchosen boy is falrly neutral, and the rejected boy is soclally unacceptable. In a relatively closed environment where it is hypothesized that peer status is even more important tisan where a child lives in his own home, unacceptability stands to enhance feelings of insecur 1 ty. 


\section{GROUP RORSCHACH. BLANK}

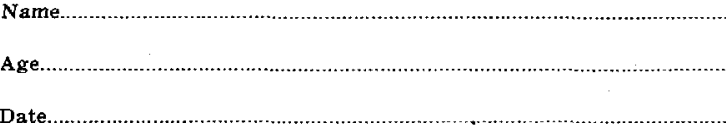

Date.

Occupation

INSTRUCTIONS

You will see on the screen ten inkblot pictures.

Your task is to write down what these inkblots, or any parts of them, resemble or look like to you.

You will see each inkblot for three minutes.

Always write your answers on the right hand side of the open double page, and do not concern yourself with the left hand side until instructed to do so.

Turn the page each time the slide is changed.

Do not be disturbed if the light is not very bright while you are looking at the inkblots and writing your answers, handwriting is not important.

When the first slide is on the screen, open this blank and record your answers where it says

"Write your answers to inkblot I here"

Number your answers for each inkblot. 


\section{INKBLOT I}

INSTRUCTIONS FOR INQUIRY

Put the number of your answer under any of these words if by 30 doing you feel you can amplify it in the way the examiner has just explained.

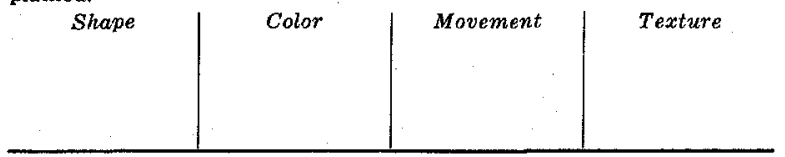

ALTERNATE INSTRUCTIONS FOR INQUIRY

Write anything eise about your answers which you think will describe them to the examiner more fully.

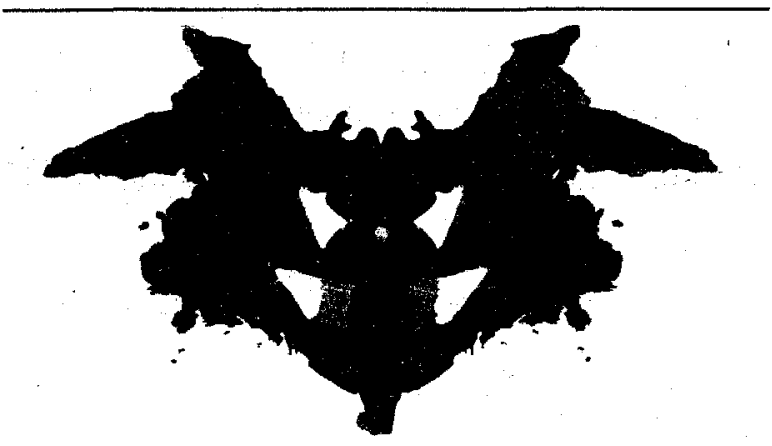

Where did you see your answers? Mark off the areas on this little diagram as nearly as you can.
Write Your Answer or Answers to Inkblot I Here

Before you turn to the next page, draw a line under your last answers. 


\section{INKBLOT II}

INSTRUCTIONS FOR INQUIRY

Put the number of your answer under any of these words if by so doing you feel you can amplify it in the way the examiner has just explained.

Shape

Color

Movement

Texture

\section{ALTERNATE INSTRUCTIONS FOR INQUIRY}

Write anything else about your answers which you think will describe them to the examiner more fully.

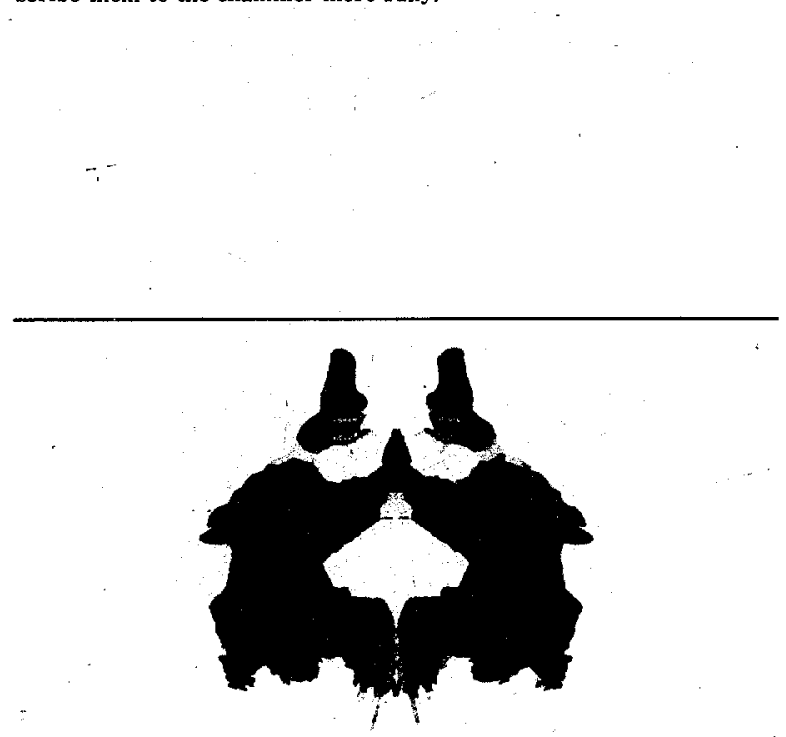

Where did you see your answers? Mark off the areas on this little diagram as nearly as you can.
Write Your Answer or Answers to Inkblot II Here

Before you turn to the next page, draw a line under your last answers. 


\section{INKBLOT III}

INSTRUCTIONS FOR INQUIRY

Put the number of your answer under any of these words if by so doing you feel you can amplify it in the way the examiner has just exdoing you

Shape

Color

Movement

Texture

ALTERNATE INSTRUCTIONS FOR INQUIRY

Write anything else about your answers which you think will describe them to the examiner more fully.

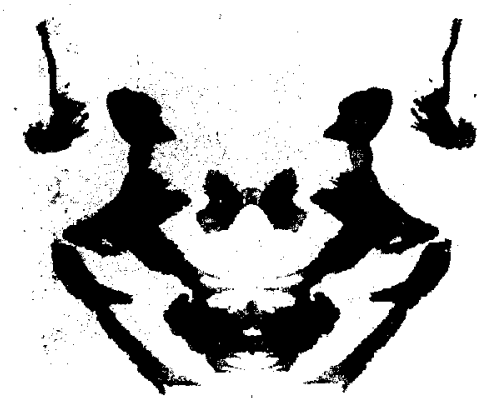

Where did you see your answers? Mark off the areas on this little diagram as nearly as you can.
Write Your Answer or Answers to Inkblot III Here

Before you turn to the next page, draw a line under your last answers. 
INKBLOT IV

INSTRUCTIONS FOR INQUIRY

Put the number of your answer under any of these words if by so doing you feel you can amplify it in the way the examiner has just expained.

Shape

Color

Movement

Texture

ALTERNATE INSTRUCTIONS FOR INQUIRY

Write anything else about your answers which you think will describe them to the examiner more fully.

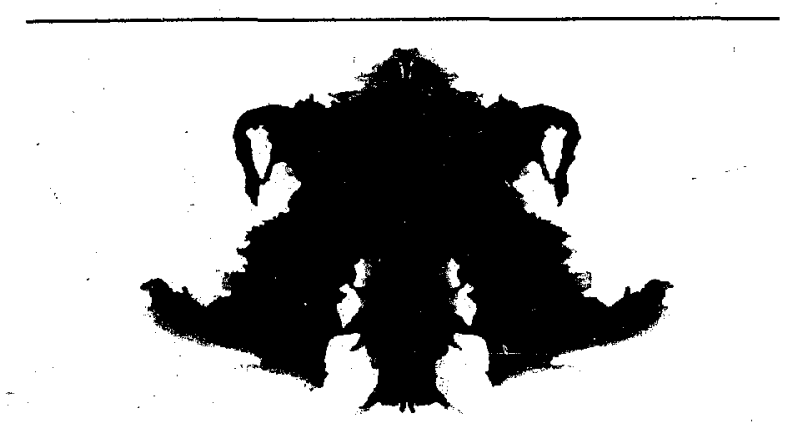

Where did you see your answers? Mark off the areas on this little diagram as nearly as you can.
Write Your Answer or Answers to Inkblot IV Here Before you turn to the next page, draw a line under your last answers.

301 


\section{INKBLOT V}

INSTRUCTIONS FOR INOUIRY

Put the number of your answer under any of these words if by so doing you feel you can amplify it in the way the examiner has just explained.

Shape

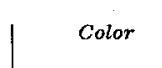

Movement

Texture

ALTERNATE INSTRUCTIONS FOR INQUIRY

Write anything else about your answers which you think will describe them to the examiner more fully.

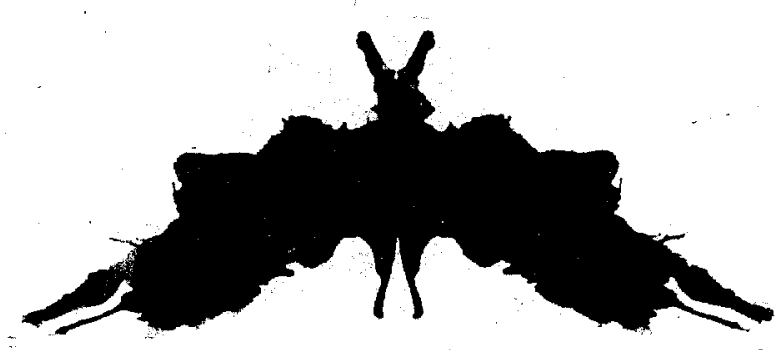

Where did you see your answers? Mark off the areas on this little diagram as nearly as you can.
Write Your Answer or Answers to Inkblot V Here

Before you turn to the next page, draw a line under your last answers. 
INKBLOT VI

INSTRUCTIONS FOR INQUIRY

Put the number of your answer under any of these words if by so doing you feel you can amplify it in the way the examiner has just explained.

$$
\text { Shape }
$$

Color

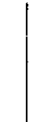

Movement

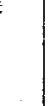

ALTERNATE INSTRUCTIONS FOR INQUIRY

Write anything else about your answers which you think will describe them to the examiner more fully.

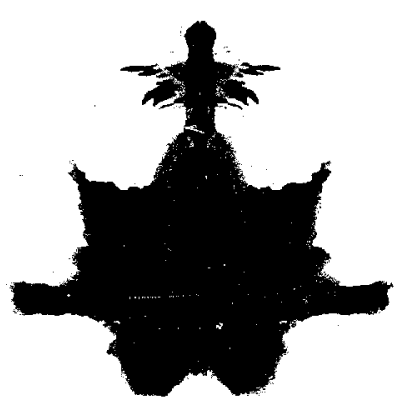

Where did you see your answers? Mark off the areas on this little diagram as nearly as you can.
Write Your Answer or Answers to Inkblot VI Here

Before you turn to the next page, draw a line under your last answers. 
INKBLOT VII

INSTRUCTIONS FOR INQUIRY

Put the number of your answer under any of these words if by so doing you feel you can amplify it in the way the examiner has just explained.

$$
\text { Shape }
$$

$$
\text { Color }
$$

Movemen

Texture

ALTERNATE INSTRUCTIONS FOR INQUIRY

Write anything else about your answers which you think will describe them to the examiner more fully.

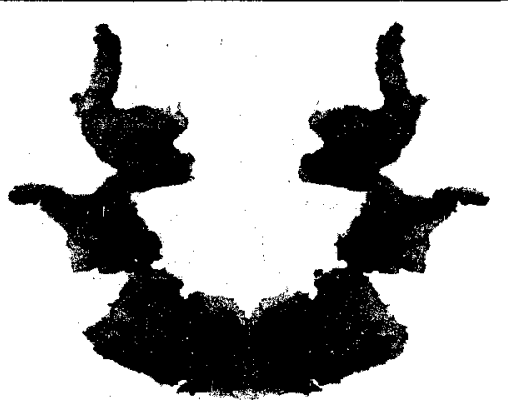

Where did you see your answers? Mark off the areas on this little diagram as nearly as you can.
Write Your Answer or Answers to Inkblot VII Here

Before you turn to the next page, draw a line under your last answers. 
INKBLOT VIII

INSTRUCTIONS FOR INQUIRY

Put the number of your answer under any of these words if by so doing you feel you can amplify it in the way the examiner has just explained.

Shape

Color

Movement

Texture

Shaper

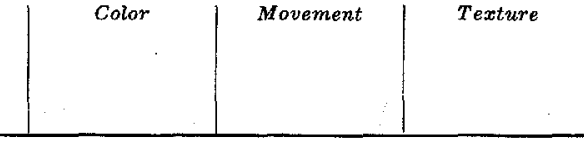

ALTERNATE INSTRUCTIONS FOR INQUIRY

Write anything else about your answers which you think will describe them to the examiner more fully.

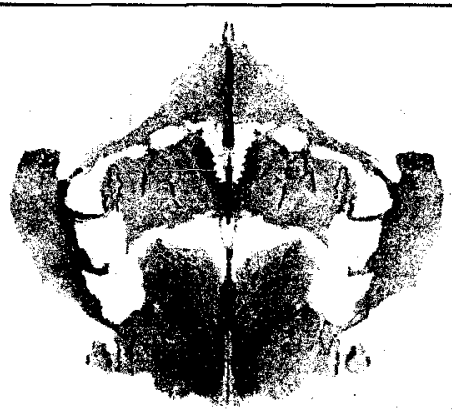

Where did you see your answers? Mark off the areas on this little diagram as nearly as you can.
Write Your Answer or Answers to Inkblot VIII Here Before you turn to the next page, draw a line under your last answers. 
INKBLOT IX

INSTRUCTIONS FOR INQUIRY Put the number of your answer under any of these words if by so
doing you feel you can amplify it in the way the examiner has just exdoing you feel you can amplify it in the way the examiner has just

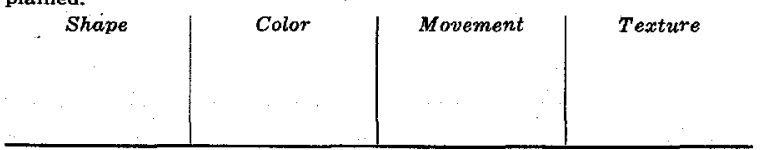

ALTERNATE INSTRUCTIONS FOR INQUIRY

Write anything else about your answers which you think will describe them to the examiner more fully.

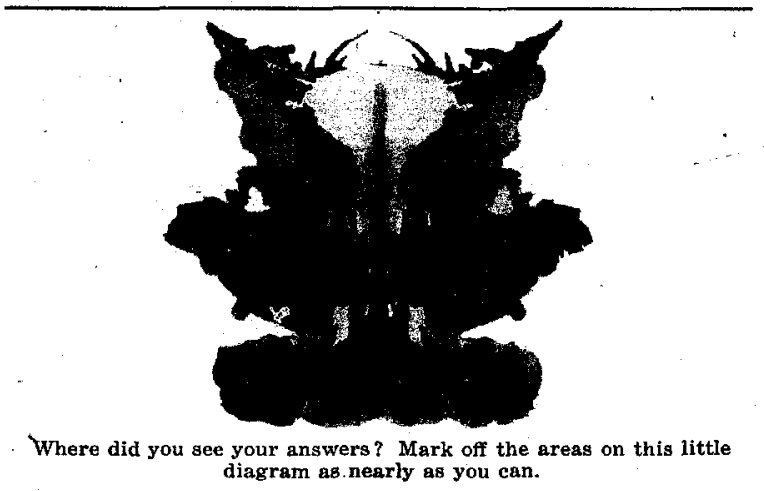

Write Your Answer or Answers to Inkblot IX Here Before you turn to the next page, draw a line under your last answers. 
INKBLOT $\mathrm{X}$

INSTRUCTIONS FOR INQUIRY

Put the number of your answer under any of these words if by so doing you feel you can amplify it in the way the examiner has just explained.

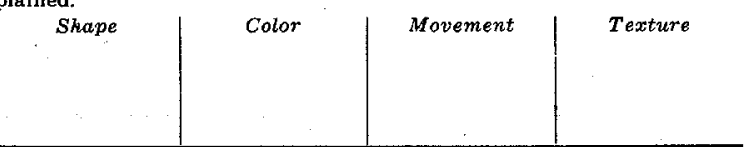

ALTERNATE INSTRUCTIONS FOR INOUIRY

Write anything else about your answers which you think will deWrite anything else about your ans
scribe them to the examiner more fully.

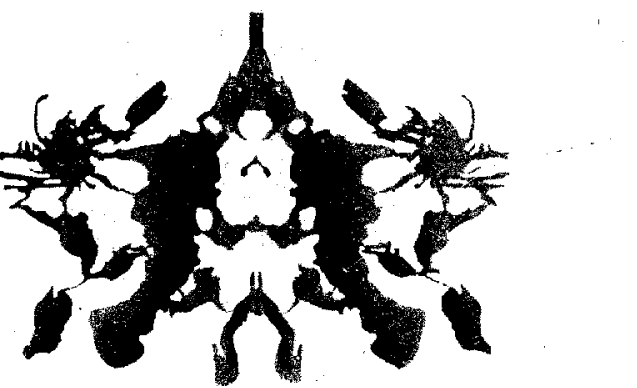

Where did you see your answers? Mark off the areas on this little diagram as nearly as you can.
Write Your Answer or Answers to Inkblot X Here

Before you turn to the next page, draw a line under your last answers. 
FOR EXAMINER'S USE FOR SCORING AND PSYCHOGRAM
W $D$ d Scoring after Klopfer.
FOR EXAMINER'S USE

MUNROE'S CHECK LIST. (Ror.Res.Ex, 1944.8.46-70)

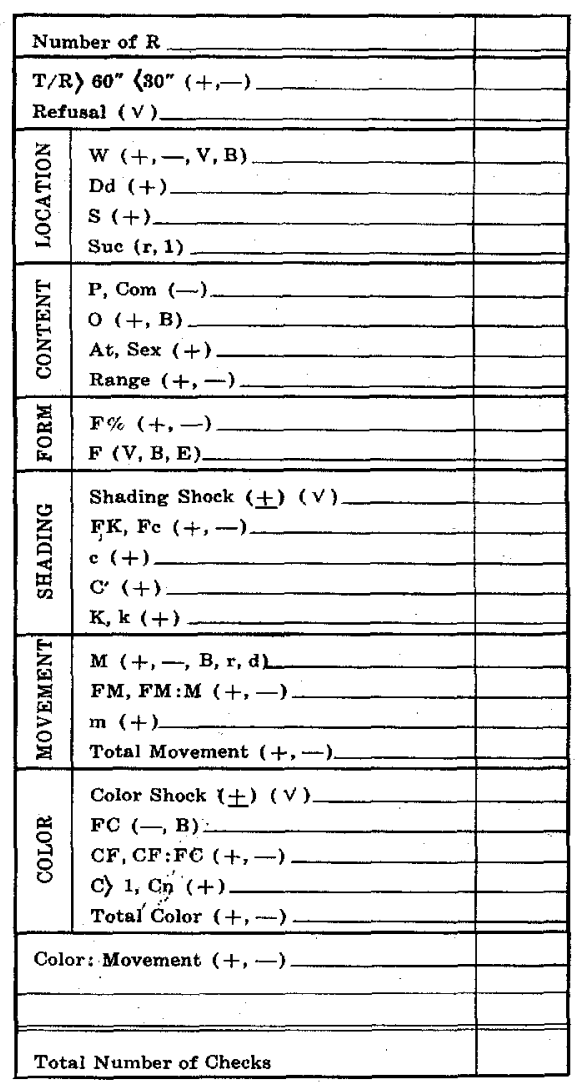


FOR EXAMINER'S USE

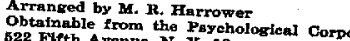

622 Fitth Avenue, N. Y. 18

was. 
INCOMPLETE SENTENCES BLANK - HIGH SCHOOL FORM

Name
School

Complete these sentences to express your real feelings. Try to do every one.

Be sure to make a complete sentence.

1. I like

2. The happiest time

3. I want to know

4. At home

5. I regret

6. At bedtime

7. Boys

8. The best

9. What annoys me

10. People

11. A mother

12. I feel

13. My greatest fear

14. In the lower grades

15. I can't

(TURN PAGE OVER AND CONTINUE) 


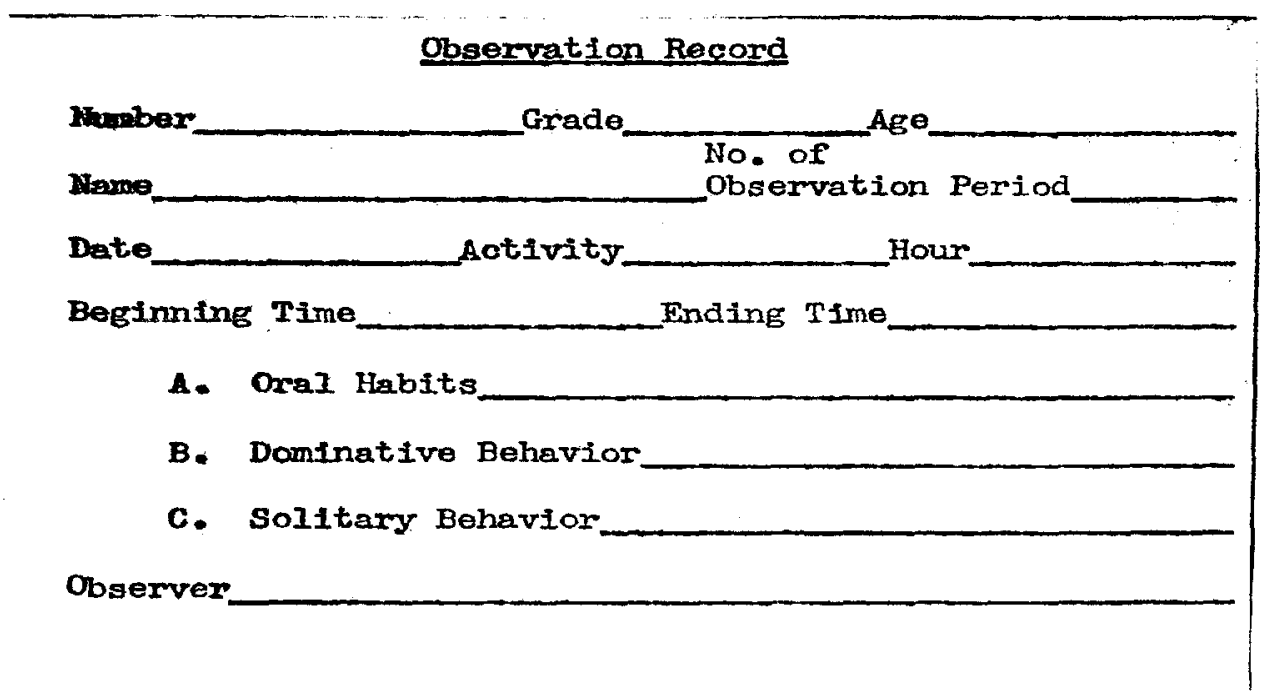




\section{ORSERVATIOAT RECORD}

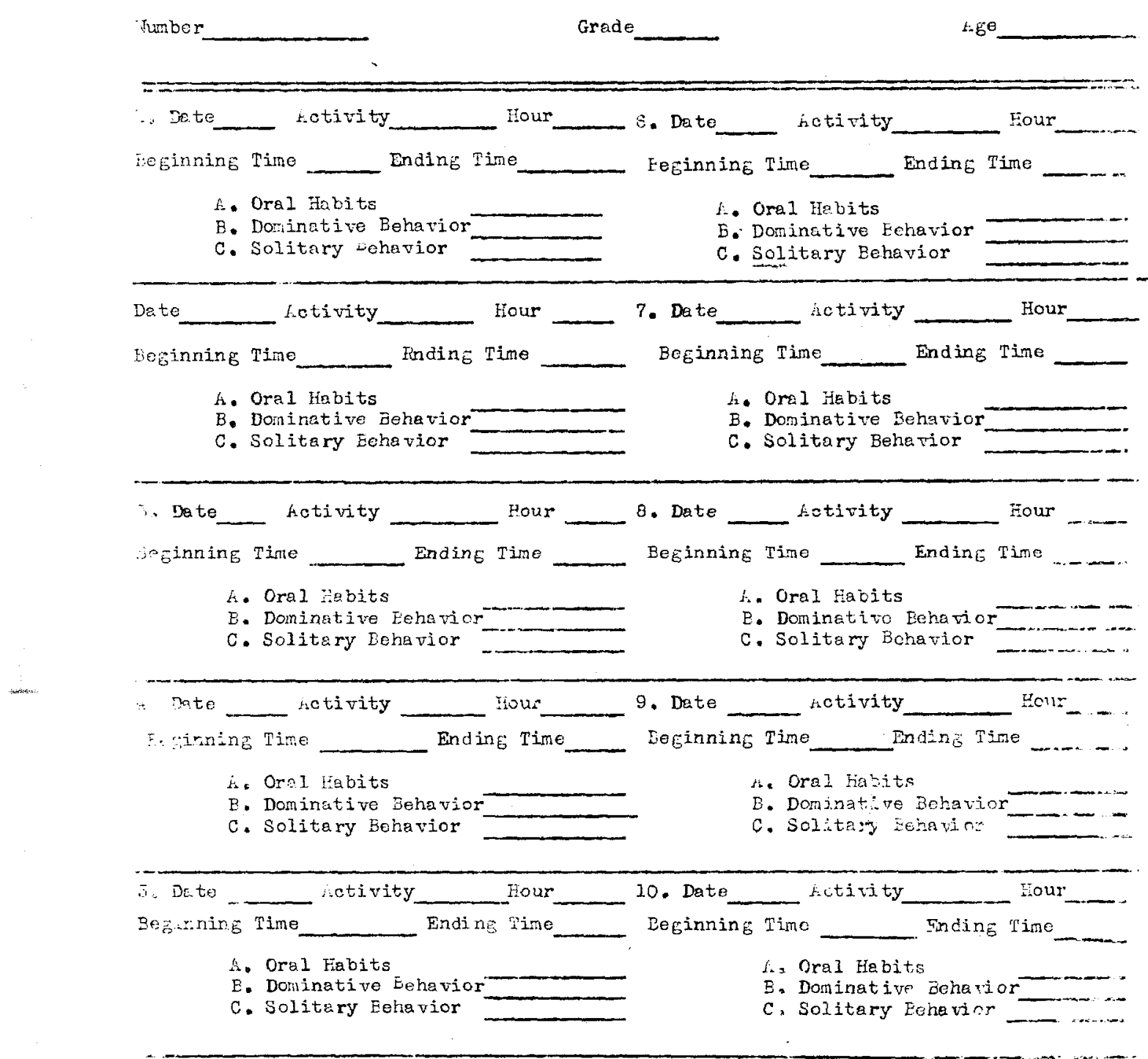

Totel Number of Checks

Name of Observer

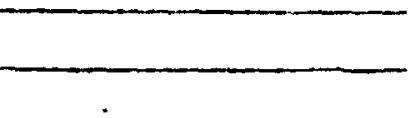

